\title{
Automated Demand Response Technology Demonstration for Small and Medium Commercial Buildings
}

Janie Page, Sila Kiliccote, Junqiao Han Dudley, Mary Ann Piette, Lawrence Berkeley National Laboratory

Albert K. Chiu, Bashar Kellow, Pacific Gas and Electric Company

Ed Koch, Paul Lipkin, Akuacom

July 2011 


\section{Disclaimer}

This document was prepared as an account of work sponsored by the United States Government. While this document is believed to contain correct information, neither the United States Government nor any agency thereof, nor The Regents of the University of California, nor any of their employees, makes any warranty, express or implied, or assumes any legal responsibility for the accuracy, completeness, or usefulness of any information, apparatus, product, or process disclosed, or represents that its use would not infringe privately owned rights. Reference herein to any specific commercial product, process, or service by its trade name, trademark, manufacturer, or otherwise, does not necessarily constitute or imply its endorsement, recommendation, or favoring by the United States Government or any agency thereof, or The Regents of the University of California. The views and opinions of authors expressed herein do not necessarily state or reflect those of the United States Government or any agency thereof or The Regents of the University of California. 


\section{ACKNOWLEDGEMENTS}

This work was sponsored in part by the Demand Response Research Center which is funded by the California Energy Commission (Energy Commission), Public Interest Energy Research (PIER) Program, under Work for Others Contract No. 500-03-026 and by the U.S. Department of Energy under Contract No. DE-AC02-05CH11231. Additional funding was provided by Pacific Gas and Electric Company's Emerging Technologies Program.

The authors would like to thank the following participants, vendors and the reviewers:

Paul Lipkin, Dan Hennage, Marcelo Pereira (Akuacom)

Jake Masters, Olcay Ungun (Enmetric)

Larry Terrill, Michel Kohanim, Bob Holz, Jami Manastyrski (HD Supply Team)

Andres Pineda (LimeAmps)

Gale Van Nostern, John Burdette, David C Wilson (Trane)

Thomas Nasti, Brant Small, Ted Economy (Lutron)

Janet Peterson, Pete Peterson, Tristan de Frondeville (Our Home Spaces)

Joe Trevino, Zip Wallace, Robert Wallace, Rick Costanza (EnergyETC)

Sam Boutros, Tatum Nolan (InThrMa)

Harish Raisinghani, Jeremy Goldstrom, Greg Galvin, Andy Taylor, Bruce Herzer (Pulse Energy)

Doug Black, Johanna Mathieu, Maya Minamihara (Lawrence Berkeley National Laboratory)

Jon Starr (Enernoc)

Eric Martinez (San Diego Gas and Electirc Company)

Roger Levy (Levy Associates) 


\section{ABSTRACT}

Small and medium commercial customers in California make up about 20-25\% of electric peak load in California. With the roll out of smart meters to this customer group, which enable granular measurement of electricity consumption to this customer group, the investor-owned utilities plan to offer dynamic prices as default tariffs by the end of 2011. Pacific Gas and Electric Company, which successfully deployed Automated Demand Response (AutoDR) Programs to its large commercial and industrial customers, started investigating the same infrastructures application to the small and medium commercial customers. This project aims to identify available technologies suitable for automating demand response for small-medium commercial buildings; to validate the extent to which that technology does what it claims to be able to do; and determine the extent to which customers find the technology useful for DR purpose.

Ten sites, enabled by eight vendors, participated in at least four test AutoDR events per site in the summer of 2010. The results showed that while existing technology can reliably receive OpenADR signals and translate them into pre-programmed response strategies, it is likely that better load sheds could be obtained than what is reported here if better understanding of the building systems were developed and the DR strategies had been carefully designed and optimized for each site.

Keywords: demand response, OpenADR, small commercial, emerging technologies, small commercial business, medium commercial business

Please use the following citation for this report:

J. Page, Kiliccote, S., Dudley, J.H., Piette, M.A., (Lawrence Berkeley National Laboratory), Chiu, A.K., Kellow, B., (Pacific Gas and Electric Company), Koch, E., Lipkin, P. (Akuacom), 2011. Automated Demand Response Technology Demonstration for Small and Medium Commercial Buildings. 


\section{TABLE OF CONTENTS}

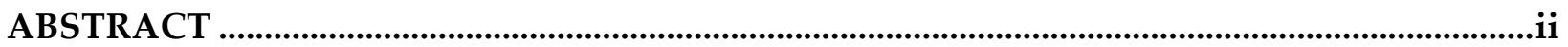

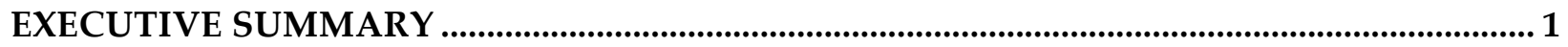

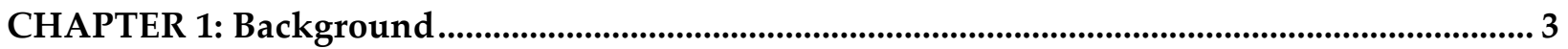

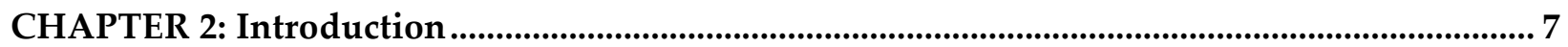

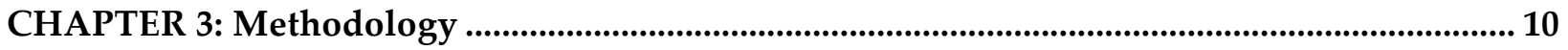

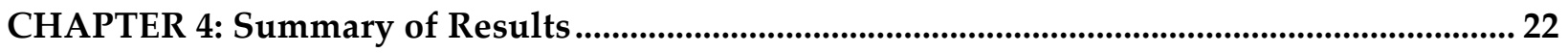

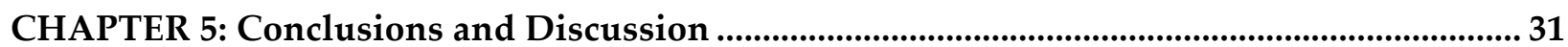

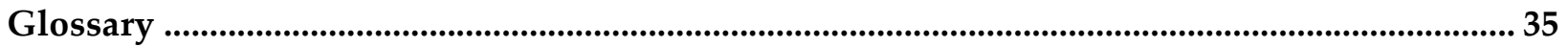

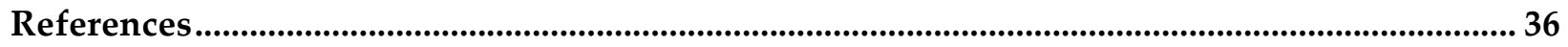

Appendices (Volume 2)

APPENDIX A. Procurement Documents

APPENDIX B. Summary of Peak Day Pricing Tariff

APPENDIX C. Site Descriptions and Data

APPENDIX D. User Surveys Conducted by Lutron 


\section{LIST OF FIGURES}

Figure 1: OpenADR (represented by double ended arrows) communicates the details of a demand response event from the utility or ISO to sites via the Internet. ....................................... 6

Figure 2: Site locations for Small-Medium Commercial DR Project............................................. 10

Figure 3: General architecture for Small-Medium Commercial Facilities Emerging Technologies

Demand Response Project ....................................................................................................... 12

Figure 4: Varieties of architectures within project......................................................................... 13

Figure 5: Demand as a function of outdoor air temperature at Palo Alto site .............................. 24

Figure 6: Demand as a function of outdoor air temperature at Campbell site ............................ 25

Figure 7: Demand as a function of outdoor air temperature at the Sebastopol site..................... 26

Figure 8: DR response with limited sustainability (sample data from Pittsburg site, 9/1/2010,

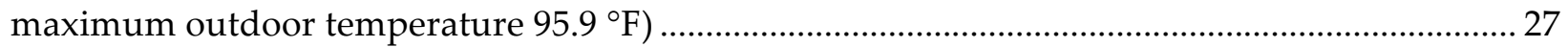

Figure 9: DR response showing cycling of constant volume RTU (sample data from Union City

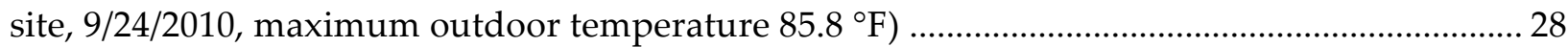

Figure 10: Cyclic DR response at site where DR strategy only controlled lighting (sample data from Oakland site, 9/22/2010, maximum outdoor temperature $\left.69.9^{\circ} \mathrm{F}\right)$....................................... 29

Figure 11: DR response of lighting circuits only (Oakland site on 9/22/2010) …........................ 29

Figure 12: Aggregate DR response of all sites participating in September 2, 2010 DR event...... 30

\section{LIST OF TABLES}

Table 1: Site characteristics for small-medium commercial facilities project............................... 11

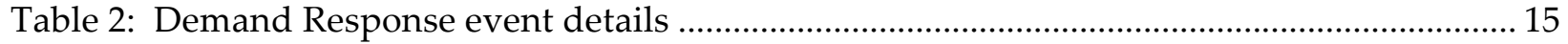

Table 3. Demand response strategies by site location ................................................................ 17

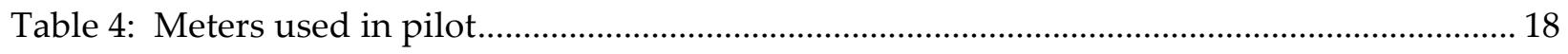

Table 5: Source locations for weather data for each site .................................................................. 20

Table 6: Summary of demand savings by site location ............................................................... 22 


\section{EXECUTIVE SUMMARY}

Demand response (DR) programs encourage customers to change their electricity use, by reducing their usage during peak periods or shifting usage to off peak periods. DR is used to mitigate grid management problems including generation constraints, transmission constraints and or to reduce costs in utility programs with variable prices. DR programs and tariffs are designed to improve the reliability of the electric grid and reduce the use of electricity during peak times in order to drive down total system costs. This study examines the automated response of small and medium commercial sites to DR events communicated via the Internet using Open Automated Demand Response (OpenADR). OpenADR is an information exchange model that provides utility price, reliability, or other DR event signals to initiate preprogrammed customer demand management strategies. Essentially, OpenADR facilitates automated demand response (AutoDR) through continuous, secure, standardized and open communication signals.

Pacific Gas and Electric Company (PG\&E) offers AutoDR programs to its large commercial and industrial (C\&I) customers. With the future roll out of default dynamic pricing tariffs for small and medium commercial customers, PG\&E wanted to assess the applicability of the same infrastructure to this customer group. The tests reported in this paper aim to provide insights about the readiness of available technology to provide DR response capability for small and medium commercial buildings.

The goal of this DR emerging technology assessment was to determine how well small and medium commercial buildings could respond to OpenADR signals using available technologies that are able to receive and interpret these signals. Specifically, this study looked at the capability of existing technologies to automatically shed demand to determine the extent to which these technologies, as applied, provided significant DR from non-aggregated small to medium commercial sites. In general, the work reported here was intended to help equipment manufacturers modify or improve their products so that their products can be more appropriately responsive to the needs of this customer group.

OpenADR signals used in this project modeled the Peak Day Pricing (PDP) tariff that is planned to be the default for small and medium commercial buildings in November 2011. AutoDR test events were published by the demand response automation server (DRAS) on warmer days during the summer of 2010. All events lasted four hours, except for one event that was called for six hours. Most DR events were called with a day-ahead notification in most cases, but some events in this study were called with notifications only on the day of the DR event to verify the ability of systems to respond in the case of grid emergencies.

\section{Key findings:}

All participating systems in this project were able to receive and translate OpenADR signals to shed strategies that were implemented upon receipt of the $D R$ event signals. Essentially, this work achieved its goal of showing that a wide range of technology options are available and can respond to OpenADR signals by translating them into pre-programmed DR strategies for a variety of sites. 
Optimization of DR strategies is critical to obtaining sufficient demand strategies. This study found that the DR strategies were not necessarily optimized for each site, which resulted in limited demand savings. There are several possible causes:

- Site customers had not practiced DR previously, and may have been conservative in selecting DR strategies for these tests.

- Some strategies used in these tests provided demand savings that yielded little savings compared to the demand of other building systems in the facility. This observation was common to most sites that did not include HVAC controls in their DR strategies.

- DR strategies involving HVAC controls were not able to maintain the demand response strategy over an extended time period. After a clear response to the initial DR event signal, loads returned to baseline levels within about two hours after the start of the DR event. This may have been due to limitations of on-site conditions such as duct leakage or undersized HVAC equipment. 


\section{CHAPTER 1: Background}

Occasional storms and heat waves, as well as periodic power plant repairs and maintenance, have the potential to affect California's supply and demand for electricity. When electric demand reaches supply limits, power interruptions may occur. Building enough power plants to satisfy every possible supply and demand scenario is costly and has a high environmental impact.

The Federal Energy Regulatory Commission (2011) defines demand response (DR) as "changes in electric use by demand-side resources from their normal consumption patterns in response to changes in the price of electricity, or to incentive payments designed to induce lower electricity use at times of high wholesale market prices or when system reliability is jeopardized."

Demand response (DR) programs encourage customers to change their electricity use, by shifting it to a time with lower demand, or shedding it during the high peak period, before demand reaches supply limits or when the market price of electricity is high. This improves the reliability of the electric grid.

Dynamic pricing programs, which incur high prices when demand is expected to approach supply limits, have become the default option for large commercial sites within the Pacific Gas and Electric Company (PG\&E) territory, and will become the default for small and medium commercial buildings in November $2011^{1}$. Automated demand response (AutoDR) programs allow customers to pre-program their DR strategies into their existing energy management and control system (EMCS), if it exists, or some other equipment control device (the simplest of which might be a set of relays that turn equipment on or off in response to a signal).

Prior to the work reported here, there was limited understanding of how decisions related to demand response were made within these smaller sites, except manually or in aggregate (Kiliccote, 2009). Two recent examples of DR applied to groups of small commercial buildings are (1) EnerNOC's (an aggregator) recent acquisition of SmallFoot's wireless demand control solutions for the small commercial market (EnerNOC, 2010) and (2) San Diego Gas and Electric's automated capacity bidding program (AutoCBP), where Sure Grid ${ }^{2}$ bundles small commercial demand savings from directly controlling end use systems to qualify for incentives offered under the program (Kiliccote and Piette, 2008).

\footnotetext{
${ }^{1}$ Time of use (TOU) tariffs are not dynamic pricing because there is no dynamic change in rate due to market or system conditions. Rate changes are static, and associated with specific times of the day. By contrast, the peak day pricing (PDP) tariff studied here overlays a critical peak pricing (CPP) rate on the TOU tariff, creating a dynamic pricing tariff.

${ }^{2}$ SureGrid is a software platform available from Siemens that enables buildings to dynamically interact with the electrical grid based on local business rules and real-time asset and environmental conditions.
} 
California Public Utilities Commission (CPUC) reports ${ }^{3}$ that medium and large businesses, or (peak electric demand greater than $200 \mathrm{~kW}$ demand) account for about 5 to $7 \mathrm{GW}$, or 10 to 15 percent of the summer peak demand. By contrast, small commercial buildings account for 10 to $12 \mathrm{GW}$, or 20 to 25 percent of the peak. Enabling small and medium commercial buildings to participate in AutoDR programs and tariffs can substantially decrease summer peak demand.

California's highest peak demand (52,863 megawatts) occurred July 10, 2002 ${ }^{4}$. According to CPUC reports, although this particular peak has not been matched in eight years, according to CPUC reports, California's peak demand is growing at 2.4 percent per year, or roughly the equivalent of three new 500-megawatt power plants per year. Residential and commercial air conditioning systems are believed to represent at least 30 percent of summer peak electricity loads 5 .

Kiliccote et al. (2009) identified regional concentrations of small commercial facilities and identified associated end uses and controls in California. The study found that the majority of small commercial facilities are small offices, restaurants, and retail buildings with single zone packaged units servicing most of their HVAC needs. Manually controlled fluorescent tube lighting with magnetic ballast predominated. The report contained a look at the DR of aggregated small commercial facilities, without a priori knowledge of the DR strategies employed, to determine critical issues impacting baseline development. It found that both weather sensitivity and load variability were key contributors to baseline variability. The baselines used in the study reported here account for weather sensitivity. That same earlier study developed a framework for communications infrastructure required to implement demand response within these facilities, and then compared the results of implementing that framework with a single technology at two similar small commercial buildings in Southern California. In both facilities, meter data confirmed the DR sheds. However, the HVAC units were undersized and lighting was not included in the DR strategies. That work confirmed that demand response automation is possible for small commercial facilities, but that strategies applied to undersized HVAC units do not produce optimal results over an extended DR period if the units continue to run at high capacity to meet the new temperature setpoints.

Previous work by Lockheed (2006) noted that DR technology for homes and small commercial buildings should be:

- capable of receiving a signal from the utility indicating a DR event automatically,

- able to characterize the magnitude of change in demand as a result of responding to the DR signal,

- reliable, with a means of verifying operation through low cost, non-intrusive means,

- capable of delivering significant load reductions,

${ }^{3}$ As reported in Kiliccote et al., 2009

${ }^{4}$ This value from CPUC is in contrast to that reported by the Federal Energy Regulatory Commission which records California's all time peak demand at 50,270 MW, achieved on July 24, 2006.

${ }^{5}$ Ibid. 
- cost-effective (economical), and

- non-disruptive during operation and minimally disruptive during installation.

The work reported by Lockheed (2006) emphasized direct load control instead of the AutoDR model used here, where sites receiving a DR signal default into a previously defined strategy unless the occupants choose to opt out via a local computer interface.

Herter et al. (2009) showed that incentives such as rebates or special time of use pricing, coupled with energy efficiency consultation (specific to a small commercial site in advance of a summer DR program) could be beneficial. Herter's work showed that incentives and appropriate equipment can yield $20 \%$ or greater energy savings, with the potential for an additional $14-20 \%$ demand savings during DR events. This held true for all site types except restaurants. Herter also found that heating, ventilation, and air conditioning (HVAC) units that are inherently undersized for the facility could not be expected to provide demand savings during DR events.

The study reported here was conducted between August and October in 2010 and focused on reducing peak electricity demand of small and medium commercial buildings on hot summer days. It examines how well existing technologies provided by vendors can receive and translate OpenADR signals into DR strategies. Implementing DR in small and medium commercial buildings in a way that allows end users to choose their response to a DR event is more complicated than in large commercial sites: Most small to medium commercial sites do not have a centralized EMCS, nor are they likely to have facility managers to control and coordinate systems and controls.

OpenADR is an information data exchange model that delivers utility price, reliability, or other DR event signals to devices that initiate pre-programmed DR strategies. Essentially, OpenADR implements AutoDR through continuous, secure, standardized, open communication signals published to the Internet where various bridge devices can acquire and act on them. OpenADR has been proven as an effective way to communicate price and reliability information to large commercial buildings because of the ability to use existing Energy Management Control Systems (EMCS) to automate the DR control strategies. Figure 1 shows the general architecture. DR signal is published from the Demand Response Automation Server (DRAS) to sites using OpenADR by the utility or ISO. These signals are received by the clients on site. Clients then trigger pre-programmed DR strategies. The client's user interface provides the end user a way to opt-out of responding to an event when needed. 
Figure 1: OpenADR (represented by double ended arrows) communicates the details of a demand response event from the utility or ISO to sites via the Internet.

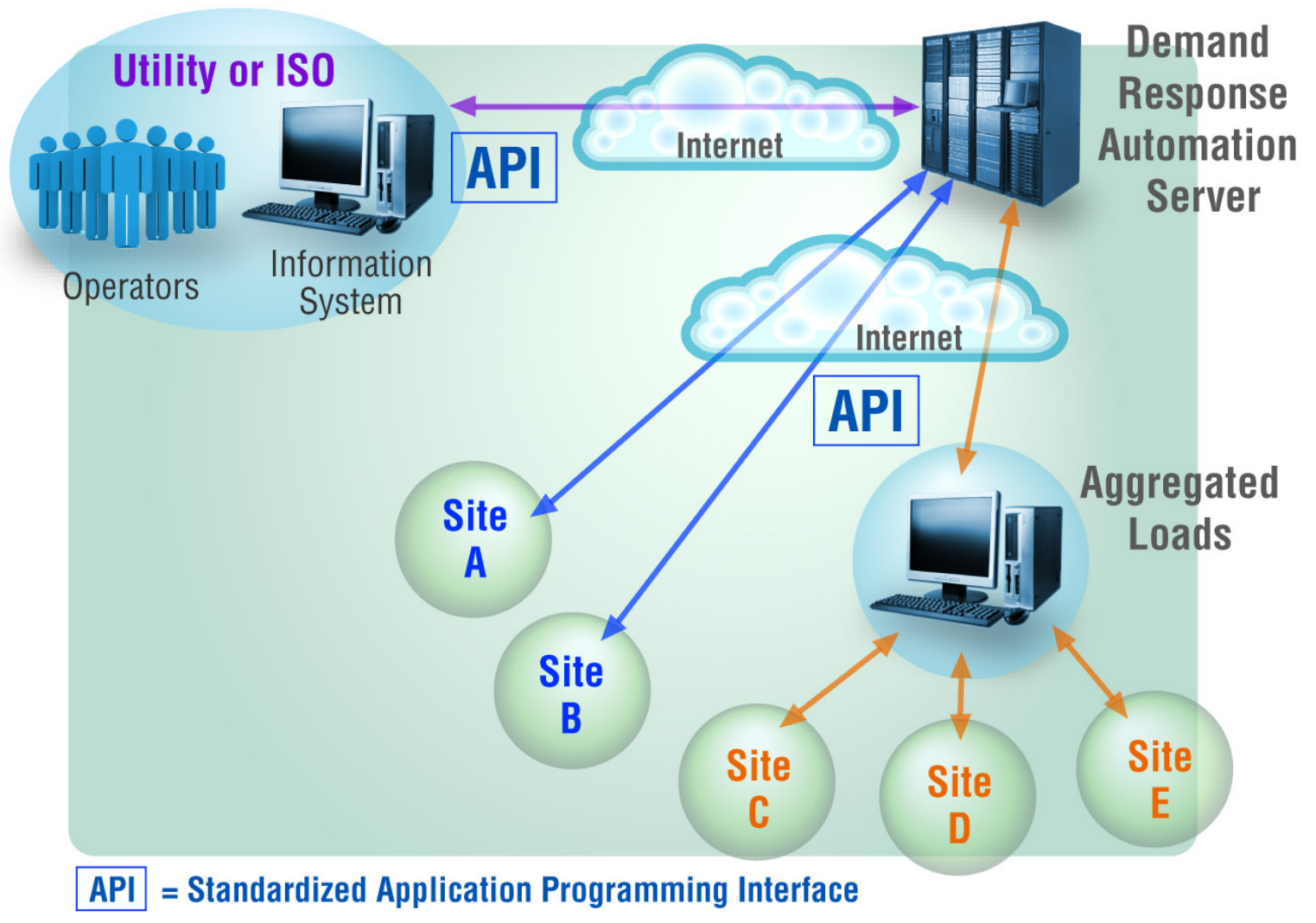

The structure of this report is as follows:

Introduction chapter describes the approach used, outlines the project objectives, and describes the procurement process used. Methodology chapter describes the methods used to study the DR capabilities of vendor and site equipment. An overview of the extent to which demand response in the ten sites provided DR load reductions are outlined in Results chapter. Finally, Conclusions and Discussion chapter reviews lessons learned during the project, and identifies additional work needed to further clarify small-medium buildings' roles in demand response efforts.

The details of the project process, the DR program description and the description of the technologies at each site are provided in Appendices A through D. 


\section{CHAPTER 2: Introduction}

The goals of this project were to:

- Identify available technologies suitable for automating demand response (DR) for smallmedium commercial buildings,

- Validate the extent to which that technology does what it claims to be able to do, and

- Determine the extent to which customers find the technology useful for DR purpose.

This study investigated the individual responses of small and medium commercial buildings, using vendor installed technology to respond to AutoDR events without additional guidance ${ }^{6}$ on DR measures and without incentives other than incidental savings that might occur as a result of reducing loads on hot summer days. Specifically, this study evaluated the capability of equipment at a variety of business types (a restaurant, a convenience store, a preschool, several small offices, and some small warehouse facilities) to automatically shed demand during summer months when DR events were called on hotter days and to what extent these sheds provided significant load reductions. DR strategies developed by the vendors should not be assumed to provide optimal responses for the particular sites.

There are no DR programs for small and medium commercial buildings in PG\&E's territory other than the SmartAC program, or the capacity bidding program (CBP), which typically require some aggregation of small business customers for participation. Thus, it was unlikely at the start of this project that any small and medium commercial buildings would already have equipment installed to respond to demand response events or that the businesses participating in this program would have experience with DR programs.

At the time of this project, the state of California was moving towards dynamic pricing across retail electricity markets. Since 2007, AutoDR infrastructure has been used to automate pricebased DR programs such as ${ }^{7}$ :

- $\quad$ Critical Peak Pricing (CPP)

- Demand Bidding Program (DBP)

- Peak Choice

- Capacity Bidding Program (CBP)

In addition to these programs, Peak Day Pricing (PDP) is a new dynamic pricing tariff, replacing PG\&E's CPP tariff, that provides time of use energy prices throughout the year with credits during summer in exchange for additional charges (higher rates) during peak hours on 9-15 event days per year. This tariff is designed to be revenue neutral to the class average load shape. This means that over the course of the year, if no site implemented any DR strategies,

\footnotetext{
${ }^{6}$ All participants were offered guidance from LBNL staff, but none took advantage of the offer.

${ }^{7}$ See http://www.pge.com/mybusiness/energysavingsrebates/demandresponse/ for details on all demand response programs currently offered by PG\&E
} 
the accumulated benefits to users as a result of the changes imposed by the tariff would be exactly balanced by the additional costs to other users within the class. All large commercial and industrial customers ( $200 \mathrm{~kW}$ and up) in the PG\&E's territory were defaulted in this new PDP tariff in May 2010 unless they specifically opted out. Since PG\&E plans to make this tariff the default for their small and medium commercial customers in November 2011, OpenADR signals used in this project modeled the PDP tariff (see Appendix B for additional details on this tariff).

The actual DR capability of small commercial buildings is not well understood due to the variety of end uses that typically do not have integrated controls or are difficult to control with existing equipment.

This project asked vendors to identify appropriate technologies to facilitate AutoDR responses in small and medium commercial buildings. Although this was initially envisioned to be a competitive process, since the goal was to evaluate a wide range of technologies prior to the introduction of the default PDP tariff to this business class, we ultimately offered the opportunity to participate to all interested parties providing they met certain criteria, while providing limited funding to well-qualified vendors.

\section{Request for Proposals (RFP)}

On April 6, 2010, Akuacom, in consultation with Lawrence Berkeley National Laboratory (LBNL), on behalf of PG\&E, issued the RFP for this project, sending it to over seventy potential vendors. (A copy of the RFP is included as Appendix B of this report.)

To address questions raised by potential bidders, we conducted an online meeting was held with all potential bidders on April 13, 2010 (Akuacom, 2010). In particular, the bidders were told that this project was intended to address the market between residential and large commercial and industrial facilities, specifically focusing on what building control equipment was capable of interpreting OpenADR signals to be used effectively in the small and medium commercial buildings. Formal responses to questions raised at and prior to this meeting were subsequently published to all interested parties on April 16, 2010, and are included as Appendix $\mathrm{C}$ of this report. Proposals were due on April 26, 2010. In response to the request for proposals, 20 bids were received.

Shortly after proposals were received, Akuacom, the company responsible for maintaining the DRAS, was acquired by Honeywell, a potential bidder on this project. As a result, LBNL took over the RFP process, and Honeywell was disqualified from participation in the project as a vendor.

One bidder, Advanced Telemetry, was not offered the opportunity to participate because their technology had already successfully been proven during an earlier project funded by Southern California Edison (Kiliccote et al., 2009). 


\section{Selection Criteria}

The RFP indicated that there was limited funding to cover installation costs for vendors. Selection criteria focused primarily on complete systems that were capable of receiving and responding to OpenADR signals from the DRAS. All technology supplied by vendors for use in these tests was required to be OpenADR complaint, commercially available off-the-shelf, and, where applicable, certified by Underwriters Laboratories (UL) or the Federal Communications Commission (FCC).

PG\&E, working with LBNL, initially selected four vendors to participate with limited funding to cover basic installation costs, and offered the opportunity to participate without reimbursement to the remaining bidders, regardless of perceived ability to respond to OpenADR signals, provided they could:

- provide a site at which testing could occur,

- use OpenADR to the test site premised without intermediate proprietary code,

- reliably provide trend logs of electricity consumption on demand throughout the test period, and

- adhere to the proposed testing timeline.

This created two categories of participants: funded and unfunded. Ultimately eight vendors participated using ten distinct test sites. 


\section{CHAPTER 3: Methodology}

Once vendors were selected and they identified the sites for this program, whole building power demands were measured and recorded at least every fifteen minutes throughout the test period at each site. Analysis of this data compared the demand on event days against two baselines created from measured site data. Each of these baselines estimated the site electric demand in the absence of an event.

\section{Description of Sites, Business Types, Location}

The sites participating in this project spanned a wide range of business types and size. In addition, site locations covered a wide range of climate zones in Northern California within PG\&E's service territory, as illustrated in Figure 2.

Figure 2: Site locations for Small-Medium Commercial DR Project

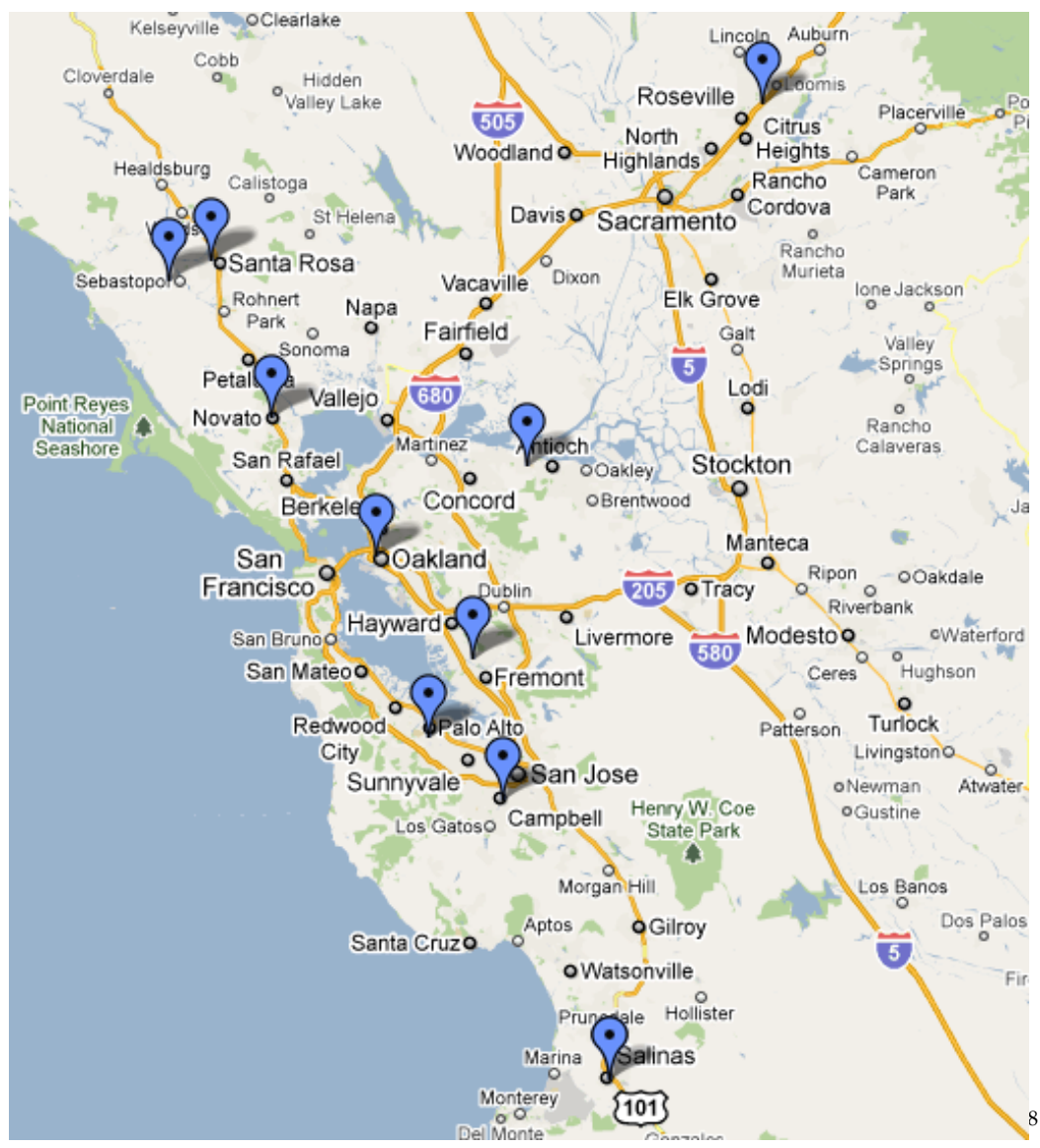

Source: Google Maps, 2010 
Table 1 summarizes the sites by business type, floor space, and peak demand. Note that while some peak demands fall outside the stated range for this project, all sites were pre-qualified for this project on the basis of their PG\&E rate plan, which in all cases was consistent with the small and medium commercial customer designation.

Table 1: Site characteristics for small-medium commercial facilities project.

\begin{tabular}{|c|c|c|c|c|}
\hline Site Location & Business type & $\begin{array}{c}\text { Floor } \\
\text { space }^{*}, \\
\mathrm{ft}^{2}\end{array}$ & \begin{tabular}{|c|} 
Peak \\
Demand $^{* *}$ \\
kW
\end{tabular} & $\mathrm{W} / \mathrm{ft}^{2}$ \\
\hline Rocklin & Warehouse, office & 25,000 & 319.23 & 12.8 \\
\hline Santa Rosa & Convenience store & 3,531 & 33.83 & 9.6 \\
\hline Sebastopol & Restaurant & 4,200 & 44.79 & 10.7 \\
\hline Novato & Small office & 800 & 6.09 & 7.6 \\
\hline Pittsburg & Pre-school & 18,250 & 56.96 & 3.1 \\
\hline Oakland & Small office & 20,000 & 71.38 & 3.6 \\
\hline Palo Alto & Small office & 13,000 & 25.84 & 2 \\
\hline Union City & Small office & 2,200 & 6.59 & 3 \\
\hline Campbell & Small office & 2,070 & 18.24 & 8.8 \\
\hline Salinas & $\begin{array}{c}\text { Food warehouse, } \\
\text { small retail }\end{array}$ & 6000 & 25.83 & 4.3 \\
\hline \multicolumn{5}{|c|}{ * Controlled floor space may be smaller in some cases } \\
\hline
\end{tabular}

\section{Communicating DR events using OpenADR}

OpenADR is an open data model specification for DR price and event information exchange, based on a client-server architecture, which was used to implement AutoDR in these tests. OpenADR's open standards approach creates an interoperable environment that is expected to reduce the cost of automation over the long term by providing a common automation interface that is not tied to a particular vendor. 
The DR signal, initiated by the utility, is published via the DR automation server (DRAS) to the Internet. Each site monitored the DRAS continuously via their client to determine when an event was called. Upon receipt of a DR event signal, the site client translated the signal to predefined, site-specific shed strategies, as illustrated in Figure 3. Earlier work (Kiliccote, 2009) suggested that establishing the required internet-based communication with the DRAS might be a concern for smaller businesses. However, we found that Internet connections were available in 9 out of 10 sites in this project. One site established Internet connection just prior to testing using a cellular network that eventually proved adequate to receive the DR signal.

Figure 3: General architecture for Small-Medium Commercial Facilities Emerging Technologies Demand Response Project

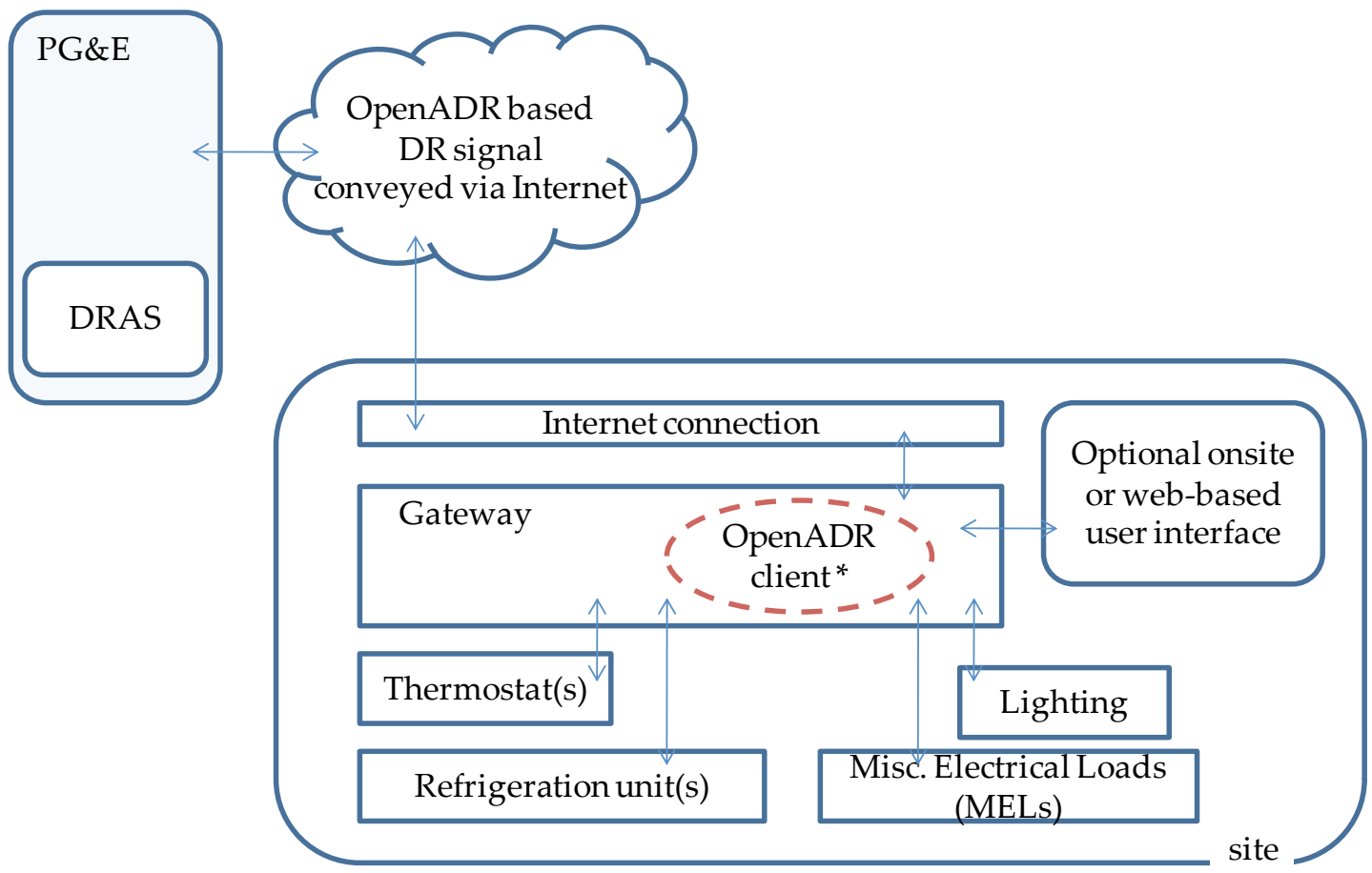

- OpenADR client typically in gateway, but could be located in the devices (Thermostat(s), Refrigeration unit(s), Lighting, MELs)

The architectures for the associated technologies (Figure 4) ranged from a fairly straightforward receipt of the AutoDR signal from the DRAS, converting it to a control strategy within a gateway and relaying that directly to site equipment (a) to the incorporation of the gateway within the equipment itself (b). Some sites incorporated a form of Internet or cloud-based monitoring system (c) that provided both ongoing verification of site response and monitoring and fault detection capability at the start of testing. For example, one site reported accidentally causing air conditioning to start at the beginning of a DR event. This was quickly discovered and fixed by the vendor during the first DR event. Specific site details, architectures, and responses are provided in Appendix $\mathrm{C}$ of this report. 
Figure 4: Varieties of architectures within project

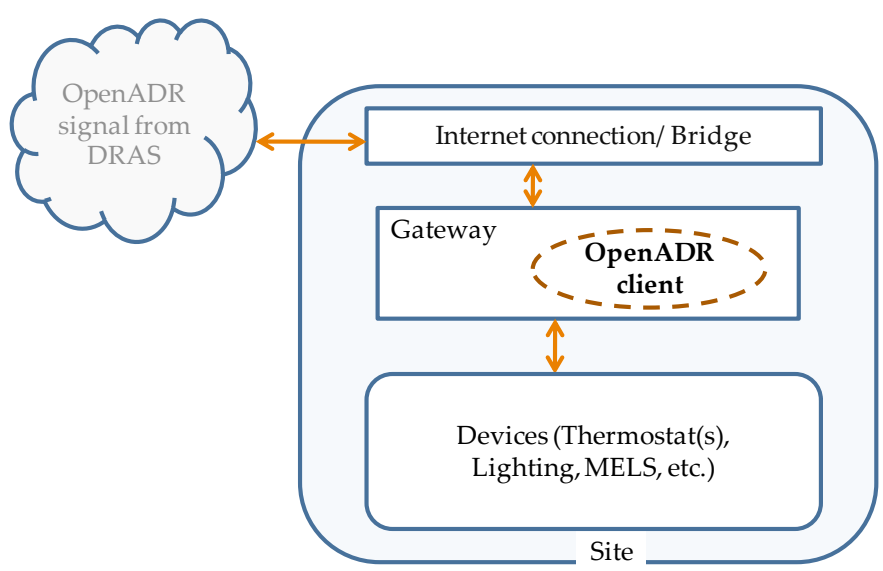

(a) Sample architecture with OpenADR client in Gateway

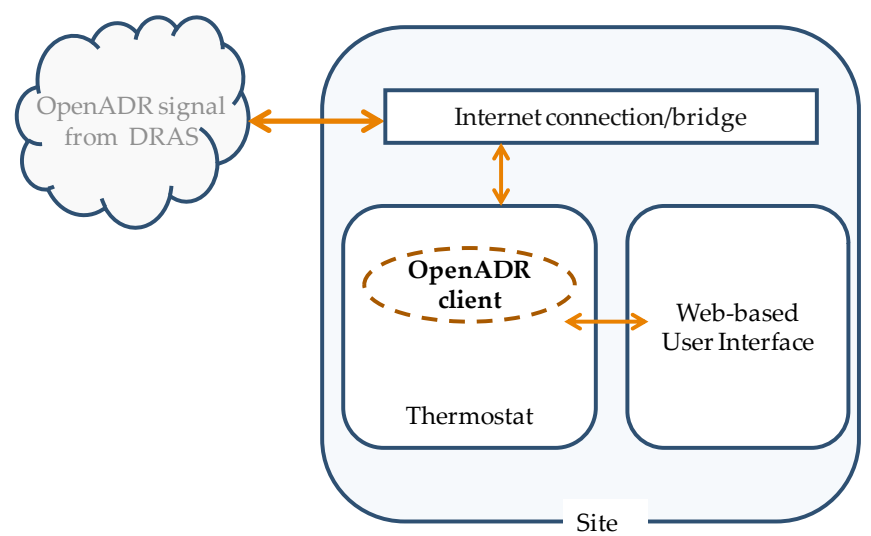

(b) Sample Architecture with OpenADR client embedded in device

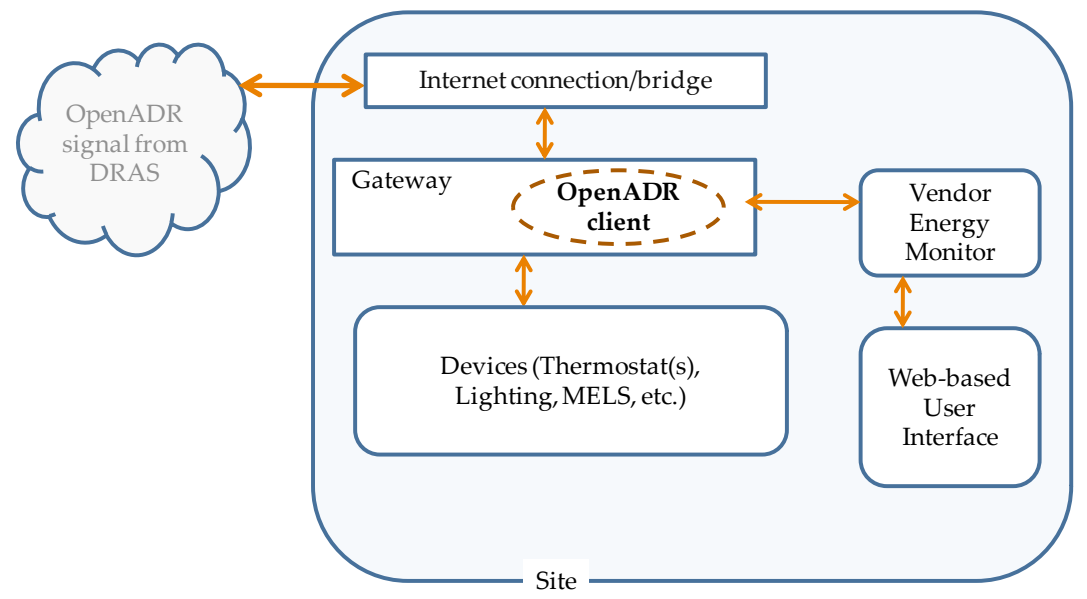

(c) Sample architecture with optional Internet based monitoring system 


\section{AutoDR Test Events}

AutoDR test events reported here were called on warmer days during the summer of 2010. All events lasted four hours, except for one event that was called for six hours. Events were called with either day-ahead notification or day-of notification. Day-of DR events were called to verify the ability of systems to respond in the case of grid emergencies.

Test dates were determined largely by weather conditions since warmer weather is a primary indicator for increased electricity demand. 2010 had an unusually cool summer in the San Francisco Bay area, with few warm days, but we were able to call sufficient test events were called to provide the opportunity for full participation by each site. Sites had the option to opt out of a test event if it imposed a business concern.

Specifically,

- The testing period ran from August $2^{\text {nd }}$ through October $15^{\text {th }}, 2010$. During this time, we called AutoDR tests events were called when the temperature at two of the more moderate weather sites were predicted to exceed $85^{\circ} \mathrm{F}$.

- Consistent with other DR programs, any site could opt out of responding to any event if it occurred at a time when it might have adverse business impacts. None of these sites were enrolled in the PDP tariff. If they had been enrolled, a choice not to shift or shed load during an actual DR event day could have resulted in a higher bill at the end of the month due to the higher energy costs during the event time.

- AutoDR test events, when they were called, generally lasted for four hours, typically from $2 \mathrm{pm}-6 \mathrm{pm}$. The event duration is consistent with the default PDP tariff. The last event lasted six hours, which is also an option for customers under the PDP tariff. Exceptions to $2 \mathrm{pm}$ - $6 \mathrm{pm}$ event times were accounted for in the data analysis.

- To make the tests meaningful, we tried to make sure that each site had ongoing operations for which it had loads to shed during the AutoDR test event time period. Sites with operating schedules outside of typical weekday patterns participated when they were operational.

- The AutoDR test events were primarily triggered by weather (temperatures above $85^{\circ} \mathrm{F}$ ) but in limited instances were called for other reasons. For example, at the Lutron site, a special event was called to specifically test the lighting load shed, and this event happened on a relatively cooler day.

- The research team tried to avoid calling AutoDR test events on consecutive days. However, due to the unusually cool summer experienced by most sites, two event days were called back-to-back during a brief heat wave in early September.

A total of twelve demand response events ${ }^{9}$ were called: eleven during the Auto DR test period (August 2, 2010 through October 15, 2010) and one additional event called after this period for a

\footnotetext{
${ }^{9}$ DR events refer to periods of time when strategies are implemented to reduce load at a particular site. Event days refer to the days when there is a DR event at a particular site. Non-event days refer to days when there was no DR event during the testing period (August 2 - October 15, 2010 for all sites except Salinas, where the testing period ran from October 15 - November 3, 2010).
} 
vendor experiencing difficulties establishing an Internet connection to the site. Events were called using OpenADR (v1.0) ${ }^{10}$. Eight event days were called with notification given to sites a day prior to the AutoDR test event, and notifications for four events were given on the day of the AutoDR test event.

Of the AutoDR test event days called during this project, five were limited participation events focused on particular sites, and seven were open to all sites. The AutoDR test events are summarized in Table 2.

Table 2: Demand Response event details

\begin{tabular}{|c|c|c|c|}
\hline Notification & Start time & End time & Open to \\
\hline $8 / 23 / 201015: 53$ & $8 / 24 / 201014: 00$ & $8 / 24 / 201018: 00$ & All sites \\
\hline $8 / 31 / 201015: 23$ & 9/1/2010 14:00 & 9/1/2010 18:00 & All sites \\
\hline $9 / 2 / 201011: 59$ & 9/2/2010 14:00 & $9 / 2 / 201018: 00$ & All sites \\
\hline $9 / 21 / 201013: 21$ & 9/22/2010 13:00 & $9 / 22 / 201017: 00$ & Limited (1 site) \\
\hline $9 / 24 / 20108: 00$ & $9 / 24 / 201014: 00$ & $9 / 24 / 201018: 00$ & All sites \\
\hline $9 / 24 / 20108: 00$ & 9/27/2010 14:00 & 9/27/2010 18:00 & All sites \\
\hline 9/27/2010 8:56 & 9/28/2010 14:00 & 9/29/2010 18:00 & All sites \\
\hline 10/7/2010 12:21 & $10 / 7 / 201012: 30$ & 10/7/2010 14:30 & Limited (2 sites) \\
\hline 10/11/2010 9:39 & $10 / 12 / 201014: 00$ & 10/12/2010 18:00 & Limited (1 site) \\
\hline 10/12/2010 14:27 & 10/13/2010 14:00 & 10/13/2010 18:00 & All sites \\
\hline 10/15/2010 9:33 & $10 / 15 / 201014: 00$ & 10/15/2010 18:00 & Limited (2 sites, only one active) \\
\hline $11 / 2 / 201011: 48$ & $11 / 3 / 201012: 00$ & $11 / 3 / 201018: 00$ & Limited (1 site) \\
\hline
\end{tabular}

*events with notification on the day of the event shown with grey highlight

Participants were allowed to change demand response strategies between test events, but were asked not to change strategies during an event.

\section{Responding to AutoDR Test Events}

Typically the AutoDR test event signal was received at each site by a broadband modem that in turn relayed it to a gateway. The gateway translated the signal into pre-programmed shed strategies (as determined by each vendor). However, the implementation took different forms at different sites, as described in Appendix C. Controllable end uses in this project included HVAC, refrigeration, lighting and miscellaneous electrical loads (MELs). Some sites controlled more than one end use whereas other sites focused on a single end use.

Sites in this study used one or more of these strategies:

- thermostat controls, if used, allowed for changing the set point up or down or cycling of the compressors as part of the shed strategy.

\footnotetext{
${ }^{10}$ OpenADR versioning commenced after this project. Technically, OpenADR version 1.0 was used here.
} 
- lighting controls, if used, allowed for turning lights on and off or support dimming, and support the bi-level switching required by Title 24 .

- MELs controls, if used, turned devices plugged into the controller on or off on demand. There was no strict requirement on the type or size of the loads that must be supported by the MELs controller.

- refrigeration controls, if used, were able to turn off anti-sweat heaters, or provide temperature controls or performed cycling of the compressors.

Specific DR strategies used at each site are summarized in Table 3. In some cases, shed strategies planned for the site were modified after they were found to be in conflict with business practices (e.g., lighting changes originally planned for the pre-school in Pittsburg conflicted with Department of Education rules; refrigeration changes at the Santa Rosa site proved erratic during the first DR response so they were discontinued in later tests). 
Table 3. Demand response strategies by site location

\begin{tabular}{|c|c|c|c|}
\hline Vendor and site location & Facility type & Strategy & HVAC details, if relevant \\
\hline Trane, & Warehouse, office & $\begin{array}{c}\text { Precool, reset } \\
\text { thermostat }\end{array}$ & $\begin{array}{l}\text { Ten constant volume RTU's } \\
\text { each with } 2 \text { stage compressors }\end{array}$ \\
\hline \multicolumn{4}{|l|}{ Rocklin } \\
\hline LimeAmps, & Grocery, retail & $\begin{array}{c}\text { Duty cycle HVAC, } \\
\text { deli counter, and ice } \\
\text { machine }\end{array}$ & $\begin{array}{c}2 \text { single stage constant volume } \\
4 \text { ton units; compressors at } \\
\text { ground level }\end{array}$ \\
\hline \multicolumn{4}{|l|}{ Santa Rosa } \\
\hline LimeAmps, Sebastopol & Restaurant & $\begin{array}{c}\text { Duty cycle HVAC, } \\
\text { walk-in cooler }\end{array}$ & $\begin{array}{l}3 \text { packaged units: Two } 5 \text { ton } \\
\text { units and one } 4 \text { ton unit }\end{array}$ \\
\hline $\begin{array}{c}\text { Our Home Spaces, } \\
\text { Novato }\end{array}$ & Office & Reset thermostat & $\begin{array}{l}\text { Information not provided by } \\
\text { vendor }\end{array}$ \\
\hline InThrMa, Pittsburg & Pre-school & $\begin{array}{c}\text { Reset thermostats, } \\
\text { duty cycle appliances }\end{array}$ & 2 constant volume units \\
\hline Lutron, & Office & $\begin{array}{c}\text { Reduce lighting levels } \\
\text { by zones }\end{array}$ & Not applicable \\
\hline \multicolumn{4}{|l|}{ Oakland } \\
\hline Enmetric, & \multirow[t]{2}{*}{ Office } & \multirow{2}{*}{$\begin{array}{l}\text { Control MELs (plug } \\
\text { loads) }\end{array}$} & \multirow[t]{2}{*}{ Not applicable } \\
\hline Palo Alto & & & \\
\hline $\begin{array}{c}\text { Our Home Spaces, Union } \\
\text { City }\end{array}$ & Office & Reset thermostat & $\begin{array}{l}\text { One constant volume single } \\
\text { compressor RTU }\end{array}$ \\
\hline Pulse Energy, Campbell & Office & $\begin{array}{c}\text { Reduce lighting levels } \\
\text { by zone, reset } \\
\text { thermostat }\end{array}$ & $\begin{array}{l}2 \text { RTU's rated } 20 \mathrm{~A} \text { and } 16 \mathrm{~A}, \\
\text { respectively }\end{array}$ \\
\hline HD Supply, Salinas & Warehouse, office, retail & $\begin{array}{l}\text { Reset thermostat, } \\
\text { duty cycle freezers, } \\
\text { control MELs }\end{array}$ & $\begin{array}{c}\text { Information not provided by } \\
\text { vendor }\end{array}$ \\
\hline
\end{tabular}

RTU = Roof top (HVAC) unit

One vendor noted that the sites for which his technology was used were new to the concept of demand response and hypothesized that customers "learn from their first year on DR and are more willing to try new load strategies after reviewing the results at the end of the season" 11 .

\section{Data Collection}

To measure the impact of the DR events, each site was asked to collect an ongoing log of the whole facility electrical demand continuously from the start through the conclusion of the test season, sampled at a minimum of fifteen-minute intervals. Electricity demand data were collected at each site through power monitoring and logging equipment installed at each facility

${ }^{11}$ Andres Pineda, LimeAmps, private communication 
for this project or via their SmartMeter (if installed at the site by PG\&E prior to testing, data from SmartMeters was provided by PG\&E's SmartMeter data system). Ultimately the amount of data collected and analyzed for each site depended on how long the particular site participated in the project, whether the logger or meter was installed properly, and whether any data was lost during the testing period.

Table 4 summarizes the metering used for data collection. Smart Meters provided data at fifteen-minute intervals using the average of data sampled at ten second intervals. For the remaining sites where loggers or embedded systems were used, data was either obtained from fixed five-minute sample blocks that were averaged into fifteen-minute reports, or using a sliding window method where average power readings are compiled at each subinterval and the oldest subinterval is discarded.

Table 4: Meters used in pilot

\begin{tabular}{|c|c|c|}
\hline Site location & Meter & Meter Strategy \\
\hline Rocklin & Wattnode & sliding window \\
\hline SantaRosa & Conzerv & sliding window \\
\hline Sebastopol & Conzerv & sliding window \\
\hline Novato & Dent Elite/pro & five minute samples \\
\hline Pittsburg & SmartMeter & average demand over $15 \mathrm{~min}$ \\
\hline Oakland & Dent Elite/pro & five minute samples \\
\hline PaloAlto & Agilewave & five minute samples \\
\hline UnionCity & SmartMeter & average demand over $15 \mathrm{~min}$ \\
\hline Campbell & SmartMeter & average demand over $15 \mathrm{~min}$ \\
\hline Salinas & Dent Scout 18 & five minute samples \\
\hline
\end{tabular}

Some of the technologies also provided near real-time feedback to users via some form of graphical interface. Although sites were asked not to change their DR strategies during an AutoDR test event in this project, near real-time feedback provided users with a check of their strategies and a way of verifying that the site participated in the DR event.

\section{Baselines}

The demand reduction associated with a DR event is calculated by subtracting the demand measured during the event from calculated baseline values representing the estimated electrical load shape if there had not been a DR event. Negative demand savings indicate that the actual demand is higher than the estimated demand for that day.

There are several ways to estimate baselines. Previous research (Goldberg and Agnew 2003) recommends a modeling estimation and an adjustment. Based on LBNL's evaluation of different baseline models to measure load-shed performance (Coughlin et al. 2008), we used two distinct baseline models to calculate demand reductions for this project: a 10/10 ("ten ten") baseline model, and an outside air temperature regression (OAT) model. 
The 10/10 baseline is an average of the whole building demand over the previous ten business (non-weekend, non-holiday) days. If the site is particularly weather sensitive, there may be discrepancies between the 10/10 baseline and actual demand for a given day if the weather on the past ten days were different than the DR event day.

To compensate for what are typically warmer event days, the OAT model estimates the demand based on an assumed correlation between outside air temperature and site power demand. OAT baselines extrapolate from data acquired prior to an event (using data from up to 20 business days prior to an event) using measured outdoor air temperatures during the event day.

A "morning adjustment" factor (Goldberg and Agnew, 2003) was implemented to each OAT baseline to account for possible occupancy and usage variations that cannot be captured otherwise. The "morning adjustment" factor is a multiplicative factor, calculated from the four hours preceding an event (excluding the hour immediately before the event) that calibrates the OAT baseline with the 10/10 baseline.

Of the two models used here, the OAT baseline model tends to be the more accurate, less biased model and works best for weather-sensitive buildings (Coughlin et al. 2008). However, this requires collecting detailed, reliable weather data for each site. In this study, we used data from stations that are currently active and maintained by the National Oceanic and Atmospheric Administration's National Climatic Data Center (NCDC, 2011) that could reliably supply historical hourly outdoor dry bulb air temperature data over the entire test period. Stations from which hourly temperature readings were obtained for this project are identified in Table 5. 
Table 5: Source locations for weather data for each site

\begin{tabular}{|c|c|c|}
\hline Site Location & $\begin{array}{c}\text { Weather } \\
\text { Station }\end{array}$ & $\begin{array}{c}\text { Distance } \\
\text { (miles) }\end{array}$ \\
\hline Rocklin & Sacramento & 21 \\
\hline SantaRosa & Santa Rosa & 4.4 \\
\hline Sebastopol & Santa Rosa & 7.1 \\
\hline Novato & Santa Rosa & 33.1 \\
\hline Pittsburg & Concord & 9.5 \\
\hline Oakland & Oakland & 1.8 \\
\hline PaloAlto & Moffett & 5.2 \\
\hline UnionCity & Hayward & 3.6 \\
\hline Campbell & San Jose & 7.4 \\
\hline Salinas & Salinas & 1.7 \\
\hline
\end{tabular}

In some cases, the archived data were insufficient to develop the two baselines, so an averageof-similar-days model was used, based on the amount of data actually available (as long as there were at least three full days of data prior to the event day). For example, at one site the whole building power logger was installed in late August (two business days before the first DR event) and then later its recordings overwrote part of the buffer between events. In this case, the average-of-similar-day baseline was used because of insufficient prior data. For this site, available whole day data, typically less than five days, were averaged to develop the baseline.

\section{Analysis}

Data acquired from measuring whole building power demand were evaluated against the baselines calculated for each event at each site. The evaluations performed included:

- Demand saving $(\Delta \mathrm{kW})$

- Demand savings intensity $\left(\mathrm{W} / \mathrm{ft}^{2}\right)$

- Comparison of whole building demand with outside air temperature

Demand saving $(\Delta \mathrm{kW})$ measures the change in demand during DR events, calculated by subtracting the actual whole-building power during an event from baseline estimates of what the demand would have been without the DR response. This value can be more readily compared between sites when it is normalized against the amount of conditioned space $\left(\mathrm{W} / \mathrm{ft}^{2}\right)$, they.

The comparison of whole building demand with outside air temperature provides a visual measure of how whole building demand varies with outside air temperature and business practices. For these graphs, the average site temperature during the DR event time (typically 2- 
$6 \mathrm{pm})$ was calculated, as was the average demand during the same time period. These averages were calculated for event days as well as non-event days so that comparisons could be made. 


\section{CHAPTER 4: Summary of Results}

A key objective of this study was to determine whether there was a variety of existing equipment that could automatically implement DR in small and medium commercial buildings. The data suggests that all vendor equipment in this project were able to reliably receive and translate OpenADR signals to pre-established shed strategies at each site. Because these strategies were not optimized, the tests did not accurately yield how much load reduction was possible at any given site.

Measured demand and savings estimates by site from the tests conducted here are summarized in Table 6 below.

Table 6: Summary of demand savings by site location

\begin{tabular}{|c|c|c|c|c|c|c|c|c|c|c|c|c|}
\hline \multirow[b]{2}{*}{ Location } & \multirow[b]{2}{*}{ Vendor } & \multirow{2}{*}{$\begin{array}{l}\text { \# of DR } \\
\text { events }\end{array}$} & \multirow[b]{2}{*}{ Size $\mathrm{ft}^{2 *}$} & \multirow{2}{*}{$\begin{array}{c}\text { Peak } \\
\text { Demand, } \\
\text { kW } \\
\end{array}$} & \multirow{2}{*}{$\begin{array}{c}\text { Maximum } \\
\text { Temperature } \\
\text { during DR } \\
\text { event, }{ }^{\circ} \mathrm{F} \\
\end{array}$} & \multicolumn{3}{|c|}{$\mathrm{kW}$} & \multicolumn{3}{|c|}{$\mathrm{W} / \mathrm{ft}^{2}$} & \multirow[t]{2}{*}{ Baseline } \\
\hline & & & & & & $\max$ & ave & $\min$ & $\max$ & ave & $\min$ & \\
\hline \multirow[b]{2}{*}{ Rocklin } & \multirow[b]{2}{*}{ Trane } & \multirow[b]{2}{*}{6} & \multirow[b]{2}{*}{22,500} & \multirow[b]{2}{*}{319} & \multirow[b]{2}{*}{96.8} & 73.44 & -18.78 & -73.81 & 2.94 & -0.75 & -2.95 & OAT w MA \\
\hline & & & & & & 34.70 & -26.62 & -85.18 & 1.39 & -1.07 & -3.41 & $10 / 10$ \\
\hline \multirow[b]{2}{*}{ Santa Rosa } & \multirow[b]{2}{*}{ LimeAmps } & \multirow[b]{2}{*}{8} & \multirow[b]{2}{*}{3,531} & \multirow[b]{2}{*}{34} & \multirow[b]{2}{*}{106.6} & 12.15 & 0.32 & -10.03 & 3.44 & 0.09 & -2.84 & OAT w MA \\
\hline & & & & & & 11.95 & -0.14 & -9.08 & 3.38 & -0.04 & -2.57 & $10 / 10 \mathrm{BL}$ \\
\hline \multirow[b]{2}{*}{ Sebastopol } & \multirow[b]{2}{*}{ LimeAmps } & \multirow[b]{2}{*}{5} & \multirow[b]{2}{*}{4,200} & \multirow[b]{2}{*}{45} & \multirow[b]{2}{*}{100.9} & 11.20 & -0.02 & -10.71 & 2.67 & -0.01 & -2.55 & OAT w MA \\
\hline & & & & & & 8.62 & -2.83 & -14.10 & 2.05 & -0.67 & -3.36 & $10 / 10 \mathrm{BL}$ \\
\hline \multirow[b]{2}{*}{ Novato } & \multirow[b]{2}{*}{$\mathrm{OHS}$} & \multirow[b]{2}{*}{5} & \multirow[b]{2}{*}{800} & \multirow[b]{2}{*}{7} & & 6.01 & 0.29 & -4.10 & 7.51 & 0.37 & -5.13 & OAT w MA \\
\hline & & & & & 100.9 & 1.99 & -0.47 & -4.62 & 2.49 & -0.59 & -5.78 & $10 / 10 \mathrm{BL}$ \\
\hline & & & & & & 15.10 & 1.20 & -18.10 & 6.04 & 0.48 & -7.24 & OAT w MA \\
\hline Pittsburg & InThrMa & 7 & 2,500 & 57 & 105 & 14.92 & 2.48 & -15.14 & 5.97 & 0.99 & -6.06 & $10 / 10 \mathrm{BL}$ \\
\hline & & & & & & 17.18 & 1.17 & -16.48 & 0.86 & 0.06 & -0.82 & OAT w MA \\
\hline Oakland & Lutron & 8 & 20,000 & 71 & 96.9 & 8.73 & -4.24 & -22.22 & 0.44 & -0.21 & -1.11 & $10 / 10 \mathrm{BL}$ \\
\hline & & & & & & 7.60 & -0.66 & -8.12 & 15.20 & -1.33 & -16.23 & OAT w MA \\
\hline Palo Alto & Enmetric & 7 & 500 & 26 & 99.9 & 10.38 & 0.45 & -5.93 & 20.77 & 0.89 & -11.86 & $10 / 10 \mathrm{BL}$ \\
\hline & & & & & & 2.98 & 0.36 & -2.16 & 1.36 & 0.16 & -0.98 & OAT w MA \\
\hline Union City & $\mathrm{OHS}$ & 7 & 2,200 & 7 & 98.6 & 2.54 & -0.04 & -2.23 & 1.15 & -0.02 & -1.01 & $10 / 10 \mathrm{BL}$ \\
\hline & & & & & & 7.36 & 0.31 & -10.18 & 3.56 & 0.15 & -4.92 & OAT w MA \\
\hline Campbell & Pulse Energy & 7 & 2,070 & 18 & 101.9 & 6.62 & -0.16 & -7.30 & 3.20 & -0.08 & -3.52 & $10 / 10 \mathrm{BL}$ \\
\hline & & & & & & 0.17 & -2.95 & -4.11 & 0.03 & 0.49 & -0.69 & OAT w MA \\
\hline Salinas & HD Supply & 1 & 6,000 & 26 & 85.8 & -3.23 & -4.62 & -6.55 & -0.54 & -0.77 & -1.09 & $10 / 10 \mathrm{BL}$ \\
\hline
\end{tabular}

* DR strategies implemented on only a portion of the indicated space, so demand savings intensity has been adjusted accordingly (Palo Alto site controlled approximately $500 \mathrm{ft}^{2}$ (out of 13,000 ft'); Pittsburg site controlled $2500 \mathrm{ft}^{2}$ (out of 18,250 $\mathrm{ft}^{2}$ ).

** Peak demand measured over the entire testing period

Note that the values for the Palo Alto and Pittsburg sites are somewhat skewed by the fact that the conditioned space is so much smaller than the space over which the power was metered during tests.

The Santa Rosa and Sebastopol sites used the same vendor technology on different kinds of sites (but with different strategies), and the Novato and Union City sites used a common vendor technology on two different small offices (same strategies). The Novato site was occupied intermittently whereas the Union City site was occupied on a more regular basis. In each case, variations in results were observed. Data for the Salinas site is limited to a single test. 
In general, the results show at best limited demand savings. There are several possible causes:

- Site customers had not practiced DR previously, and may have been conservative in selecting DR strategies for these tests.

- Some strategies provided small demand savings that could not be seen above the demands of other building systems in the facility. This problem was common to most sites that did not include HVAC control in their DR strategies.

- DR strategies may not have been optimized for the particular sites.

- Strategies involving HVAC control were not able to maintain the demand response strategy over an extended time period. After a clear response to the initial DR event signal, loads return to baseline levels within about two hours after the start of the DR event. This may have been due to on-site conditions such as leaking ducts or undersized HVAC equipment.

Comparing the average demand with the average outside air temperature during event times at each site provides useful insights about how business practices influenced demand in some cases. In the following three figures, "No Event" is a measure of the average demand during the DR period on a day during which no DR event occurred plotted against the average outside air temperature at the site during the same time period. "Event" refers to the average demand during a DR event, plotted against the average outside air temperature during that same time period. 
Figure 5: Demand as a function of outdoor air temperature at Palo Alto site

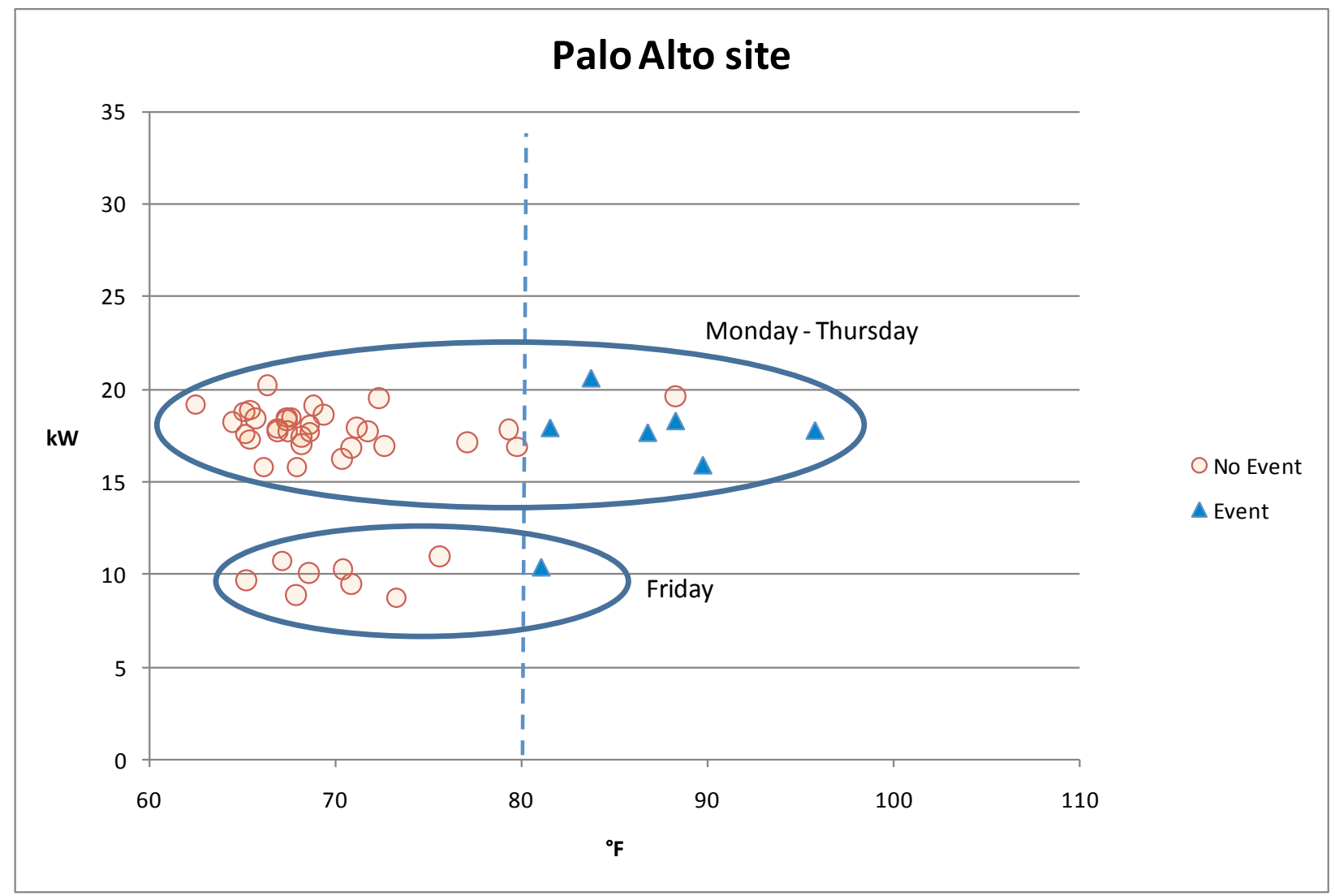

At the Palo Alto site (Figure 5), there was a clear distinction between demand measured Monday-Thursday compared with that measured on Friday. Note that data for Fridays is not especially predictive of data for other days of the week. With one exception, there is no nonevent day data to suggest the anticipated response of the site on warmer days when the DR events took place. The demand at this site appears to be fairly flat and not sensitive to weather to $80^{\circ} \mathrm{F}$, but the data provides no indication of what the demand would be above this temperature on a non-event day (e.g., if additional cooling was needed when the outside air temperature is higher than $80^{\circ} \mathrm{F}$ ).

By contrast, at the Campbell site (Figure 6), there were some non-event days with higher average temperatures than event days, providing limited context to suggest that demand on at least 3-4 of the event days was, on average, reduced from what would be expected without DR strategies in place. 
Figure 6: Demand as a function of outdoor air temperature at Campbell site

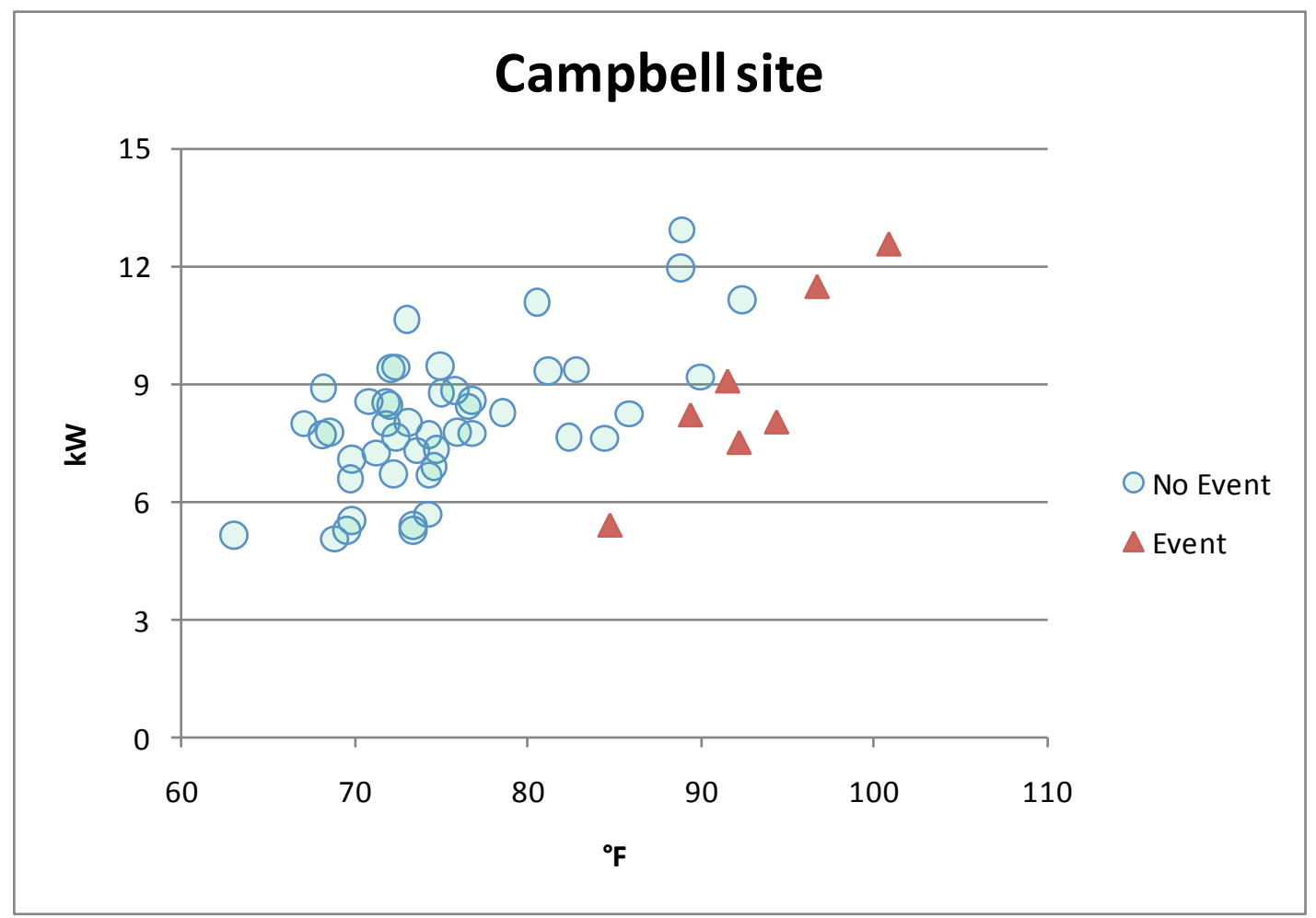

At the Sebastopol site (Figure 7), the business was closed on Mondays and Tuesdays, but the vendor equipment continued to control the HVAC equipment in response to DR events on those days. A distinction in demand between business days and days when the business was closed indicates why those days are not included in baseline calculations. For days when the business was closed, data was excluded from the analyses presented for this site (Appendix C3). 
Figure 7: Demand as a function of outdoor air temperature at the Sebastopol site

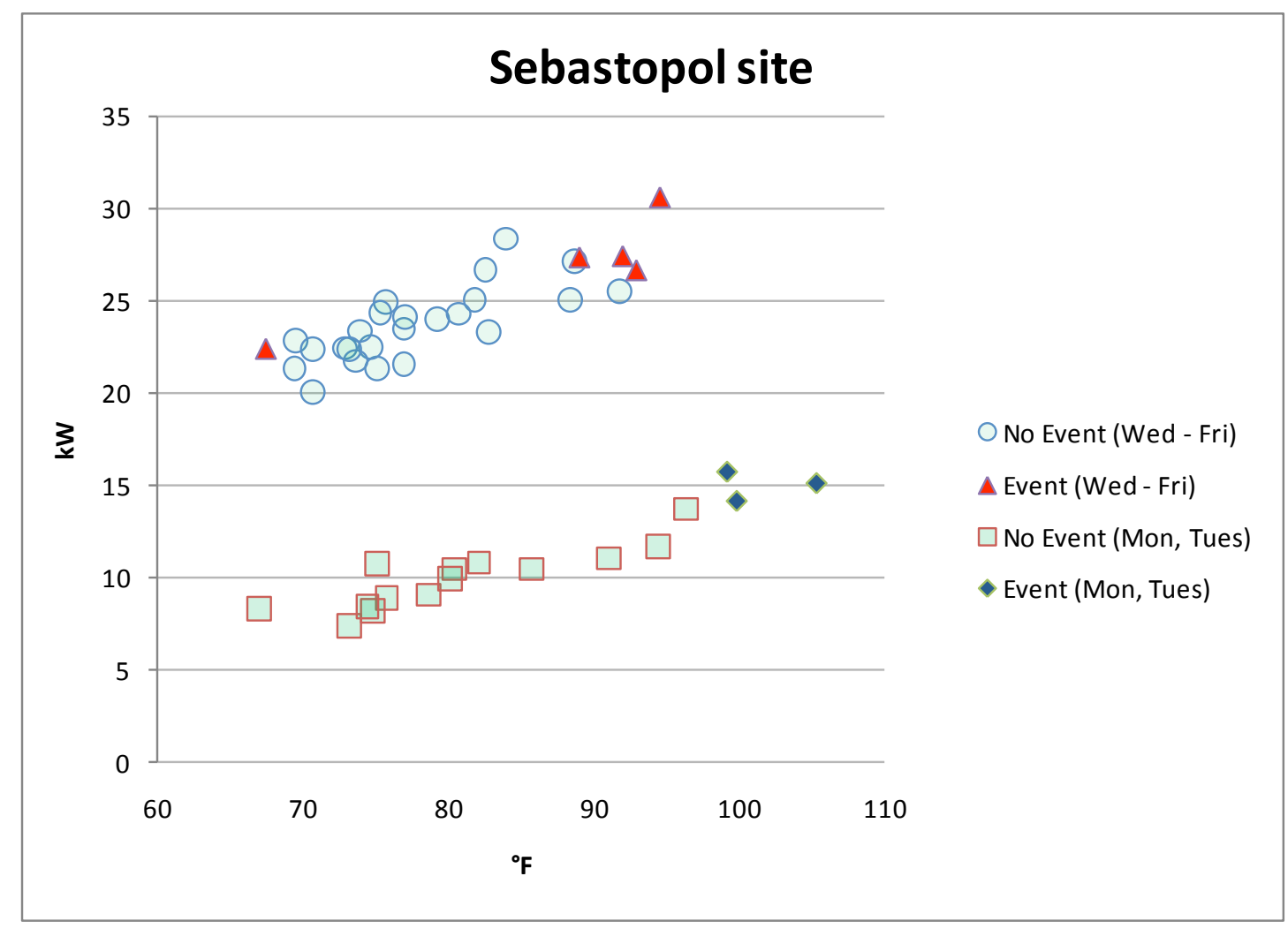

Evaluation of site responses on individual event days gives more insight into issues that may reduce the overall DR response of small and medium commercial buildings. In most cases, these issues are related to equipment already on-site rather than the vendor equipment introduced during these tests to implement DR strategies, and point to the need for strategies that are more consistent with on-site equipment capabilities (as well as a need for commissioning on-site equipment to make sure it is performing optimally).

Data from the Pittsburg site, shown in Figure 8, illustrates one problem common to many sites: the inability of equipment to maintain the DR strategy over an extended time period. (This problem manifested in a variety of ways at different sites but was most clear in this data.) Note that this was not an issue for sites controlling only lights or MELs, except when other site loads not part of the DR strategy obscured the controlled site loads, as discussed below. 
Figure 8: DR response with limited sustainability (sample data from Pittsburg site, 9/1/2010, maximum outdoor temperature $95.9^{\circ} \mathrm{F}$ )

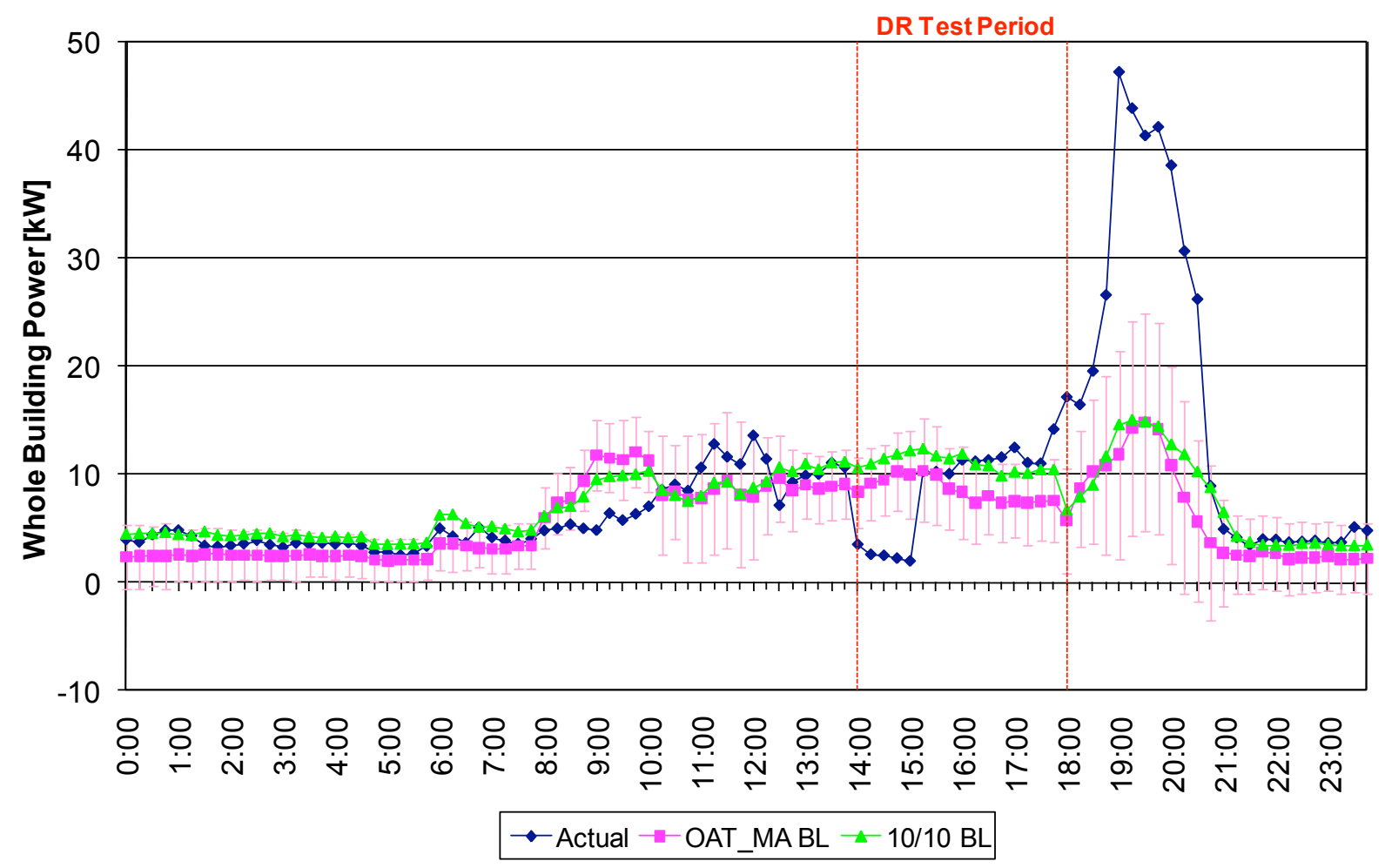

A clear response to the DRAS signal initiating an AutoDR test event is seen at the start of the DR period, but after over one hour, the facility's demand returns to baseline levels. (Note that the much larger power demand seen after the DR period is related to operations at other parts of the site connected to the same meter and were not part of the test.)

In other sites, we observe fluctuations in the response after the initial reduction of demand at the start of the event. An example of this is the apparent cycling of a constant volume air rooftop unit after the initial response of the site to the DR event signal illustrated in Figure 9. Here the site clearly responds at the start of the DR event, but is unable to maintain the shed over the entire DR period due to limitations inherent with the onsite equipment. This may have been due to leaky duct work or undersized HVAC units working overtime to compensate after about two hours of DR response. 
Figure 9: DR response showing cycling of constant volume RTU (sample data from Union City site, $9 / 24 / 2010$, maximum outdoor temperature $85.8^{\circ} \mathrm{F}$ )

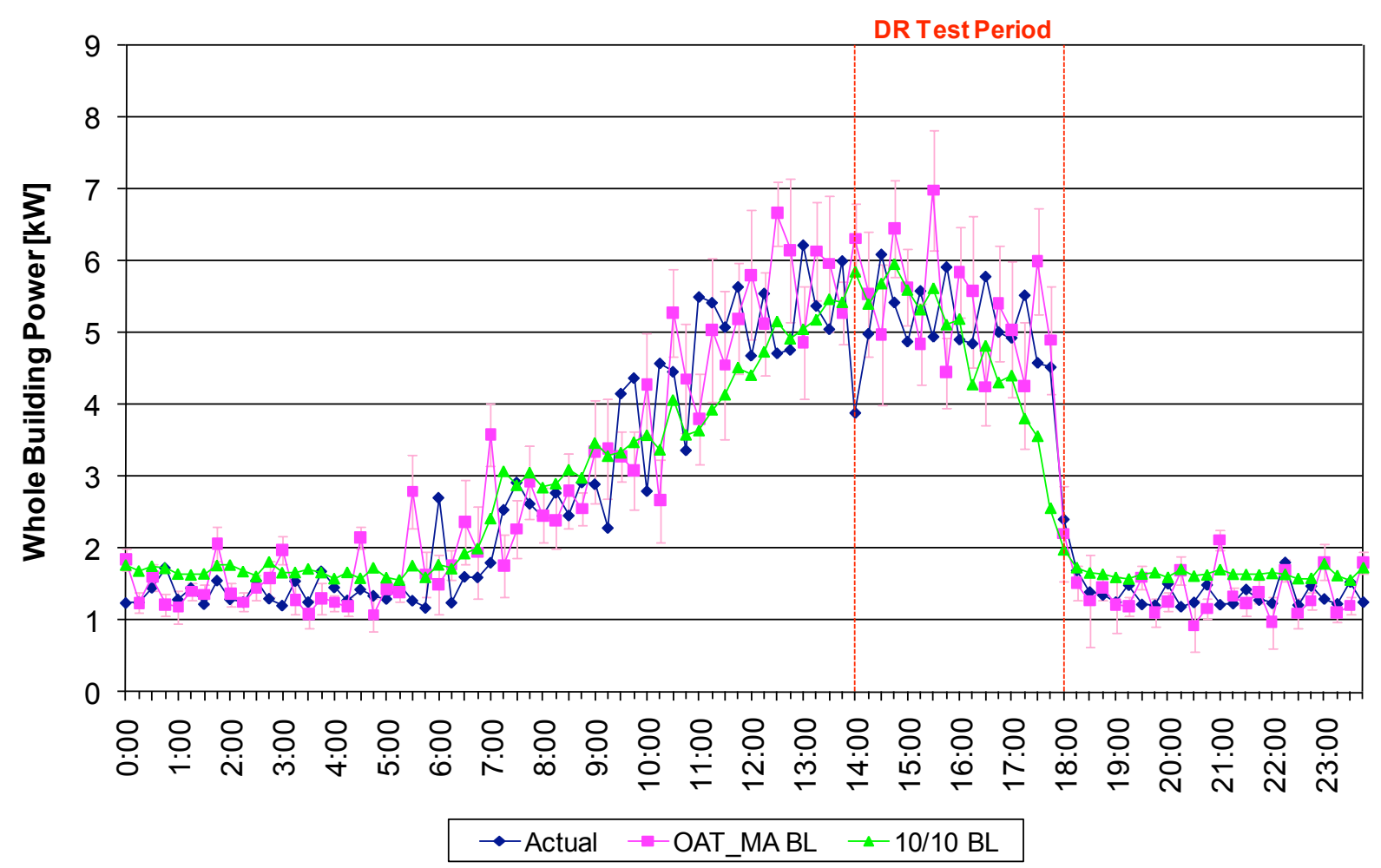

Constant air volume system cycling is also seen in the load profile of the Oakland site on a relatively cool day (September 22, 2010, maximum outdoor air temperature during DR event was $70^{\circ} \mathrm{F}$ ), where only the lighting was controlled during the DR tests (Figure 10). Examining the sub-meter data for only the lighting circuits, seen in Figure 11, shows a clear demand reduction that was essentially in the noise of the overall building demand of Figure 10 that was dominated by cyclic HVAC operations. Aggregation of these types of sites may smooth out the noise and may make the lighting sheds more visible. 
Figure 10: Cyclic DR response at site where DR strategy only controlled lighting (sample data from Oakland site, 9/22/2010, maximum outdoor temperature $69.9^{\circ} \mathrm{F}$ )

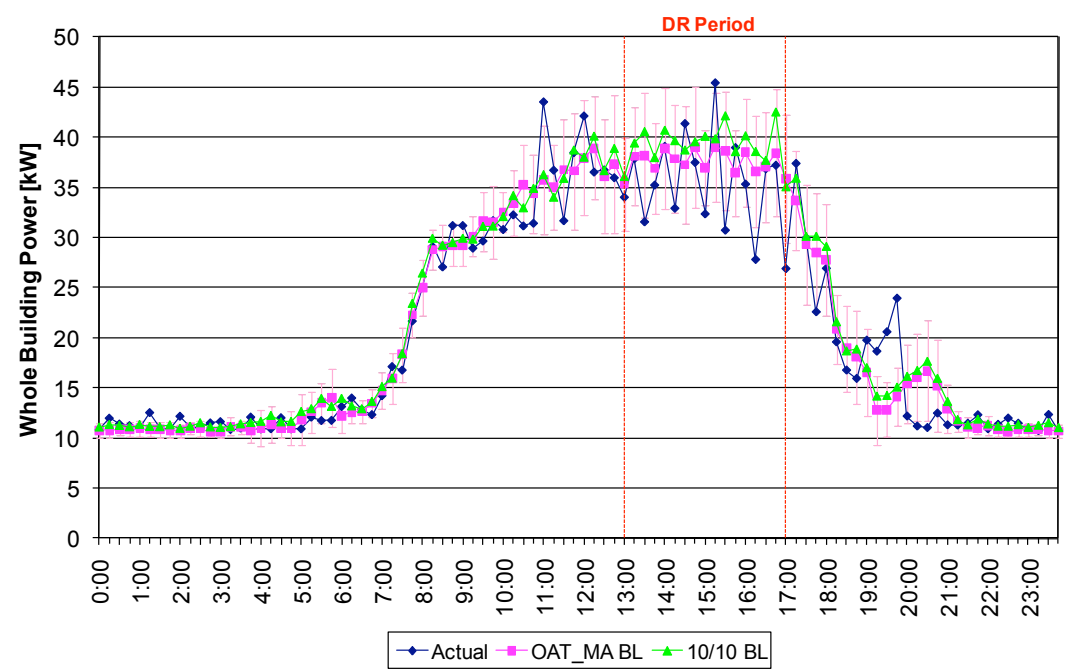

Figure 11: DR response of lighting circuits only (Oakland site on 9/22/2010)

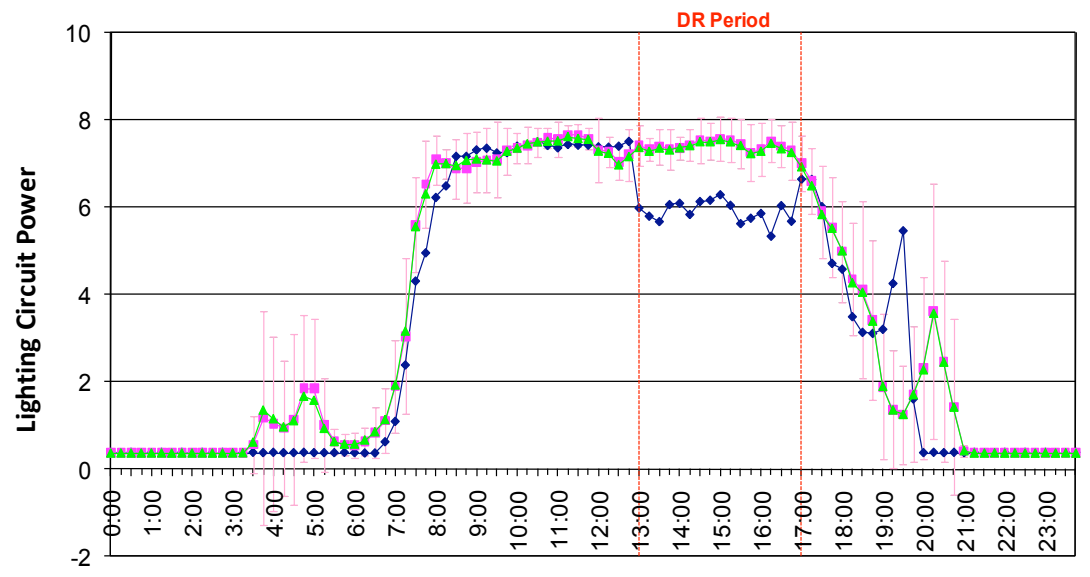

$\rightarrow$ Actual - -OAT_MABL $₫ 10 / 10 \mathrm{BL}$

Details of the individual site characteristics, vendor technology applied, strategies used, and site responses to the DR events called during this project are contained in Appendix C of this report. Evaluation of aggregate of the responses (Figure 12) on a selected DR test day, we see a clear DR response that lasts for only about two hours. What appears to be an extra demand after the DR event is, as noted above for the Pittsburg site, actually related to other activities on that site that were unrelated to the DR testing. This suggests that DR in small and medium commercial 
buildings, even without optimized strategies, can produce an aggregate demand reduction for part of the DR period. Note that the Rocklin (Trane) and Salinas (HD Supply) sites are not included because they were not yet instrumented on this test day, and the Novato site (OHS) data is not included because its logger accidentally lost the information for this test day.

Figure 12: Aggregate DR response of all sites participating in September 2, 2010 DR event

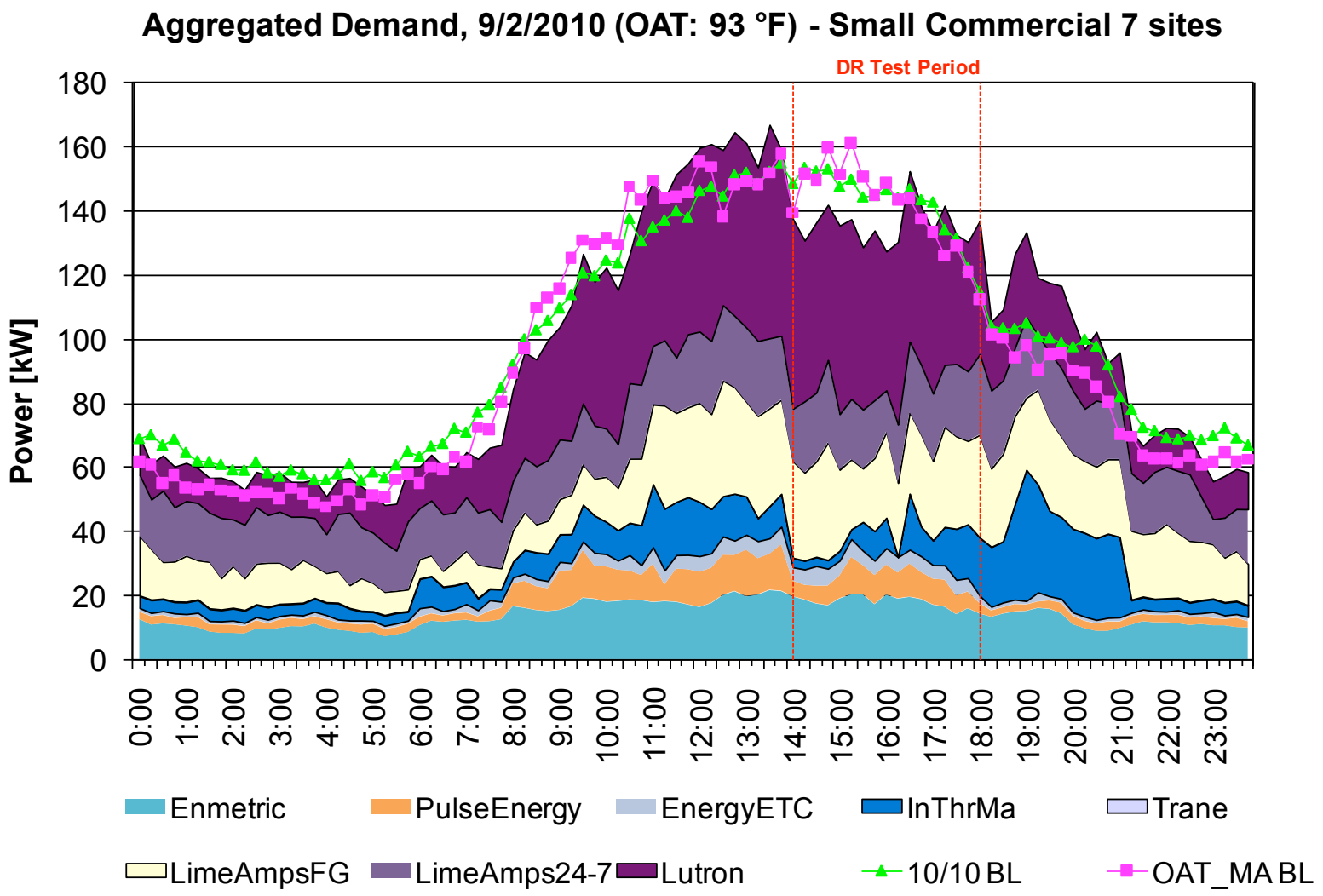




\section{CHAPTER 5: Conclusions and Discussion}

Essentially, this project showed that currently available technology works in terms of reliably receiving OpenADR signals and translating them into pre-programmed DR strategies for each site. These tests did not identify how well each site could respond to DR events. It is likely that better levels of load sheds could be obtained if the response strategies were more carefully designed and optimized for each site.

In terms of specific goals for this project:

Identifying available technology that is suitable for automating demand response for smallmedium commercial buildings

Through this project, technology from eight different vendors was studied, representing a wide range of approaches to DR in small and medium commercial buildings. Each technology was capable of responding to OpenADR signals at the start of an event, and allowed resumption of normal building operations at the conclusion of events. Therefore, the project verified that small and medium commercial buildings will be able to choose from several options of currently available technologies that can respond to an OpenADR signals when the PDP tariff becomes the default.

\section{Validating how well that technology does what it claims to be able to do}

At each site, the associated vendor provided equipment that was shown to be OpenADR compliant and able to trigger a predefined DR strategy. Some DR strategies, such as lighting and MEL control, provided immediate response to indicate the technology performed as expected. In other cases, the associated vendor verified operations through some other form of monitoring (one scheme used a night light on a controlled circuit: when it glowed, the control equipment had turned off that circuit). In some cases, the moderately increased temperature in the occupied space provided confirmation.

\section{Determining whether customers find the technology useful}

Overall, the technology was well accepted at each site with minimal to no impact on business operations. In general, the only concerns expressed were related to the particular DR strategy and not with the AutoDR technology.

At one site, a salesclerk within a convenience store expressed discomfort during a DR event on a particularly warm day, but no impact on customers was noted, as the customers were not exposed to the higher indoor temperatures for an extended time.

At the site where only lighting was differentially controlled within the site, the vendor conducted a survey to determine how this change impacted occupants (see Appendix D). The survey found that among those who perceived a change in lighting levels, there was a generally inaccurate estimation of the amount by which the lights had changed. Curiously, a subsequent 
survey on a day with no DR (i.e., no lighting changes) showed a surprising number of occupants continued to think there was a change in the lighting when there was none.

\section{Characterizing how well the technology provides demand response options for customers}

For the strategies tested, the technology performed as expected. However, in many cases, we did not see distinct load reductions were not discernable compared to the site's baselines. The data suggest two somewhat interrelated reasons for this, all related to the strategies chosen for responding to DR events rather than any inherent weakness in the technology itself:

- In some cases, the loads being controlled were too small to distinguish from the whole building load (e.g. lighting or MELs), or the uncontrolled loads were too noisy, or key site loads were not controlled as part of the DR response.

- At most of the sites where HVAC was controlled, either via resetting the thermostat or by directly controlling the equipment, DR was not maintained. This may arise from incorrectly sized or poorly functioning building systems (e.g. HVAC), insufficient insulation within the building, improperly designed or overridden shed strategies, leaking ducts, or some other cause related to the design and/or operations of the building systems.

Little to no observed savings in demand may have been due to, as one vendor noted after the testing concluded, "there was no direct incentive for the customer to participate other than curiosity and the spirit of going green."12 It may well be that as financial incentives are introduced and as customers become more familiar with DR, they will be more willing to try innovative or deeper DR strategies.

An unexpected side benefit of this project was enhancing the DRAS communication link to small and medium commercial customers. Prior to the work reported here, that communication had been more focused on the needs of large commercial and industrial sites, where the DRAS was interacting with an EMCS rather than individual pieces of site equipment. During this project, the need for a simplified interface to the DRAS to make it more appropriate to the needs of small and medium commercial buildings was identified. Since these buildings typically do not have an onsite facility manager, simpler interfaces ultimately provided an easier way for them to adopt OpenADR based DR technologies while also providing a more direct means for sites to opt out of DR events and modify DR strategies.

However, additional education is needed to help manufacturers and vendors of demand response technologies identify more effective DR strategies for various end uses in order to get more substantial and consistent demand savings during DR events. In a small or medium commercial site, individual equipment is typically not well coordinated with other site equipment.

Earlier work by Herter (2009) identified one-on-one consultation as a useful supplement to DR programs so that DR strategies can consider any inherent weaknesses in the overall facility

\footnotetext{
${ }^{12}$ Andres Pineda of LimeAmps, private communication.
} 
electricity use. A lower cost approach that creates value for both the utility and the site owner may be to educate vendors about (1) the limitations and opportunities possible in controlling end uses differently in response to DR events, (2) more effective DR strategy development for small to medium sized sites, and (3) ways to evaluate the efficacy of different approaches.

Feedback may also be a useful way to enhance DR strategies. Several systems incorporated essentially real-time displays of electricity demand so that site occupants could monitor the results of the testing. None of the technologies tested here provided automated feedback on customer's DR performance in real time to fine tune the site DR response, but results from the real time displays informed strategy changes between events in some cases.

While the economics of the PDP program were not specificially analyzed, we note that other DR programs have tried different kinds of incentives to motivate demand reductions during DR events. The PDP tariff does this indirectly via surcharges during DR events. Alternate program incentives may be needed to encourage participation of smaller customers.

Future work is needed in the areas of:

- Developing an education program geared towards identifying useful strategies for different kinds of customers. The target for such a program would be small commercial technology vendors so that they can respond more effectively to DR events. Now that the technology has generally been proven in terms of its ability to reliably receive an AutoDR signal and convert that to a change in building operation, there is a need to make those applications provide consistent demand savings during DR events. It is insufficient to simply install the AutoDR equipment without consideration for inherent operation and constrains of end uses in the overall electricity use at a facility.

- Developing more detailed integrated energy audits that focus on both energy efficiency measures and peak load reductions.

- Economic analyses to identify ways to encourage customer adoption of AutoDR technologies, streamline the implementation process, and encourage ongoing efforts to improve and sustain DR responses.

- Identification of the best approach and program design in order to widespread the implementation of OpenADR equipment to facilitate AutoDR at small and medium commercial buildings, including but not limited to awareness of options, appropriate technologies, measurement and feedback of equipment performance, and fine tuning of DR strategies for classes of small and medium commercial buildings.

- Determining if and how any of the following can improve the DR response of smallmedium commercial facilities: aggregation, customer performance feedback loops, and centralized building controls.

- Performing tariff analyses to determine typical savings under different dynamic pricing models.

- Testing different user interfaces from SmartMeters to determine what is most useful in promoting DR.

- Identifying ways to measure or characterize the load reductions possible from different sources during DR events. 
- Characterizing how useful customers find technology associated with DR in terms of its ability to (a) control loads, (b) achieve desired economic results, and (c) balance comfort and economic benefits throughout the entire DR event period.

- Developing audit tools to tune DR responses to make them more effective throughout the DR event period.

- Finding useful incentives to encourage rebates for DR equipment purchase and installation (once better DR strategies for this market segment are understood). 


\section{Glossary}

10/10 Baseline energy consumption generated from previous ten business days at site

CBP Capacity Bidding Program (DR program)

CPP Critical Peak Pricing (DR tariff)

CPUC California Public Utilities Commission

DR Demand Response

DRAS Demand Response Automation Server

DRRC Demand Response Research Center

EMCS Energy Management and Control Systems

GW gigawatt ( $10^{6}$ watts)

HVAC Heating, Ventilation and Air Conditioning

kW kilowatt

LBNL Lawrence Berkley National Laboratory

MA Morning adjustment

NCDC National Climatic Data Center

OAT Outside Air Temperature

OpenADR Open, Non-Proprietary Automated Demand Response

PDP Peak Day Pricing (DR tariff)

PG\&E Pacific Gas and Electric Company

RFP Request for Proposals

RTU Rooftop (HVAC) unit

SMB Small Medium Business 


\section{References}

Akuacom. (2010). A recording of the online meeting associated with the procurement for this project can be found at:

https://akuacom.webex.com/akuacom/ldr.php?AT=pb\&SP=MC\&rID=39626747\&rKey=c0 5452b3f86d7997

Coughlin, K., M. A. Piette, C. Goldman and S. Kiliccote. (2008). Estimating Demand Response Load Impacts: Evaluation of Baseline Load Models for Non-Residential Building in California. Demand Response Research Center, Lawrence Berkeley National Laboratory. LBNL-63728.

CPUC (California Public Utilities Commission) FAQ (frequently asked questions): Accessed November 22, 2010.

http://www.cpuc.ca.gov/cfaqs/howhighiscaliforniaselectricitydemandandwheredoesthe powercomefrom.htm

EnerNOC Expands Small Commercial Offering through Acquisition of SmallFoot, LLC. Press Release. Accessed June 24, 2010. http://www.enernoc.com/press/releases/171/enernocexpands-small-commercial-offering-through-acquisition-of-smallfoot-llc.php

Federal Energy Regulatory Commission. (2011). 2010 Assessment of Demand Response and Advanced Metering: Staff Report. February 2011.

Federal Energy Regulatory Commission. Electric Power Markets: California (CAISO). Accessed Accessed June 29, 2011. www.ferc.gov/market-oversight/mkt-electric/california.asp

Goldberg, M.L. and Agnew, G.K. (2003). Protocol Development for Demand Response Calculation - Findings and Recommendations, 400-02-017F. Sacramento, CA: Prepared for the California Energy Commission by KEMA-Xenergy.

Herter, K., S. Wayland, J. Rasin. (2009). A Successful Case Study of Small Business Energy Efficiency and Demand Response with Communicating Thermostats. International Energy Program Evaluation Conference, August 2009. LBNL-2743E.

Kiliccote, S., Piette, M. A., Dudley, J. H., Koch, E., Hennage, D. (2009). Open Automated Demand Response for Small Commercial Buildings. Lawrence Berkeley National Laboratory. LBNL-2195E, July 2009

Kiliccote, Sila, and Mary Ann Piette. (2008). Automation Development and Testing of the Capacity Bidding Program for San Diego Gas and Electric Company. California Energy Commission,PIER Program. CEC-500-03-026, April 2008.

Lockheed Martin Aspen. (2006). Demand Response Enabling Technologies for Small-Medium Businesses. A Technical Report prepared in conjunction with the 2005 California Statewide Pricing Pilot R.02.06.001 by Lockheed Martin Aspen, Rockville, MD, 12 April 2006 (http://sites.energetics.com/MADRI/pdfs/LMADRT_060506.pdf) 
National Climatic Data Center. (2011). Accessed July 1, 2011.

http://www.ncdc.noaa.gov/oa/ncdc.html

OpenADR Alliance. Accessed June 29, 2011. http://www.openadr.org/ 


\section{APPENDICES}

APPENDIX A. Procurement Documents

APPENDIX B. Summary of Peak Day Pricing Tariff APPENDIX C. Site Descriptions and Data APPENDIX D. User Surveys Conducted by Lutron 


\section{TABLE OF CONTENTS}

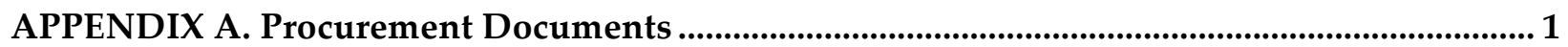

APPENDIX B. Summary of Peak Day Pricing Tariff ............................................................................ 25

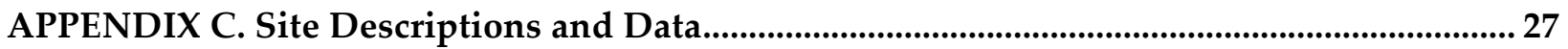

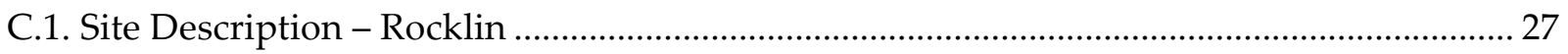

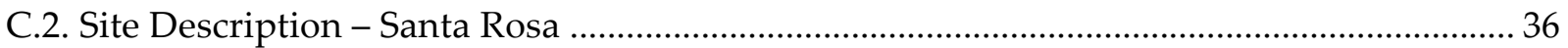

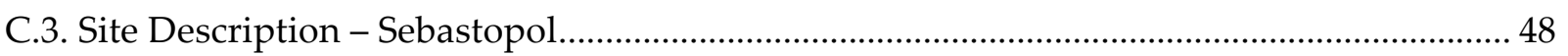

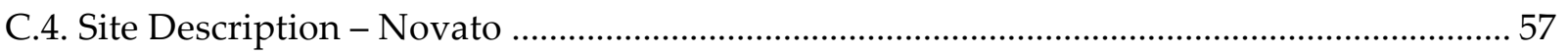

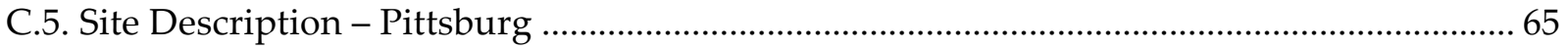

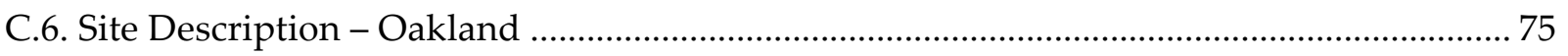

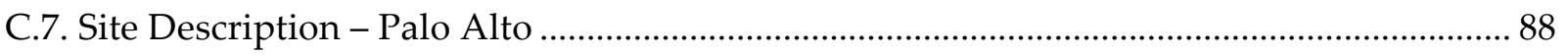

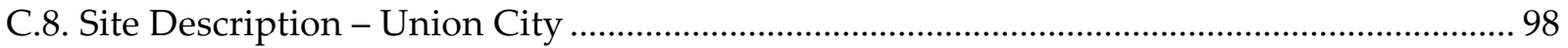

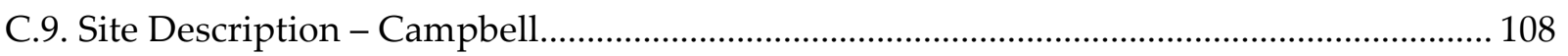

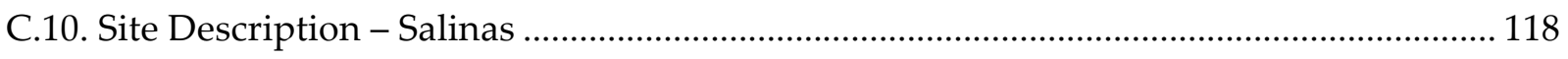

APPENDIX D. User Surveys Conducted by Lutron ............................................................................ 122 


\section{TABLE OF CONTENTS}

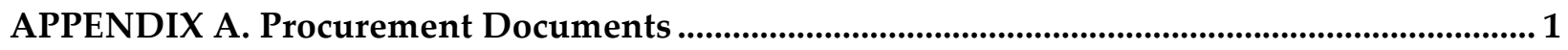

APPENDIX B. Summary of Peak Day Pricing Tariff ............................................................................ 25

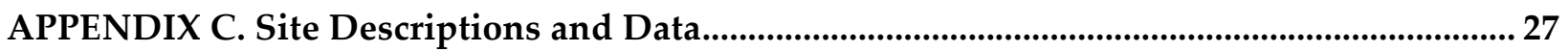

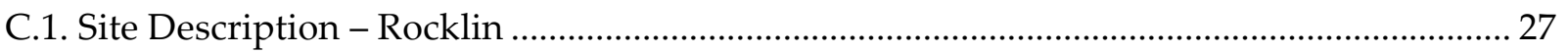

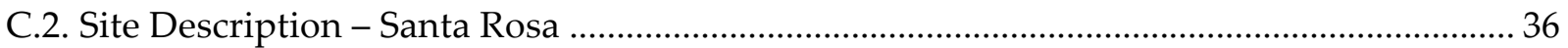

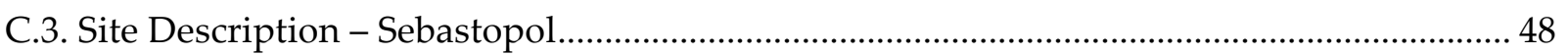

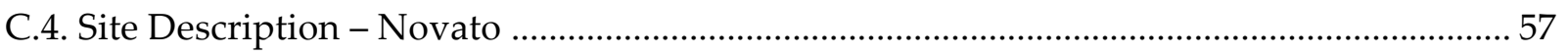

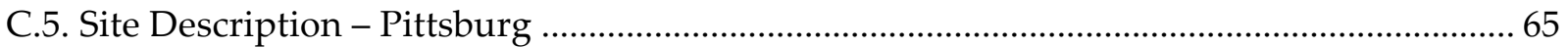

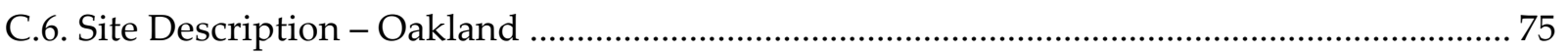

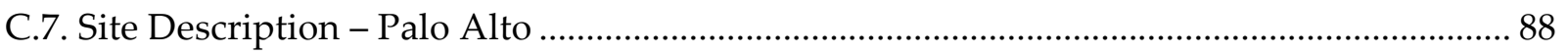

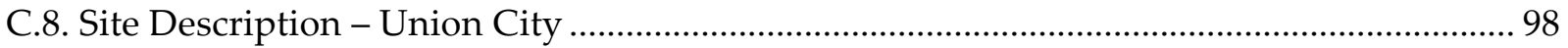

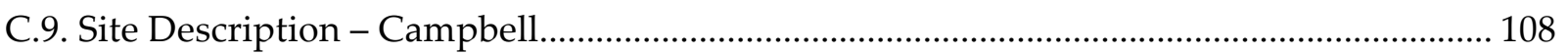

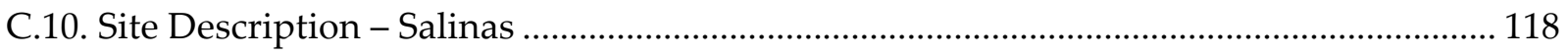

APPENDIX D. User Surveys Conducted by Lutron ............................................................................ 122 


\section{LIST OF FIGURES}

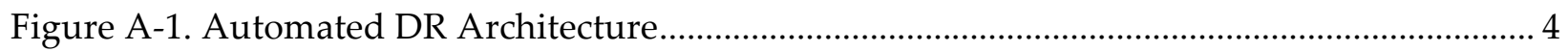

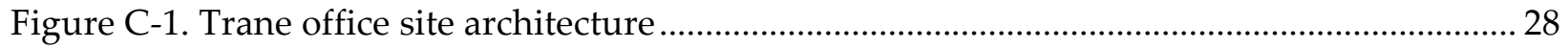

Figure C-2. Trane, September 24, 2010 (Max OAT: 89² F) ............................................................ 29

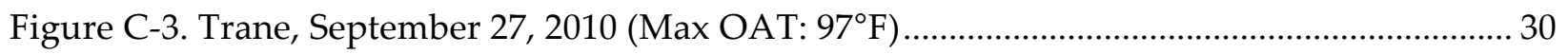

Figure C-4. Trane, September 28, 2010 (Max OAT: 100º) .......................................................... 31

Figure C-5. Trane, October 12, 2010 (Max OAT: 90 F)................................................................ 32

Figure C-6. Trane, October 13, 2010 (Max OAT: 92º F)................................................................. 33

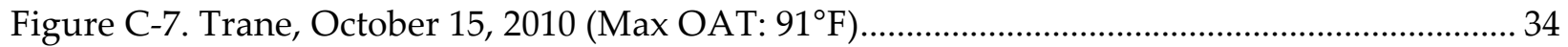

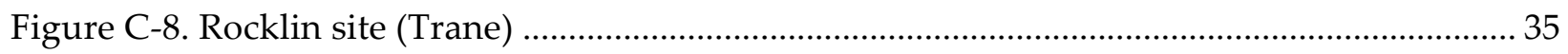

Figure C-9. 24 Seven Fuel \& Food Site Architecture ...................................................................... 38

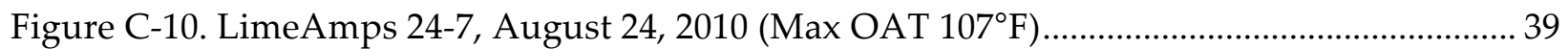

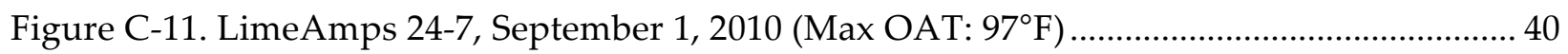

Figure C-12. LimeAmps 24-7, September 2, 2010 (Max OAT: $\left.98^{\circ} \mathrm{F}\right)$.............................................. 41

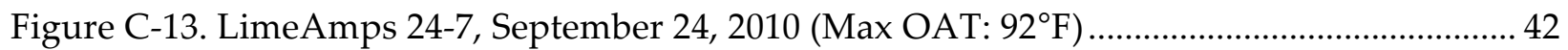

Figure C-14. LimeAmps 24-7, September 27, 2010 (Max OAT: 101ํF) ......................................... 43

Figure C-15. LimeAmps 24-7, September 28, 2010 (Max OAT: 103 $\left.{ }^{\circ} \mathrm{F}\right)$............................................ 44

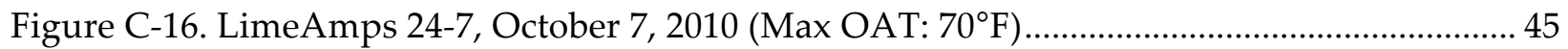

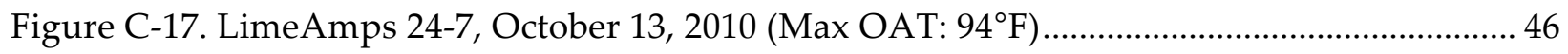

Figure C-18. Santa Rosa Site (LimeAmps 24-7) …....................................................................... 47

Figure C-19. French Restaurant site architecture …...................................................................... 50

Figure C-20. LimeAmpsFG, September 1, 2010 (Max OAT: 97 F) …......................................... 51

Figure C-21. LimeAmpsFG, September 2, 2010 (Max OAT: $\left.98^{\circ} \mathrm{F}\right)$................................................ 52

Figure C-22. LimeAmpsFG, September 24, 2010 (Max OAT: 92ํ) …........................................ 53

Figure C-23. LimeAmpsFG, October 7, 2010 (Max OAT: 70 F) .................................................... 54

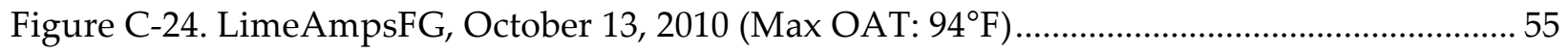

Figure C-25. Sebastopol site (LimeAmps French Garden) ............................................................ 56

Figure C-26. OHS office site architecture ................................................................................ 58 


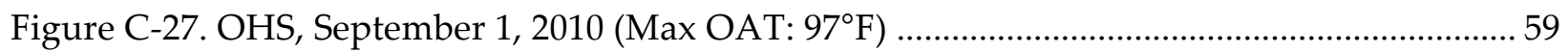

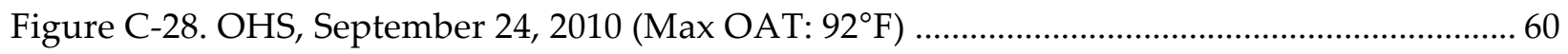

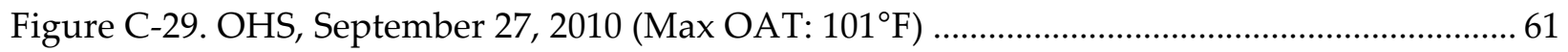

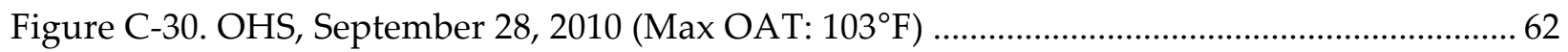

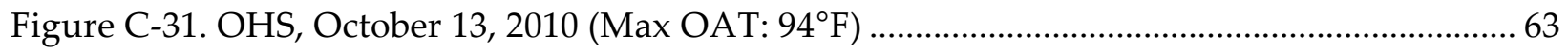

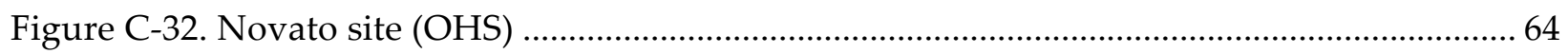

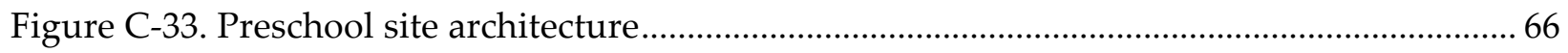

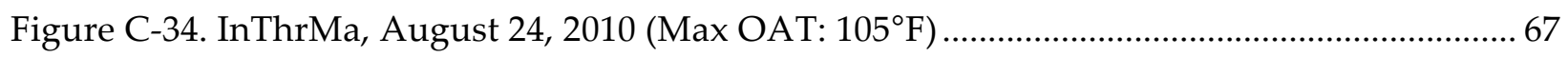

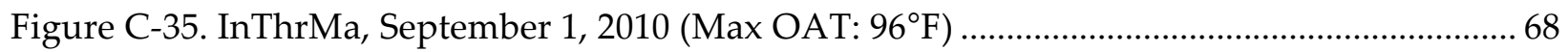

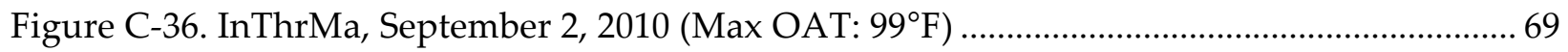

Figure C-37. InThrMa, September 24, 2010 (Max OAT: 90 F) .................................................... 70

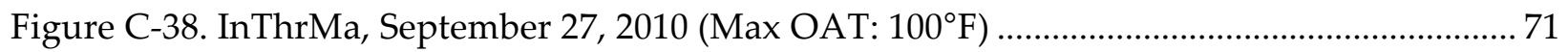

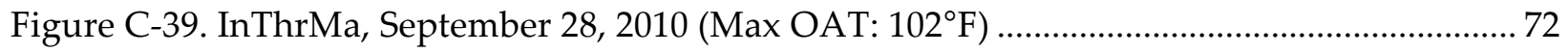

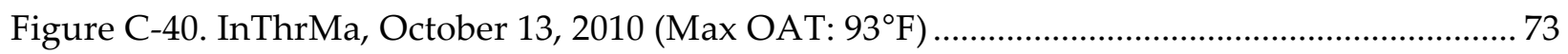

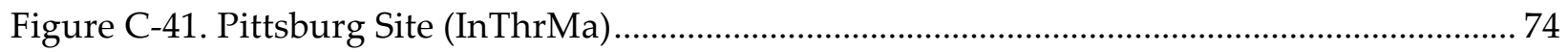

Figure C-42. Associated Lighting Representatives' Main Office Site Architecture....................... 77

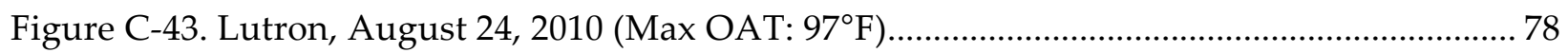

Figure C-44. Lutron, September 1, 2010 (Max OAT: 91ํF) .......................................................... 79

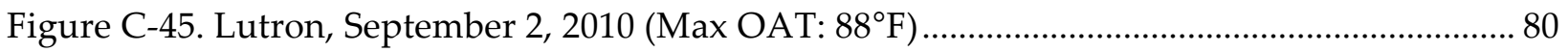

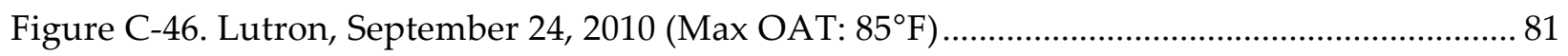

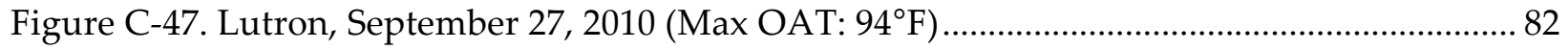

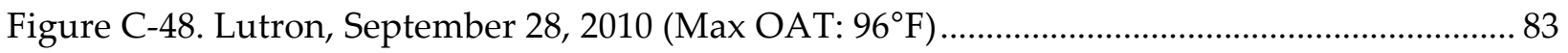

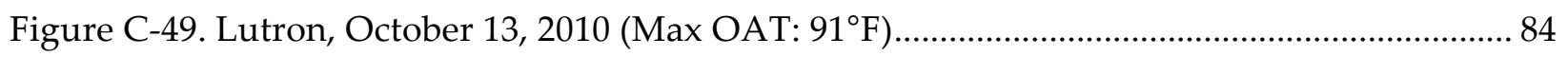

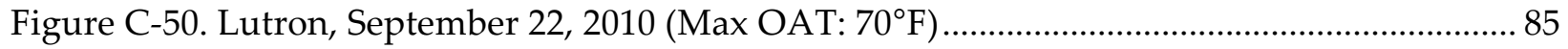

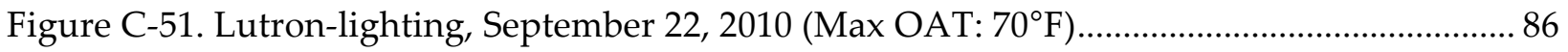

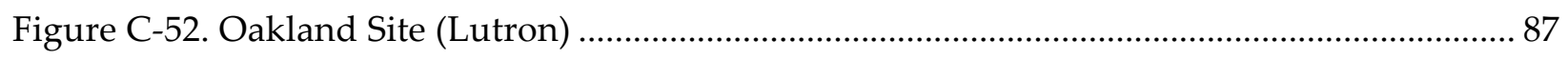

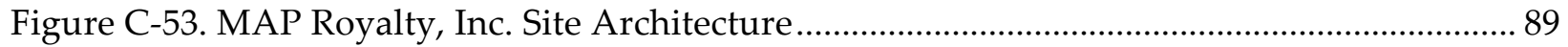

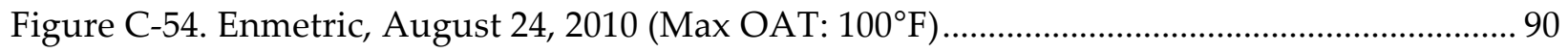




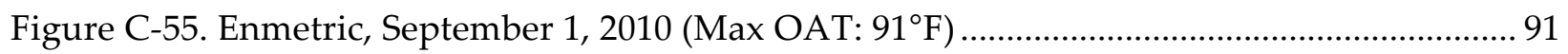

Figure C-56. Enmetric, September 2, 2010 (Max OAT: 91ํํ) ….................................................. 92

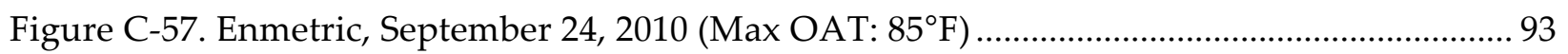

Figure C-58. Enmetric, September 27, 2010 (Max OAT: 92º F) .................................................... 94

Figure C-59. Enmetric, September 28, 2010 (Max OAT: 95º) ….............................................. 95

Figure C-60. Enmetric, October 13, 2010 (Max OAT: 90² F) ....................................................... 96

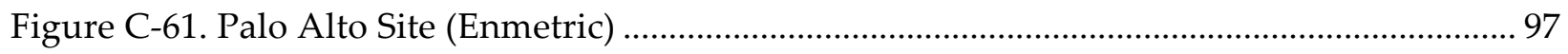

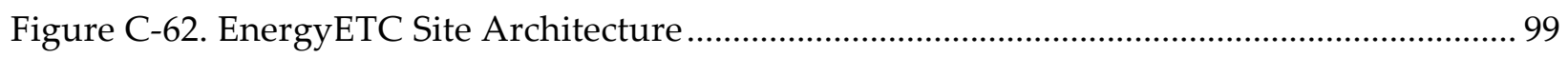

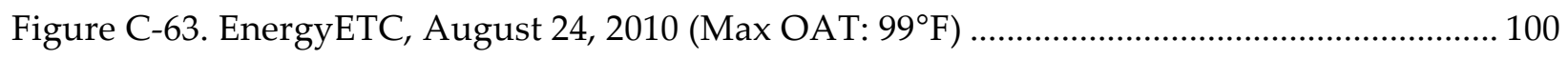

Figure C-64. EnergyETC, September 1, 2010 (Max OAT: 90 F) …............................................... 101

Figure C-65. EnergyETC, September 2, 2010 (Max OAT: 91 ${ }^{\circ}$ F) .................................................... 102

Figure C-66. EnergyETC, September 24, 2010 (Max OAT: 86 F) ................................................ 103

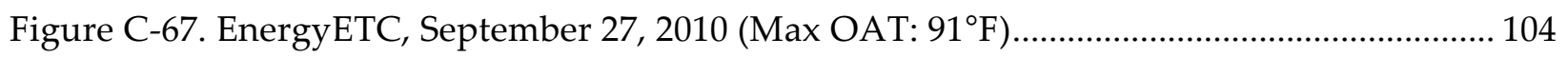

Figure C-68. EnergyETC, September 28, 2010 (Max OAT: 97F) .............................................. 105

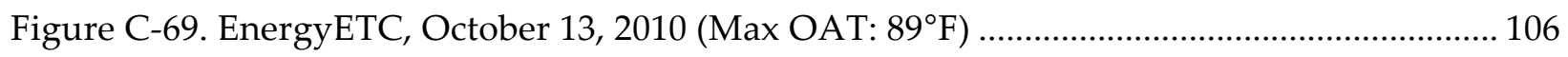

Figure C-70. Union City Site (OHS with EnergyETC) ............................................................ 107

Figure C-71. Applied Power Technologies, Inc. Site Architecture............................................... 109

Figure C-72. PulseEnergy, August 24, 2010 (Max OAT: 102 ${ }^{\circ} \mathrm{F}$ ) …............................................... 110

Figure C-73. PulseEnergy, September 1, 2010 (Max OAT: 93º) F.............................................. 111

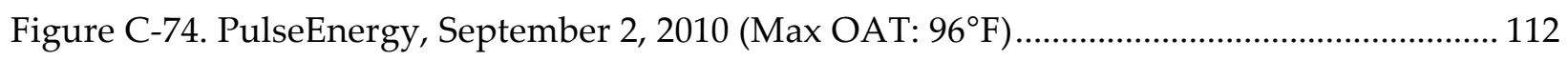

Figure C-75. PulseEnergy, September 24, 2010 (Max OAT: 86º F).............................................. 113

Figure C-76. PulseEnergy, September 27, 2010 (Max OAT: 96 F) ….......................................... 114

Figure C-77. PulseEnergy, September 28, 2010 (Max OAT: 99² F) .............................................. 115

Figure C-78. PulseEnergy, October 13, 2010 (Max OAT: 92º F).................................................. 116

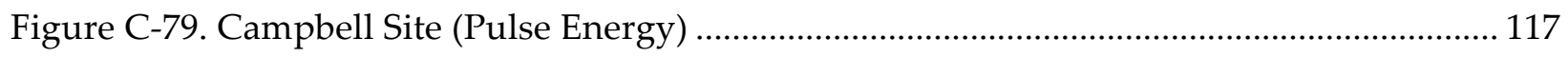

Figure C-80. Salinas Meats, Inc. Site Architecture......................................................................... 119

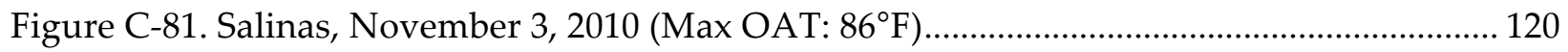

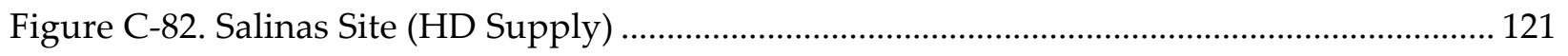




\section{LIST OF TABLES}

Table B-1. PG\&E PDP credits and charges for Small and Medium Commercial Businesses.....26 


\title{
APPENDIX A. Procurement Documents
}

\author{
SMALL/MEDIUM COMMERCIAL \\ DEMAND RESPONSE EMERGING TECHNOLOGY ASSESSMENT \\ REQUEST FOR PROPOSALS
}

\begin{abstract}
Akuacom, acting on behalf of Pacific Gas and Electric Company (PG\&E) and Lawrence Berkeley National Lab (LBNL), invites proposals from manufacturers of HVAC or lighting control equipment that can be installed in small to medium sized businesses $(20-200 \mathrm{~kW}$ peak power consumption). The control equipment must be able to receive OpenADR signals via the internet and respond to DR signals by some form of preprogrammed shed strategy to reduce electric demand during peak times. Proposed equipment can include control for HVAC, refrigeration, lighting, plug load controllers, or any combination of these.

Responding to this request for proposals ("RFP") does not commit or obligate Akuacom, PG\&E and LBNL in any way to pay or reimburse any costs incurred by any Bidder in the preparation of any response to this RFP or proposal, or to procure or contract for services. Akuacom, PG\&E and LBNL reserves the right, at its sole and absolute discretion, to modify, suspend or withdraw any and all aspects of this RFP or the selection process; obtain additional information from any respondent; waive any defects as to form or content of the RFP or any other document or procedure used in the selection process; negotiate with Bidders to resolve technical or contractual issues; reject any and all responses or proposals submitted; accept or reject any Bidder for entry into any contract; and to terminate negotiations at any time. Akuacom, PG\&E and LBNL shall not be deemed to have accepted any response or proposal, and shall not be bound by any term thereof, unless and until an authorized representative of PG\&E executes a definitive agreement.
\end{abstract}

\section{Solicitation Process Overview}

Proposals are due to Akuacom on April 23, 2010. Akuacom will accept written questions about this solicitation from Bidders until Monday, April 12, 2010. Questions may be sent by email to commercialpilot@akuacom.com. Written responses to Bidder questions will be made available to all Bidders on Friday, April 16, 2010.

\section{Solicitation Process - Key Dates}

Proposal Preparation and Evaluation

1. RFP Release

$04 / 05 / 2010$

2. Bidder Questions Due

$04 / 12 / 2010$

3 Akuacom Response to Questions Issued

$04 / 16 / 2010$ 


\section{BACKGROUND}

Demand Response (DR) - Occasional storms and heat waves, as well as periodic power plant repairs and maintenance, have the potential to affect California's supply and demand for electricity. When demand is high and supply is short, power interruptions can sometimes be the result. Building enough power plants to satisfy every possible supply and demand scenario is one possibility, but the cost and environmental impact of that would be tremendous.

Demand response programs are designed to be both fiscally and environmentally responsible ways to respond to occasional and temporary peak demand periods. PG\&E DR programs offer incentives to businesses that volunteer and participate by temporarily reducing their electricity use when demand could outpace supply.

Automated Demand Response (Auto DR) - Based on the technology and market results of PG\&E's 2005-2006 Automated Critical Peak Pricing pilot program conducted by Lawrence Berkeley National Lab and Technologies, the Automated Demand Response (Auto DR) program utilizes a communications infrastructure to transmit demand response signals from PG\&E to customers facility control systems so that they can automatically implement preprogrammed load reductions. Prior to a DR event, customers develop specific control strategies for reducing electrical loads in their facilities during DR periods, such as dimming or turning off non-critical lights, changing zone temperature set points, and turning off non-critical equipment to obtain these savings in ways that do not significantly impact building tenants.

Open Automated Demand Response (OpenADR) - A non-proprietary communications data model specification to exchange DR information developed by the California Energy Commission's Demand Response Research Center and Lawrence Berkeley National Laboratory to facilitate Auto $\mathrm{DR}^{1}$. It provides a platform for communicating price, reliability and emergency signals between the utility or independent system operator (ISO) and individual or aggregated groups of electric customers. OpenADR was identified on May 18, 2009 by the U.S. Department of Energy (DOE)'s National Institute of Standards (NIST) as one of the "initial batch of sixteen recognized interoperability standards" for the SmartGrid "that will help ensure that software and hardware components from different vendors will work together seamlessly, while securing the grid against disruptions" ${ }^{2}$ The Open ADR specification is the basis for ongoing demand response communications standards development efforts within both the Organization for the Advancement of Structured Information Systems (OASIS) ${ }^{3}$ and the UCA

\footnotetext{
${ }^{1}$ http://openadr.lbl.gov/pdf/cec-500-2009-063.pdf

${ }^{2}$ http://www.energy.gov/news2009/7408.htm

${ }^{3}$ http://www.oasis-open.org/home
} 
International Users Group (UCAIug) ${ }^{4}$, and it is anticipated to become a formal standard within organizations such as the International Electrotechnical Commission (IEC) ${ }^{5}$.

\section{Automated Demand Response Program Overview}

Auto DR has consistently demonstrated that automating customer strategies increases DR participation, improves the certainty and reliability of DR, and expands customer options for participating in the higher value wholesale ancillary services market. OpenADR's open, nonproprietary standards approach also creates an interoperable environment that reduces customer, utility and vendor equipment and operating costs.

Auto DR is being implemented by three Investor Owned Utilities in California in response to a California Public Utilities Commission (CPUC) order granting \$40-50 Million to promote this technology from 2009-2011. PG\&E currently automates the following demand response (DR) programs:

- Critical Peak Pricing (CPP)

- Demand Bidding Program (DBP)

- Peak Choice

For details about these programs, please see:

http://www.pge.com/mybusiness/energysavingsrebates/demandresponse/

In addition to these programs, PG\&E plans to automate the new Peak Day Pricing (PDP) tariff. PDP is a new dynamic pricing tariff that provides reduced energy prices during the summer in exchange for higher rates on 9-15 peak event days per year. All large commercial customers ( $200 \mathrm{~kW}$ and up) will be automatically enrolled in this tariff in May 2010 unless they specifically opt out. The OpenADR signals used in this test will model the PDP tariff. On November 1st, 2011, all small and medium business customers will be defaulted into the PDP tariff.

\section{Type of Facilities Targeted for Pilot}

PG\&E's existing Auto DR programs focus on larger commercial and industrial facilities above $200 \mathrm{~kW}$. Some of these facilities have existing automation or energy management and control systems (EMCS) capable of receiving DR signals. The goal of this RFP is to explore how Auto DR technology can potentially be applied to small - medium size customers $(20-200 \mathrm{KW})$ that may or may not have existing EMCS systems. The purpose of this RFP is to identify and test OpenADR compliant systems in small to medium size facilities to verify their capability to automatically shed demand during summer months when needed. We anticipate testing equipment in a variety of business types (restaurants, grocery stores, small retail, small offices, etc.). PG\&E plans to use the experience developed through the field test to design a program

\footnotetext{
${ }^{4}$ http://www.ucaiug.org

${ }^{5}$ http://www.iec.ch
} 
(such as, but not limited to, direct installation) to provide automation technologies to its medium and small commercial customers participating in PDP.

\section{Requirements}

PG\&E currently utilizes OpenADR (www.openadr.org) to publish DR signals to facilities participating in the Auto DR program. OpenADR is a communication mechanism that converts utility price, reliability, or other event signals to location specific signals that initiate preprogrammed customer energy management strategies via a central Demand Response Automation Server (DRAS). Upon receipt of an OpenADR signal, a local energy management and control system (EMCS) initiates pre-programmed shed strategies in HVAC, refrigeration, and/or lighting equipment or other miscellaneous plug loads. At a minimum, OpenADR signals contain information about peak demand price multipliers or levels of required demand sheds. These are converted at the local level to actual pre-programmed sheds in different kinds of equipment, such as HVAC, lighting, or plug loads.

A typical system (or proposed technology) might look like:

Figure A-1. Automated DR Architecture

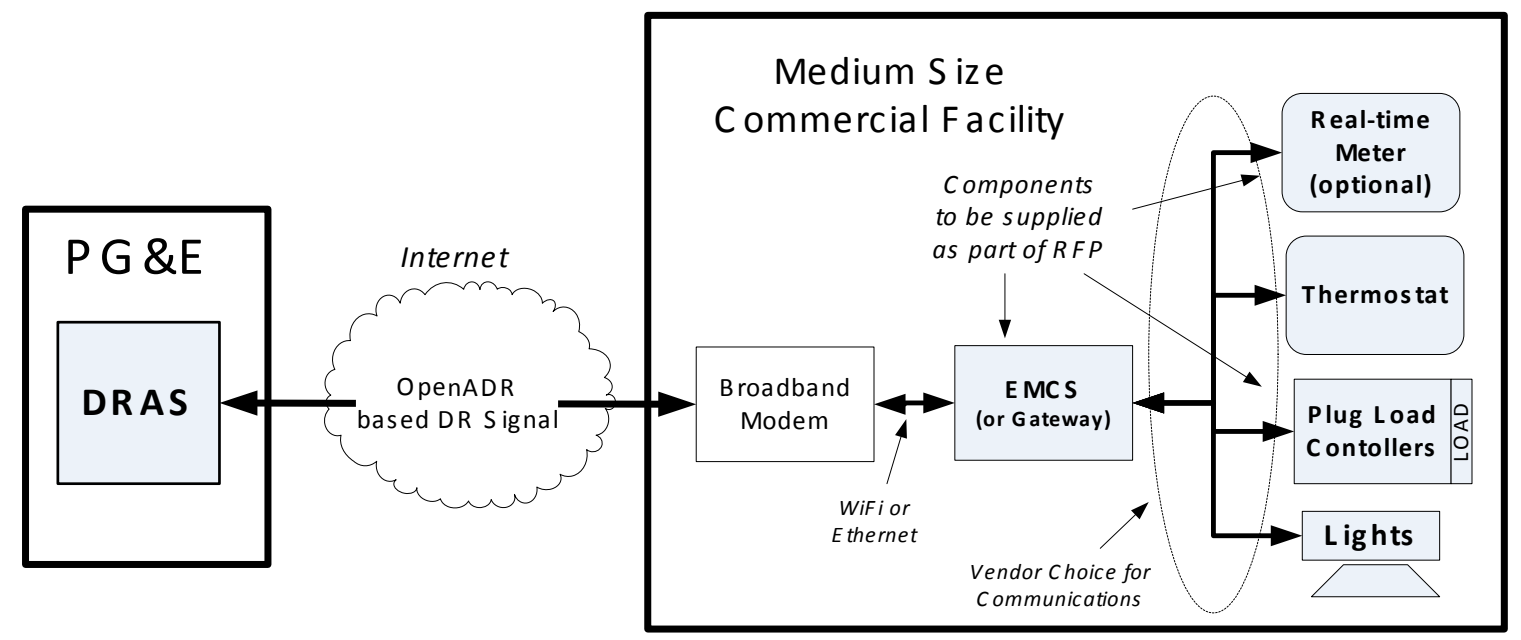

\section{Automated DR Architecture}

Note that the component designated as the EMCS (or Gateway) in the diagram (above) represents the component that receives the OpenADR signals and translates them into shed strategies. It is not a requirement that this component be a separate physical component. If appropriate in your proposed technology, it may be incorporated into one of the load controllers on the right (e.g., programmable communicating thermostat). 


\section{PROCUREMENT DETAILS}

The goal of this DR emerging technology assessment is to evaluate the best delivery channels for OpenADR compliant technology for small and medium business customers. All technology proposed here must be commercially available off- the shelf (COTS), UL listed, and FCC certified, as applicable. Funds are not for research and development (R\&D) of any equipment. Teaming to provide a consolidated solution is encouraged, as long as one company is responsible for delivering the complete package (and is identified as such in the proposal). We intend to select multiple vendors under this procurement.

Preference will be given to bidders with complete systems who can install the equipment at test sites in time for summer tests (May - October 2010). Additional preference will be given to bidders who include agreements with potential test sites within their proposals. Preference will be given to test sites that already have smart interval meters capable of gathering usage data.

While it is not a requirement that respondents include equipment for monitoring usage information (i.e. metering equipment) in their proposals it is an optional component that may add value to the overall offering and for the purposes of this pilot may allow the system to be installed at test sites that do not yet have smart interval meters installed.

Equipment proposed in response to this procurement must be capable of receiving OpenADR information via the internet. Respondents should assume the customers' site equipped with a typical off the shelf broadband modem interface within the test site that will be used to communicate with the DRAS to receive the OpenADR messages. Respondents can also assume that if their equipment can interface to the broadband modem via Ethernet or WiFi then no additional equipment is required. Likewise if the communications between the respondent's equipment and the broadband modem requires translation to a communications interface other than WiFi or Ethernet then any necessary communications bridges or gateways must be included in the response to this RFP. Any equipment that interfaces to the DRAS and receives OpenADR messages must adhere to the security requirements of OpenADR which includes support for secure sockets layer (SSL, a communication protocol).

All communication equipment for the internet connection will be provided if it does not already exist. Any proposed systems must be able to translate OpenADR signals to shed strategies that are implemented upon receipt of the signals. For example, thermostats should be capable of changing set points up or down or cycling the compressor as part of their shed strategy whereas lighting controls must be capable of turning lights on or off in preprogrammed patterns or support dimming, and must support bi-level switching. There is no requirement on the type or size of load supported by a plug controller.

Proposed equipment for testing must be user programmable with shed strategies that will translate the OpenADR price multipliers or simple shed levels into actions at the thermostat, lighting control, refrigeration control, and plug load controllers. The equipment may have any kind of interface that allows programming of shed strategies as long as it can be changed, on an as needed basis, to receive and respond to OpenADR signals after the equipment is installed. Specific requirements on building level controls for this procurement include: 
- Thermostat controls must allow for changing the set point up or down or cycling the compressor as part of the shed strategy.

- Lighting controls must allow for turning lights on and off or support dimming, and should support the bi-level switching required by title 24 .

- Plug load controls should turn devices plugged into the controller on or off on demand. There is no strict requirement on the type or size of the loads that must be supported by the plug load controller.

- Refrigeration controls must be able to turn off anti-sweat heaters, or provide temperature controls or perform cycling on the compressor.

After this demonstration project, PG\&E may use the information collected to design a program that will assist small and medium business customers to automate their responses for dynamic rates such as PDP.

To be considered for award, each proposal must contain:

1. Completed Exhibit 1 (Company Information)

2. Brief description of proposed system or technology (include data sheets as appropriate

3. Completed Exhibit 2 (Proposed technology/Product features)

4. Completed Exhibit 3 (Equipment/Installation costs)

5. Provide program implementation plan and customer description

6. Provide relevant Project Experience and Results in the past

\section{Proposal Review - Questions and Communications}

Akuacom, PG\&E and LBNL reserves the right to contact a Bidder, at anytime, for clarifications about any part of the Bidder's proposal, including, but not limited to, the proposal, technical documentation, cost, company information, etc.

\section{Submission of Proposal Responses}

Bidders must submit electronic versions of their proposals via email to commercialpilot@akuacom.com by the due date and times listed below. Any proposals received after the date and time will be rejected.

Time and Place for Submission:

Due Date: $\quad$ April 23, 2010

To: commercialpilot@akuacom.com

Attention: PG\&E DR ET Assessment - Auto DR for SMB

Proposal Submission -Bidder shall include with its submission one electronic copy of their proposal via email using Microsoft Office 2003 software (Word, PowerPoint, Excel), or Adobe Acrobat documents (i.e., pdf files).

Verification of Receipt of Proposal - Email replies will be sent to each submission verifying its receipt. 
Errors or Omissions - A Bidder that discovers an error or omission in its Proposal Response package may withdraw that package and resubmit, provided that it does so before the deadline for submission of proposal responses.

RFP Withdrawal - Akuacom, PG\&E and LBNL reserves the right to withdraw this RFP at any time before the duly authorized execution of the Contract(s) with Bidder for any reason including, but not limited to, action by the CPUC that modifies or withdraws the Program. Akuacom, PG\&E and LBNL may accept or reject any or all proposals, and may accept other than the least cost proposal. Akuacom, PG\&E and LBNL will not accept any liability, under any circumstances, to any Bidder submitting a proposal in response to this RFP.

Proposal Preparation Costs - Bidder accepts any and all costs and expenses incurred prior to the duly authorized execution to the Contract and will not seek any costs and expenses from Akuacom, PG\&E and LBNL.

Proposals Not Confidential - After the deadline for receipt of proposals, Akuacom, PG\&E and LBNL will not keep either the proposal submitted in response to this RFP or any Contract arising from the solicitation confidential. Furthermore, PG\&E will not assume any liability to a Bidder or other party as a result of any public disclosure of any proposal or Contract.

\section{Proposal Clarification}

Akuacom, PG\&E and LBNL may perform clarification interviews or request clarifications in writing. A clarification interview may be performed via telephone and will focus on clarifying the information set forth in the proposals, rather than offering Bidders the opportunity to revise its proposal. Bidders will not be compensated for the time spent or the costs incurred for the interview(s) or for responding to a written request for clarification.

\section{Terms and Conditions of Submission}

All proposals, along with all other documentation, submitted in connection with this RFP shall become and will remain the property of PG\&E and will not be returned to the Bidder.

By submitting a proposal pursuant to this RFP, Bidders acknowledge and agree that (a) they will be fully bound by the terms and conditions of this RFP in submitting their proposals, (b) they have had the opportunity to seek independent legal and financial advice of their own choosing with respect to the RFP and their proposals, (c) they have obtained all necessary authorizations, approvals and waivers, if any, required by them as a condition of submitting their proposals, (d) they are submitting their proposals subject to all applicable laws, and (e) they have not engaged and will not engage in communications with any other Bidder in the RFP concerning the price or other economic terms contained in their proposals and have not engaged in collusion or other unlawful or unfair business practices in connection with this RFP.

\section{Non-confidentiality of Submissions}

Bidders understand and acknowledge that the submission of a proposal or other information to Akuacom, PG\&E and LBNL does not establish any fiduciary or confidential relationship between the Bidder(s) and Akuacom, PG\&E and LBNL, nor is there one intended or created by 
reason of this RFP and/or submission of a proposal. The Bidder(s) agree that Akuacom, PG\&E and LBNL shall not be obligated to return the proposal to the Bidder(s), and the Bidder(s) release Akuacom, PG\&E and LBNL from any and all liability if the proposal is lost, misplaced, stolen or destroyed.

Bidders should not submit any information containing its or any third party's trade secrets or other proprietary or confidential information (as defined in California's Uniform Trade Secrets Acts or otherwise).

Bidders are also hereby advised that Akuacom, PG\&E and LBNL may also disclose proposals, or any information contained therein, by legal process or to judicial, governmental or regulatory authorities, including without limitation, to the California Public Utilities Commission.

Akuacom, PG\&E and LBNL may elect to enter into mutual nondisclosure agreements with Bidders selected for further participation in transactions which are the subject matter of this RFP, but is not agreeing to such an arrangement at this time and will infer that information which is submitted by each Bidder is not deemed confidential or proprietary information of the Bidder or any third party.

\section{Waiver of Claims}

The Bidder, by submitting its proposal in response to this RFP, waives any and all claims against Akuacom, PG\&E and LBNL or Akuacom, PG\&E and LBNL property by reason of any or all of the following: any aspect of this RFP, the selection process or any part thereof, any informalities or defects in the selection process, entering into any agreement, the failure to enter into an agreement, any statements, representations, acts, or omissions of Akuacom, PG\&E and LBNL, the exercise of any discretion set forth in or concerning any of the foregoing, and any other matters arising out of all or any of the foregoing.

\section{Negotiations and Finalizations}

Once the Bidder has been selected for the Program, contract negotiations will be conducted. These negotiations will relate to the scope of work, specific program design features, budgets, schedules, and payment terms. Akuacom, PG\&E and LBNL reserve the right to simultaneously conduct negotiations with both the prospective Bidder and an alternate Bidder. Akuacom, PG\&E and LBNL also reserve the right to terminate negotiations with any Bidder in the event that Akuacom, PG\&E and LBNL and the Bidder are unable to agree on contract terms and conditions within a reasonable period of time to be determined in Akuacom, PG\&E and LBNL's sole and absolute discretion. 


\section{Exhibit 1: Company Information}

Company Name:

Street Name:

Mailing Address:

City:

State:

Zip Code:

Telephone

Fax No.:

Website:

\section{CONTACT INFORMATION}

Company Name:

Street Name:

Mailing Address:

City:

State:

Zip Code:

Telephone Fax No.:

E-mail

\section{EMPLOYEE INFORMATION}

Total Number of Permanent Employees:

Total Peak Manpower for Each of the Last 3 Years:

Total Peak Manpower on a Single Project 
Exhibit 2: System/Product Features

\begin{tabular}{|c|c|}
\hline REQUIREMENT & RESPONSE \\
\hline $\begin{array}{l}\text { Does the proposed system contain an } \\
\text { EMCS? If not, how are loads controlled? }\end{array}$ & \\
\hline $\begin{array}{l}\text { Does the proposed technology presently } \\
\text { support communication with PG\&E's } \\
\text { DRAS using OpenADR? }\end{array}$ & \\
\hline $\begin{array}{l}\text { What type of loads can the proposed } \\
\text { technology control? }\end{array}$ & \\
\hline $\begin{array}{l}\text { How does the proposed technology } \\
\text { communicate with the load controllers? }\end{array}$ & \\
\hline $\begin{array}{l}\text { Can the proposed technology be } \\
\text { programmed with shed strategies to } \\
\text { control the various loads? } \\
\text { - If yes, describe what type of } \\
\text { interface is used to do the } \\
\text { programming? }\end{array}$ & \\
\hline $\begin{array}{l}\text { Does the proposed technology allow users } \\
\text { to manually override any control settings? }\end{array}$ & \\
\hline $\begin{array}{l}\text { Assuming some } 3^{\text {rd }} \text { party were to specify a } \\
\text { shed strategy, what level of expertise is } \\
\text { required to program that shed strategy into } \\
\text { the proposed technology? }\end{array}$ & \\
\hline $\begin{array}{l}\text { Does the proposed technology support } \\
\text { real-time metering? } \\
\text { - If yes how is the usage information } \\
\text { collected? (i.e. pulses off existing } \\
\text { meter, current loops installed, etc.) } \\
\text { - If yes, at what interval is usage } \\
\text { information collected? }\end{array}$ & \\
\hline $\begin{array}{l}\text { Does the proposed technology support } \\
\text { HVAC control? } \\
\text { - If yes, what aspects of the HVAC } \\
\text { can be controlled? }\end{array}$ & \\
\hline $\begin{array}{l}\text { Does the proposed technology support } \\
\text { changing the set point on a thermostat? }\end{array}$ & \\
\hline $\begin{array}{l}\text { Does the proposed technology } \\
\text { support lighting control? }\end{array}$ & \\
\hline
\end{tabular}


- If yes, where is the lighting control installed?

- Does the proposed technology support dimmable lighting control?

- For what kind of lighting (fluorescent, incandescent, halogen, other)?

- Does the proposed technology support bi-level light switching?

Does the proposed technology support general purpose plug load controls?

- If yes what type of loads that can be controlled?

Are there any proprietary aspects of the proposed technology that require special agreements with the funding agencies before testing can begin?

- If yes, what arrangements are needed so that testing can be begin within the anticipated framework of this procurement (i.e., Summer 2010)?

Exhibit 3: Equipment/Installation Costs

\section{Equipment}

\begin{tabular}{|c|l|}
\hline ITEM & COST \\
\hline Cost of EMS/EMCS or equivalent & \\
\hline Complete below as appropriate: & \\
\hline$\bullet \quad$ Unit cost of thermostat control & \\
\hline$\bullet \quad$ Unit cost of lighting control & \\
\hline$\bullet \quad$ Unit cost of plug load control & \\
\hline$\bullet \quad$ Unit cost of real-time meter & \\
\hline$\bullet \quad$ Other equipment costs & \\
\hline
\end{tabular}


Installation

\begin{tabular}{|l|l|l|}
\hline ITEM & TIME (best estimate) & LABOR COST \\
\hline Single system installation cost & & \\
\hline $\begin{array}{l}\text { OR (provide details for each proposed } \\
\text { installation): }\end{array}$ & & \\
\hline EMS/EMCS installation & & \\
\hline $\begin{array}{l}\text { Shed strategy programming (assuming } \\
\text { strategy already specified) }\end{array}$ & & \\
\hline Real-time meter installation & & \\
\hline Fan controller/unit, if applicable & & \\
\hline Lighting controller/unit, if applicable & & \\
\hline Plug load controller/unit, if applicable & & \\
\hline Other installation costs (describe) & & \\
\hline System integration and test & & \\
\hline
\end{tabular}

\section{Facilities}

List customer facilities within PG\&E territory that are candidates for participation in this pilot.

\begin{tabular}{|l|l|l|}
\hline $\begin{array}{l}\text { Type of Facility } \\
\text { (e.g. restaurant, office, etc.) }\end{array}$ & Number of Facilities & Approximate Size \\
\hline & & \\
\hline & & \\
\hline
\end{tabular}

\section{Miscellaneous}

\begin{tabular}{|l|l|}
\hline ITEM & COST \\
\hline Software costs (provide details) & \\
\hline $\begin{array}{l}\text { Regular service or maintenance costs, if } \\
\text { required (\$/year) }\end{array}$ & \\
\hline
\end{tabular}




\section{SMALL/MEDIUM COMMERCIAL \\ DEMAND RESPONSE EMERGING TECHNOLOGY ASSESSMENT}

Questions and Answers

\section{GENERAL}

Additional clarification provided by Albert Chiu during online meeting: this program is intended to address the market between residential (e.g. Zigbee) and large commercial. We understand that some small commercial facilities use residential type DR equipment, and that is not part of this test. Here, we are trying to understand what building control equipment capable of interpreting OpenADR signals can be used effectively in the small commercial market.

Q - G1: When and where is the recording of the online meeting available?

A - G1: Click on this link to play the recording of the online meeting:

https://akuacom.webex.com/akuacom/ldr.php?AT=pb\&SP=MC\&rID=39626747\&rKey=c05452b3f86d79 $\underline{97}$

PG\&E Commercial Pilot RFP Q\&A Session-20100413 2103-1

April 13, 2010, 3:09 pm San Francisco Time

56 mins

Q-G2: How will the selection be done?

A - G2: This will depend on the type of technologies the bidders propose.

Q - G3: Will you post the number of people that attended the Webcast and the number of bidders in each end use category.

A - G3: We are not planning to do this.

Q - G4: How does automated demand response differ from direct load control?

A - G4: Automated demand response uses price multipliers or simple (high, medium, low) levels to allow end user to choose their response to a DR event.

\section{BIDDING QUESTIONS}

Q-B1: Can you give us a sense of scale of this study, such as a range for how many buildings are you planning on testing?

A - B1: We anticipate $6-12$ test sites in this program.

Q - B2: I assume that, since you are thinking about multiple technologies, these numbers will be sub-divided between different bidders?

$\mathrm{A}-\mathrm{B} 2$ : This is correct

Q - B3: Can a company be involved in multiple proposals; e.g. one as a stand-alone, and one or more as a part of collaborations? 
A - B3: Yes

$\mathrm{Q}$ - B4: Does the PG\&E/Akuacom team plan to involve multiple vendors in the pilot?

A - B4: Yes

Q-B5: If so, would it be advantageous for our solution to be compatible with multiple vendors?

A - B5: Yes.

Q - B6: What are the zip codes for PG\&E service territory?

A - B6: See the Appendix to this Q/A for a complete list of ZIP codes in the PG\&E service territory.

Q - B7: Would it be of value to PG\&E/Akuacom for respondents to describe additional valueadded capabilities that their solution will provide beyond the scope of the RFP?

A - B7: Yes in general, but we may not be able to quantify the value of the non IDSM related benefits.

Q-B8: Are we required to submit an "intent to bid"?

A -B8: No.

Q - B9: The RFP states that you'll give preferential treatment to companies that we have contracts with. It'd be great if you could clarify what the scope of these contracts would be (and if the contracts are complex provide templates.)

A - B9: Additional preference will be given to bidders who include agreements with potential test sites within their proposals.

Q - B10: What is meant by "Peak Manpower"?

A - B10: Peak manpower is the highest number of staff in your company on this kind of project within the indicated time period.

\section{SCHEDULE QUESTIONS}

Q - S1: In your "Solicitation Process - Key Dates" section it says bidders proposals are due on April $26^{\text {th }}$, but in the paragraph above "Solicitation Process Overview" it says April 23 ${ }^{\text {rd }}$. Can you clarify?

A - S1: April 26, 2010 is the due date for proposals.

Q - S2: With regards to install date, you specify "May-October." Is this the desired range of install or the range in which the summer tests are proposed, meaning the install would have to be complete by May? Is there any additional insight into desired installation date?

A - S2: Equipment does not have to be installed by May. We are flexible with this as long as the equipment can be installed and functioning in advance of the dates when demand response 
events are called as part of the test. We do not expect any part of this work to run past 31 December 2010.

Q - S3: Can you provide more detail regarding summer test dates in $2010 ?$

A - S3: Test dates are determined in part by weather conditions. Customers always have the option to opt out of a test event if participation is a business concern.

\section{COST QUESTIONS}

Q - C1: We have target customers that would be interested in participating if the costs of the equipment and installation were paid for by the pilot. Will these costs be paid by PG\&E as part of the pilot?

A - C1: PG\&E will provide some incentives for the pilot, but they may not be sufficient to cover the entire costs of some projects. In those cases, the bidder would be expected to cover the rest of the cost with or without a customer's contribution. If so, that additional agreement would be between the customer(s) and the bidder.

Q - C2: When the pilot is very small (<1,000 customers) Does PG\&E have extra budget (+/- \$ 75,000 ) for our "Yet another small pilot with very long term (maybe) upside" surcharge?

A - C2: No we are not planning to provide extra resources or surcharges above and beyond those in the project.

$\mathrm{Q}$ - C3: What is the target $\$ / \mathrm{kW}$ we can anticipate to evaluate proposals?

A - C3: AutoDR incentives provide a good indicator: $\$ 125-250 / \mathrm{kW}$ is typical but $\$ 400-$ $500 / \mathrm{kW}$ reduction is not out of the allowable range

$\mathrm{Q}-\mathrm{C} 4:$ Is a more costly proposal going to get less consideration?

A - C4: No, cost is only one of the factors we will consider when evaluating the proposal.

Q-C5: Will customers pay for the pilot?

A - C5: PG\&E will provide some incentives for the pilot, but it may not enough to cover the entire project cost. The manufacturer is expected to cover the rest of the cost with or without customers' contribution. This agreement is between the customer(s) and the bidder.

\section{INSTALLATION QUESTIONS}

Q - IN1: If a vendor does not typically provide installation, is there an option of using PG\&E employees for installation?

A - IN1: No

Q - IN2: If the vendor chooses to partner with a third-party for installation, are there any preferred installation vendors? 
A - IN2: No, but we suggest the bidder to consider working with installer that the customer site is comfortable with using.

Q - IN3: Who will be responsible for installation of the proposed solution?

A - IN3: Bidders are expected to provide an installation solution in their proposal, and we suggest the bidder to consider working with installer that the customer site is comfortable with using.

Q - IN4: Who will pay for installations?

A - IN4: We will negotiate this with each selected bidder. Akuacom, acting on behalf of PG\&E, will administer the costs and reimburse according to the agreements negotiated.

\section{SCOPE QUESTIONS}

Q - P1: Is there a target cost range that PG\&E/Akuacom have in mind for this sector (i.e.: per customer, all in, including installation and hardware)?

A - P1: There is no target cost range. We anticipate that bids will vary depending on the nature of the technology being proposed and the size of the facility in which it is installed.

Q - P2: Do you have an order of magnitude level guess as to how many plug load controllers, lighting controllers and HVAC controllers and/or EMCS's would be deployed for these tests?

A - P2: This depends on the size and needs of the customer site(s) at which the equipment is proposed to be installed.

Q - P3: What is the price point/threshold for the 20-200kW sized users? PG\&E has DR solutions that target the $200+\mathrm{kW}$ segment of the market and given their size they are accustomed to deploying EMCS and the like. In the residential segment there is SmartAC - at no cost to the end user for HVAC based DR. Will PG\&E subsidize equipment and services for this market segment (20-200kW) in the same way it has for the SmartAC programs or will all the costs be the responsibility of the user? In trying to source the proper lighting \& load management components we don't want to over-spec the components and given that $20-200 \mathrm{~kW}$ is a pretty big range in terms of building sophistication - this is a good challenge.

A - P3: We cannot comment on future PG\&E program plans that are not part of this procurement. This procurement intends to pay for some part of the installation of equipment selected for these tests. Please describe how your proposed technology and associated costs scale(s) with the size of the installation.

\section{EQUIPMENT QUESTIONS}

Q - E1: We have a refrigeration DR component that will be part of the response, but the costs of the equipment and installation vary significantly depending on the customer's cold storage requirements. May we submit a "representative" customer to provide a ballpark figure even though the costs will vary by customer size? Or do you have some suggestions of how best to respond in this area? 
A - E1: Please submit representative costs for different scenarios or give some sense of how your technology scales as a function of customer needs.

Q - E2: What is meant by bi-level switching.

A - E2: Bi-level switching is required by Title 24 in California for commercial buildings. We recognize that there are different ways to control lighting in a room to respond to a DR event. If you are controlling it at the ballast level then bi-level is not an issue. If you are controlling it at the switch level, then that effort must maintain Title 24 requirements.

Q - E3: [We] are currently going through UL testing. The target date for certification is June 1st. Will this work?

A - E3: The purpose of this pilot is to test how well commercially available, off-the-shelf products respond to OpenADR demand response signals under typical operating conditions in small-medium commercial facilities. If your technology is not currently UL tested, and you choose to propose it, then please provide additional information about the status of associated UL testing so that we may assess whether it fits the needs of the project.

$\mathrm{Q}$ - E4: Does $20 \mathrm{~kW}$ translate into $10 \mathrm{~kW}$ for relay controlled plugloads and 10kW for lighting loads?

A - E4: We are not promoting a specific translation of these values. We are looking for cost effective solutions for this market. Bidder may tell us what your assumptions are for your selected facility.

Q - E5: What do you mean by 'plug load controls'? Are you referring to relays with on/off functionality as 'plug controls'?

A - E5: A control that accept typical three prong electric plug for different type of equipments that consume electricity. Relay with on/off function that can be controlled remotely may qualify for this pilot.

Q - E6: "Proposed equipment for testing must be user programmable..." In this statement, is the 'user' the installer (RFP respondent) or the installee (the test site facility owner)?

A - E6: 'User' means installee or end user.

Q - E7: Reference "Procurement Details" paragraph 3: Are you interested in systems that can approximate energy usage information in an open loop fashion (e.g. projecting lighting energy usage based on light level and load characteristics)?

A - E7: Our focus in this procurement is on demand response (DR) as measured by a site meter rather than energy estimations, so additional features such as those you propose do not add or subtract from our consideration of your proposal.

$\mathrm{Q}$ - E8: Is there an equipment maintenance company involved?

A - E8: We expect the bidders to provide all services. 
Q - E9: Who will be responsible for 1e, 2e \& third line?

A - E9: We expect the bidders to provide all services.

$\mathrm{Q}$ - E10: Is any decentralized energy production or storage foreseen in the pilot?

A - E10: No.

Q - E11: In our solution the EMCS is integrated in a touch display which doubles a thermostat. Is this allowed?

A - E11: Yes.

Q - E12: What is meant by "lighting control"? Is it allowable to use (dimmable) plug controllers for this?

A - E12: Yes.

\section{METERING QUESTIONS}

Q - M1: Regarding the availability of real-time energy usage information - is it possible to use existing utility infrastructure (e.g. Smart Meters, web portal) to present energy usage information as opposed to manually measuring this information?

A - M1: If Smart Meter infrastructure exists, then it may be used for metering.

Q - M2: Are the Smart Meters placed outside or inside the building?

A - M2: Depends on the facility.

Q - M3: Do you have information about PG\&E customers who have Smart Meters?

A - M3: This information will not be made available.

Q - M4: Are there any avenues for getting interval meters installed by PG\&E to support these pilot installations?

A - M4: Not by PG\&E per se, but as part of this pilot interval data loggers may be provided.

Q - M5: Are you interested only in data logging or do we need to send data to a server (implied that bidder did not have server resources for this)?

Q-M5: There is no real-time requirement and no requirement to have a server. If needed, Akuacom can provide a secure server and interface to which bidder can send data.

Q - M6: Are customer behavior monitoring tools required?

A - M6: Energy meters will be provided, if not supplied by the bidder or test site. Any other customer behavior monitoring tolls are not required.

Q - M7: What Service Level is requested $\left(24^{*} 7,24^{* 5}\right)$ ?

A - M7: Depends on customer operation hours and their agreement with the bidder. 
Q - M8: Will the meters have KYZ pulse output?

A - M8: No.

Q - M9:Will the CLIR boxes be available?

A - M9: No. We'd like to see technologies directly receiving signals from the DRAS.

Q-M10: What about metering where Smart Meters are not installed?

A - M10. Based on availability, data loggers maybe provided to bidder for capturing energy usage information.

\section{COMMERCIAL SITE CHARACTERISTICS QUESTIONS}

Q - CS1: For the purposes of this RFP, are common areas of MDU's/Apartments under 200KW considered "commercial"?

A - CS1: No.

Q - CS2: Reference "Procurement Details" paragraph 2: Can bidders use existing system installations for this pilot? Can existing DR participants with working system participate in this program?

A - CS2: Yes, but we will still need to know the actual installation cost as part of your proposal.

Q - CS3: Can you please clarify whether PG\&E/Akuacom will identify customers for this pilot, or whether respondents will be required to identify them?

A - CS3: Respondents should identify customers themselves if possible.

Q - CS4: How will pricing affect the end-user? Will users get paid for responding to an individual DR event?

A - CS4: Users will remain on their original rate schedule for this test and will not be paid per DR event during this test.

Q - CS5: Is the pilot project (install) expected to be conducted at no cost to the C\&I customer?

A - CS5: PG\&E will provide some incentives for the pilot, but it may not enough to cover the entire project cost. The manufacture is expected to cover the rest of the cost with or without customers' contribution. This agreement is between the customers and the bidder.

Q - CS6: What do we anticipate as reimbursements for customers in this program?

A - CS6: Incentives will be site specific. In contrast to other DR programs, there could be something like a 60 cent adder per $\mathrm{kWh}$. PG\&E does not have a participation benefit/incentive per se, and is not planning to pay for each event, but there may be sign on benefits. We will be providing some form of economic analysis for customers.

Q - CS7: What obligations do customers have regarding keeping the systems up and running, 
what pricing programs to be on, etc.?

A - CS7: There are no requirements on customers to keep the system running outside of what is required for their business. During the pilot, the customer (site or you as bidder) is expected to maintain and operate the equipment so that testing can be done. After the pilot there are no ongoing obligations.

$\mathrm{Q}$ - CS8: Can the commercial site continue to use the equipment after the program is over?

A - CS8: This depends on bidder's agreement with the site.

Q - CS9: Will OpenADR/DRAS be available after the pilot?

A - CS9: Yes, only if the customers participate in an PG\&E Automated DR program.

Q - CS10: The RFP talks about commercial consumers with $20 \mathrm{KW}$ to $200 \mathrm{KW}$ peak demand. I wanted to confirm that this RFP is not meant to address residential consumers who might easily have a $20 \mathrm{KW}$ peak demand.

A - CS10: This procurement does not address residential customers.

Q - CS11: Will you consider aggregation so that a collection of facilities might look more like a large facility?

A - CS11: Yes, as long as the end to end communication is OpenADR compliant.

Q - CS12: Point of clarification: Will C\&I customers be served by an alternate RFP? May have multiple strategies using aggregation for large C\&I customers.

A - CS12: This pilot focuses only on small to medium commercial businesses.

Q - CS13: What should customers expect as to the summer 2011 billing cycles, considering that the universal conversion to PDP doesn't occur until Nov 2011? (i.e.: will there be a grace period where the customer does not risk higher costs in the $1^{\text {st }}$ year of 2011, similar to the $+200 \mathrm{KW}$ incentive programs?)

A - CS13: This question appears to be beyond the scope of this procurement.

\section{OTHER QUESTIONS}

Q - X1: When will the Akuacom ADR system be available for test accounts for integration testing?

A - X1: It is available now. Akuacom personnel will contact you (or you may contact us directly) to address any issues you are having with integrating to our system.

Comment: Client developer program at Akuacom publishes the signals used by California customers to allow development by end users. To participate in the client development program, send an e-mail with your interest to devprog@akuacom.com. 
Q - X2: Is this a proposal for a pilot of the Wholesale market or the Retail market (or both?) A couple of differentiators I see between Wholesale and Retail include: the Retail consumer can almost always opt out of the event; the DR signal is for a fixed load reduction or to reduce load to no more than a fixed level; or the load is not what the ISO/RTO's in the Wholesale market (grid balancing) call "dispatchable load."

A- X2: While we are focused on the retail market with this procurement, this is a technology demonstration pilot study that is not specifically dependent on any retail or wholesale program.

Q - X3: Here's one for PG\&E. In the Peak Day Pricing write-up on their website at http://www.pge.com/mybusiness/energysavingsrebates/demandresponse/peakdaypricing/facts/ under the section heading PDP Charges and Credits, it describes the charges as: Applied to kWh usage above reservation capacity on event days and will vary by rate. Can you be more explicit as to what that rate is? I can see the PDP Adder in the bar charts on the Peak Day Pricing details page, http://www.pge.com/mybusiness/energysavingsrebates/demandresponse/peakdaypricing/details/ is $\$ 1.20 / \mathrm{kWh}$. One can't tell if it's worth staying in the PDP program without knowing what it might cost.

A - X3: This question is beyond the scope of the procurement. The focus of the current project is on equipment that might prove useful for customers participating in this program in the future.

$\mathrm{Q}-\mathrm{X} 4:$ Are there security issues with the implementation?

A - X4: While there are security issues in getting OpenADR signals from the server, these are not on the client side. We don't anticipate these are an issue, since we provide the secure infrastructure to your equipment to deliver the signal.

Q - X5: How does this relate to the upcoming filing with CPUC regarding the $2012-2014$ DR program?

A - X5: The information gained during this pilot will inform this filing. We recognize that some small businesses may use Zigbee, but that others use OpenADR with their EMCS. The goal here is to distinguish where the boundary effectively is and to better understand how small businesses use OpenADR signals to respond to DR events.

Q - X6: Can you tell us anything about what to expect in 2011?

A-X6: That is beyond the scope of this procurement.

Q - X7: (Questions about PDP tariffs)

A - X7: Refer to PG\&E website for the responses to these questions.

Q - X8: What about ongoing energy savings?

A - X8: This is up to the particular agreement between the vendor (bidder) and site.

$\mathrm{Q}$ - X9: Is there additional leverage in this program? 
A - X9: To the extent you can be transparent to allow sites outside of the PG\&E territory, SCE and SDG\&E may get involved and expand this program.

$\mathrm{Q}-\mathrm{X10}$ : What is the description of "shed-able load"?

A - X10: This is the measured shed loads at each DR event from the 10/10 with morning adjustment baseline.

\section{APPENDIX: ZIP CODES IN PG\&E's TERRITORY}

The following ZIP codes are in PG\&E's territory: 03444, 03465, 04028, 05301, 05492, 08101, 10022, 10036, 11802, 14580, 14615, 15370, 17011, 17105, 23219, 23320, 23326, 23466, 29221, 30083, 32202, 32859, 33143, 33607, 34749, 40033, 40223, 40232, 42401, 43218, 43666, 45431, 45839, 49014, 49470, 53201, 55987, 58108, 60179, 60606, 61832, 61834, 63131, 63212, 64043, 64105, 64112, 64566, 68101, 68179, 70160, 70181, 72712, 73124, 74004, 74119, 74651, 75001, 75006, 75015, 75221, 75231, 75265, 76185, 77002, 77079, 77210, 77251, 77842, 78724, 80012, 80217, 80919, 83333, 83501, 83726, 83906, $85020,85038,85260,85302,85376,85540,88401,89451,89460,89502,89513,9 * 542,90007,90010$, 90014, 90046, 90060, 90069, 90071, 90210, 90212, 90221, 90254, 90266, 90267, 90274, 90404, 90406, 90503, 90707, 90720, 91006, 91110, 91210, 91353, 91403, 91453, 91480, 91587, 91740, 91741, 91767, 91769, 91775, 91789, 91801, 92037, 92054, 92075, 92101, 92110, 92205, 92260, 92264, 92304, 92311, 92319, 92327, 92340, 92347, 92349, 92351, 92356, 92363, 92365, 92368, 92392, 92394, 92506, 92612, 92624, 92626, 92629, 92647, 92658, 92660, 92674, 92680, 92691, 92693, 92707, 92711, 92713, 92780, 92799, 92806, 92833, 92887, 92927, 93001, 93003, 93028, 93035, 93060, 93067, 93092, 93101, 93103, 93105, 93110, 93111, 93160, 93201, 93202, 93203, 93204, 93205, 93206, 93210, 93212, 93214, 93215, 93216, 93217, 93219, 93220, 93221, 93222, 93224, 93225, 93230, 93232, 93234, 93239, 93241, 93242, 93243, 93244, 93245, 93246, 93247, 93249, 93250, 93251, 93252, 93254, 93256, 93257, 93260, 93262, 93263, 93264, 93265, 93266, 93267, 93268, 93271, 93272, 93274, 93276, 93277, 93279, 93280, 93282, 93286, 93290, 93291, 93292, 93301, 93302, 93303, 93304, 93305, 93306, 93307, 93308, 93309, 93311, 93312, 93313, 93314, 93315, 93321, 93337, 93350, 93357, 93368, 93380, 93381, 93383, 93384, 93385, 93386, 93387, 93388, 93389, 93390, 93396, 93401, 93402, 93403, 93404, 93405, 93406, 93407, 93408, 93409, 93412, 93413, 93420, 93421, 93422, 93423, 93424, 93426, 93427, 93428, 93429, 93430, 93431, 93432, 93433, 93434, 93435, 93436, 93437, 93438, 93440, 93441, 93442, 93443, 93444, 93445, 93446, 93447, 93448, 93449, 93450, 93451, 93452, 93453, 93454, 93455, 93456, 93457, 93458, 93460, 93461, 93462, 93463, 93464, 93465, 93466, 93483, 93485, 93501, 93502, 93505, 93507, 93510, 93512, 93513, 93516, 93518, 93522, 93523, 93527, 93532, 93533, 93540, 93545, 93555, 93557, 93560, 93561, 93562, 93581, 93601, 93602, 93603, 93604, 93605, 93606, 93607, 93608, 93609, 93610, 93611, 93612, 93613, 93614, 93615, 93616, 93617, 93618, 93619, 93620, 93621, 93622, 93623, 93624, 93625, 93626, 93627, 93628, 93630, 93631, 93632, 93633, 93634, 93635, 93636, 93637, 93638, 93639, 93640, 93641, 93643, 93644, 93645, 93646, 93647, 93648, 93649, 93650, 93651, 93652, 93653, 93654, 93656, 93657, 93658, 93660, 93661, 93662, 93664, 93665, 93666, 93667, 93668, 93669, 93670, 93673, 93675, 93690, 93698, 93700, 93701, 93702, 93703, 93704, 93705, 93706, 93707, 93709, 93710, 93711, 93718, 93719, 93720, 93721, 93722, 93723, 93724, 93725, 93726, 93727, 93728, 93729, 93730, 93737, 93740, 93741, 93744, 93745, 93747, 93760, 93764, 93765, 93771, 93772, 93775, 93776, 93777, 93778, 93779, 93790, 93792, 93794, 93816, 93837, 93901, 93902, 93904, 93905, 93906, 93907, 93908, 93912, 93915, 93920, 93921, 93922, 93923, 93924, 93925, 93926, 93927, 93928, 93930, 93932, 93933, 93940, 93941, 93942, 93943, 
93944, 93950, 93953, 93954, 93955, 93960, 93962, 94000, 94002, 94004, 94005, 94006, 94010, 94011, 94013, 94014, 94015, 94016, 94017, 94018, 94019, 94020, 94021, 94022, 94023, 94024, 94025, 94026, 94027, 94028, 94030, 94034, 94035, 94037, 94038, 94039, 94040, 94041, 94042, 94043, 94044, 94045, 94059, 94060, 94061, 94062, 94063, 94064, 94065, 94066, 94070, 94074, 94076, 94080, 94082, 94083, 94084, 94085, 94086, 94087, 94088, 94089, 94098, 94099, 94101, 94102, 94103, 94104, 94105, 94106, 94107, 94108, 94109, 94110, 94111, 94112, 94113, 94114, 94115, 94116, 94117, 94118, 94119, 94120, 94121, 94122, 94123, 94124, 94125, 94127, 94128, 94129, 94130, 94131, 94132, 94133, 94134, 94135, 94137, 94143, 94150, 94151, 94158, 94163, 94177, 94184, 94187, 94188, 94197, 94205, 94206, 94207, 94219, 94240, 94274, 94283, 94298, 94301, 94303, 94304, 94305, 94306, 94307, 94309, 94315, 94318, 94326, 94392, 94401, 94402, 94403, 94404, 94405, 94409, 94421, 94451, 94453, 94497, 94500, 94501, 94502, 94503, 94504, 94505, 94506, 94507, 94508, 94509, 94510, 94511, 94512, 94513, 94514, 94515, 94516, 94517, 94518, 94519, 94520, 94521, 94522, 94523, 94524, 94525, 94526, 94527, 94528, 94529, 94530, 94531, 94533, 94534, 94535, 94536, 94537, 94538, 94539, 94540, 94541, 94542, 94543, 94544, 94545, 94546, 94547, 94548, 94549, 94550, 94551, 94552, 94553, 94555, 94556, 94558, 94559, 94560, 94561, 94562, 94563, 94564, 94565, 94566, 94567, 94568, 94569, 94570, 94571, 94572, 94573, 94574, 94575, 94576, 94577, 94578, 94579, 94580, 94581, 94582, 94583, 94584, 94585, 94586, 94587, 94588, 94589, 94590, 94591, 94592, 94595, 94596, 94597, 94598, 94599, 94601, 94602, 94603, 94604, 94605, 94606, 94607, 94608, 94609, 94610, 94611, 94612, 94613, 94614, 94615, 94616, 94618, 94619, 94620, 94621, 94622, 94623, 94625, 94626, 94627, 94632, 94641, 94645, 94654, 94656, 94659, 94660, 94661, 94662, 94666, 94670, 94680, 94687, 94688, 94700, 94701, 94702, 94703, 94704, 94705, 94706, 94707, 94708, 94709, 94710, 94720, 94801, 94802, 94803, 94804, 94805, 94806, 94807, 94808, 94850, 94883, 94901, 94902, 94903, 94904, 94912, 94913, 94914, 94915, 94917, 94920, 94922, 94923, 94924, 94925, 94926, 94927, 94928, 94929, 94930, 94931, 94933, 94937, 94938, 94939, 94940, 94941, 94942, 94945, 94946, 94947, 94948, 94949, 94950, 94951, 94952, 94953, 94954, 94955, 94956, 94957, 94960, 94963, 94964, 94965, 94966, 94970, 94971, 94972, 94973, 94975, 94976, 94977, 94978, 94998, 94999, 95000, 95001, 95002, 95003, 95004, 95005, 95006, 95007, 95008, 95009, 95010, 95012, 95013, 95014, 95015, 95017, 95018, 95019, 95020, 95021, 95022, 95023, 95024, 95025, 95026, 95027, 95028, 95030, 95031, 95032, 95033, 95034, 95035, 95036, 95037, 95038, 95039, 95040, 95041, 95042, 95043, 95044, 95045, 95046, 95050, 95051, 95052, 95053, 95054, 95057, 95060, 95061, 95062, 95063, 95064, 95065, 95066, 95070, 95071, 95073, 95075, 95076, 95077, 95085, 95087, 95088, 95101, 95102, 95103, 95106, 95110, 95111, 95112, 95113, 95114, 95115, 95116, 95117, 95118, 95119, 95120, 95121, 95122, 95123, 95124, 95125, 95126, 95127, 95128, 95129, 95130, 95131, 95132, 95133, 95134, 95135, 95136, 95137, 95138, 95139, 95140, 95141, 95148, 95150, 95151, 95152, 95153, 95154, 95155, 95157, 95159, 95160, 95161, 95188, 95191, 95192, 95200, 95201, 95202, 95203, 95204, 95205, 95206, 95207, 95208, 95209, 95210, 95211, 95212, 95213, 95215, 95219, 95220, 95221, 95222, 95223, 95224, 95225, 95226, 95227, 95228, 95229, 95230, 95231, 95232, 95233, 95234, 95236, 95237, 95239, 95240, 95241, 95242, 95243, 95245, 95246, 95247, 95248, 95249, 95250, 95251, 95252, 95253, 95254, 95255, 95257, 95258, 95267, 95270, 95276, 95301, 95303, 95304, 95305, 95306, 95307, 95309, 95310, 95311, 95312, 95313, 95314, 95315, 95316, 95317, 95318, 95319, 95320, 95321, 95322, 95323, 95324, 95325, 95326, 95327, 95328, 95329, 95330, 95332, 95333, 95334, 95335, 95336, 95337, 95338, 95339, 95340, 95341, 95343, 95344, 95345, 95346, 95347, 95348, 95349, 95350, 95351, 95352, 95353, 95354, 95355, 95356, 95357, 95358, 95360, 95361, 95363, 95364, 95365, 95366, 95367, 95368, 95369, 95370, 95372, 95373, 95374, 95375, 95376, 95377, 95378, 95379, 95380, 95381, 95382, 95383, 95384, 95385, 95386, 95387, 95388, 95389, 95391, 
95401, 95402, 95403, 95404, 95405, 95406, 95407, 95409, 95410, 95411, 95412, 95414, 95415, 95416, $95417,95418,95419,95420,95421,95422,95423,95424,95425,95426,95427,95428,95429,95430$, 95432, 95433, 95434, 95435, 95436, 95437, 95439, 95440, 95441, 95442, 95443, 95444, 95445, 95446, $95448,95449,95450,95451,95452,95453,95454,95455,95456,95457,95458,95459,95460,95461$, 95462, 95463, 95464, 95465, 95466, 95467, 95468, 95469, 95470, 95471, 95472, 95473, 95474, 95476, 95477, 95480, 95481, 95482, 95483, 95485, 95486, 95488, 95489, 95490, 95492, 95493, 95494, 95497, 95499, 95501, 95502, 95503, 95511, 95514, 95518, 95519, 95521, 95524, 95525, 95526, 95527, 95528, 95531, 95534, 95535, 95536, 95537, 95538, 95540, 95542, 95545, 95546, 95547, 95549, 95550, 95551, 95552, 95553, 95554, 95555, 95556, 95558, 95559, 95560, 95561, 95562, 95563, 95564, 95565, 95568, 95569, 95570, 95571, 95573, 95585, 95587, 95589, 95595, 95599, 95601, 95602, 95603, 95604, 95605, 95606, 95607, 95608, 95610, 95611, 95612, 95613, 95614, 95615, 95616, 95617, 95618, 95619, 95620, 95621, 95622, 95623, 95624, 95625, 95626, 95627, 95628, 95629, 95630, 95631, 95632, 95633, 95634, 95635, 95636, 95637, 95638, 95640, 95641, 95642, 95643, 95645, 95647, 95648, 95650, 95651, 95652, 95653, 95654, 95655, 95656, 95657, 95658, 95659, 95660, 95661, 95662, 95663, 95664, 95665, 95666, 95667, 95668, 95669, 95670, 95671, 95672, 95673, 95674, 95675, 95676, 95677, 95678, 95679, 9568, , 95680, 95681, 95682, 95684, 95685, 95686, 95687, 95688, 95689, 95690, 95691, 95692, 95693, 95694, 95695, 95696, 95697, 95698, 95699, 95701, 95703, 95704, 95706, 95707, 95709, 95710, 95712, 95713, $95714,95715,95717,95720,95721,95722,95723,95724,95725,95726,95728,95731,95733,95735$, 95736, 95738, 95741, 95742, 95746, 95747, 95757, 95758, 95762, 95763, 95765, 95766, 95773, 95775, 95776, 95778, 95779, 95798, 95799, 95804, 95811, 95812, 95813, 95814, 95815, 95816, 95817, 95818, 95819, 95820, 95821, 95822, 95823, 95824, 95825, 95826, 95827, 95828, 95829, 95830, 95831, 95832, 95833, 95834, 95835, 95836, 95837, 95838, 95841, 95842, 95843, 95851, 95853, 95858, 95864, 95867, 95868, 95869, 95876, 95899, 95901, 95903, 95905, 95910, 95911, 95912, 95913, 95914, 95915, 95916, 95917, 95918, 95919, 95920, 95922, 95923, 95924, 95925, 95926, 95927, 95928, 95929, 95930, 95931, 95932, 95934, 95935, 95936, 95937, 95938, 95939, 95940, 95941, 95942, 95943, 95944, 95945, 95946, 95947, 95948, 95949, 95950, 95951, 95952, 95953, 95954, 95955, 95956, 95957, 95958, 95959, 95960, 95961, 95962, 95963, 95964, 95965, 95966, 95967, 95968, 95969, 95970, 95971, 95972, 95973, 95974, 95975, 95977, 95978, 95979, 95980, 95981, 95982, 95983, 95984, 95986, 95987, 95988, 95989, 95990, 95991, 95992, 95993, 96001, 96002, 96003, 96007, 96008, 96009, 96010, 96011, 96013, 96016, 96019, 96020, 96021, 96022, 96024, 96028, 96029, 96030, 96033, 96035, 96036, 96040, 96041, 96046, 96047, 96048, 96049, 96050, 96051, 96052, 96053, 96055, 96056, 96059, 96061, 96062, 96063, 96064, 96065, 96067, 96068, 96069, 96070, 96071, 96073, 96074, 96075, 96076, 96078, 96079, 96080, 96084, 96087, 96088, 96089, 96090, 96091, 96092, 96093, 96095, 96096, 96099, 96103, 96117, 96120, 96122, 96125, 96127, 96128, 96130, 96134, 96137, 96160, 96206, 96211, 96311, 96411, 96461, 96591, 96628, 96646, 96682, 96963, 97007, 97144, 97228, 97401, 97478, 97701, 98052, 98101, 98331, 98639, 98663, 98684, 98706, 99210, 99331, 99561, 99999. 


\section{APPENDIX B. Summary of Peak Day Pricing Tariff}

Beginning November, 2011, all PG\&E small and medium business customers (except those who participate in Direct Access or other Demand Response programs, other than SmartRate and CPP) will automatically transition to Peak Day Pricing6 (PDP).

On this plan, participants will see additional charges during peak hours (weekdays from 2 - 6 p.m.) on a limited number of "Event Days" throughout the year. In exchange, they will receive usage credits throughout the summer. Under PDP tariff rules:

Customers will receive credits on their energy use from May through October.

Event days are generally triggered by high temperature, but California ISO system emergencies and market-price conditions may also lead to an event. PG\&E will call a minimum of 9 and a maximum of 15 Event Days per year.

Customers receive notification 24 hours prior to an Event Day.

On Event Days, the cost of energy increases during peak demand times (weekdays from 2 - 6 p.m., for customers with A-1, A-6, A-10 rate schedules). On all other times, customers will be charged their normal Time of use (TOU) rates.

Customers can choose participation days (e.g. alternate days), or an optional longer event window 12 p.m. to 6 p.m., with associated changes in incentives

Customers who can reduce their load during these high cost periods, or shift load from higher cost to lower cost periods, may benefit on this plan.

\footnotetext{
${ }^{6}$ Complete information about PG\&E's PDP program for Small and Medium Commercial businesses can by found at

http://www.pge.com/mybusiness/energysavingsrebates/demandresponse/peakdaypricing/SMB/
} 
Table B-1. PG\&E PDP credits and charges for Small and Medium Commercial Businesses ${ }^{7}$

\begin{tabular}{|c|c|c|c|c|c|c|c|c|c|c|}
\hline \multirow[b]{3}{*}{ Rate } & \multirow{2}{*}{\multicolumn{2}{|c|}{$\begin{array}{l}\text { Demand Credit } \\
\qquad(\$ / \mathrm{kW})\end{array}$}} & \multicolumn{6}{|c|}{ Energy Credits $(\$ / k W h)$} & \multirow{2}{*}{\multicolumn{2}{|c|}{$\begin{array}{c}\text { Energy Charges } \\
\qquad(\$ / k W h)\end{array}$}} \\
\hline & & & \multicolumn{3}{|c|}{ Unlimited } & \multicolumn{3}{|c|}{ Alternate } & & \\
\hline & Unlimited & Alternate & On Peak & Part Peak & Off Peak & On Peak & Part Peak & Off Peak & 4 hours & 6 hours \\
\hline A1 $^{*}$ & nia & nia & $(\$ 0.01096)$ & $(\$ 0.01096)$ & $(\$ 0.01096)$ & $(\$ 0.00548)$ & $(\$ 0.00548)$ & $(\$ 0.00548)$ & $\$ 0.60$ & $\$ 0.40$ \\
\hline A6 & & & $(\$ 0.08786)$ & $(\$ 0.01757)$ & $(\$ 0.00000)$ & $(\$ 0.04393)$ & $(\$ 0.00879)$ & $(\$ 0.00000)$ & $\$ 1.20$ & $\$ 0.80$ \\
\hline $\mathrm{A} 10 \mathrm{~T}^{\mathrm{x}}$ & $(\$ 1.79)$ & $(\$ 0.90)$ & $(\$ 0.00915)$ & $(\$ 0.00915)$ & $(\$ 0.00915)$ & $(\$ 0.00458)$ & $(\$ 0.00458)$ & $(\$ 0.00458)$ & $\$ 0.90$ & $\$ 0.60$ \\
\hline $\mathrm{A} 10 \mathrm{P}^{\wedge}$ & $(\$ 1.60)$ & $(\$ 0.80)$ & $(\$ 0.01103)$ & $(\$ 0.01103)$ & $(\$ 0.01103)$ & $(\$ 0.00552)$ & $(\$ 0.00552)$ & $(\$ 0.00552)$ & $\$ 0.90$ & $\$ 0.60$ \\
\hline $\mathrm{A} 10 \mathrm{~S}^{\wedge}$ & $(\$ 1.54)$ & $(\$ 0.77)$ & $(\$ 0.01055)$ & $(\$ 0.01055)$ & $(\$ 0.01055)$ & $(\$ 0.00528)$ & $(\$ 0.00528)$ & $(\$ 0.00528)$ & $\$ 0.90$ & $\$ 0.60$ \\
\hline
\end{tabular}

* PDP credits and charges available only with Time-of-Use rates.

\footnotetext{
${ }^{7}$ http://www.pge.com/mybusiness/energysavingsrebates/demandresponse/peakdaypricing/facts/charges/ (retrieved February 22, 2011)
} 


\section{APPENDIX C. \\ Site Descriptions and Data}

\section{C.1. Site Description - Rocklin}

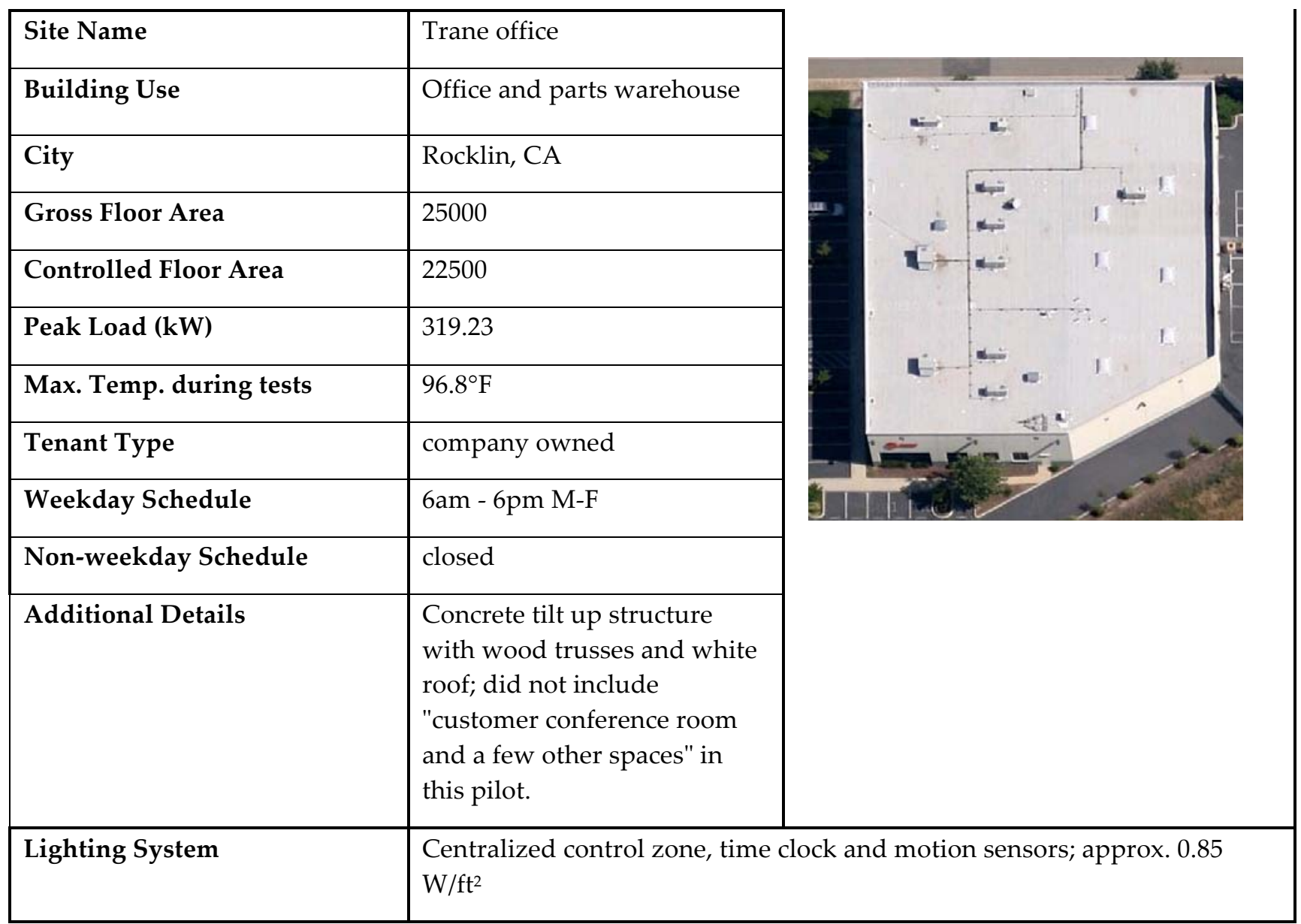

HVAC Summary

\begin{tabular}{|l|l|}
\hline Air Distribution Type & 10 constant volume RTU's, 2 stage compressors \\
\hline Cooling System & \\
\hline HVAC Control System & 6 digital thermostats \\
\hline HVAC Zoning & \\
\hline
\end{tabular}

\section{Data Collection}

\begin{tabular}{|l|l|}
\hline \hline Electric Data & Wattnode \\
\hline \multicolumn{2}{|l|}{ Vendor Information } \\
\hline \hline Vendor Name & Trane
\end{tabular}




\begin{tabular}{|c|c|}
\hline Technology Description & Thermostat control only \\
\hline \multicolumn{2}{|l|}{ DR Strategies } \\
\hline HVAC & $\begin{array}{l}\text { The building controller checks every } 5 \text { minutes to identify if an event is } \\
\text { planned for the day. If the current time is in the Precooling Period (one } \\
\text { hour prior to events), the building controller reduced the active setpoint } \\
\text { for most of the facility (a customer conference room and "a few other } \\
\text { spaces" were not included) from } 74^{\circ} \mathrm{F} \text { to } 72^{\circ} \mathrm{F} \text {. When the current time is } \\
\text { within the Event Period, the setpoint was changed to } 75^{\circ} \mathrm{F} \text {. At the end of } \\
\text { an event, the building controller reset the thermostats to } 74^{\circ} \mathrm{F} \text {. }\end{array}$ \\
\hline
\end{tabular}

\section{Site Architecture}

Figure C-1. Trane office site architecture

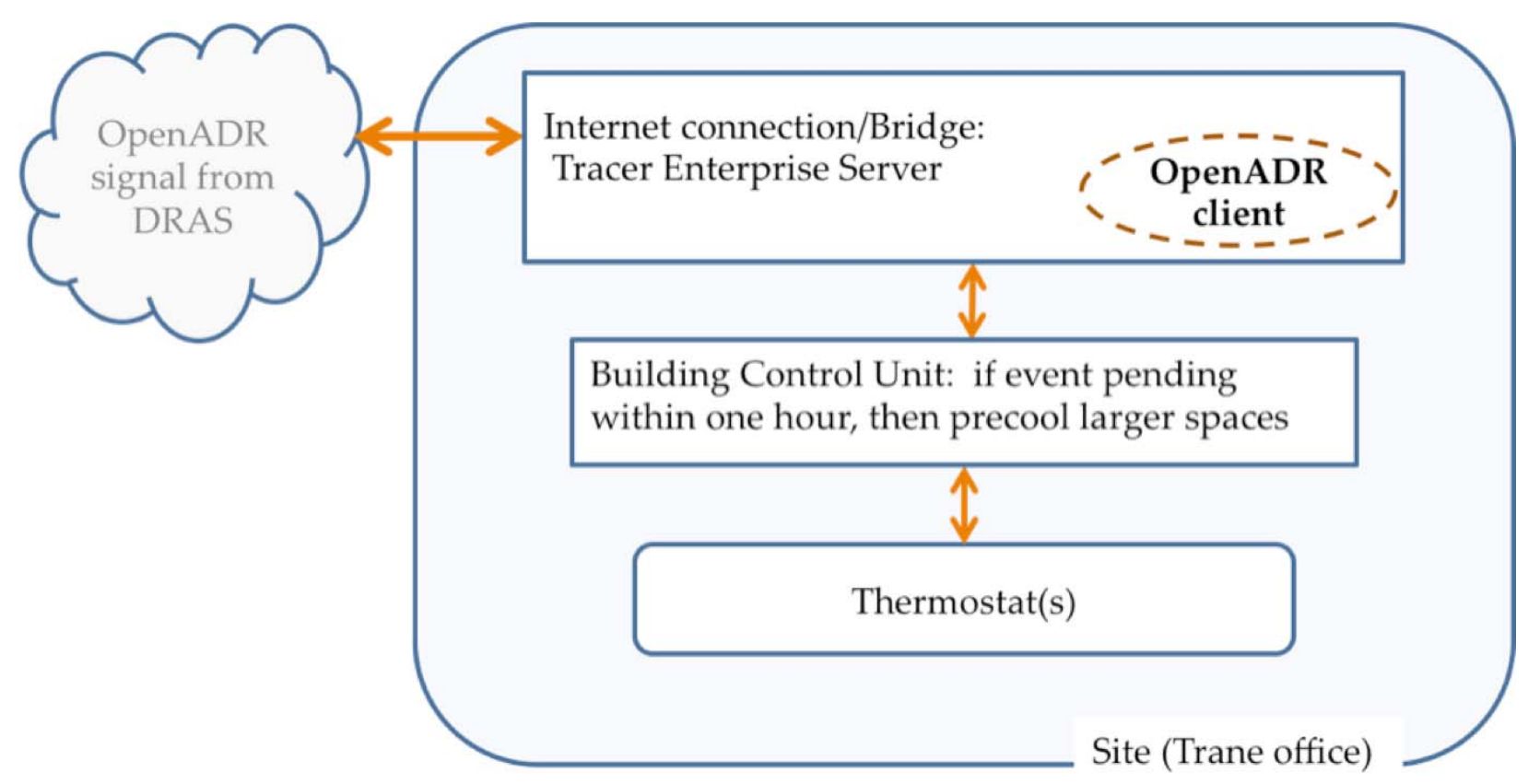

The Tracer Enterprise server acted as the gateway to receive the OpenADR signal and relay it to the site thermostat(s). Advanced notification of a DR event triggered precooling of the facility one hour before the event, so that at the onset of the event, the temperature set points could be raised. Later tests in October omitted the pre-cooling step, with the result that the reduction in demand during an event only lasted an hour before higher indoor temperatures prompted the HVAC to start. Discussions with staff at Trane suggested that the building insulation may have been insufficient because the HVAC did not appear to be undersized for the space. 


\section{Data Overview}

Figure C-2. Trane, September 24, 2010 (Max OAT: $89^{\circ} \mathrm{F}$ )

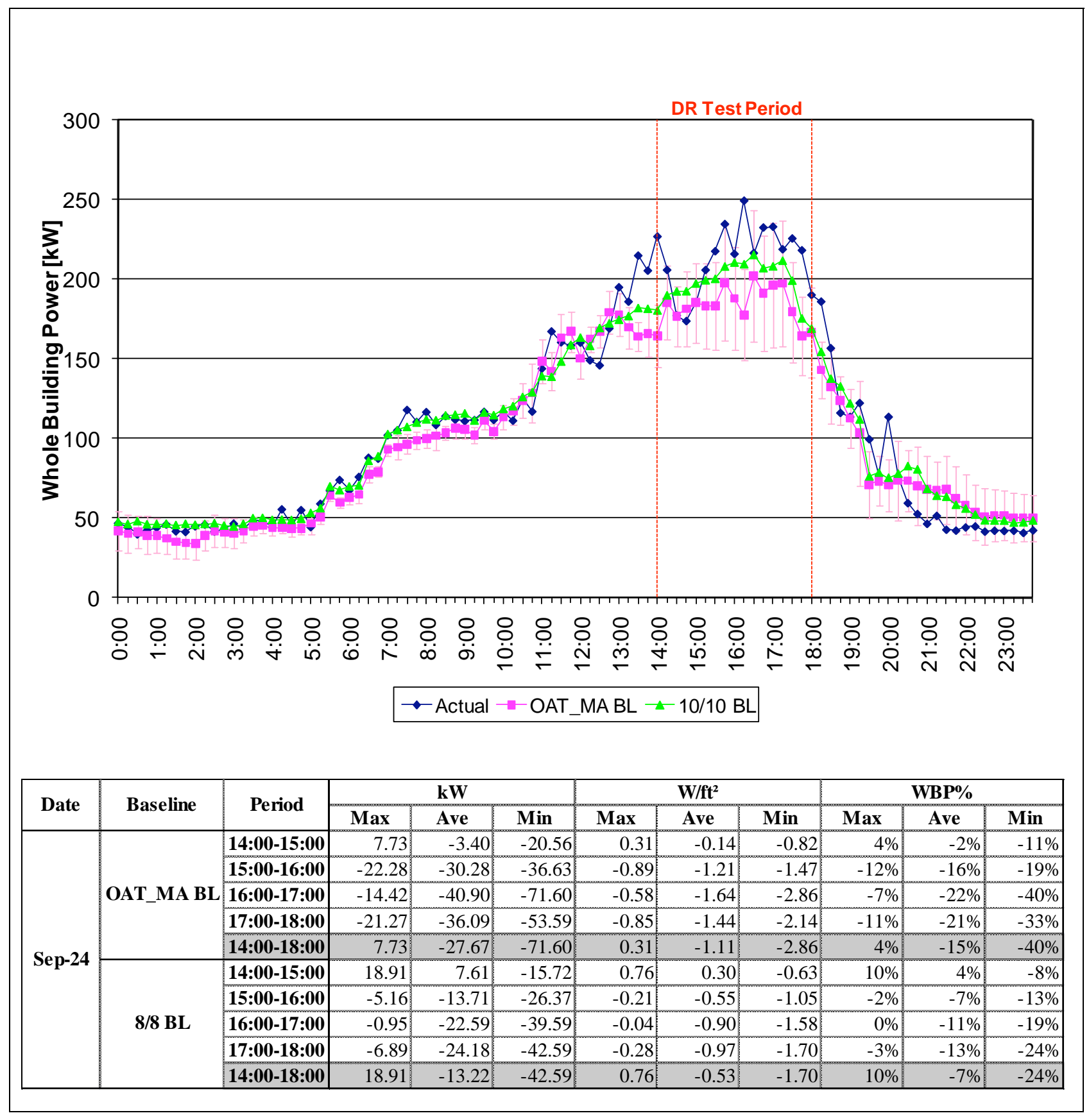


Figure C-3. Trane, September 27, 2010 (Max OAT: 97 F)

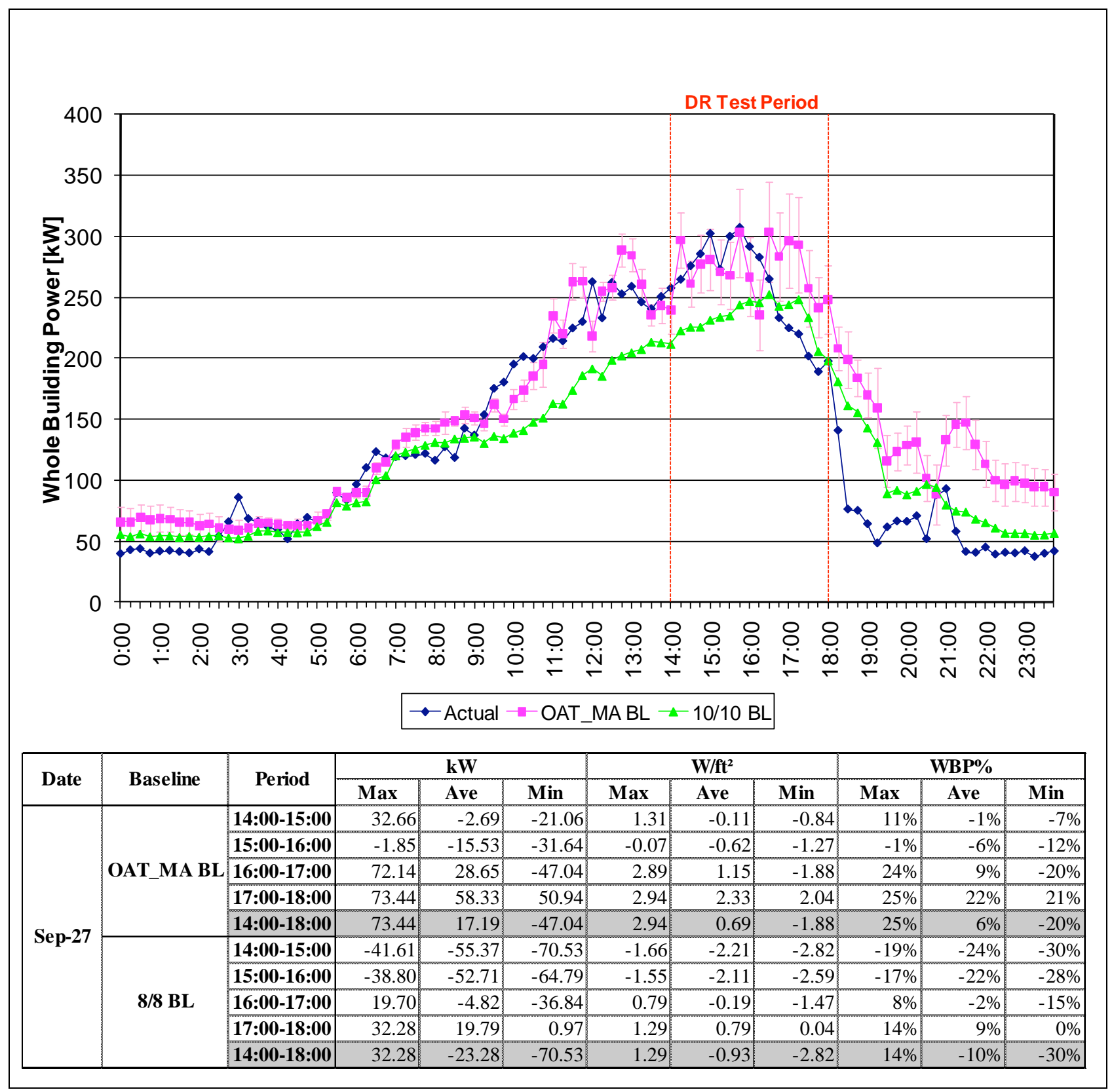


Figure C-4. Trane, September 28, 2010 (Max OAT: 100 F)

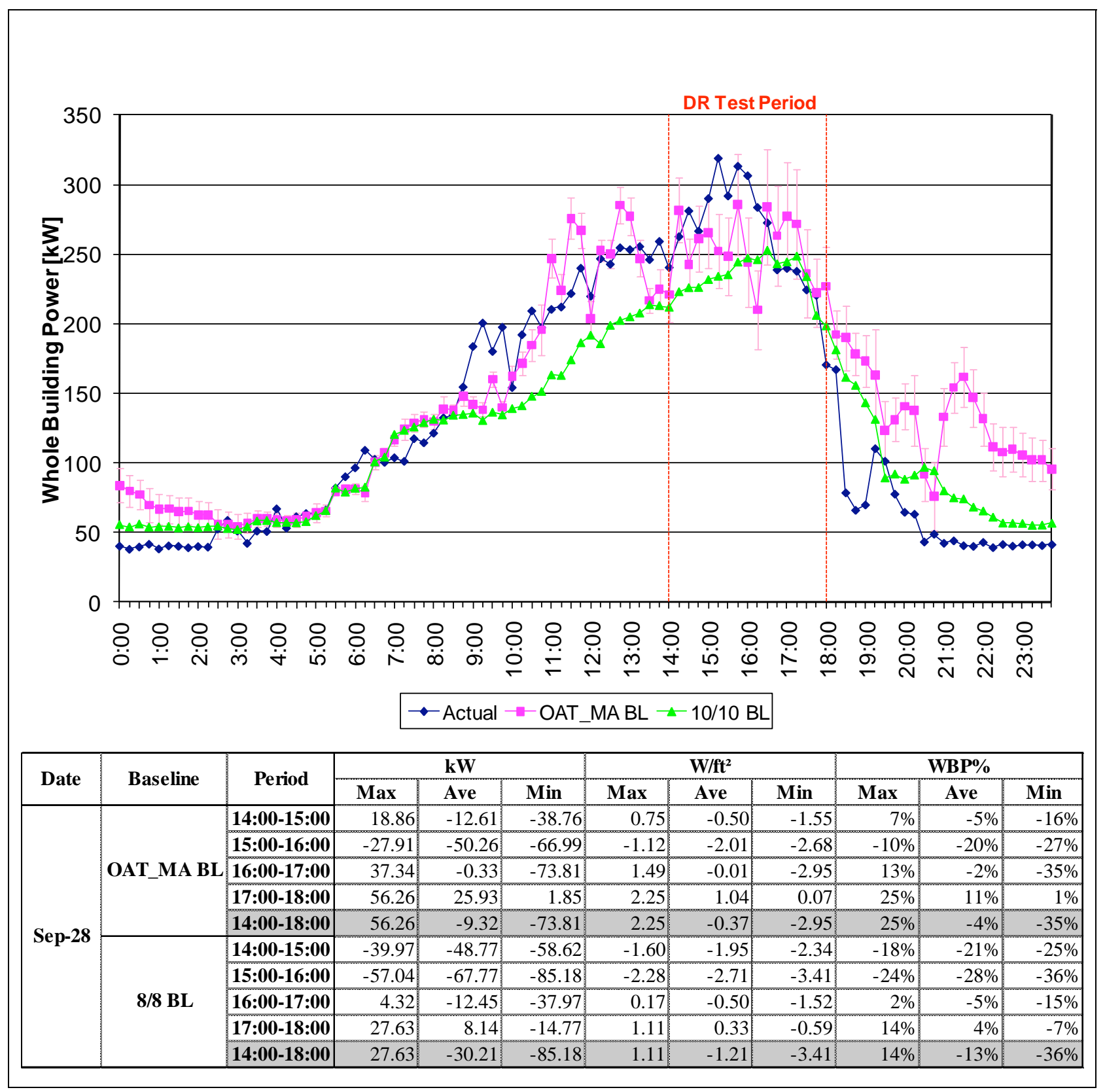


Figure C-5. Trane, October 12, 2010 (Max OAT: 90 ${ }^{\circ} \mathrm{F}$ )

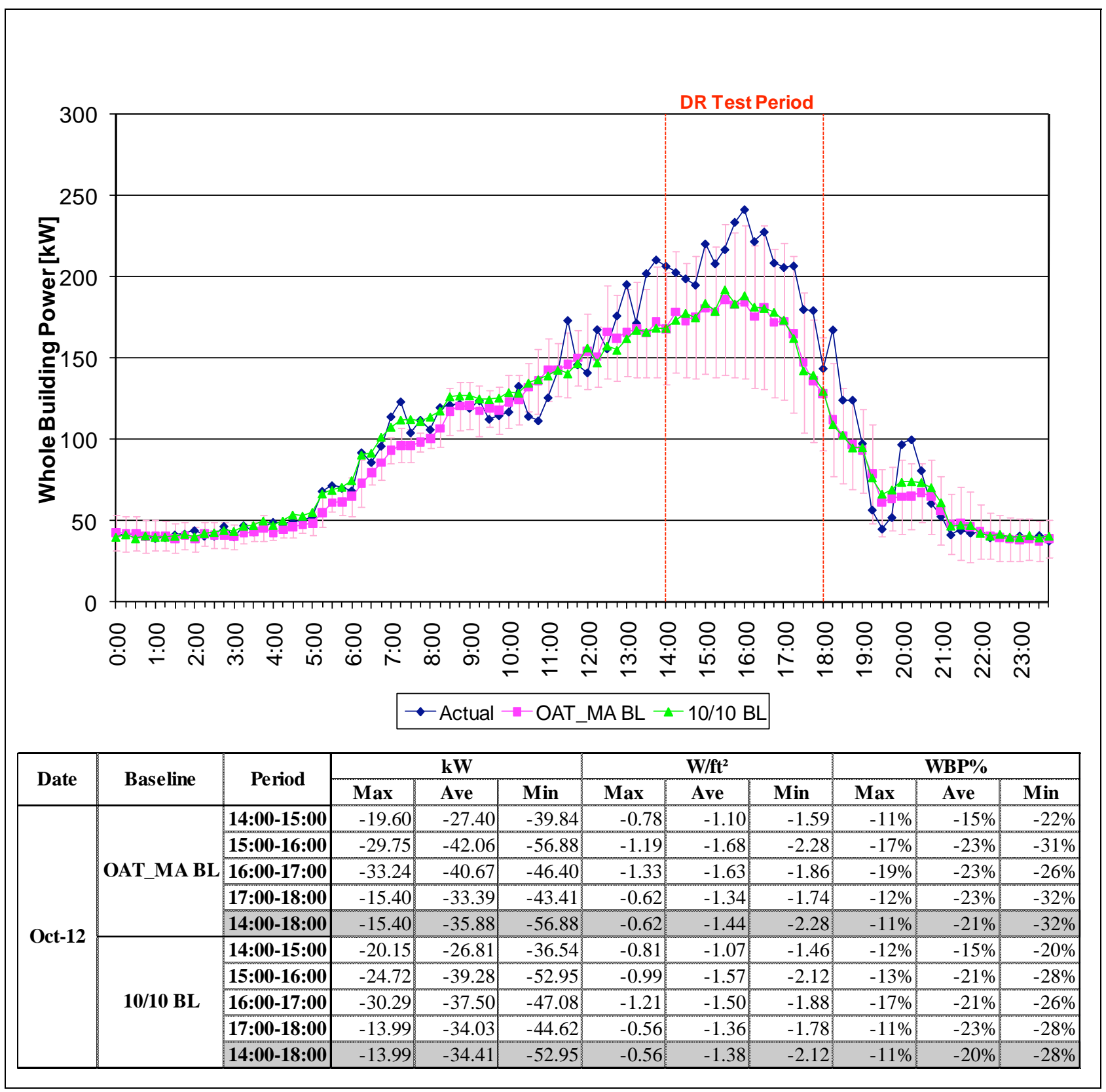


Figure C-6. Trane, October 13, 2010 (Max OAT: 92 ${ }^{\circ} \mathrm{F}$ )

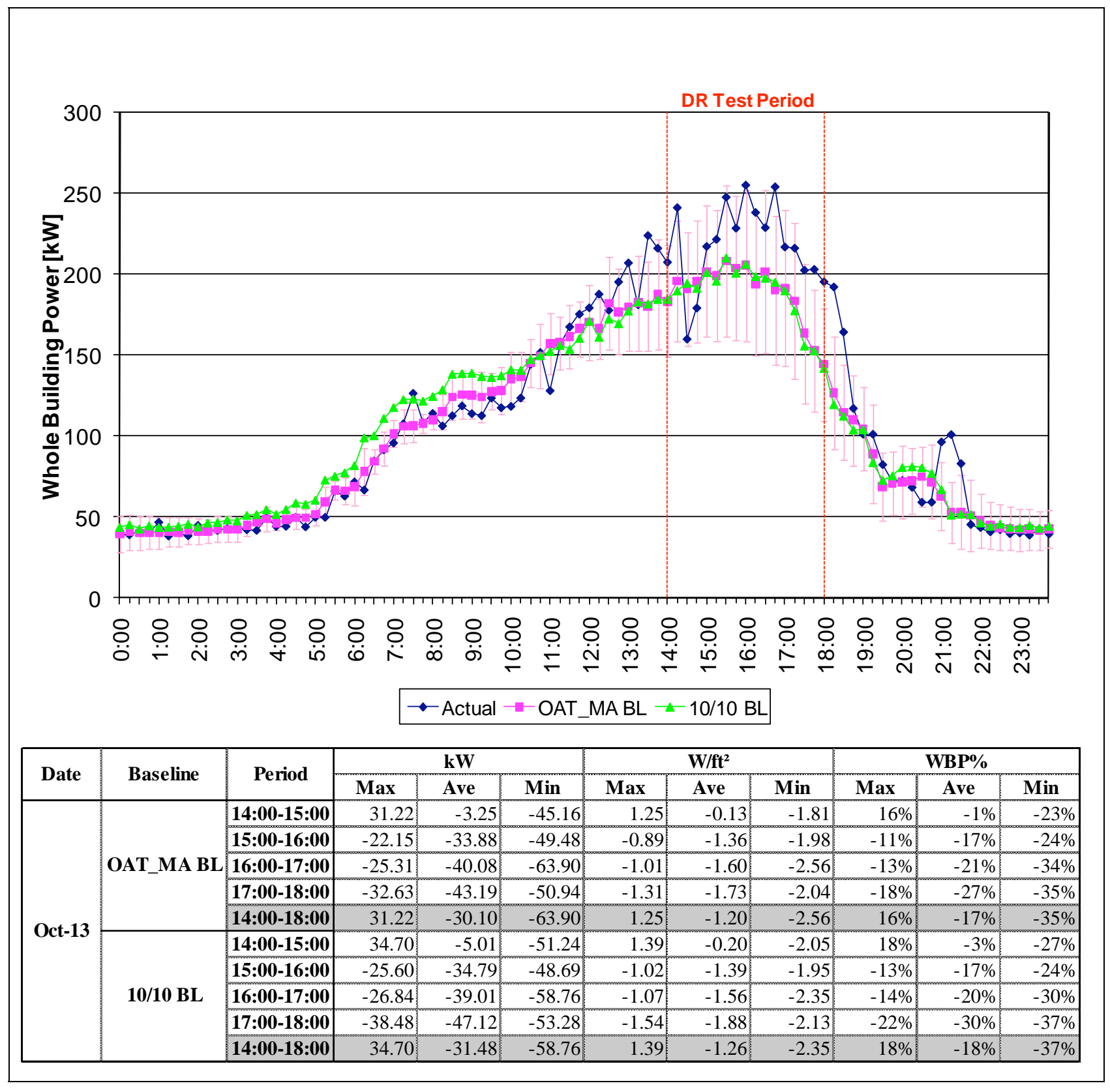


Figure C-7. Trane, October 15, 2010 (Max OAT: 91 ${ }^{\circ} \mathrm{F}$ )

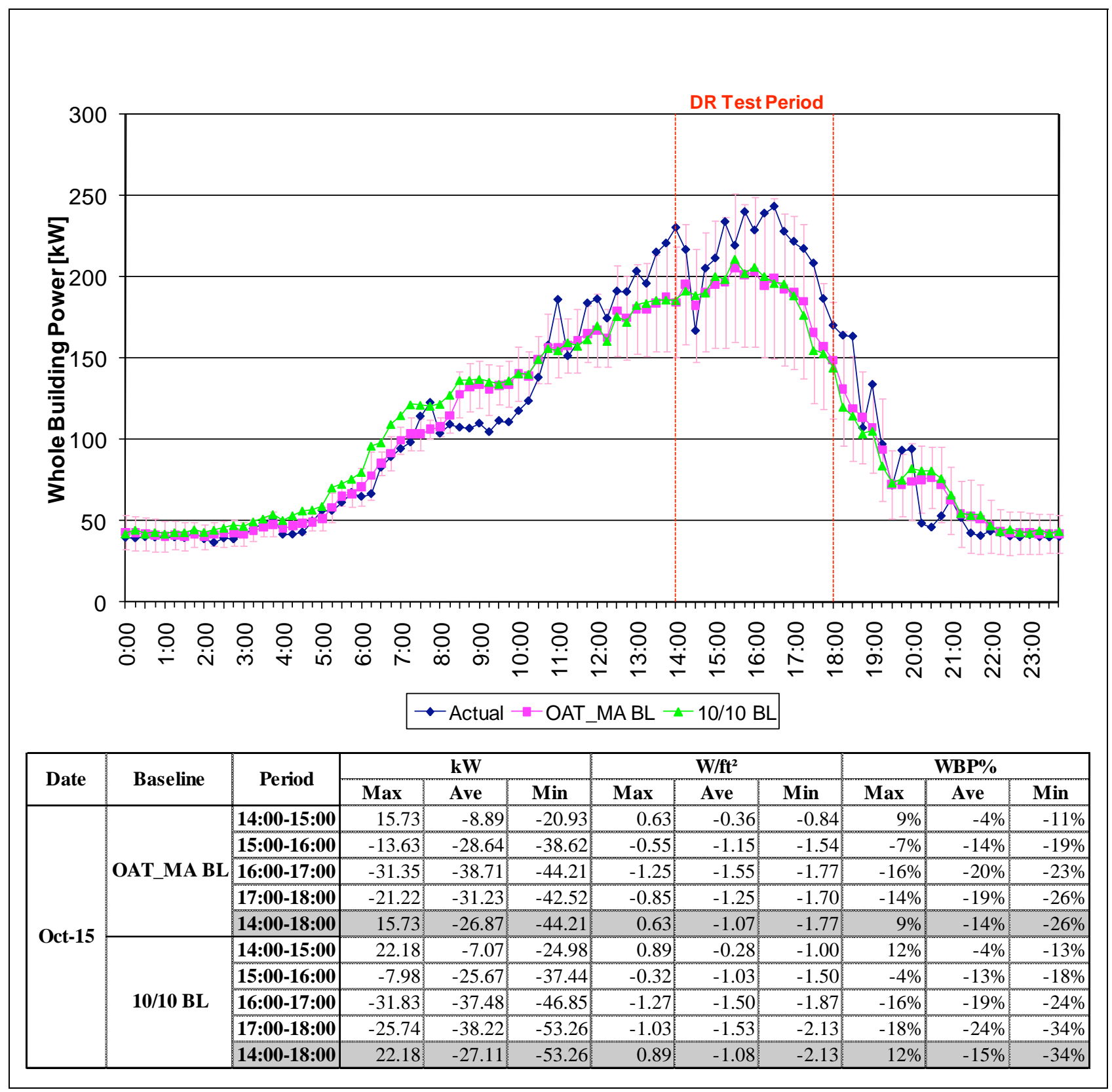


Figure C-8. Rocklin site (Trane)

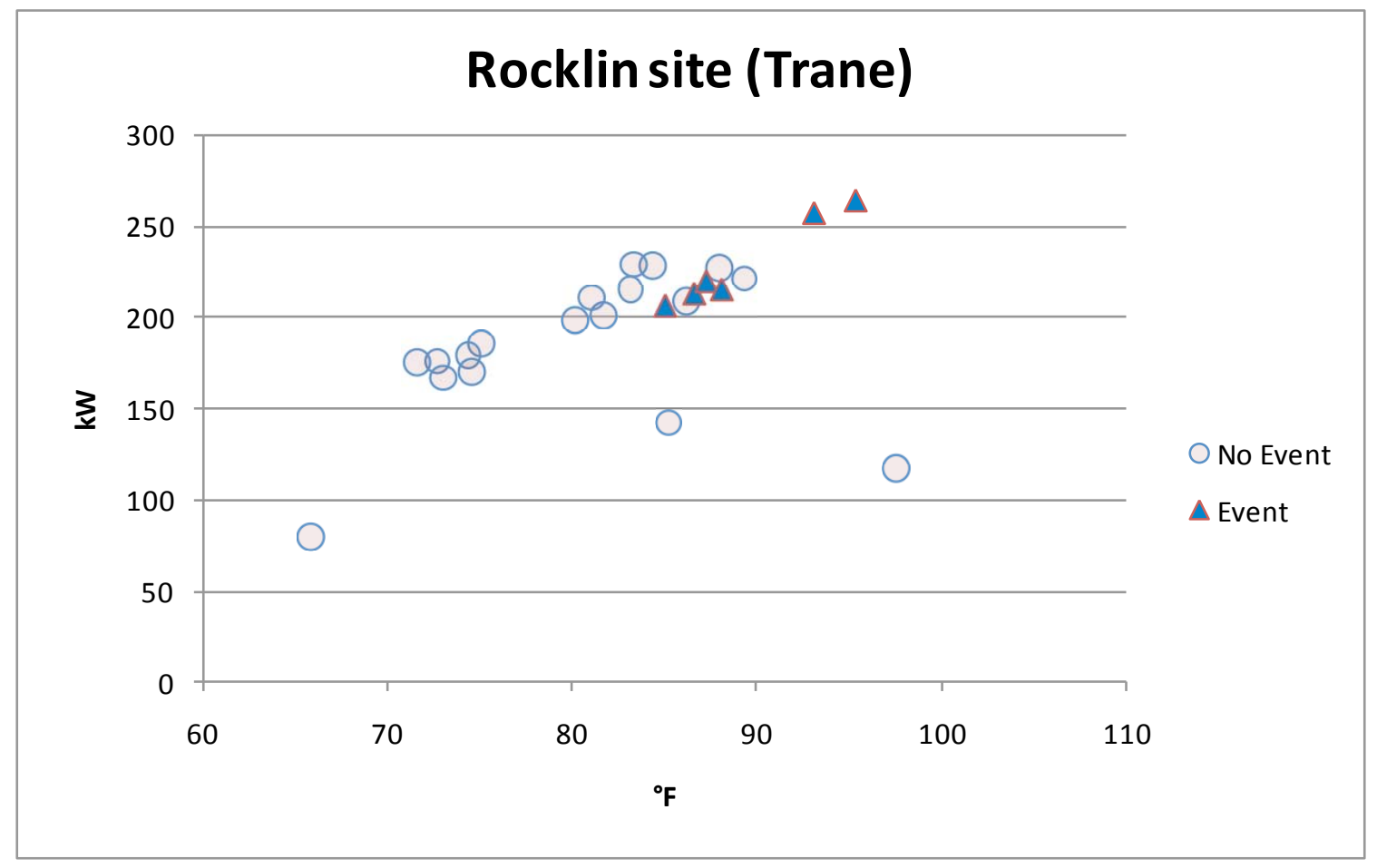

\section{Discussion}

According to DRAS records, the Rocklin site was "offline" (that is, the site did not acknowledge the DRAS signal for more than three minutes; sites were required to poll the DRAS at least once per minute) during the events called for September 27 and 28 (these days are represented by the two "Event" data points on this graph at the upper right of the plot). The response graphs for these dates also shows no apparent reduction in demand during the called event, in contrast to the graphs for the remaining events (September 24, October 12, October 13, and October 15), where there is a decline in demand for about an hour after the event is called. Since the strategy called for precooling the building about an hour before an event, this decline in demand was subsequent to a consistent increase in demand prior to the event, so it is not clear that such a strategy leads to overall savings when the site does not have sufficient thermal mass to "store" the precooling. 


\section{C.2. Site Description - Santa Rosa}

\begin{tabular}{|c|c|c|}
\hline Site Name & 24 Seven Food and Fuel & \\
\hline Building Use & $\begin{array}{l}\text { Convenience store and } \\
\text { gas station }\end{array}$ & \\
\hline City & Santa Rosa, CA & \\
\hline Gross Floor Area & 3531 & \\
\hline Controlled Floor Area & 3531 & \\
\hline Peak Load (kW) & 34 & \\
\hline Max. Temp. during tests & $106.6^{\circ} \mathrm{F}$ & \\
\hline Tenant Type & Company owned & \\
\hline Weekday Schedule & $\begin{array}{l}\text { Midnight to midnight M- } \\
\text { F }\end{array}$ & \\
\hline Non-weekday Schedule & $\begin{array}{l}\text { Midnight to midnight } \\
\text { S-S }\end{array}$ & \\
\hline Additional Details & $\begin{array}{l}\text { Property includes } 12 \text { gas } \\
\text { pumps and a car wash in } \\
\text { addition to the controlled } \\
\text { space within the } \\
\text { convenience store. }\end{array}$ & \\
\hline Lighting & \multicolumn{2}{|c|}{$\begin{array}{l}\text { The convenience store has } 29 \text { fixtures with } 2 \text { fluorescent } 32 \text { watt bulbs } \\
\text { each. Outdoor nighttime lighting is Halogen bulbs at the gas pumps. } \\
\text { The interior lights are on } 24 \times 7 \text { and are permanently wired at the } \\
\text { electrical service panel. Originally planned to control lighting but } \\
\text { turned out to be incompatible with site business. }\end{array}$} \\
\hline Lighting intensity & \multicolumn{2}{|c|}{ Approx 1856 watts / 3550 square feet $=0.5228 \mathrm{~W} / \mathrm{sq} . \mathrm{ft}}$. \\
\hline
\end{tabular}

HVAC Summary

\begin{tabular}{|l|l|}
\hline Air Distribution Type & $\begin{array}{l}\text { Two units: Each is constant volume with air handling unit on roof, } \\
\text { condensor at ground level }\end{array}$ \\
\hline Cooling System & Two single stage split 4 ton HVAC units in convenience store. \\
\hline Heating System & \\
\hline HVAC Control System & \\
\hline HVAC Zoning & \\
\hline
\end{tabular}




\begin{tabular}{|c|c|}
\hline Other & $\begin{array}{l}\text { Tried cycling the refrigeration unit in car wash building but the } \\
\text { response was erratic. The refrigerator was stopped at } 08 / 27 / 2010 \\
\text { around 13:03, but it was plugged back in around 19:36 on } 8 / 31 \text { and } \\
\text { ran for } 2 \text { days. It was finally disconnected completely on } 9 / 2 / 2010 \text { at } \\
\text { 13:02. }\end{array}$ \\
\hline \multicolumn{2}{|l|}{ Data Collection } \\
\hline Electric Data & $\begin{array}{l}\text { Conzerv 6400+: The meter is installed next to the main service panel } \\
\text { in the car wash building. The meter provides a full building reading } \\
\text { of electrical consumption. The digital meter is polled by the } \\
\text { LimeAmps Gateway every } 10 \text { seconds via a ZigBee wireless modem. }\end{array}$ \\
\hline \multicolumn{2}{|l|}{ Vendor Information } \\
\hline Vendor Name & LimeAmps (installed by Zero Energy Associates) \\
\hline Technology Description & Load controller, Gateway, Smart plug \\
\hline \multicolumn{2}{|l|}{ DR Strategies } \\
\hline HVAC & $\begin{array}{l}\text { The convenience store has two (2) } 4 \text { ton split HVAC units. A LimeAmps } \\
\text { Load Controller was connected to the two (2) thermostats located } \\
\text { inside the convenience store. Initially, the Gateway was programmed } \\
\text { to cycle between the two roof mounted HVAC units every } 15 \text { minutes } \\
\text { during the event. The goal was to turn the compressor off, but not the } \\
\text { fans. This proved to be a difficult way to control temperature. Before } \\
\text { DR testing began, the vendor chose a } 30 \text { minute 'off', } 15 \text { minute 'on' } \\
\text { strategy. The cycling values could be changed remotely or adjusted in } \\
\text { a few minutes, but were not changed during an event. }\end{array}$ \\
\hline Lighting & $\begin{array}{l}\text { Initially, the site occupant allowed the vendor to turn off } 1 / 2 \text { of the } \\
\text { overhead lights in the convenience store, but after a test event, he } \\
\text { determined that it was too dark in the store and the Load Controller } \\
\text { was reprogrammed to ignore the lighting controls. }\end{array}$ \\
\hline Refrigeration & $\begin{array}{l}\text { The convenience store has a large free standing deli food and drink } \\
\text { counter on the floor with a built in refrigeration unit. This unit was } \\
\text { automatically cycled on/off during each event using a straight } 15 \\
\text { minute on/off period. } \\
\text { An ice machine in the utility room of the store was automatically shut } \\
\text { down during the entire duration of each DR event. Onsite staff were } \\
\text { asked to move any ice in the ice machine to another freezer prior or } \\
\text { during the event. } \\
\text { The owner has an upright refrigerator located in the car wash } \\
\text { building that is used to store extra items used for replenishing the deli } \\
\text { counter during the day. The refrigeration unit was cycled every } 30 \\
\text { minutes on/off during the first event via a wireless Zigbee connection } \\
\text { but acted erratically during the test, so it was disconnected from } \\
\text { future tests. }\end{array}$ \\
\hline
\end{tabular}




\begin{tabular}{|l|l|} 
Miscellaneous Electric Loads & $\begin{array}{l}\text { A LimeAmps Plug Load controller was installed at the sales counter, } \\
\text { activated by the Gateway to turn on a lamp so that the staff were } \\
\text { aware when an event was in progress and minimize load during the } \\
\text { event. }\end{array}$ \\
\hline Other & $\begin{array}{l}\text { Consideration was given to controlling some walk-in beverage } \\
\text { coolers, but this was not implemented during these tests. }\end{array}$ \\
\hline
\end{tabular}

\section{Site Architecture}

Figure C-9. 24 Seven Fuel \& Food Site Architecture

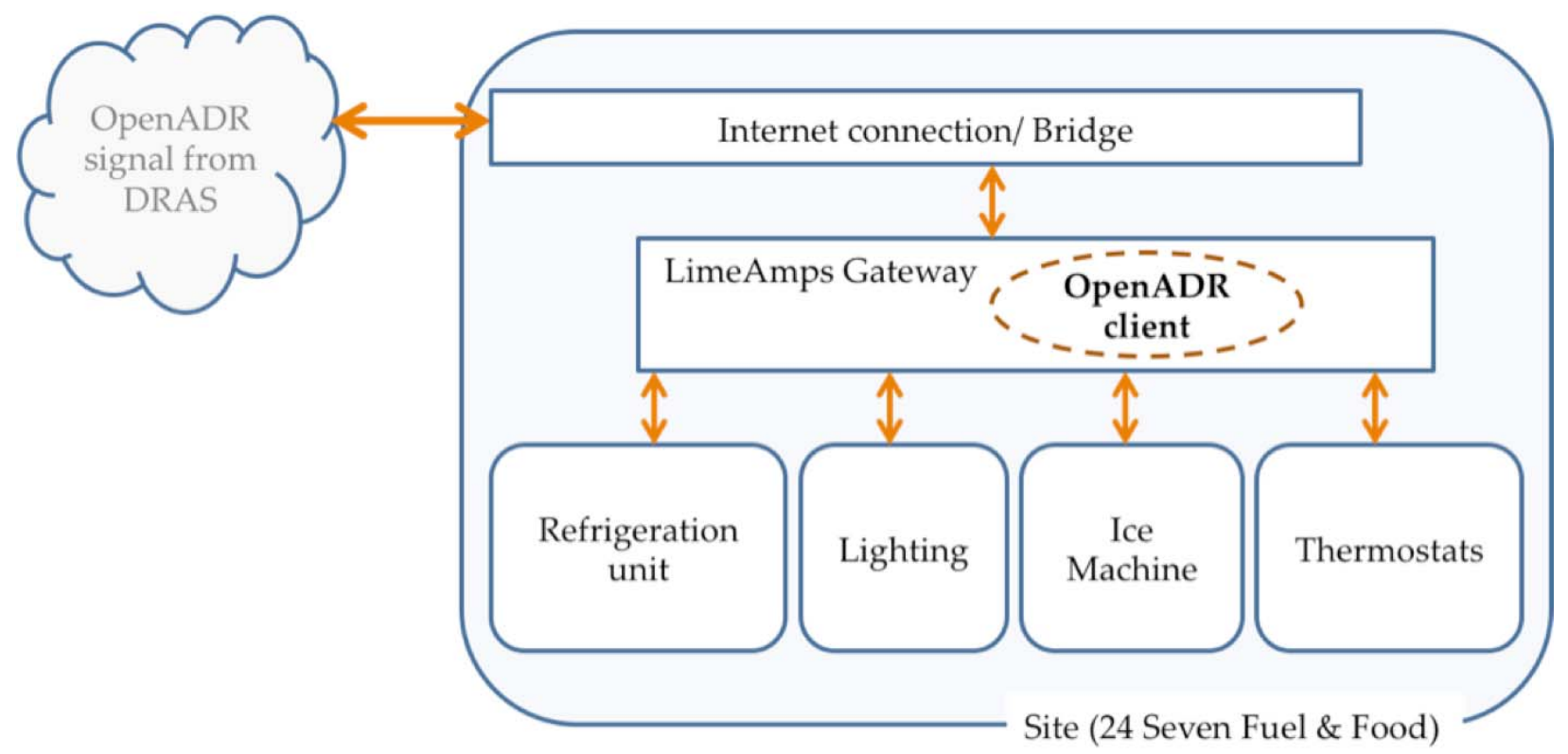

The LimeAmps gateway translates the OpenADR signal to predefined response strategies at the device level. These are conveyed via relays or signals to a programmable thermostat. 


\section{Site Data}

Figure C-10. LimeAmps 24-7, August 24, 2010 (Max OAT 107 F)

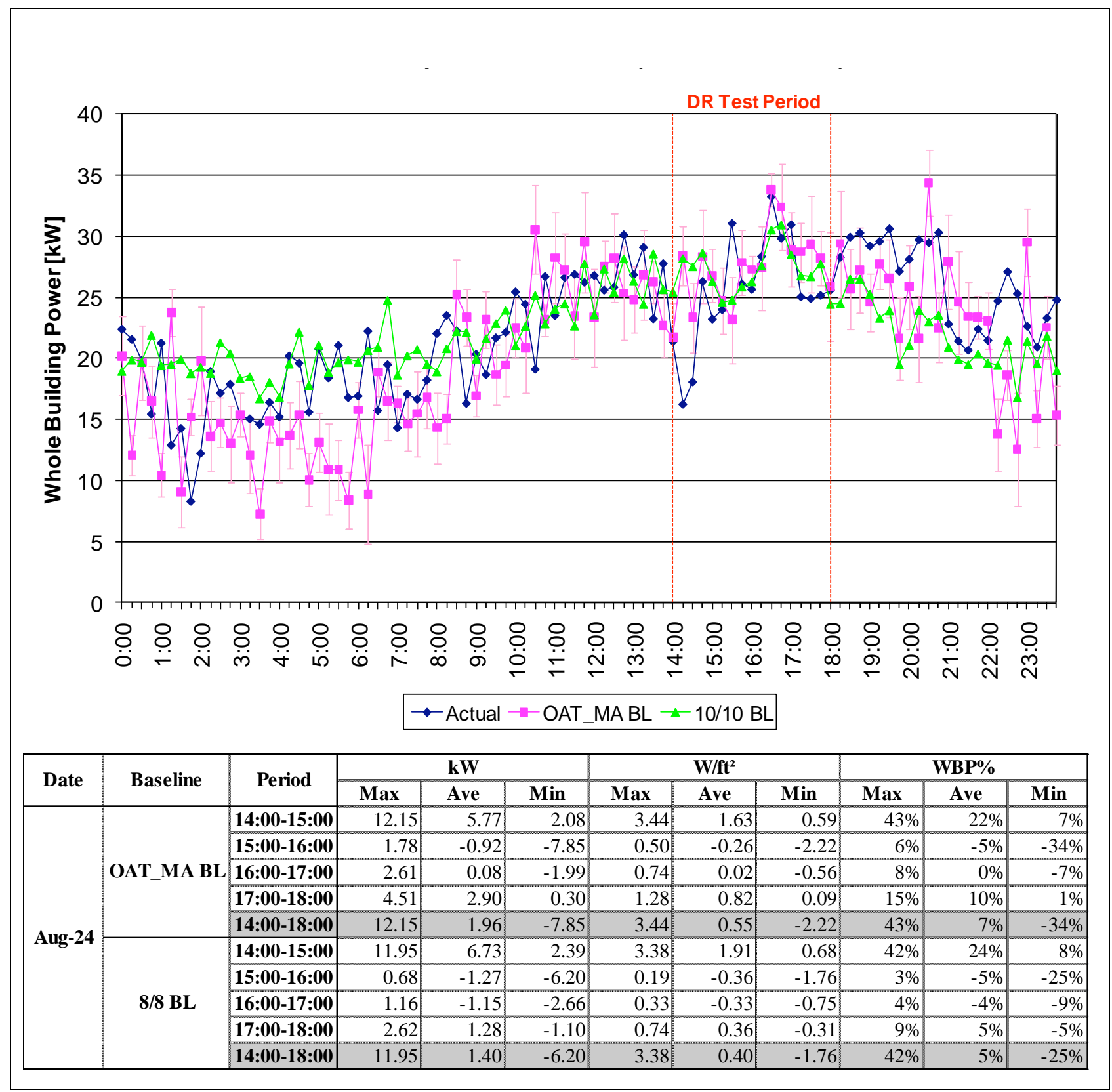


Figure C-11. LimeAmps 24-7, September 1, 2010 (Max OAT: 97 F)

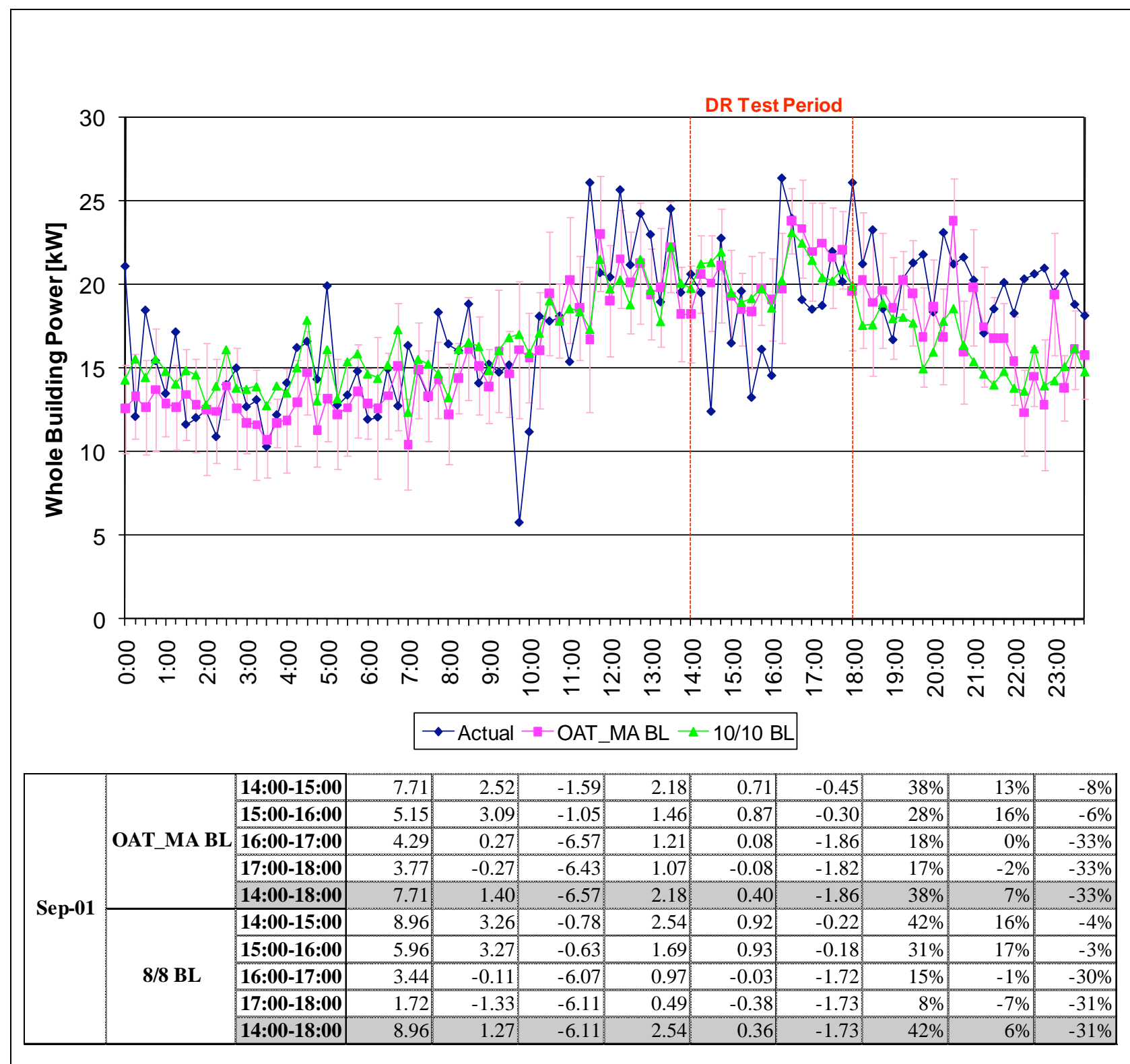


Figure C-12. LimeAmps 24-7, September 2, 2010 (Max OAT: 98 ${ }^{\circ} \mathrm{F}$ )

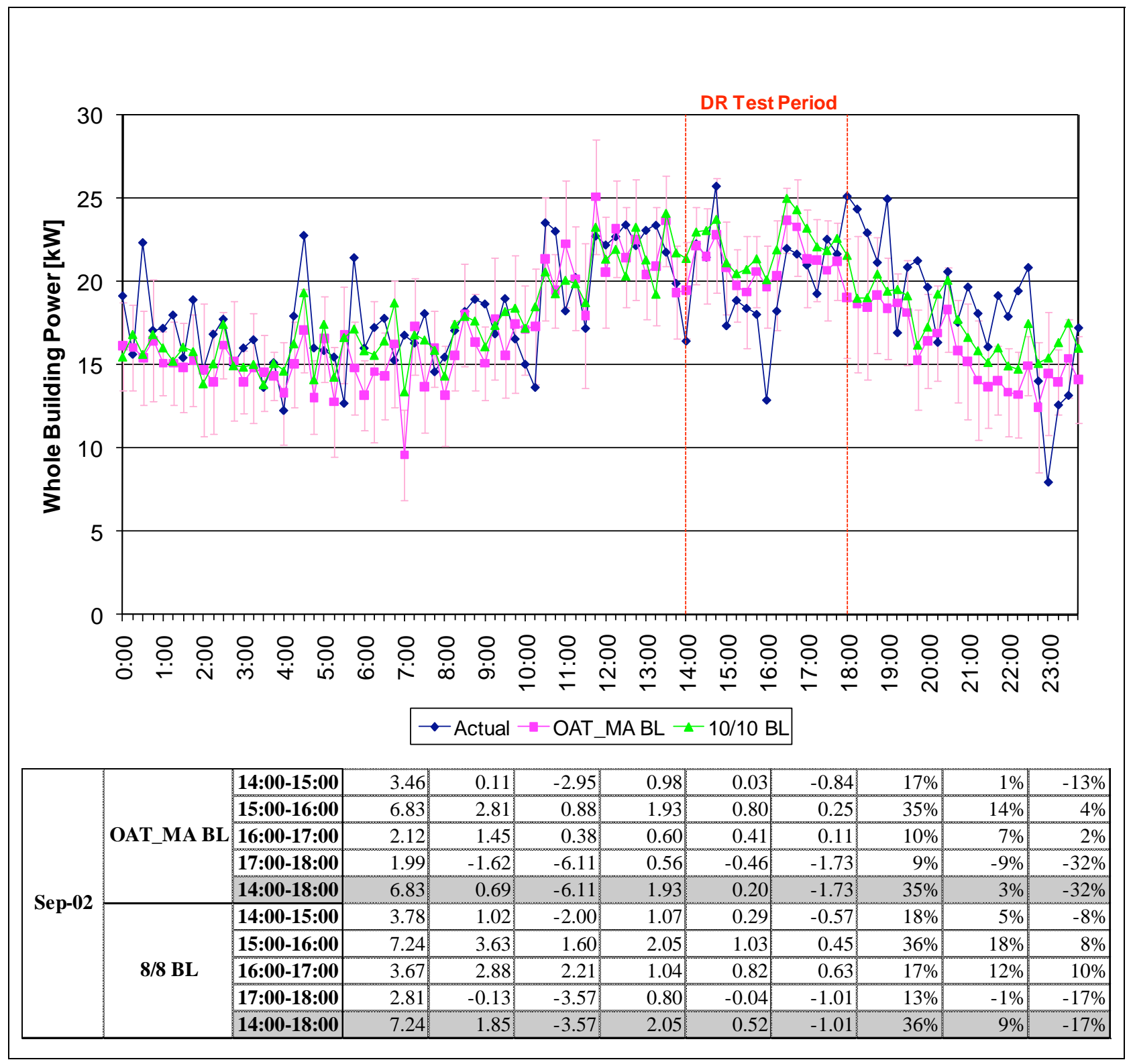


Figure C-13. LimeAmps 24-7, September 24, 2010 (Max OAT: 92 ${ }^{\circ} \mathrm{F}$ )

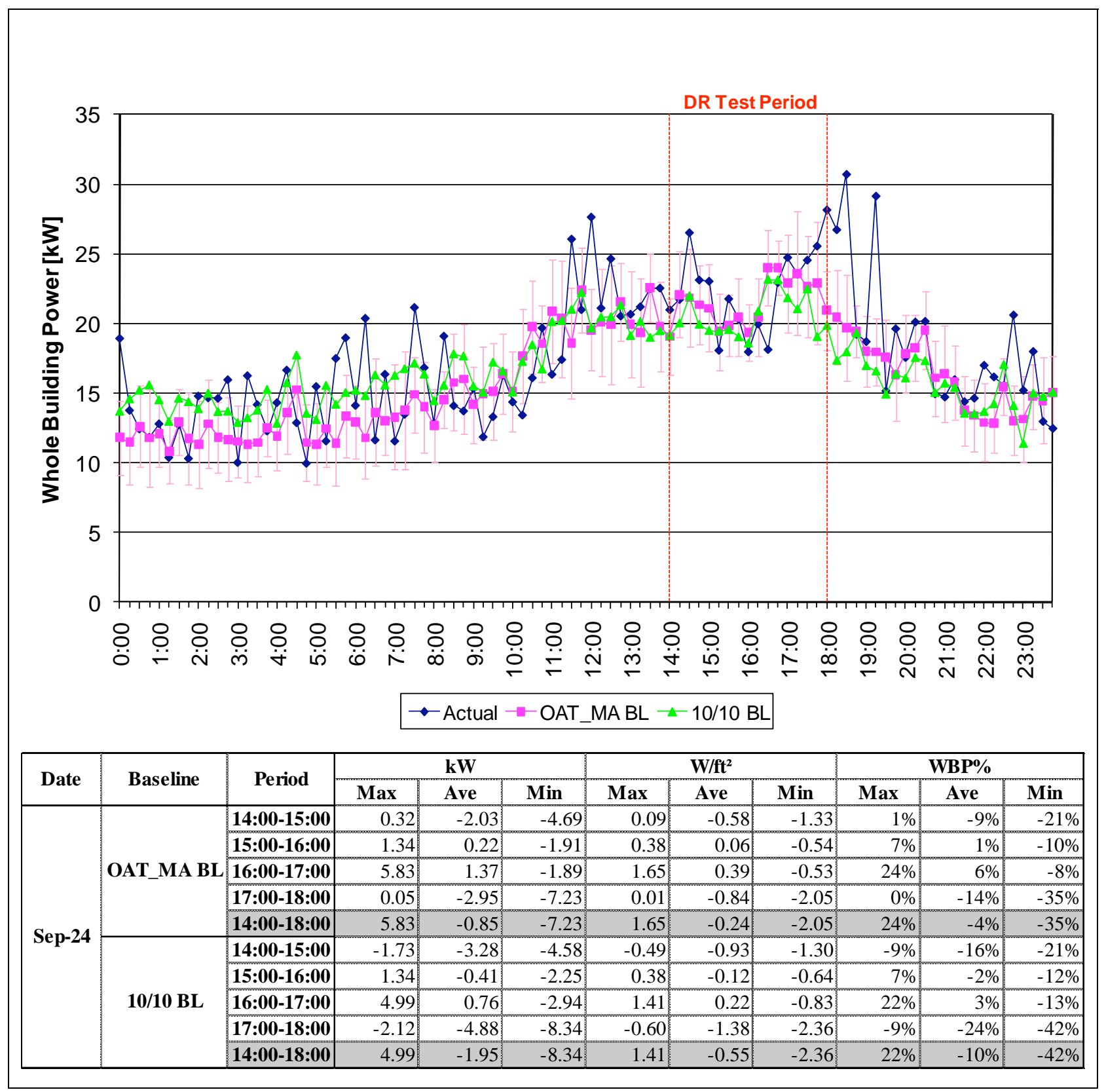


Figure C-14. LimeAmps 24-7, September 27, 2010 (Max OAT: $101^{\circ} \mathrm{F}$ )

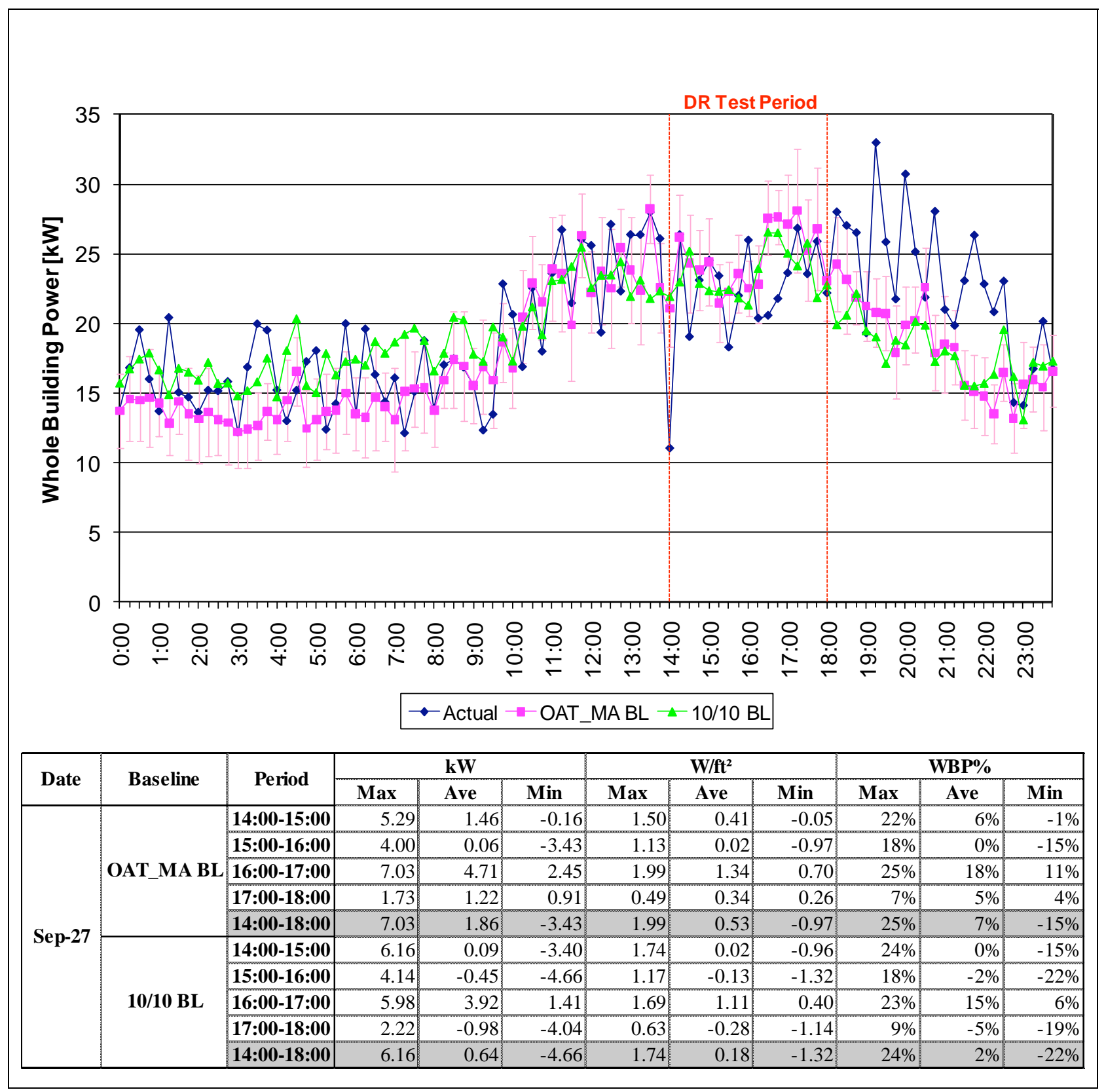


Figure C-15. LimeAmps 24-7, September 28, 2010 (Max OAT: $103^{\circ} \mathrm{F}$ )

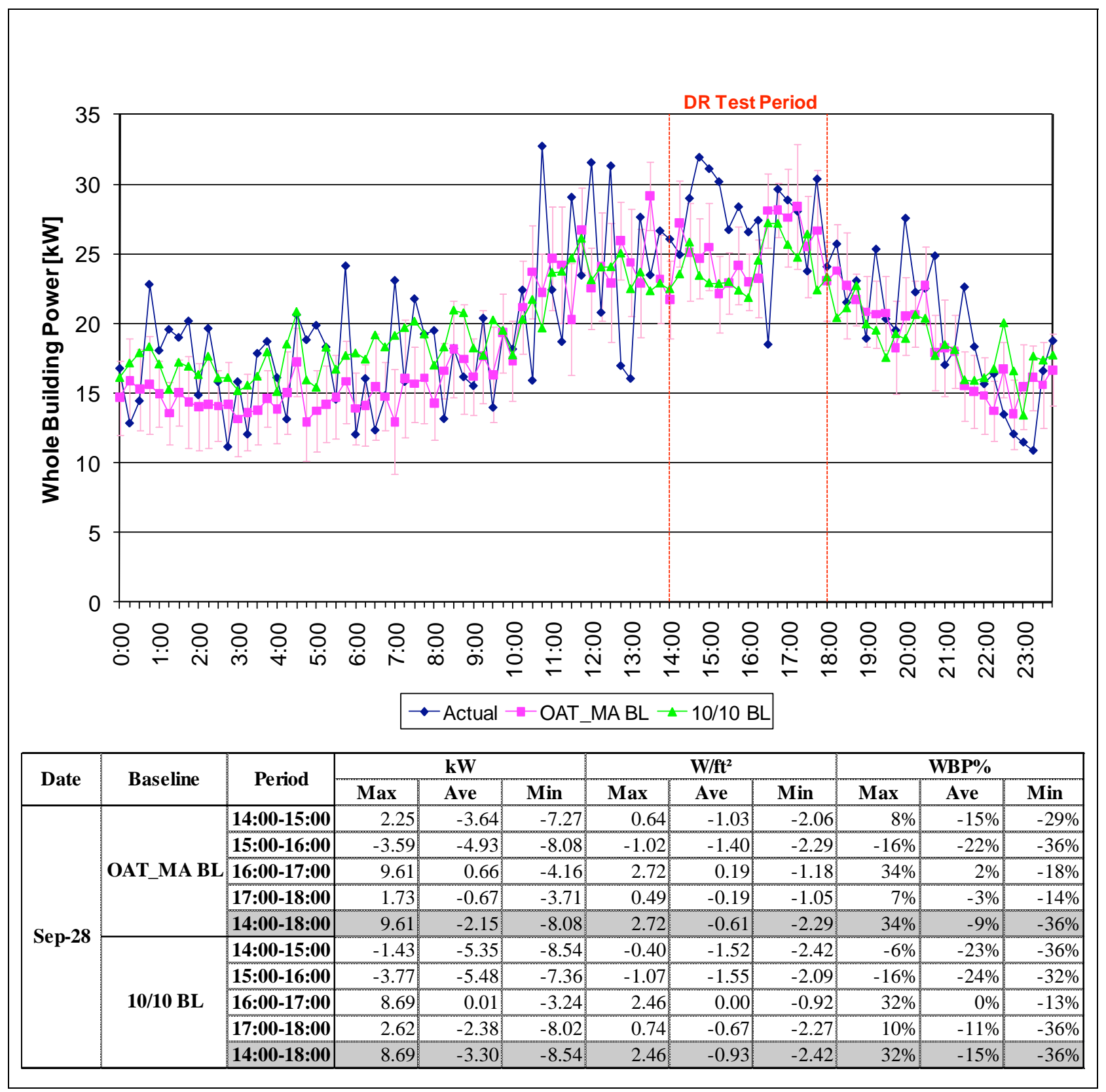


Figure C-16. LimeAmps 24-7, October 7, 2010 (Max OAT: 70 ${ }^{\circ}$ )

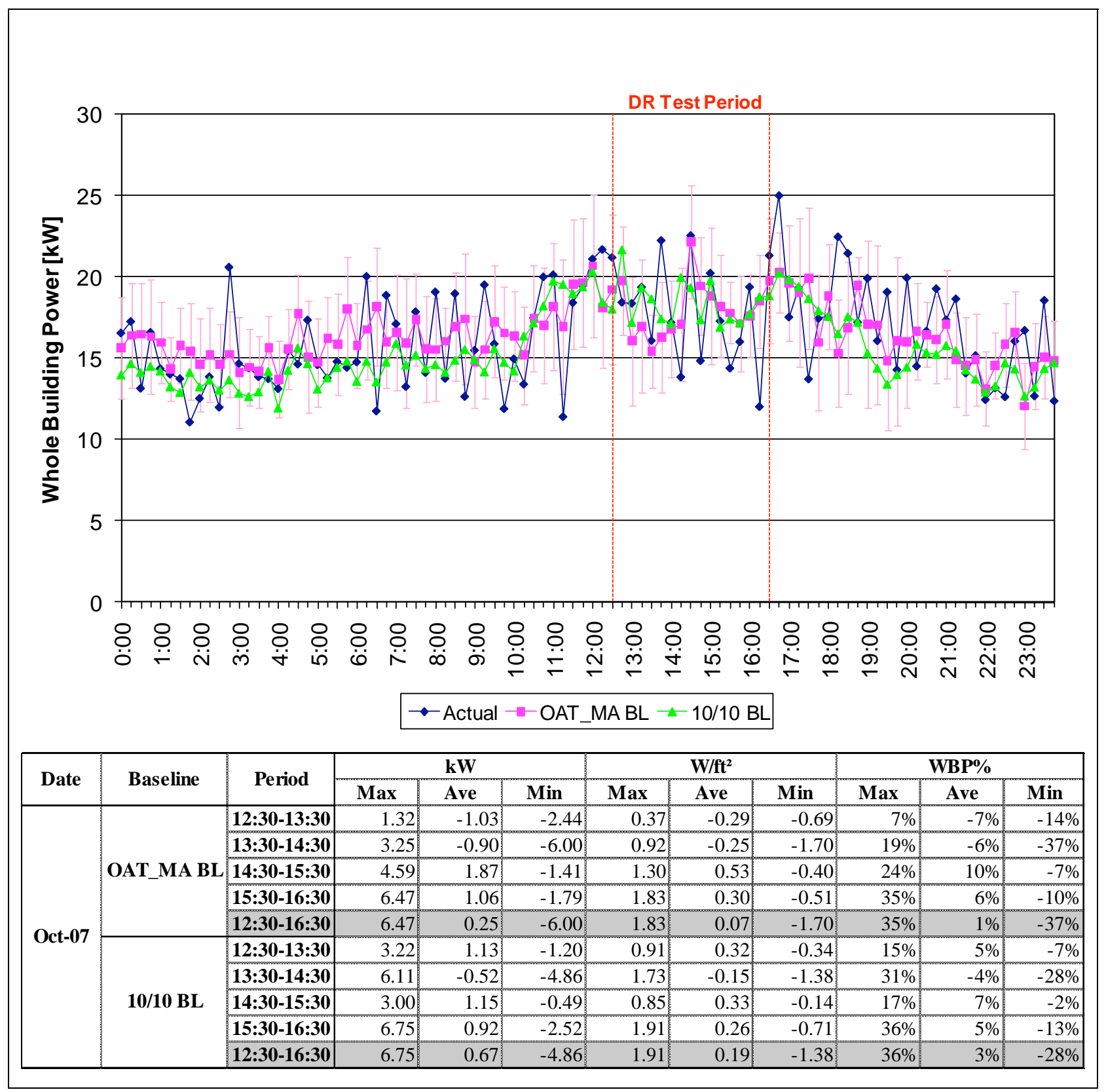

This event took place during a site visit when the outdoor air temperature was relatively cooler than other test days. 
Figure C-17. LimeAmps 24-7, October 13, 2010 (Max OAT: 94 F)

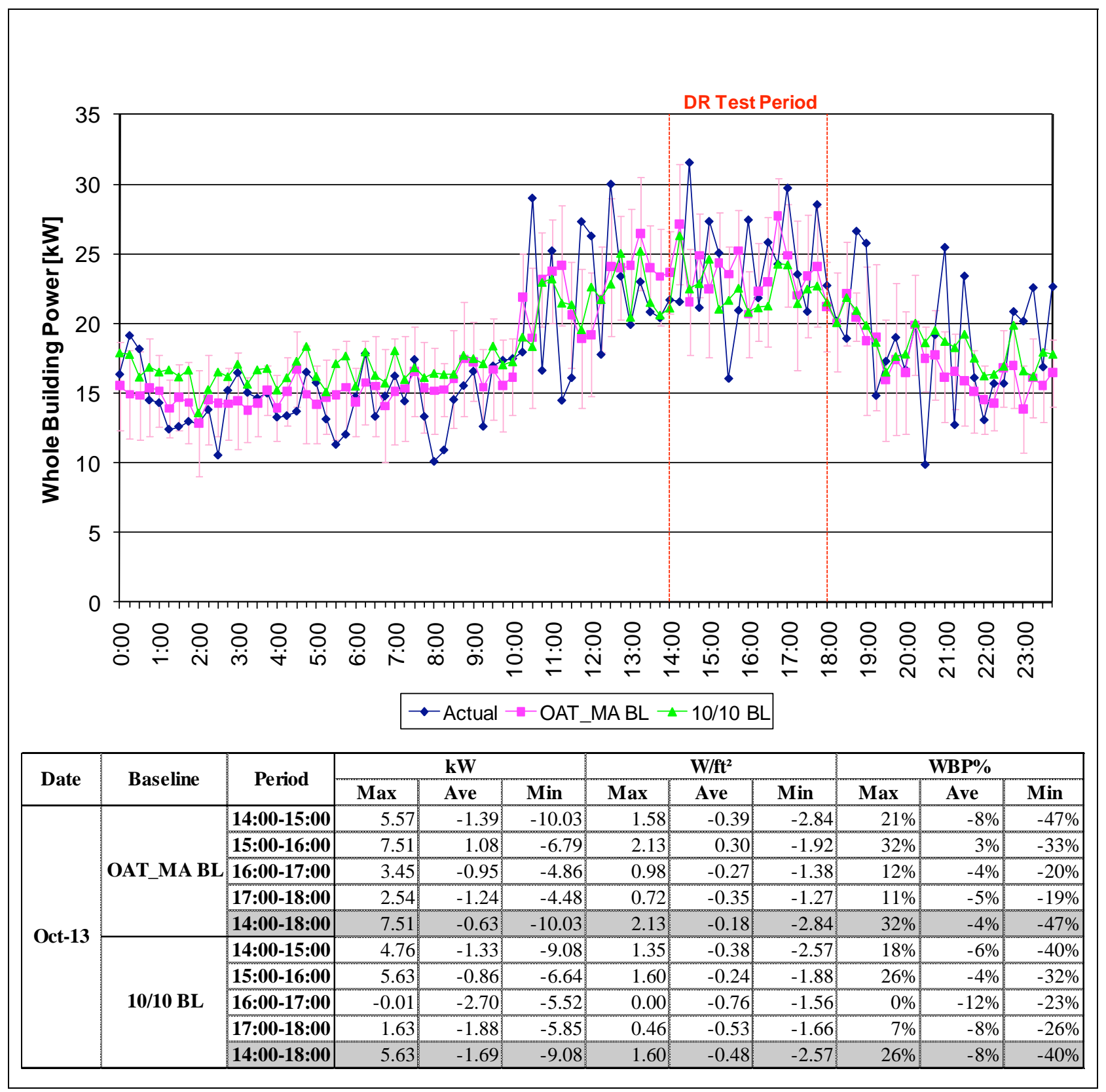


Figure C-18. Santa Rosa Site (LimeAmps 24-7)

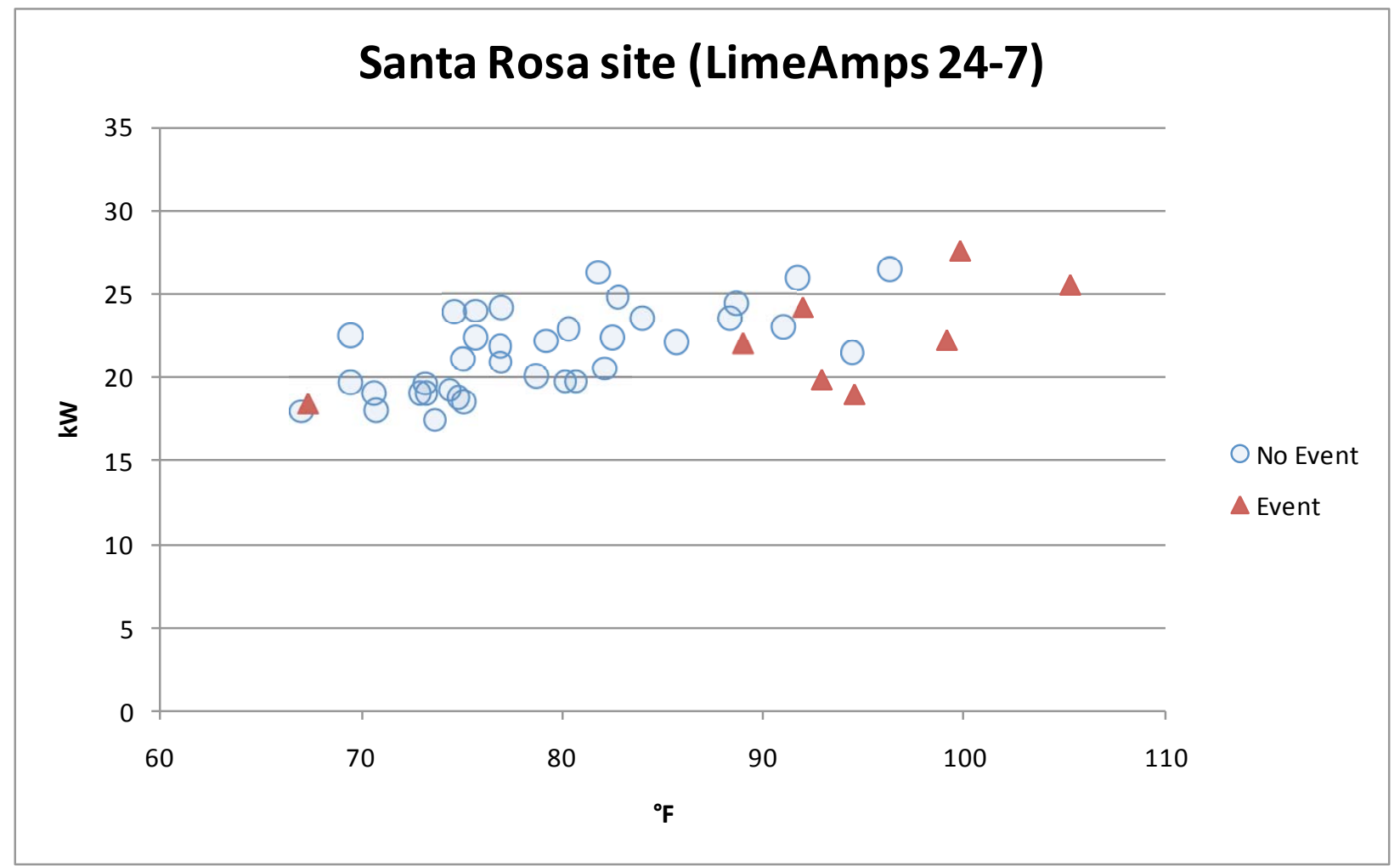

\section{Discussion}

During the first event (August $24^{\text {th }}$, represented by the rightmost data point on this graph), the two HVAC units were supposed to cycle in an alternating pattern, but cycled together instead. The vendor reported that "At the start of the event, the calculated indoor temperature was 74 degrees and at the end, it was 83 degrees. It took a little over 2 hours to get the inside temperature back to pre-event levels." All other Event data points represent appropriate cycling of the HVAC units. The data point at the far left represents a test event called during a site visit, which occurred on a cooler day. 
C.3. Site Description - Sebastopol

\begin{tabular}{|c|c|c|}
\hline Site Name & $\begin{array}{l}\text { French Garden } \\
\text { Restaurant }\end{array}$ & 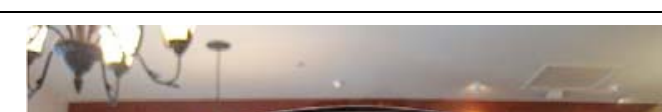 \\
\hline Building Use & Restaurant & $A \cup$ \\
\hline City & Sebastopol, CA & \\
\hline Gross Floor Area & 4,200 sq. ft. & \\
\hline Controlled Floor Area & 4,200 sq. ft. & \\
\hline Peak Load (kW) & 45 & \\
\hline Max. Temp. during testing & $100.9^{\circ} \mathrm{F}$ & \\
\hline Tenant Type & Company owned & \\
\hline Weekday Schedule & $\begin{array}{l}\text { Wednesdays - Sunday } \\
\text { 11:30 am-2:30 pm } \\
\text { and 5-9:30 pm }\end{array}$ & \\
\hline Non-weekday Schedule & $\begin{array}{l}\text { Sat/Sun: } 11: 30-2: 30 p m \\
\text { and 5-9:30pm }\end{array}$ & \\
\hline Additional Details & $\begin{array}{l}\text { Farmers Market also } \\
\text { held on Sunday at this } \\
\text { site from 10am - } 2 \mathrm{pm}\end{array}$ & \\
\hline Lighting & \multicolumn{2}{|c|}{$\begin{array}{l}\text { Separate lighting controls for dining room sconces, stage lighting } \\
\text { (live music), art spot lights and various outdoor tree lights. Mostly } \\
\text { incandescent spot lights. Low voltage spot lights in bar and directed } \\
\text { at art work. Ornate ceiling lamps in the dining area using } \\
\text { incandescent bulbs. Fluorescent lights used in the kitchen, storage } \\
\text { and office areas. No dimmable ballasts. }\end{array}$} \\
\hline
\end{tabular}

HVAC Summary

\begin{tabular}{|l|l|}
\hline Air Distribution Type & $\begin{array}{l}\text { Three roof packaged units: The restaurant has two (2) } 5 \text { ton rooftop } \\
\text { mounted HVAC packaged units: one over the dining area and } \\
\text { another over the bar area. There is a third } 4 \text { ton rooftop packaged } \\
\text { unit over the private dining area controlled by a separate thermostat. }\end{array}$ \\
\hline Cooling System & $\begin{array}{l}\text { No ceiling fans, but there are exhaust fans in the kitchen (not } \\
\text { controlled as part of these tests) }\end{array}$ \\
\hline HVAC Control System & \\
\hline HVAC Zoning &
\end{tabular}

Data Collection 


\begin{tabular}{|c|c|}
\hline \multicolumn{2}{|l|}{ Electric Data } \\
\hline Control Data & $\begin{array}{l}\text { Conzerv } 6400+\text { Digital meter. } \\
\text { The digital meter is installed next to the standalone electric service } \\
\text { panel cabinet outside the restaurant. The meter provides a full } \\
\text { building reading of electrical consumption. The digital meter is } \\
\text { polled by the LimeAmps Gateway every } 10 \text { seconds via a ZigBee } \\
\text { wireless modem. }\end{array}$ \\
\hline \multicolumn{2}{|l|}{ Other } \\
\hline \multicolumn{2}{|l|}{ Vendor Information } \\
\hline Vendor Name & LimeAmps (installation by Zero Energy Associates) \\
\hline Technology Description & Controller, Gateway, Smart plugs \\
\hline \multicolumn{2}{|l|}{ DR Strategies } \\
\hline HVAC & $\begin{array}{l}\text { A LimeAmps Load Controller is mounted on the roof and connected } \\
\text { to the three HVAC units. A current transducer is wired to each } \\
\text { compressor/condenser to measure load on an on-going basis. The } \\
\text { LimeAmps Load Controller communicates with the Gateway via a } \\
\text { Zigbee wireless modem. } \\
\text { The Load Controller is wired to interrupt the compressor contactor } \\
\text { during an event via a relay. } \\
\text { Based on tests, the vendor programmed the Load Controller to cycle } \\
\text { the compressors off for } 30 \text { minutes and on for } 15 \text { minutes alternating } \\
\text { between the bar and dining room units. }\end{array}$ \\
\hline Lighting & Not controlled. \\
\hline Refrigeration & Not controlled. \\
\hline Miscellaneous Electrical Loads & $\begin{array}{l}\text { The vendor installed a Smart Plug outlet to display an LED lamp } \\
\text { during an event. }\end{array}$ \\
\hline
\end{tabular}


Figure C-19. French Restaurant site architecture

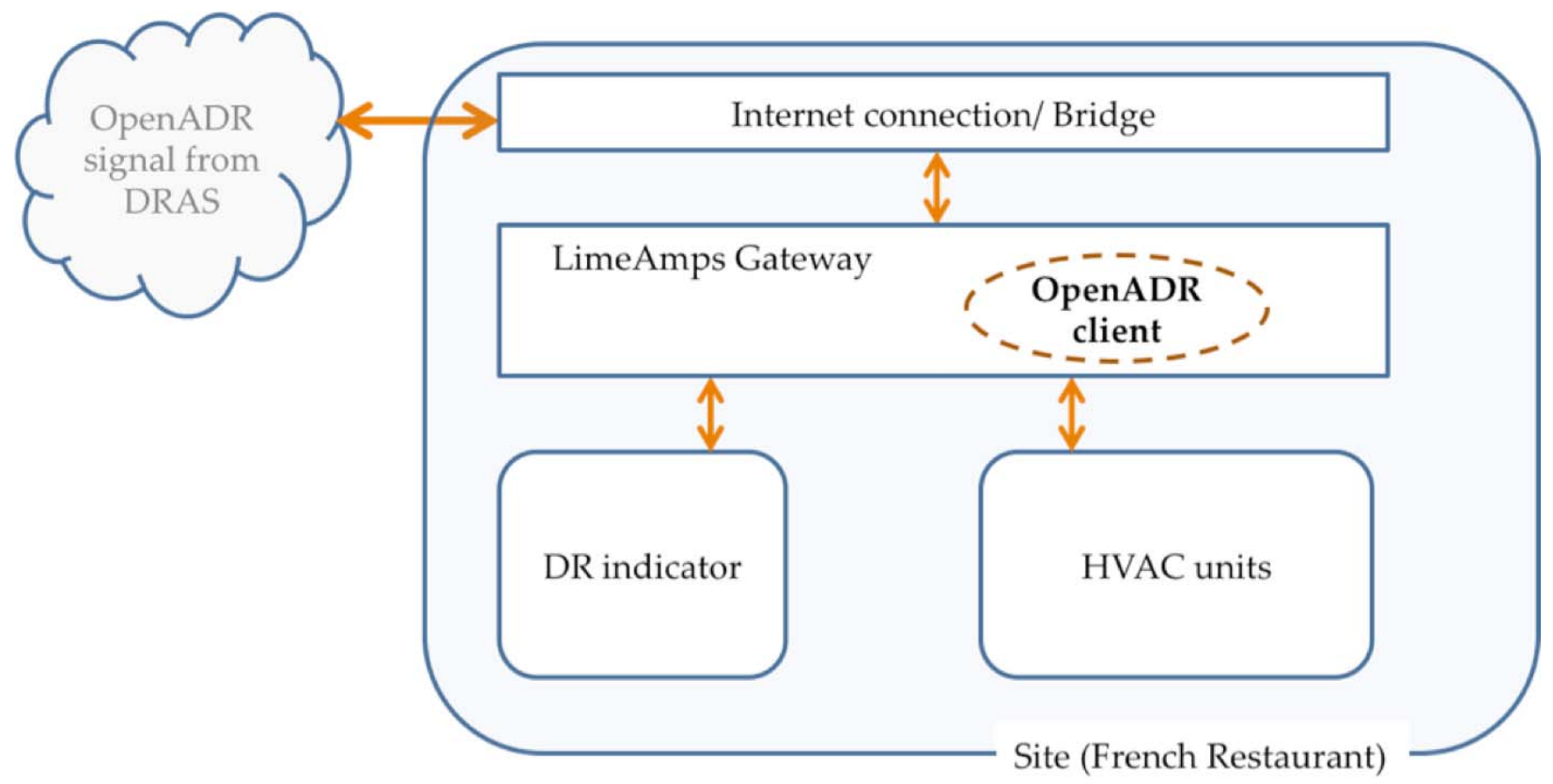

The LimeAmps gateway receives the OpenADR signal and translates it to the DR strategy: cycling the compressors of the HVAC units via load controllers as described above. The DR indicator was a LimeAmps smart plug with a light that charged when power was on and glowed when power was off.

Future plans are to cycle (at 15 minute intervals) the roof mounted compressor for the large walk-in freezer onsite.

Note that this site was closed during three generally scheduled DR events (August 24, 2010, September $27 \& 28,2010$ ) but the HVAC equipment was controlled by the LimeAmps load controllers on those days. Therefore, these dates were excluded from the baseline calculations, but they were not specifically analyzed for DR responses due to otherwise reduced site operations. 
Site Data

Figure C-20. LimeAmpsFG, September 1, 2010 (Max OAT: 97 ${ }^{\circ} \mathrm{F}$ )

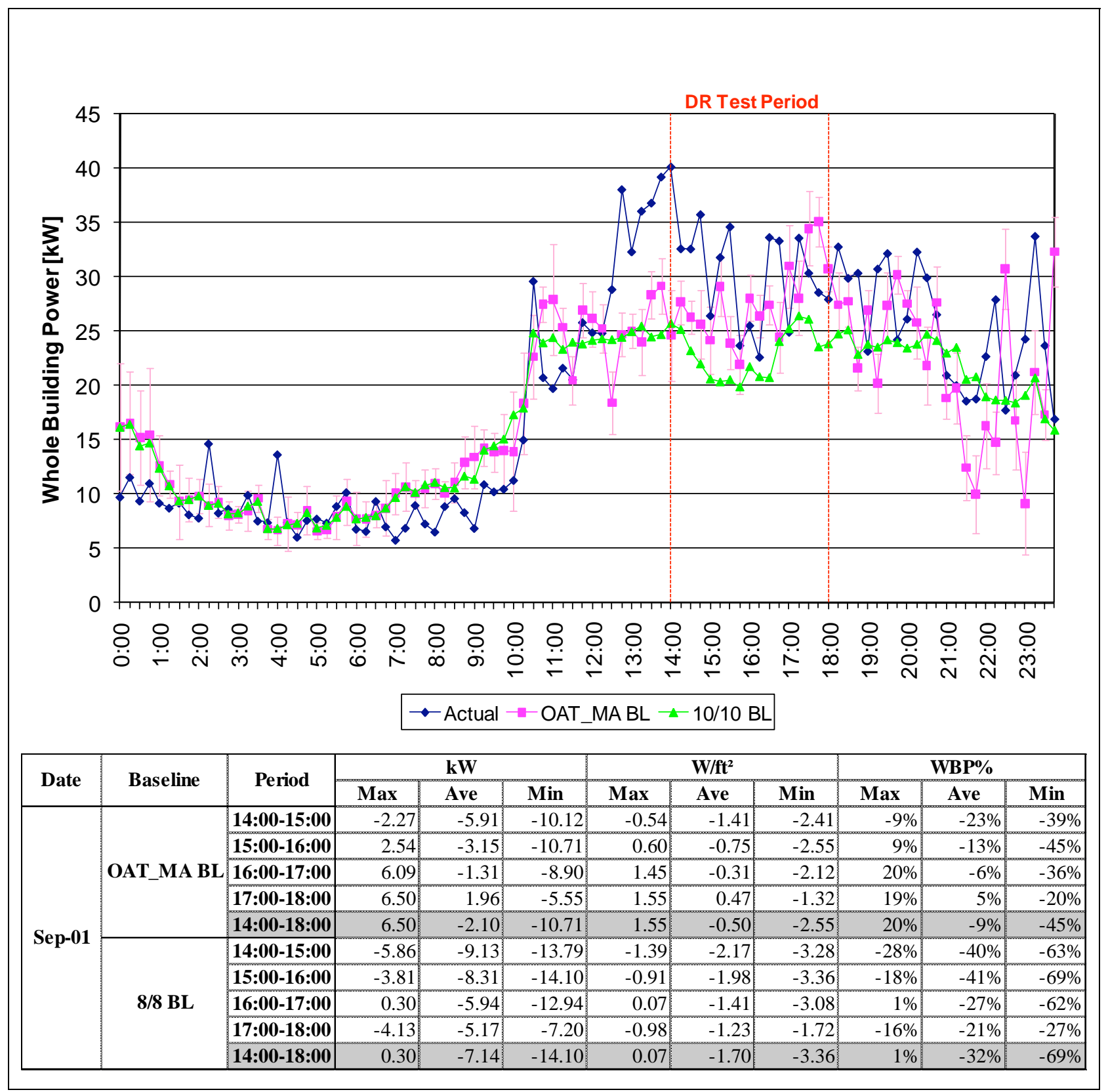


Figure C-21. LimeAmpsFG, September 2, 2010 (Max OAT: 98 ${ }^{\circ} \mathrm{F}$ )

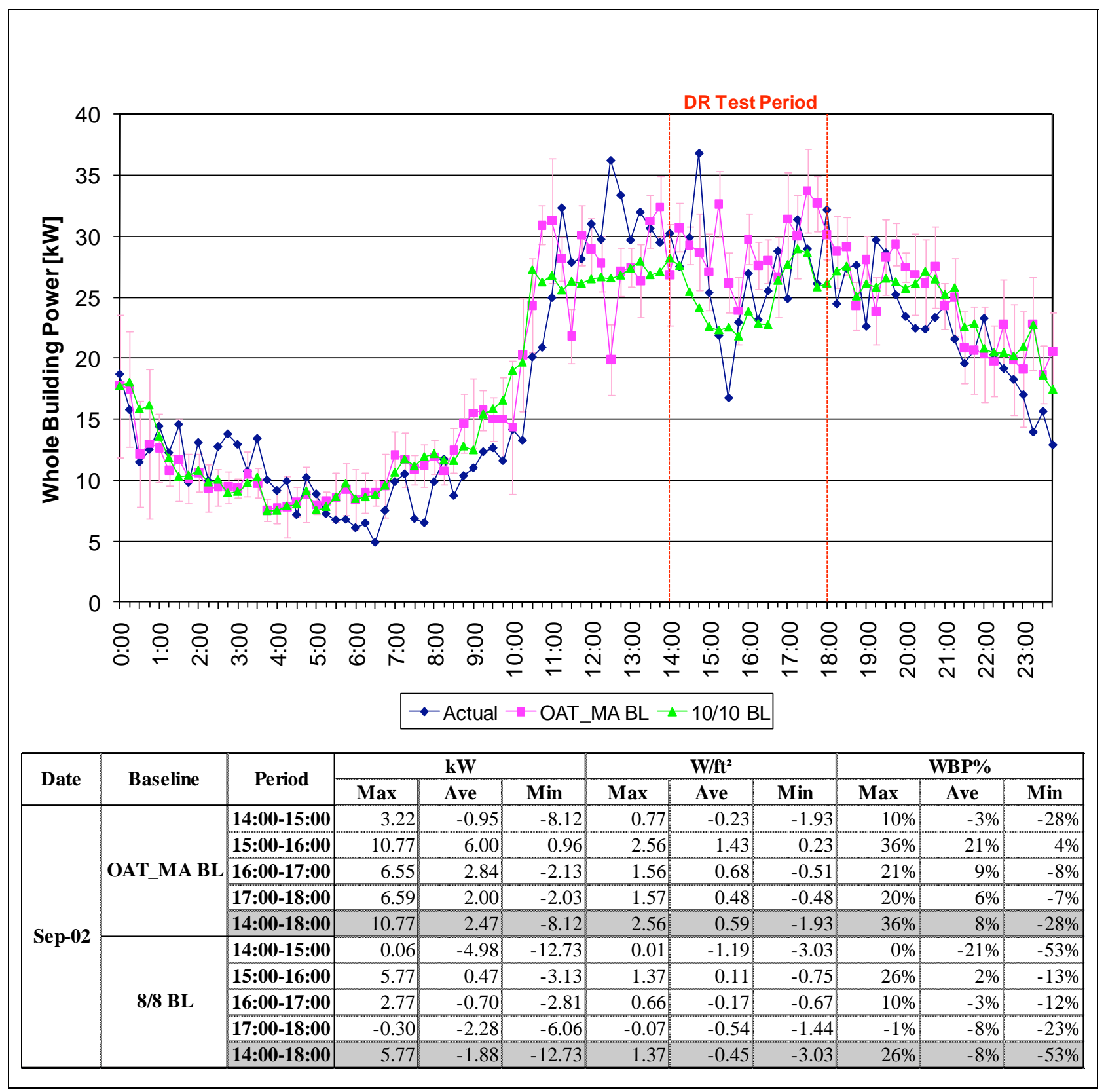


Figure C-22. LimeAmpsFG, September 24, 2010 (Max OAT: 92 ${ }^{\circ} \mathrm{F}$ )

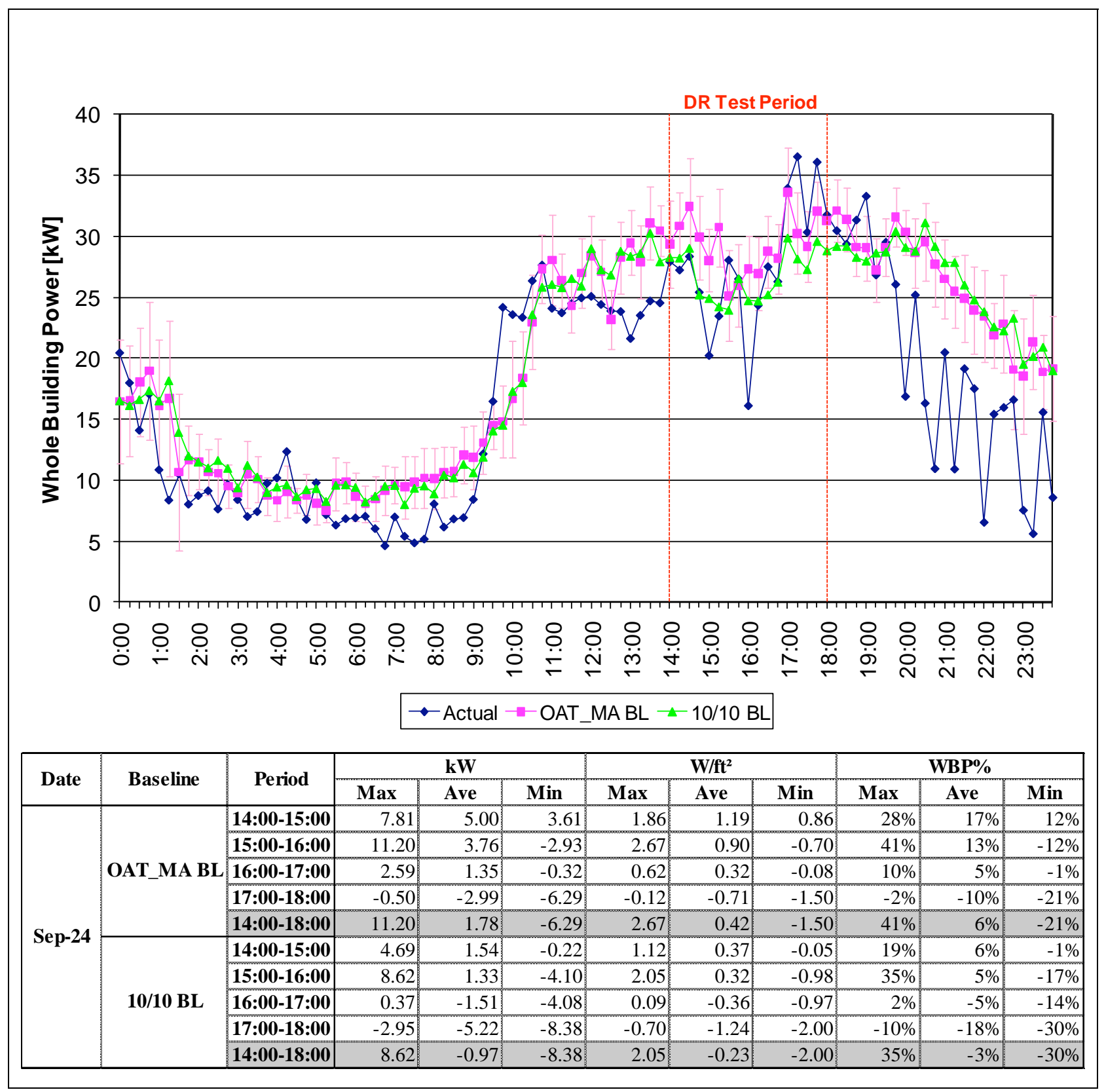


Figure C-23. LimeAmpsFG, October 7, 2010 (Max OAT: 70 ${ }^{\circ}$ )

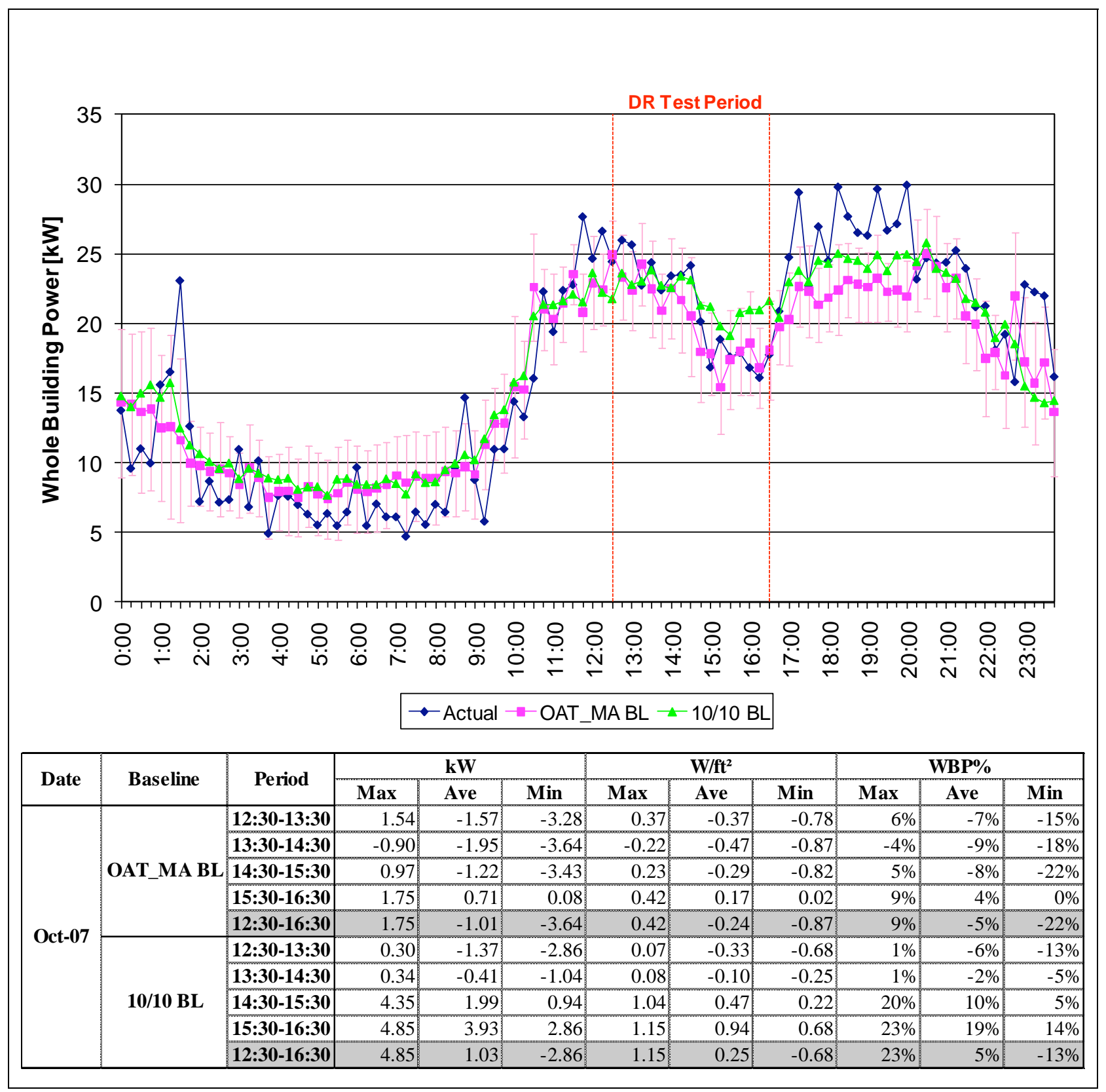

The event on October 7, 2010 was conducted during a site visit. However, because of the unseasonably low temperature on that day, the DR opportunities were limited. 
Figure C-24. LimeAmpsFG, October 13, 2010 (Max OAT: 94 ${ }^{\circ} \mathrm{F}$ )

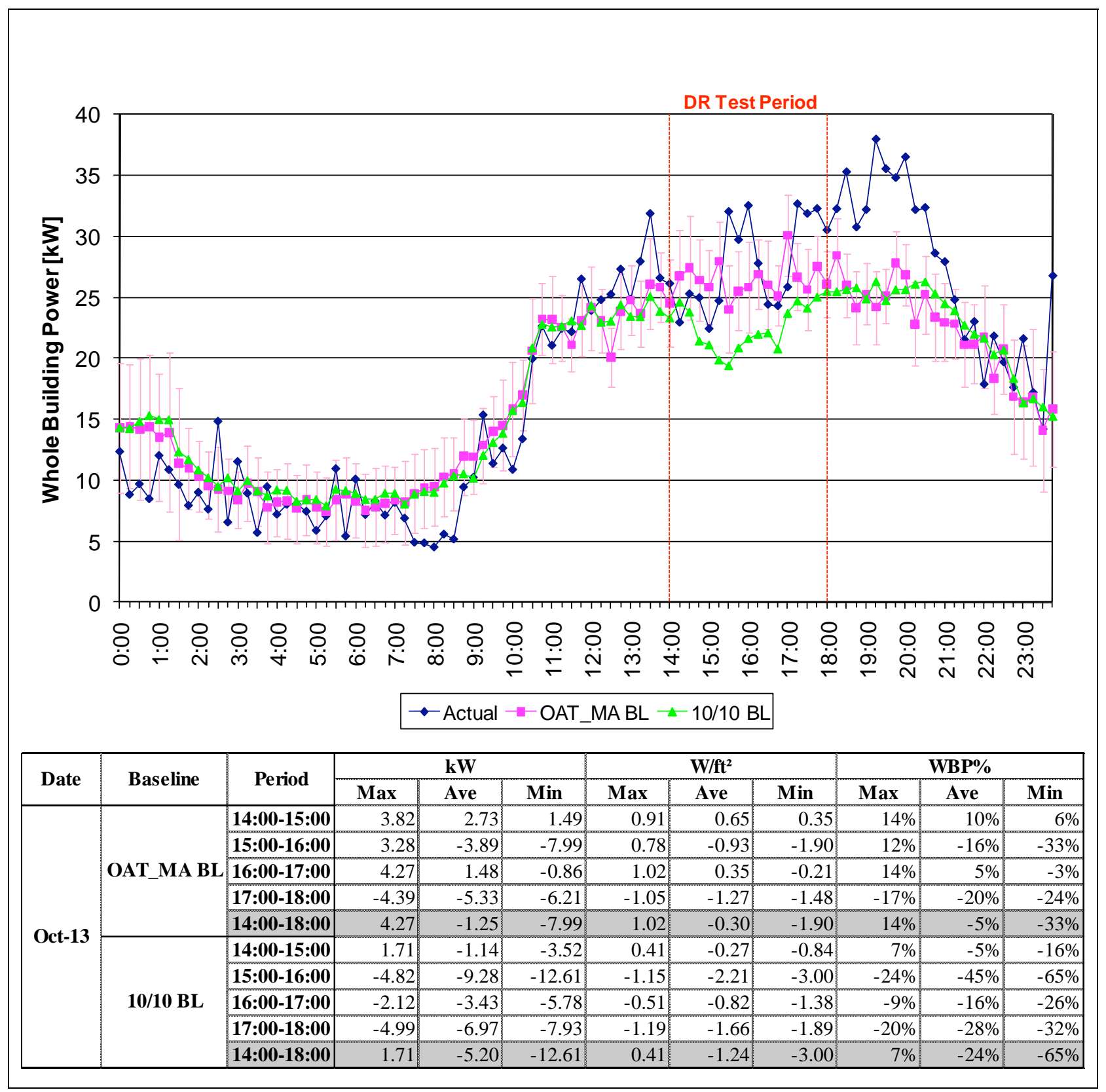




\section{Discussion}

Figure C-25. Sebastopol site (LimeAmps French Garden)

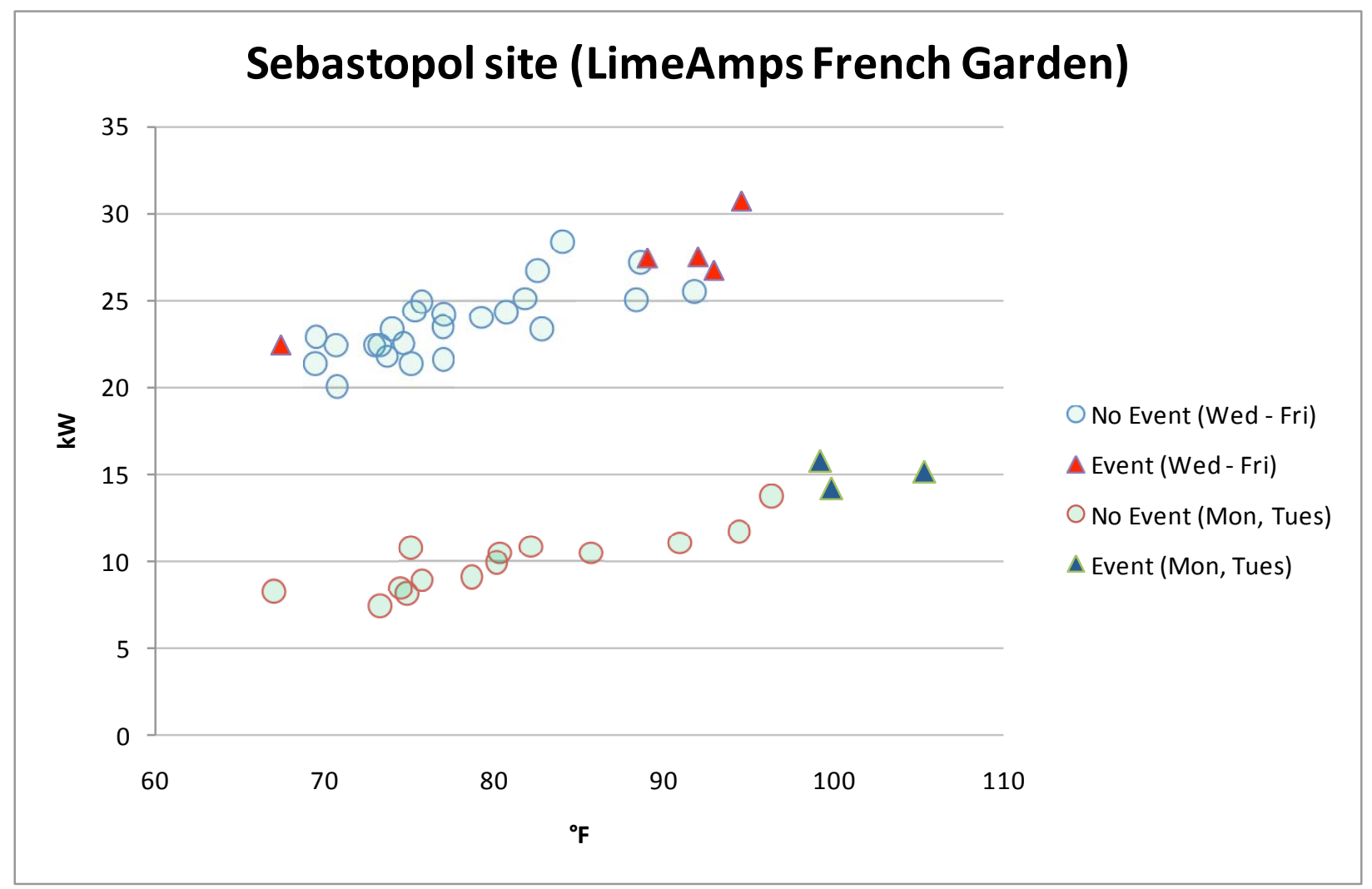

Although this site was closed during some of the called DR events, the strategies were maintained (so HVAC was curtailed on event days regardless of whether the business was operating). We did not analyze responses on days when the business was not operating, but this graph provides a sense of the distinction.

A separate issue is that the DR event time period (typically $2 \mathrm{pm}-6 \mathrm{pm}$ ) fell between the end of the lunch period and the beginning of dinner operations at this business. A general rise in demand towards the end of the DR period is associated with preparations for the dinner business. 


\section{C.4. Site Description - Novato}

\begin{tabular}{|c|c|c|}
\hline Site Name & OHS & \\
\hline Building Use & Office, warehouse & \\
\hline City & Novato, CA & speatil \\
\hline Gross Floor Area & 800 & TP \\
\hline Controlled Floor Area & 800 & 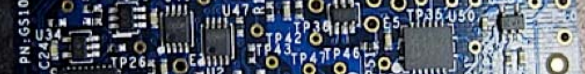 \\
\hline Peak Load (kW) & 12 & 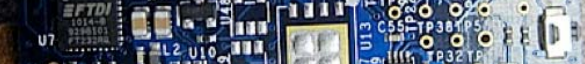 \\
\hline Max. Temp. during tests & $100.9^{\circ} \mathrm{F}$ & $\left.\frac{5}{3}-1\right)$ \\
\hline Tenant Type & $\begin{array}{l}\text { building owner manages } \\
\text { property }\end{array}$ & \\
\hline Weekday Schedule & $9 a m-6 p m ~ M-F$ & \\
\hline Non-weekday Schedule & Occasional & \\
\hline Additional Details & $\begin{array}{l}\text { Office is on southern end of } \\
\text { building, with east and west } \\
\text { exposures. There is limited } \\
\text { use of the western side of } \\
\text { their space on warm days } \\
\text { because it gets } \\
\text { uncomfortably warm. }\end{array}$ & \\
\hline
\end{tabular}

HVAC Summary

\begin{tabular}{|l|l|}
\hline Air Distribution Type & Data not provided. \\
\hline Cooling System & Data not provided. \\
\hline & \\
\hline HVAC Control System & Data not provided. \\
\hline HVAC Zoning & Single zone. \\
\hline Other & $\begin{array}{l}\text { Note: there is no centralized gateway - the gateway exists at each } \\
\text { device since OHS card receives OpenADR signal directly. }\end{array}$ \\
\hline
\end{tabular}

\section{Data Collection}

\begin{tabular}{|l|l|}
\hline Electric Data & Dent Elite Pro \\
\hline Control Data & Control via OHS proprietary card in each responding device. \\
\hline Vendor Information & \\
\hline
\end{tabular}




\begin{tabular}{|l|l|} 
Vendor Name & Our Home Spaces \\
\hline Technology Description & Controller for various types of devices via card shown above. \\
\hline DR Strategies & Change thermostat setpoint by 4 deg F \\
\hline HVAC & N/A \\
\hline Lighting & N/A \\
\hline Refrigeration & N/A \\
\hline MELs & $\begin{array}{l}\text { The responses of this site to several DR events were lost when the data } \\
\text { logger overflowed its buffers during September 2010. }\end{array}$ \\
\hline Other &
\end{tabular}

Site Architecture

Figure C-26. OHS office site architecture

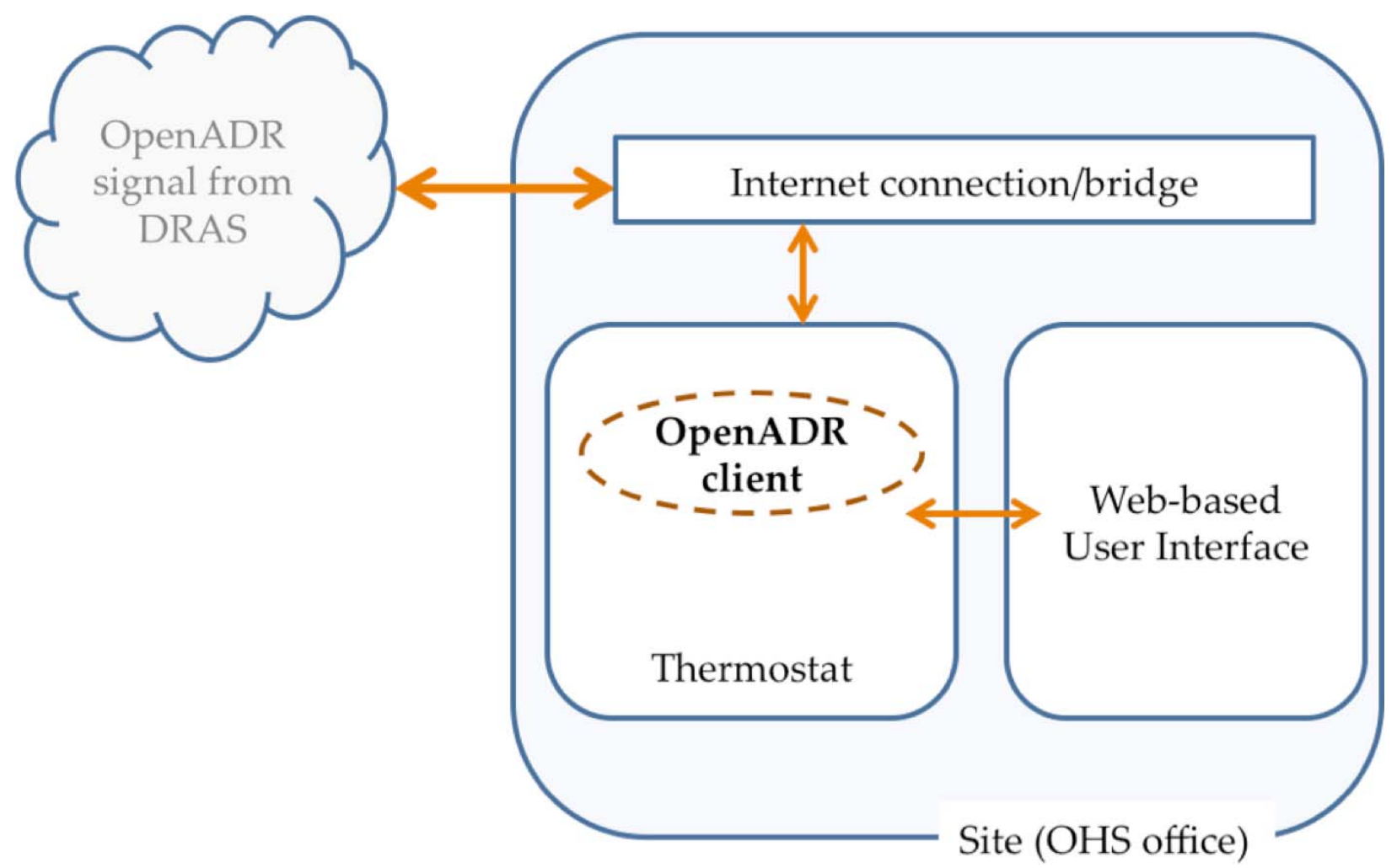

The architecture used here is the same as that used at the Union City site. The OpenADR client is physically embedded within each controlled device. Here, the device is a programmable thermostat. Upon receipt of the OpenADR signal, the thermostat's setpoint is immediately changed by four degrees Fahrenheit and returned to normal once the DR event is over. 


\section{Site Data}

Figure C-27. OHS, September 1, 2010 (Max OAT: 97 F)

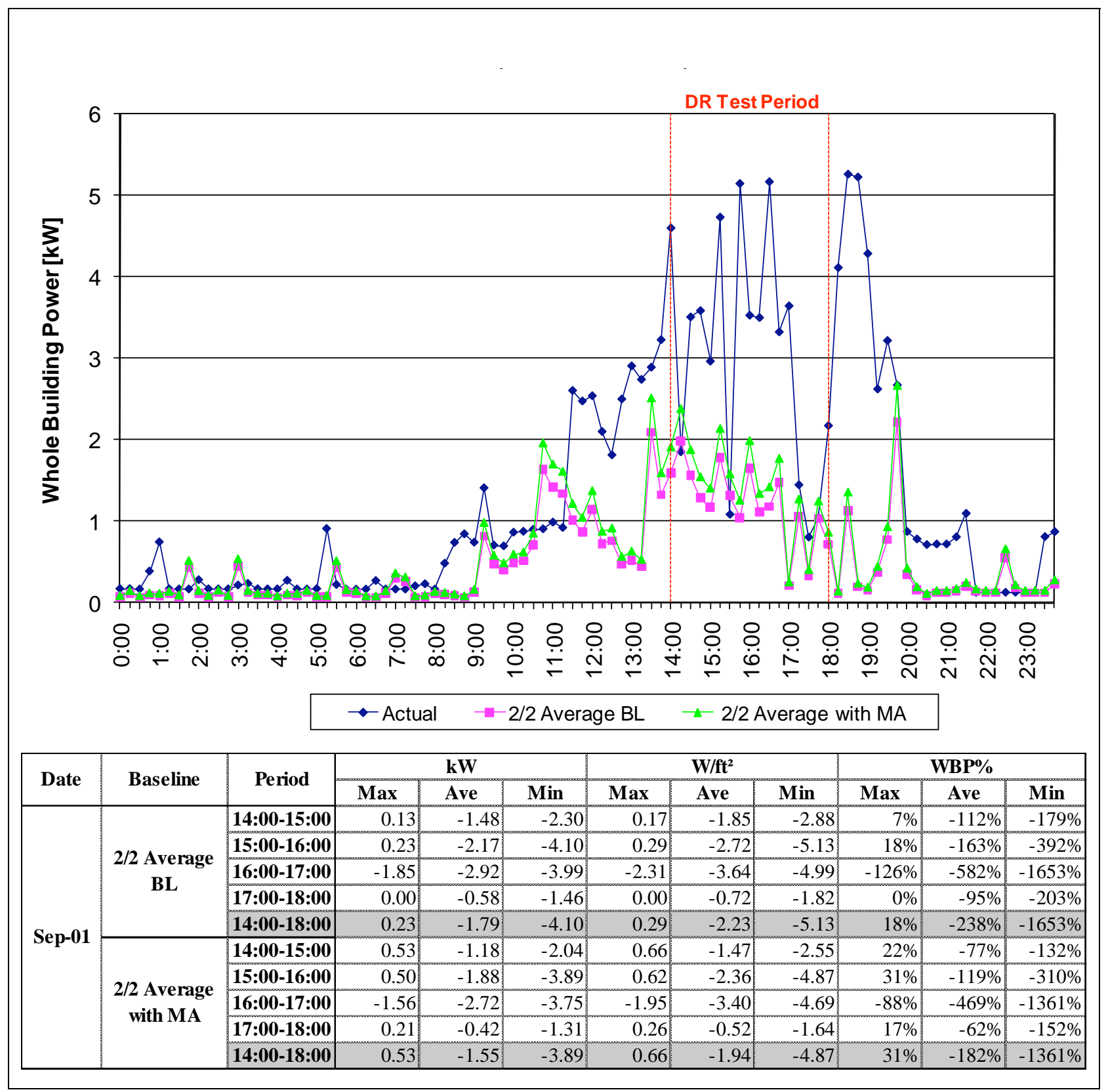


Figure C-28. OHS, September 24, 2010 (Max OAT: 92 ${ }^{\circ} \mathrm{F}$ )

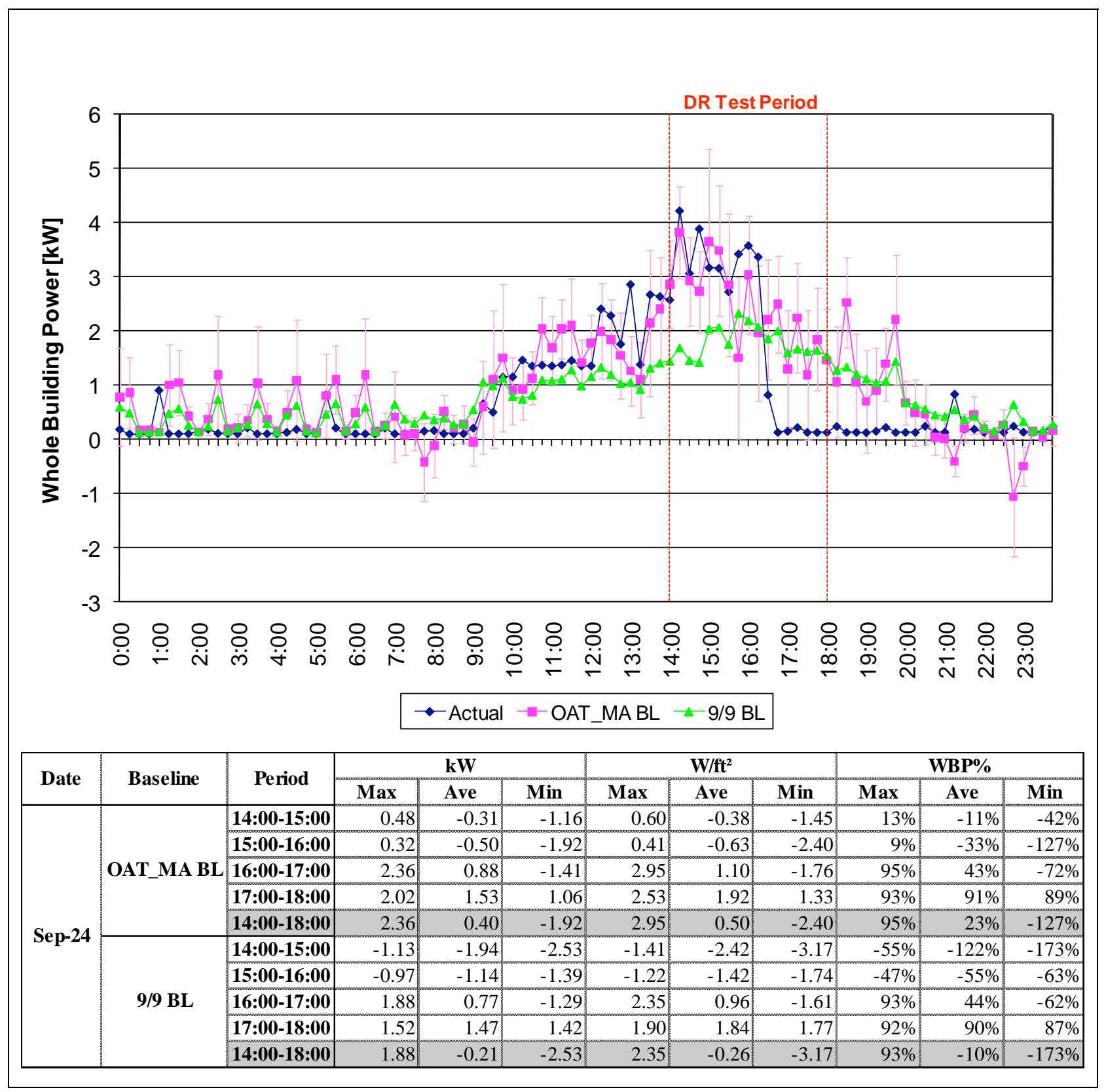


Figure C-29. OHS, September 27, 2010 (Max OAT: 101 ${ }^{\circ} \mathrm{F}$ )

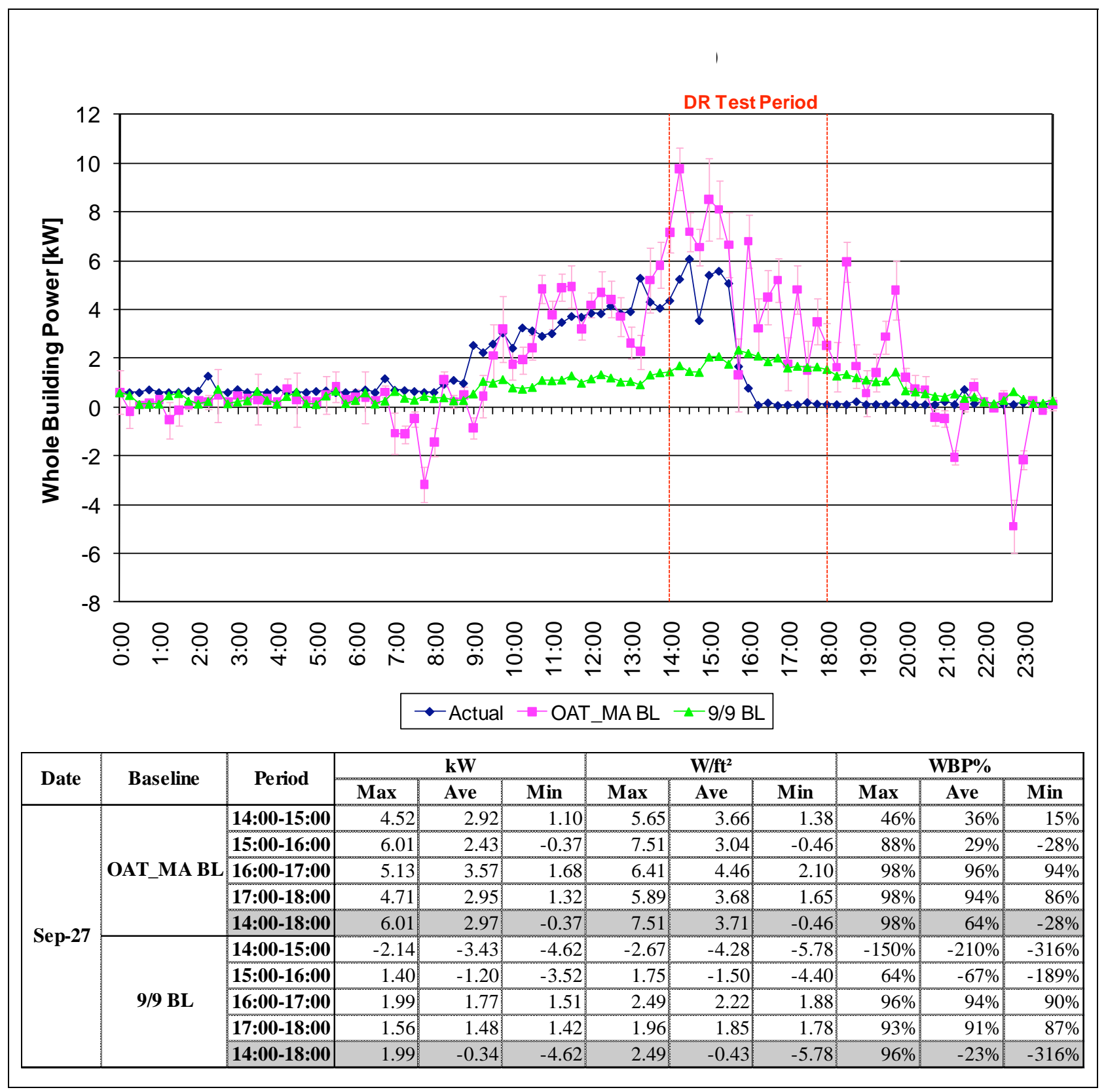


Figure C-30. OHS, September 28, 2010 (Max OAT: 103 $\mathrm{F}$ )

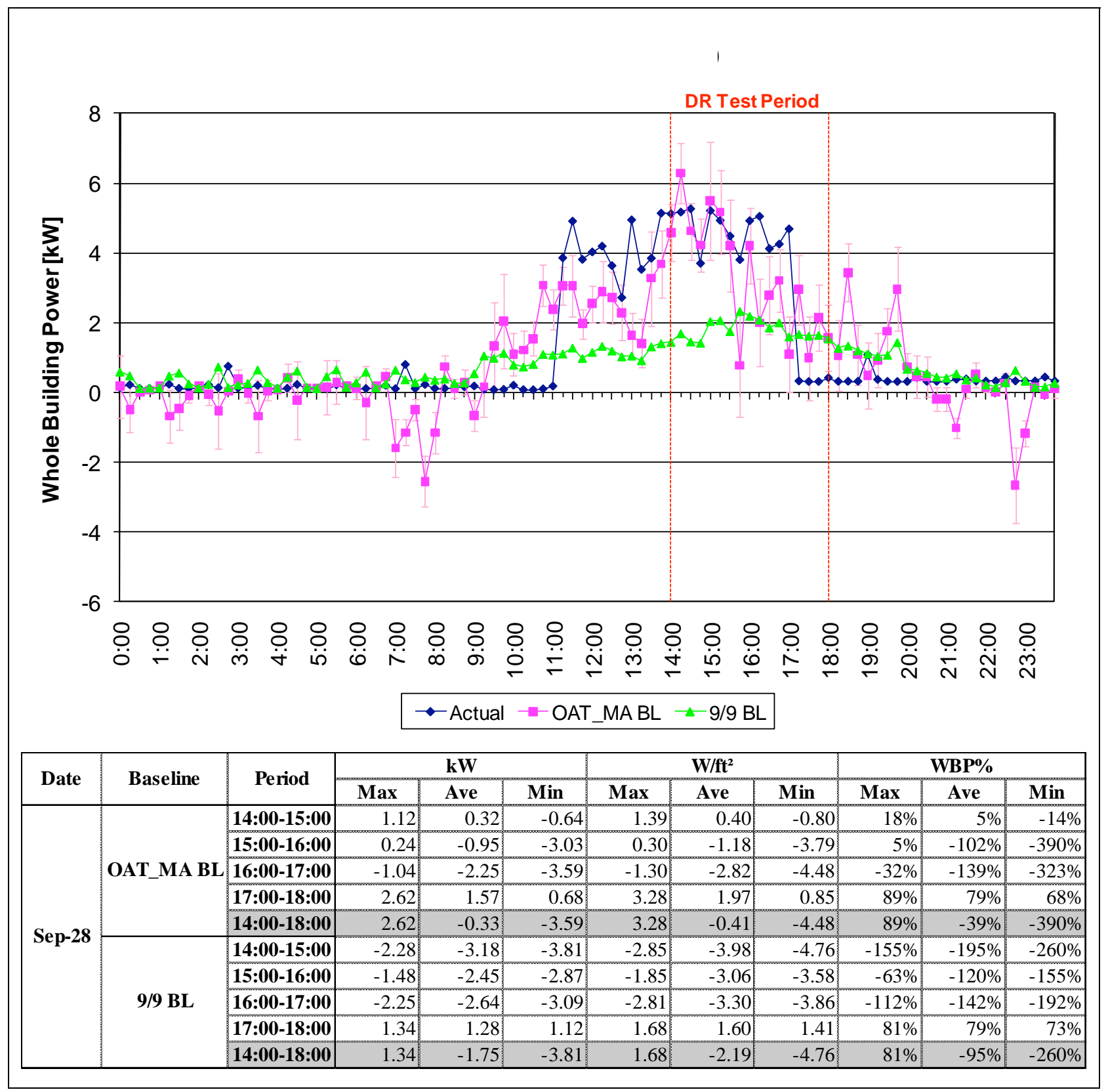


Figure C-31. OHS, October 13, 2010 (Max OAT: 94 ${ }^{\circ} \mathrm{F}$ )

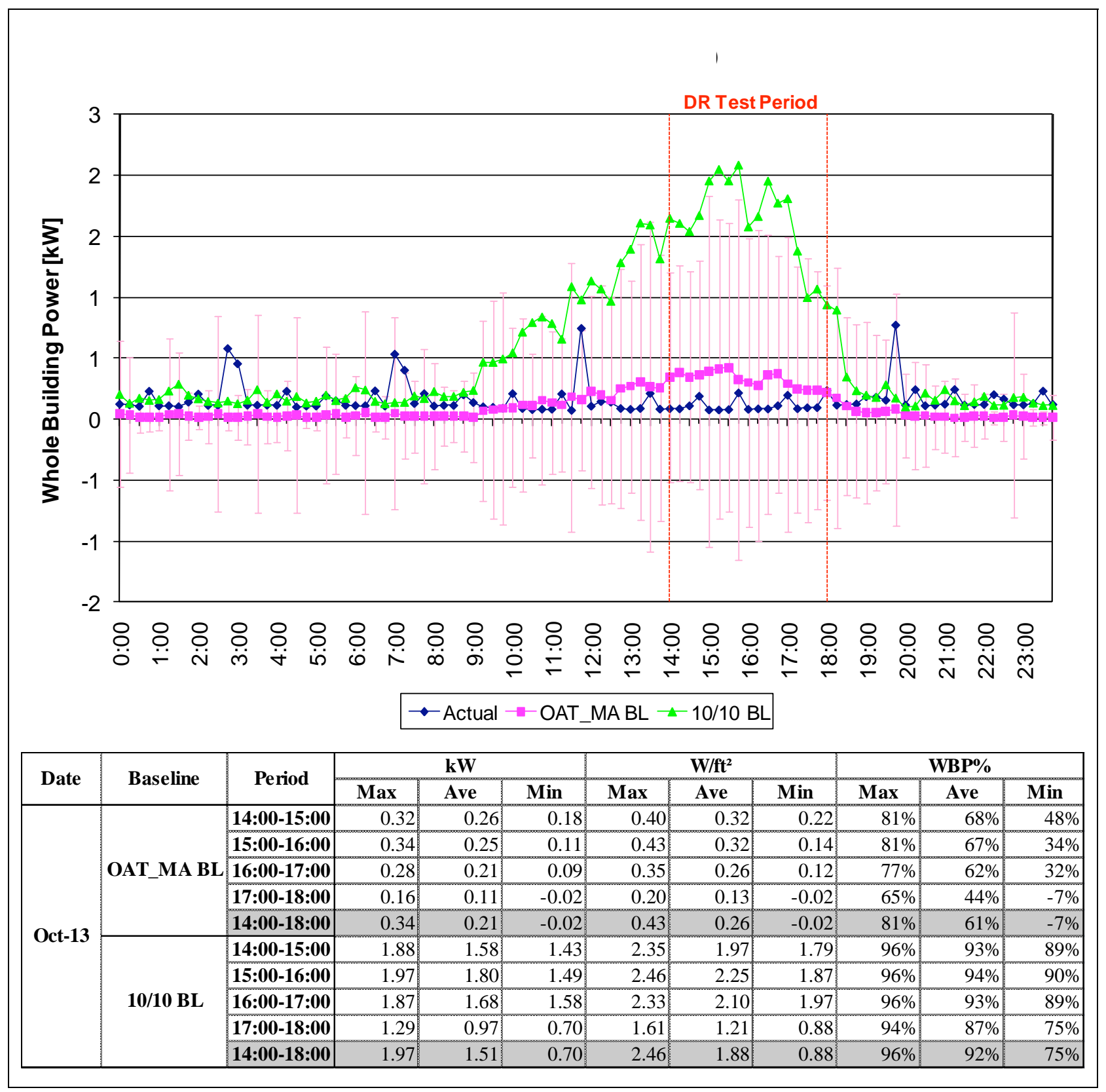




\section{Discussion}

Figure C-32. Novato site (OHS)

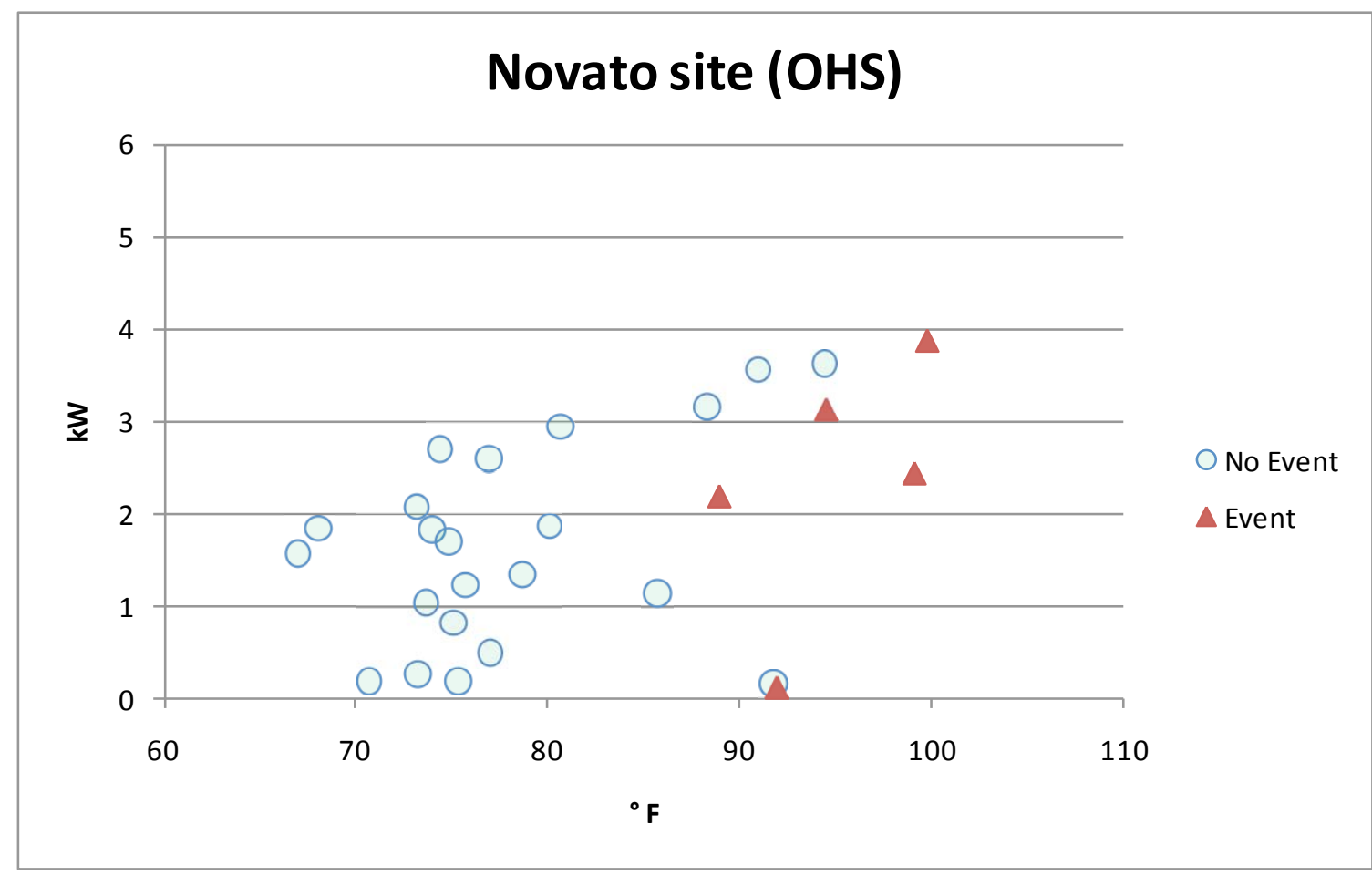

This small office was not occupied consistently throughout the DR test period. This is not unusual in small some businesses. However, this created wide variability in the baseline data. In addition, data was missing from 1 am September 2 to 3:45 am September 11 because, according to OHS, the "logger ran out of memory and overwrote data until we got back from traveling and could fix it." This, and the close timing between when data collection started at this site and the first DR event was called, limited the amount of data that was available for generating the baselines for this site.

In addition, the relatively low power demand for this site overall meant that small changes in behavior during the time when the site was occupied can be seen directly in the data, both during events and in the baselines. During most DR events, there was some activity at the site, except that it appears that no one was in the building during the last DR event (October 15).

The same technology was tested at the Union City site in another small office. At the Union City site, the data was acquired via a Smart Meter, and occupancy appears to be more consistent. 
C.5. Site Description - Pittsburg

\begin{tabular}{|c|c|c|}
\hline Site Name & Preschool & \\
\hline Building Use & School and Church & \\
\hline City & Pittsburg, CA & \\
\hline Gross Floor Area & $18250 \mathrm{sq} \mathrm{ft}$ & \\
\hline Controlled Floor Area & $2500 \mathrm{sq} \mathrm{ft}$ & 19.4. \\
\hline Peak Load (kW) & $\begin{array}{l}33 \mathrm{~kW} \text { during } \\
\text { preschool operating } \\
\text { hours. }\end{array}$ & 46 \\
\hline Max. Temp. during test & $105^{\circ} \mathrm{F}$ & \\
\hline Tenant Type & Tenant owned & \\
\hline Weekday Schedule & 6am - 6pm M-F & \\
\hline Non-weekday Schedule & $\begin{array}{l}\text { Unrelated church } \\
\text { operations included in } \\
\text { the monitored circuit. }\end{array}$ & \\
\hline Additional Details & $\begin{array}{l}\text { Higher peak of up to } 48 \\
\text { hours is believed to be } r \\
\text { separate building also o } \\
\text { represents entire metere } \\
\text { only the preschool. }\end{array}$ & $\begin{array}{l}\mathrm{kW} \text { observed outside of preschool operating } \\
\text { lated to associated church functions in } \\
\text { this site's meter. Gross square footage } \\
\text { site whereas controlled floor area represents }\end{array}$ \\
\hline \multicolumn{3}{|l|}{ HVAC Summary } \\
\hline Air Distribution Type & \multicolumn{2}{|c|}{ Numerous in-wall AC units not controlled in this project } \\
\hline Cooling System & \multicolumn{2}{|c|}{$\begin{array}{l}\text { Central AC in main building: } 2 \text { constant volume compressors each } \\
\text { controlled by a separate thermostat }\end{array}$} \\
\hline \multicolumn{3}{|l|}{ Heating System } \\
\hline HVAC Control System & \multicolumn{2}{|l|}{ Data not reported. } \\
\hline HVAC Zoning & \multicolumn{2}{|l|}{ Data not reported. } \\
\hline \multicolumn{3}{|l|}{ Data Collection } \\
\hline Electric Data & \multicolumn{2}{|l|}{ SmartMeter } \\
\hline Control Data & \multicolumn{2}{|l|}{ EcoNexus } \\
\hline Other & & \\
\hline
\end{tabular}




\begin{tabular}{|l|l|} 
Vendor Information & \\
\hline Vendor Name & InThrMa; EcoNexus \\
\hline Technology Description & Programmable Thermostat; Energy control program \\
\hline DR Strategies & Reset thermostat \\
\hline HVAC & $\begin{array}{l}\text { Originally planned to control all lighting but scaled back the shed } \\
\text { strategy to only control lighting in the school's office and an ancillary } \\
\text { spaces, not in the classroom (because of conflicts with US Department } \\
\text { of Education rules). }\end{array}$ \\
\hline Lighting & $\begin{array}{l}\text { Hot water heater, microwave, and coffeemaker turned off completely, } \\
15 \text { minute cycling of water cooler and refrigerator }\end{array}$ \\
\hline MELs &
\end{tabular}

\section{Site Architecture}

Figure C-33. Preschool site architecture

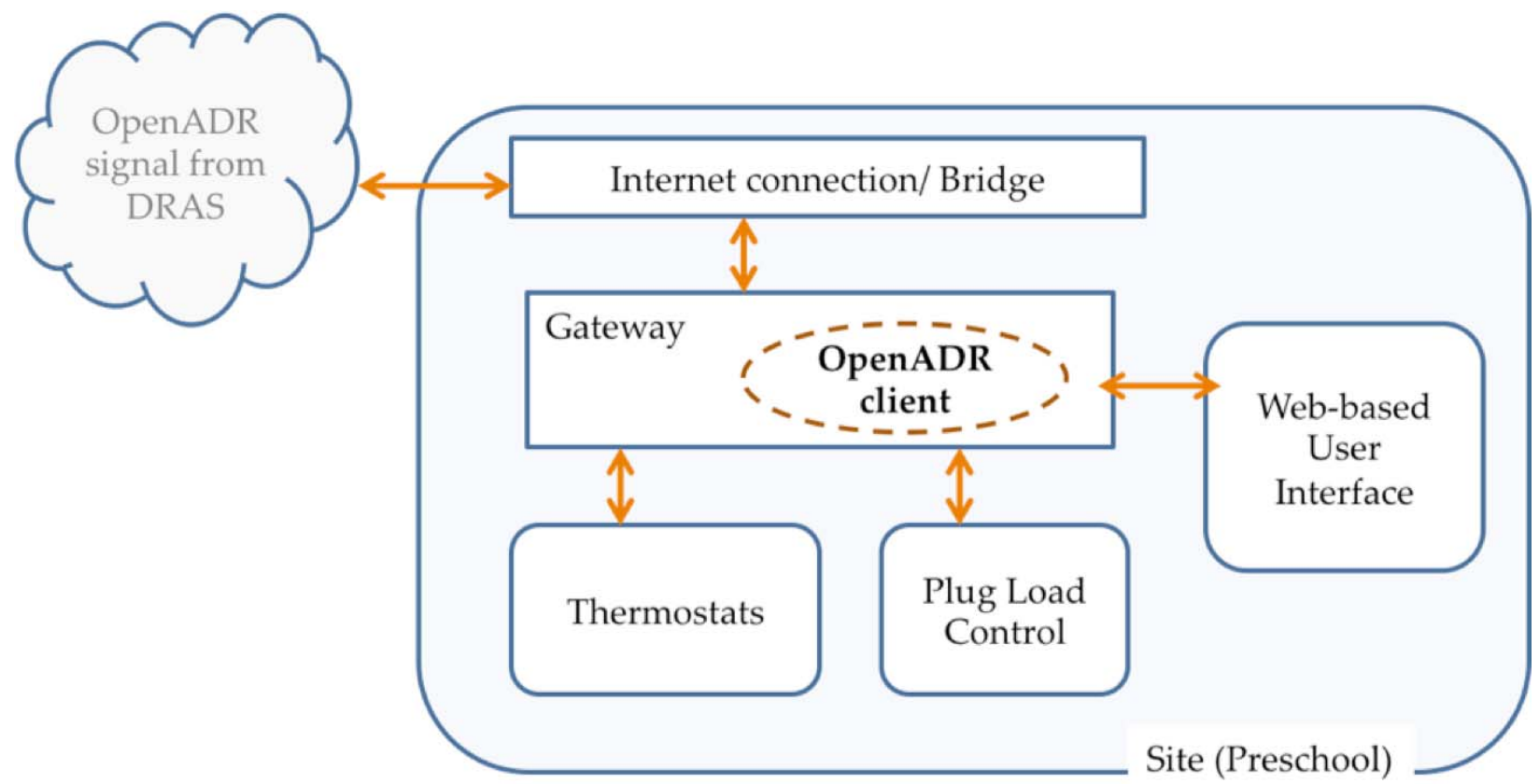

At this site, the OpenADR client was embedded in a gateway that converted OpenADR signals to commands to programmable thermostats and relays controlling other equipment. A separate web-based user interface allowed the vendor to monitor the strategies. 


\section{Site Data}

Figure C-34. InThrMa, August 24, 2010 (Max OAT: 105 F)

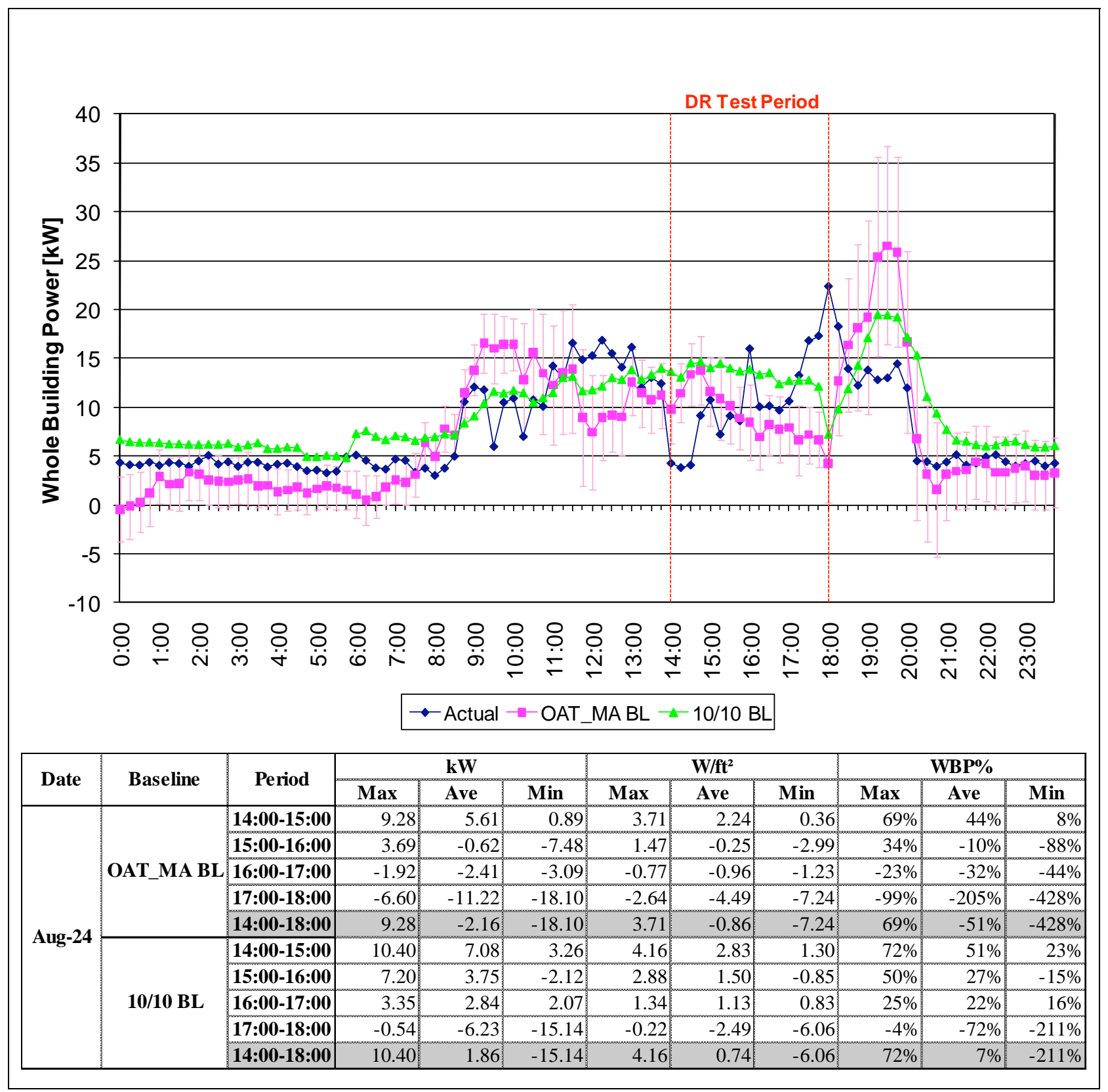


Figure C-35. InThrMa, September 1, 2010 (Max OAT: 96 ${ }^{\circ} \mathrm{F}$ )

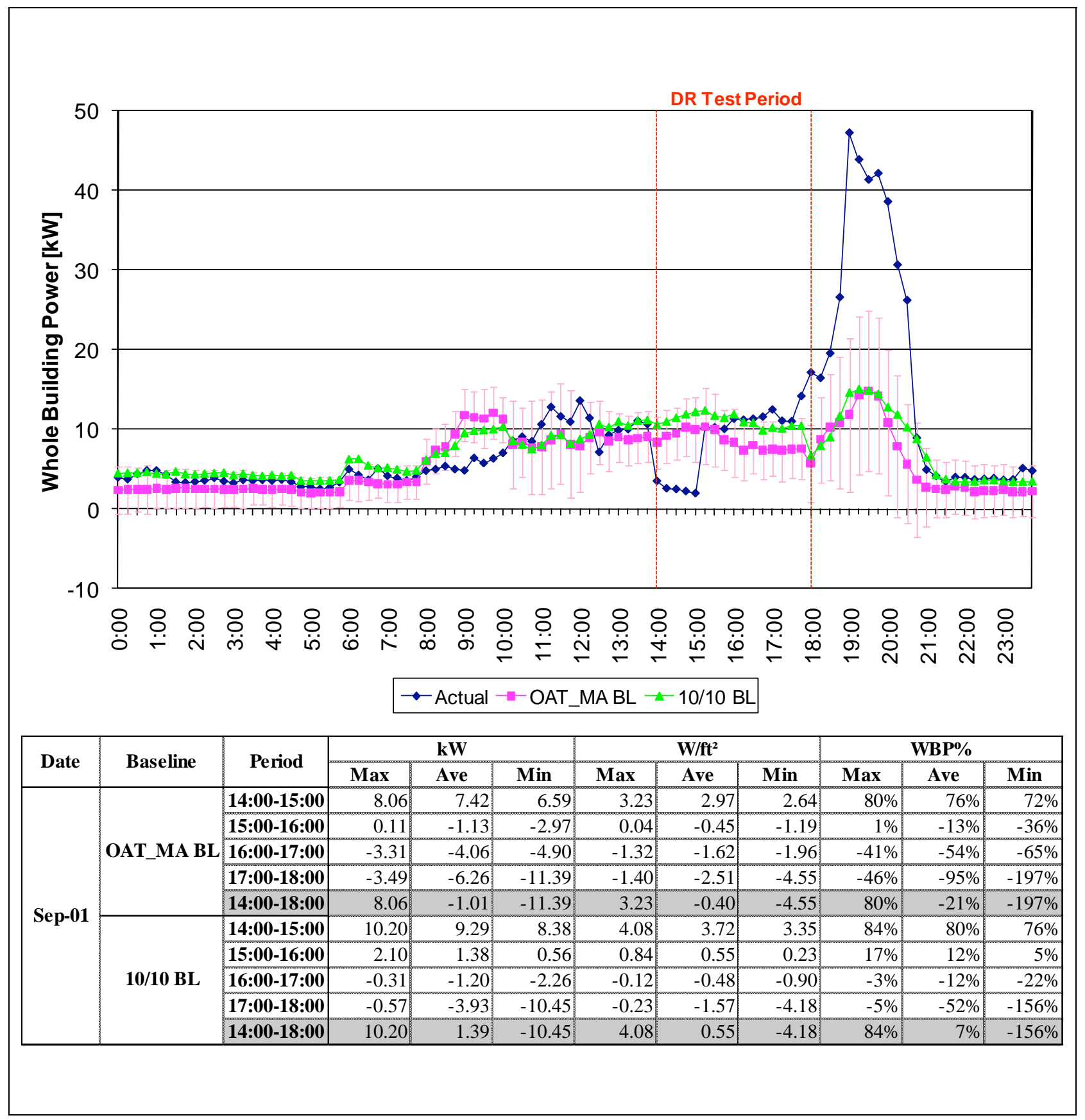


Figure C-36. InThrMa, September 2, 2010 (Max OAT: 99 ${ }^{\circ} \mathrm{F}$ )

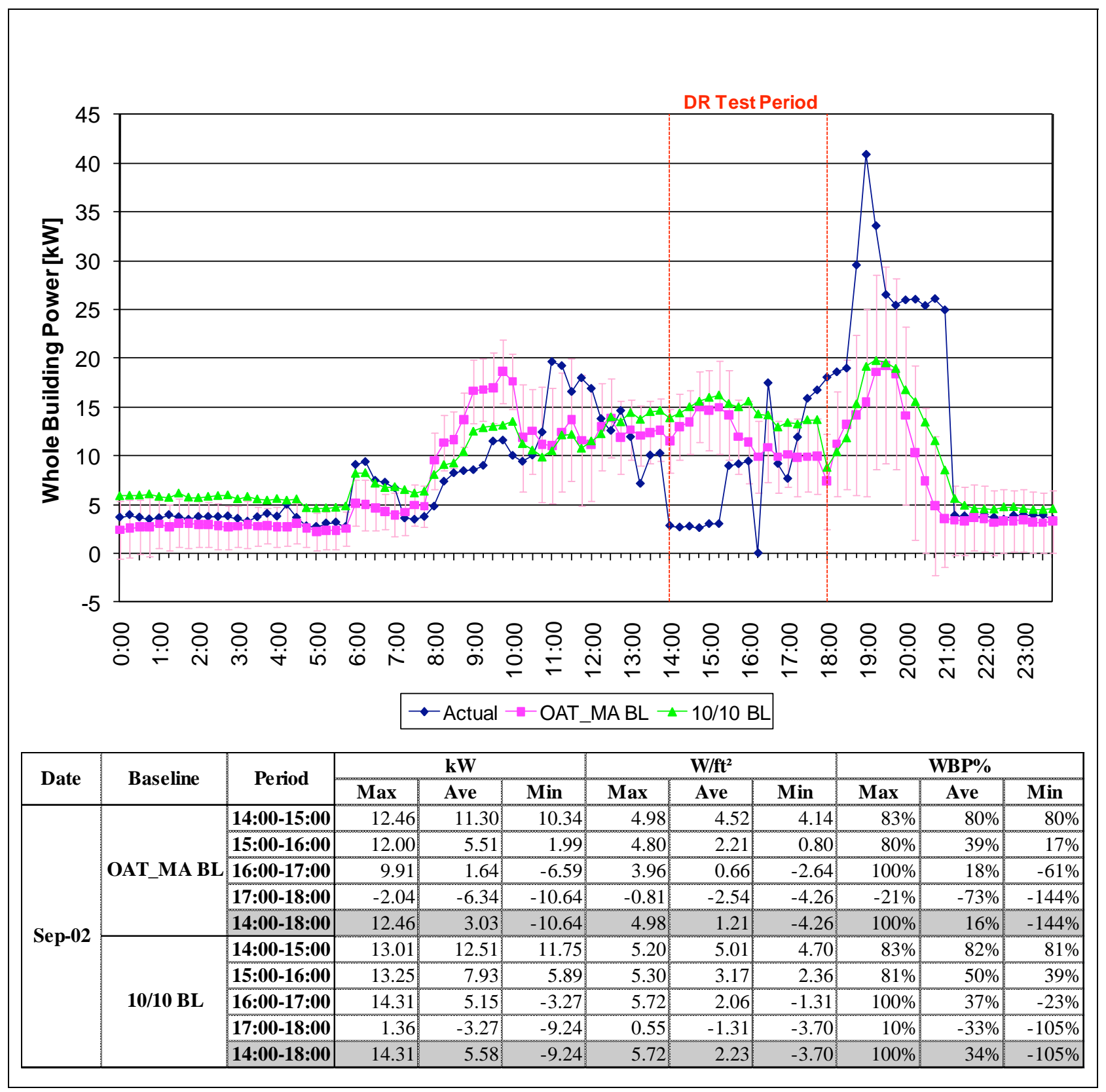


Figure C-37. InThrMa, September 24, 2010 (Max OAT: 90 F)

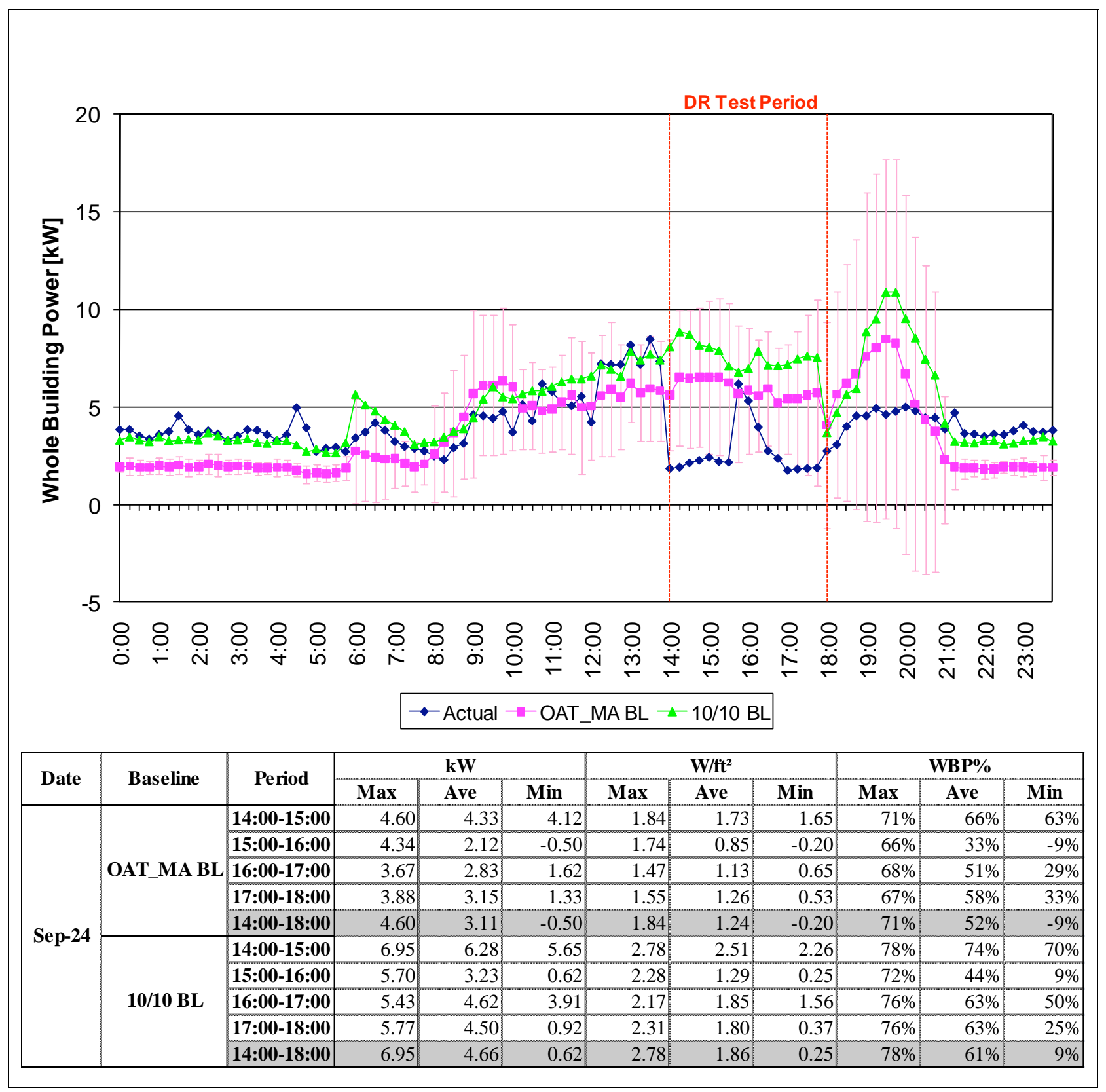


Figure C-38. InThrMa, September 27, 2010 (Max OAT: 100 F)

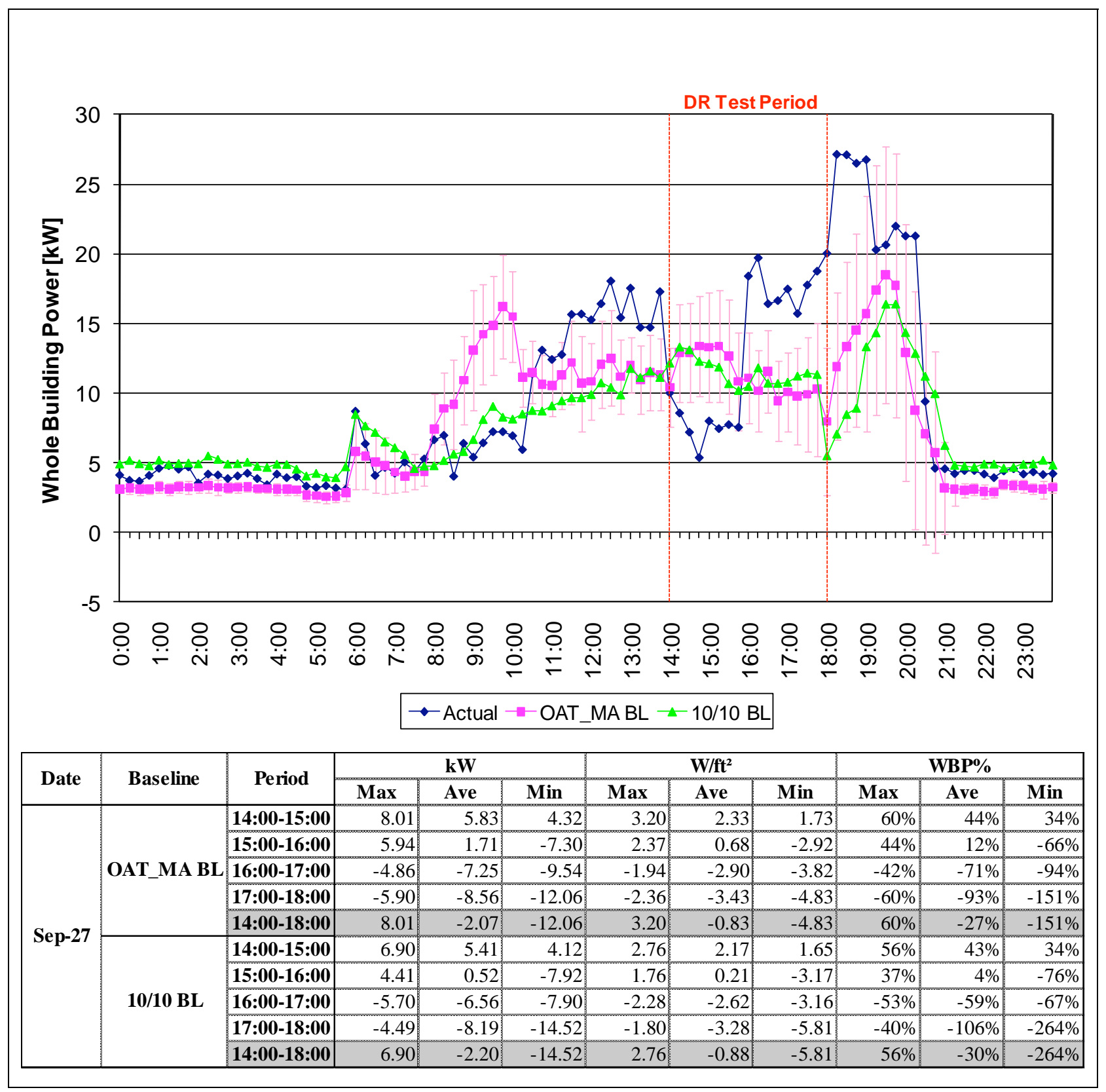


Figure C-39. InThrMa, September 28, 2010 (Max OAT: $102^{\circ} \mathrm{F}$ )

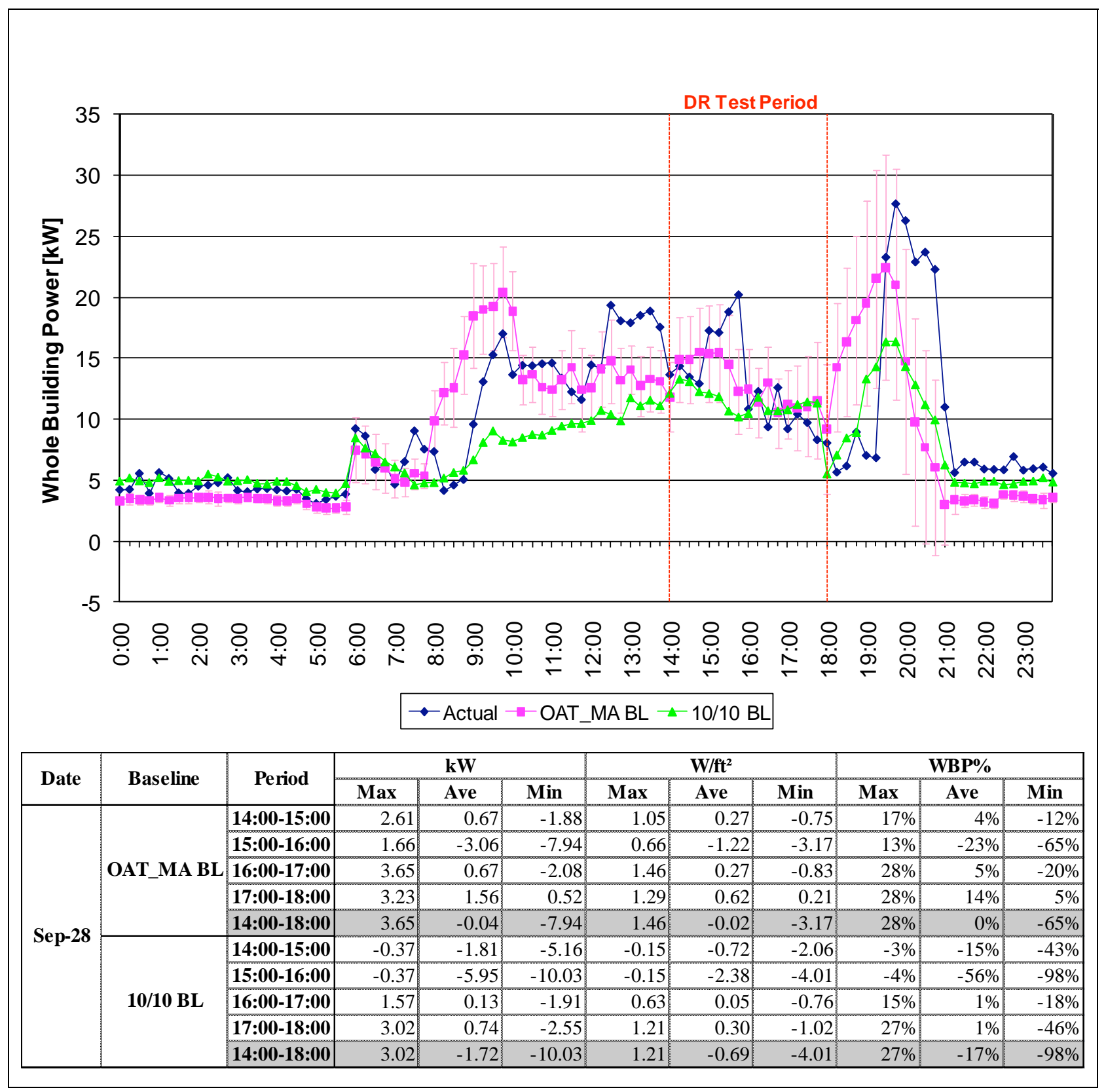

The preschool client opted out of this event at 3:20pm. 
Figure C-40. InThrMa, October 13, 2010 (Max OAT: 93 ${ }^{\circ}$ )

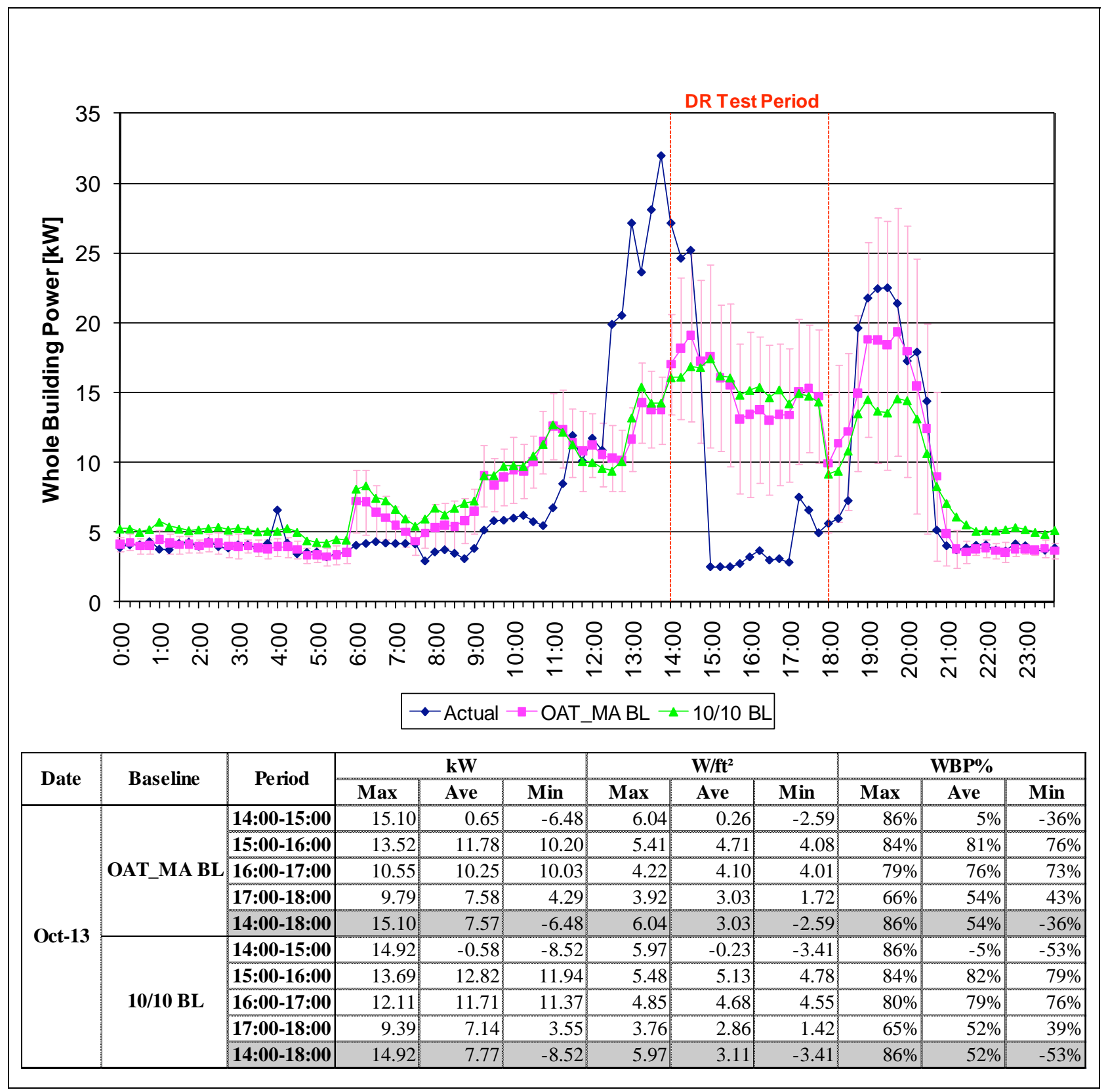




\section{Discussion}

Figure C-41. Pittsburg Site (InThrMa)

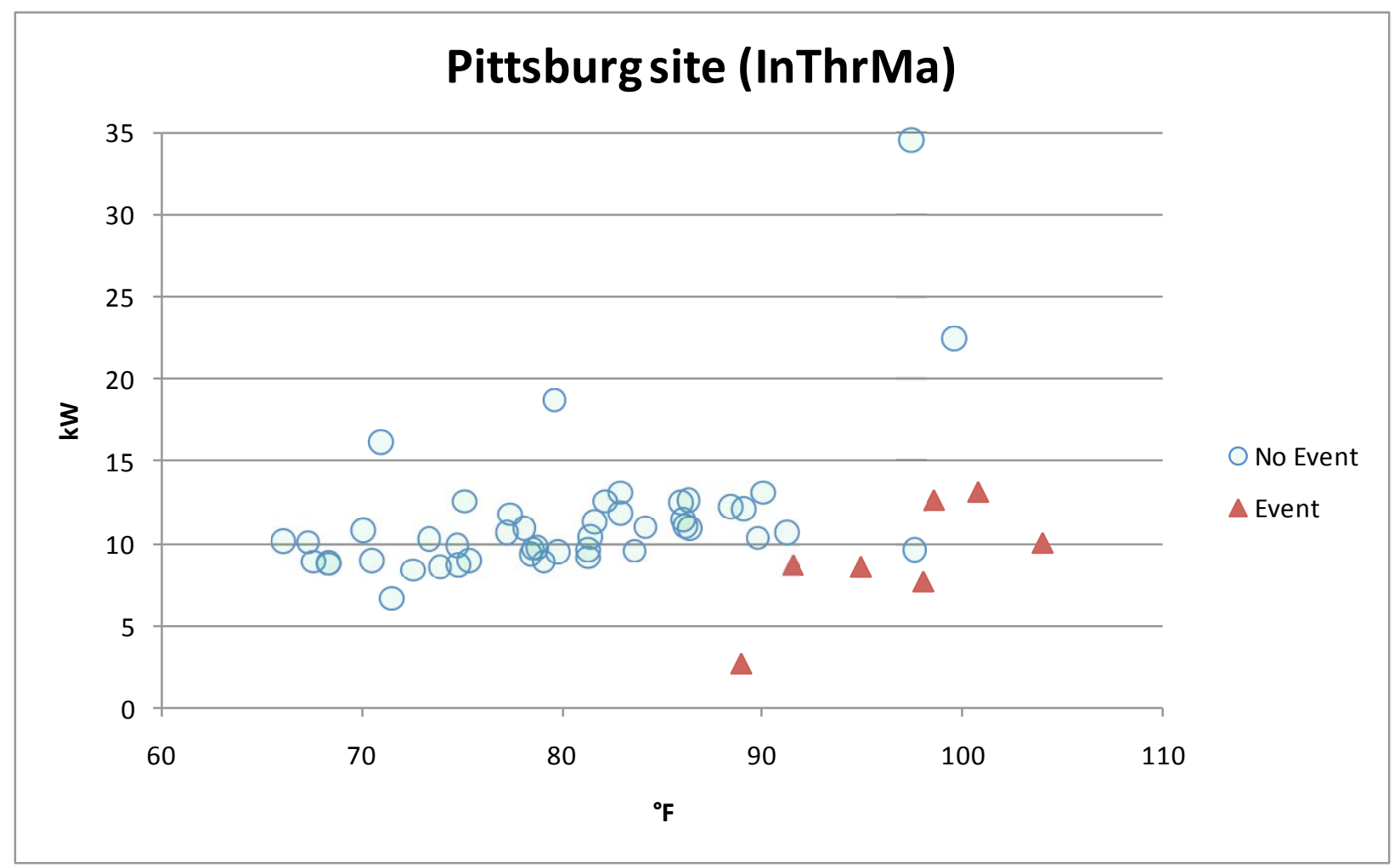

At this site, the vendor reported changing the thermostat setpoint so that temperatures inside the building could go as high as $85^{\circ} \mathrm{F}$, noting that it was still tolerable because it was cooler inside than it was outside on warm days.

Data points for "No Event" days showing increased demand consistently occurred on pairs of Wednesdays (August 18 and 25, then September 29 and October 6) and may be related to activities in another building that was on the same circuit as this preschool. The event day with the lowest demand was also the only event day to fall on a Friday (September 24).

This site started to participate in the September 28th DR event, but opted out an hour and twenty minutes into the event. 


\section{C.6. Site Description - Oakland}

\begin{tabular}{|c|c|c|}
\hline Site Name & $\begin{array}{l}\text { Associated Lighting } \\
\text { Representatives }\end{array}$ & 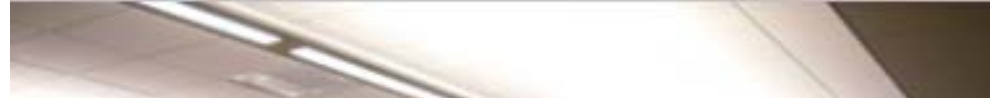 \\
\hline Building Use & Sales office & \\
\hline City & Oakland, CA & 0 \\
\hline $\begin{array}{l}\text { Gross Floor } \\
\text { Area }\end{array}$ & 20,000 & 25 \\
\hline $\begin{array}{l}\text { Controlled } \\
\text { Floor Area }\end{array}$ & 20,000 & Lifis \\
\hline $\begin{array}{l}\text { Peak Load } \\
(\mathrm{kW})\end{array}$ & 71.38 & 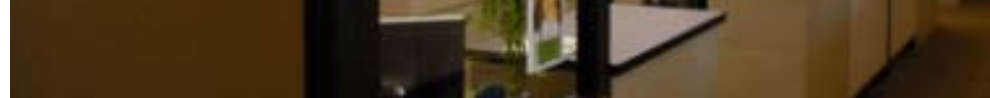 \\
\hline $\begin{array}{l}\text { Max. } \\
\text { Temperature } \\
\text { during test }\end{array}$ & $96.9^{\circ} \mathrm{F}$ & \\
\hline Tenant Type & Company owned & \\
\hline $\begin{array}{l}\text { Weekday } \\
\text { Schedule }\end{array}$ & 7am - 6pm M-F & \\
\hline $\begin{array}{l}\text { Non-weekday } \\
\text { Schedule }\end{array}$ & limited occupancy & \\
\hline $\begin{array}{l}\text { Additional } \\
\text { Details }\end{array}$ & $\begin{array}{l}\text { Focused only on } \\
\text { lighting control. } \\
\text { Lights represented } \\
\sim 20 \% \text { of building } \\
\text { load. }\end{array}$ & \\
\hline Lighting & \multicolumn{2}{|c|}{$\begin{array}{l}\text { Centralized control over most of lighting; majority of lighting is fluorescent. Connected } \\
\text { load is approx. } 0.6 \mathrm{~W} / \mathrm{sq} . \mathrm{ft} \text {; includes motion sensors and dimmable ballasts. }\end{array}$} \\
\hline $\begin{array}{l}\text { HVAC } \\
\text { Summary }\end{array}$ & \multicolumn{2}{|c|}{ No information provided. Can observe 5-8 RTUs } \\
\hline $\begin{array}{l}\text { Air } \\
\text { Distribution } \\
\text { Type }\end{array}$ & \multicolumn{2}{|l|}{ N/A } \\
\hline $\begin{array}{l}\text { Cooling } \\
\text { System }\end{array}$ & \multicolumn{2}{|l|}{ N/A } \\
\hline $\begin{array}{l}\text { Heating } \\
\text { System }\end{array}$ & \multicolumn{2}{|l|}{ N/A } \\
\hline HVAC Control & \multicolumn{2}{|l|}{ N/A } \\
\hline
\end{tabular}




\begin{tabular}{|l|l|} 
System & \\
\hline HVAC Zoning & N/A \\
\hline
\end{tabular}

\section{Data}

Collection

\begin{tabular}{|l|l|}
\hline Electric Data & Dent Elite Pro \\
\hline Control Data & Added thin client gateway to their Quantum hub to provide for DR events. \\
\hline
\end{tabular}

\section{Other}

\begin{tabular}{|l|l|}
\hline $\begin{array}{l}\text { Vendor } \\
\text { Information }\end{array}$ & \\
\hline Vendor Name & Lutron \\
\hline $\begin{array}{l}\text { Technology } \\
\text { Description }\end{array}$ & Lighting controls \\
\hline
\end{tabular}

\section{DR Strategies}

\begin{tabular}{|l|l}
\hline HVAC & N/A \\
\hline Lighting & Lutron enabled a single commercial site for this project: the Associated Lighting
\end{tabular}
Representatives (ALR) Main Office in Oakland, CA. The AutoDR system was limited to the lighting controlled by ALR's Quantum system, approximately $10 \mathrm{~kW}$ of connected load. We are currently also developing technologies to integrate our AutoDR system with HVAC and other non lighting loads. Lutron's Automated Demand Response Solution (Lutron AutoDR) comprises an existing Quantum Total Light Management System and new Interface infrastructure that will communicate with PG\&E to receive Demand Response (DR) alerts.

Lutron Quantum is a commercial light control solution that optimizes the effective use of light to save energy (60\% or more), simplify operations, and improve comfort and productivity. In both new construction and retrofit applications, Quantum automatically dims or switches all electric lighting, controls daylight using automated window shades, and provides the ability to integrate with other manufacturer's building management systems through BACnet IP communication.

The Lutron AutoDR System can be used as the default DR gateway, data conduit and controller for other systems (HVAC, etc) within the building. The AutoDR System can control these other building systems via standard protocols and interfaces, thereby fully "DR enabling" the building.

Quantum total light management works with other advancements including Lutron Hyperion solar adaptive shading, the new, external roof-mounted Cloudy Day Sensor, and Green Glance software that tracks energy savings and provides easy-to-access reporting via a large display screen. These controls work together to significantly reduce lighting load below the connected lighting load of the building. As a result, the curtailment capacity resulting from DR is minimized because the lighting use is already at 


\begin{tabular}{|l|l|} 
& $\begin{array}{l}\text { maximum efficiency. } \\
\text { These tests used differential lighting control (determined by office location) with } \\
\text { approximately } 70 \% \text { of facility lighting. Lighting is a small part }(\sim 7 \mathrm{~kW}) \text { of the facility load. }\end{array}$ \\
\hline Refrigeration & N/A \\
\hline MELs & N/A \\
\hline
\end{tabular}

\section{Site Architecture}

Figure C-42. Associated Lighting Representatives' Main Office Site Architecture

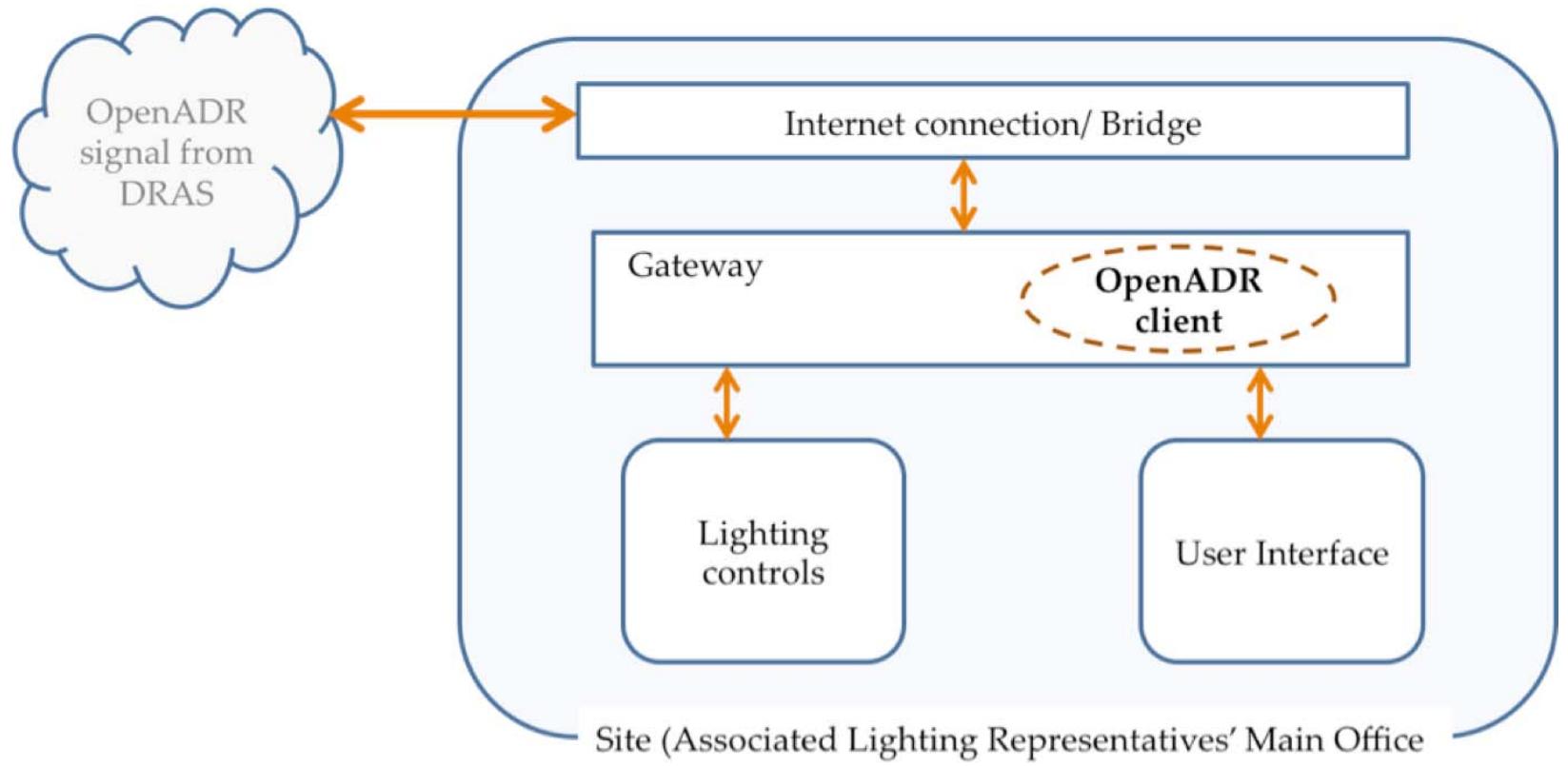

A thin gateway was added to the onsite system to receive OpenADR signals and translate them to controls previously established within onsite equipment.

The vendor conducted a site survey to determine the impact of lighting changes on occupants. This was done in two parts: the first measured occupant response on a DR event day; the second asked the same questions on a non-DR event day to calibrate the first responses. These surveys are included in Appendix D. 


\section{Site Data}

Figure C-43. Lutron, August 24, 2010 (Max OAT: 97 F)

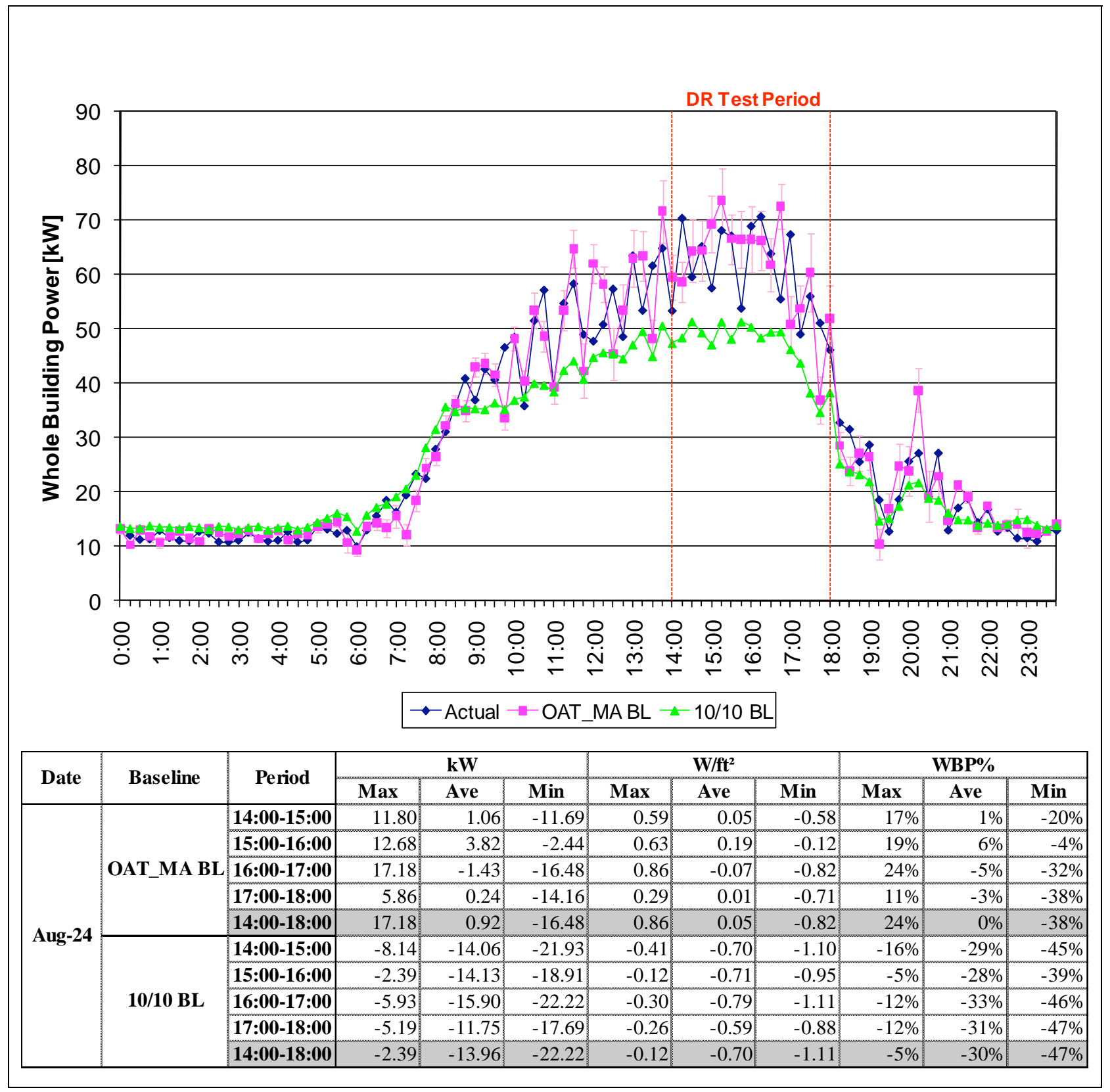


Figure C-44. Lutron, September 1, 2010 (Max OAT: 91 ${ }^{\circ} \mathrm{F}$ )

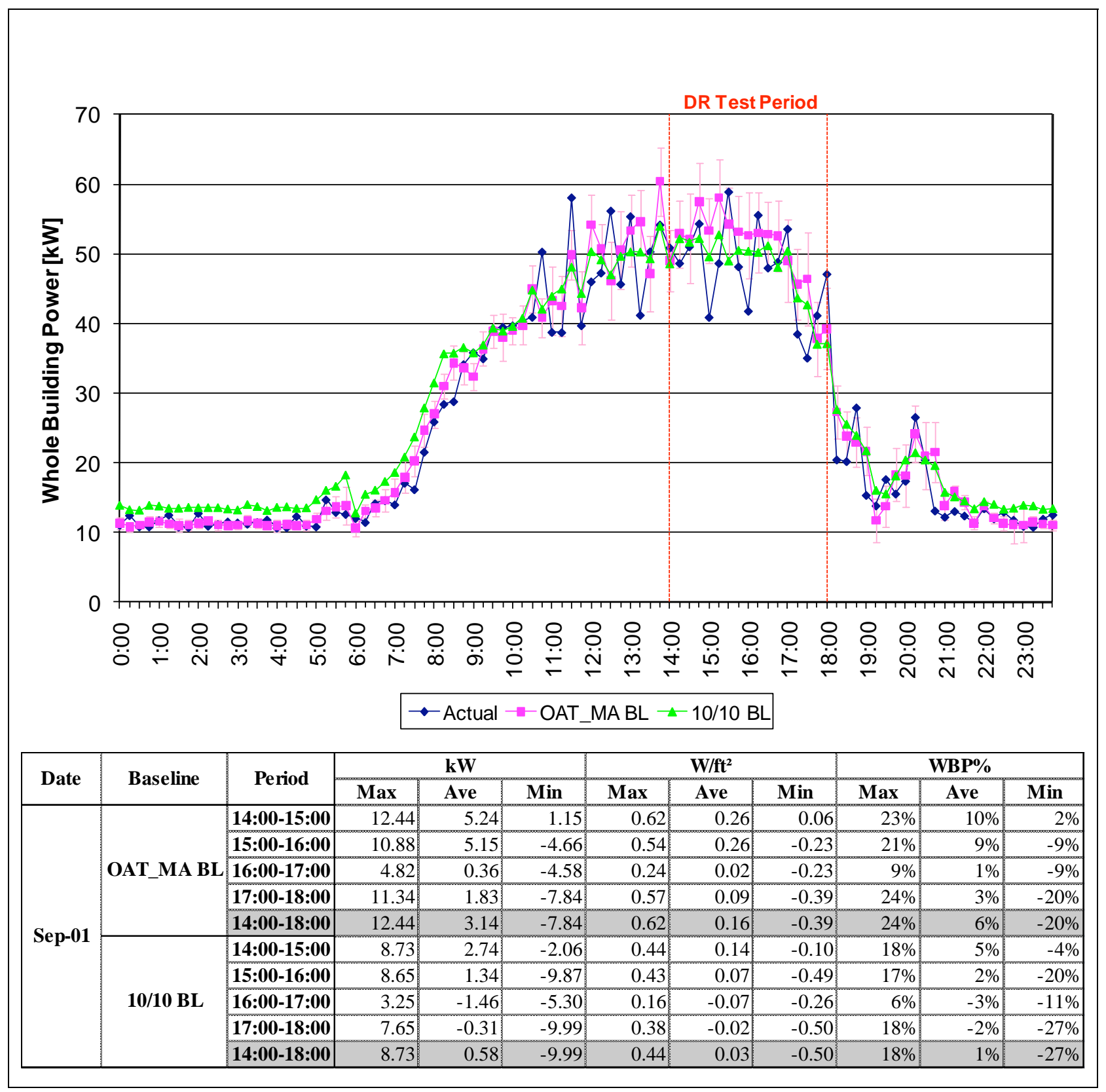


Figure C-45. Lutron, September 2, 2010 (Max OAT: 88 ${ }^{\circ}$ )

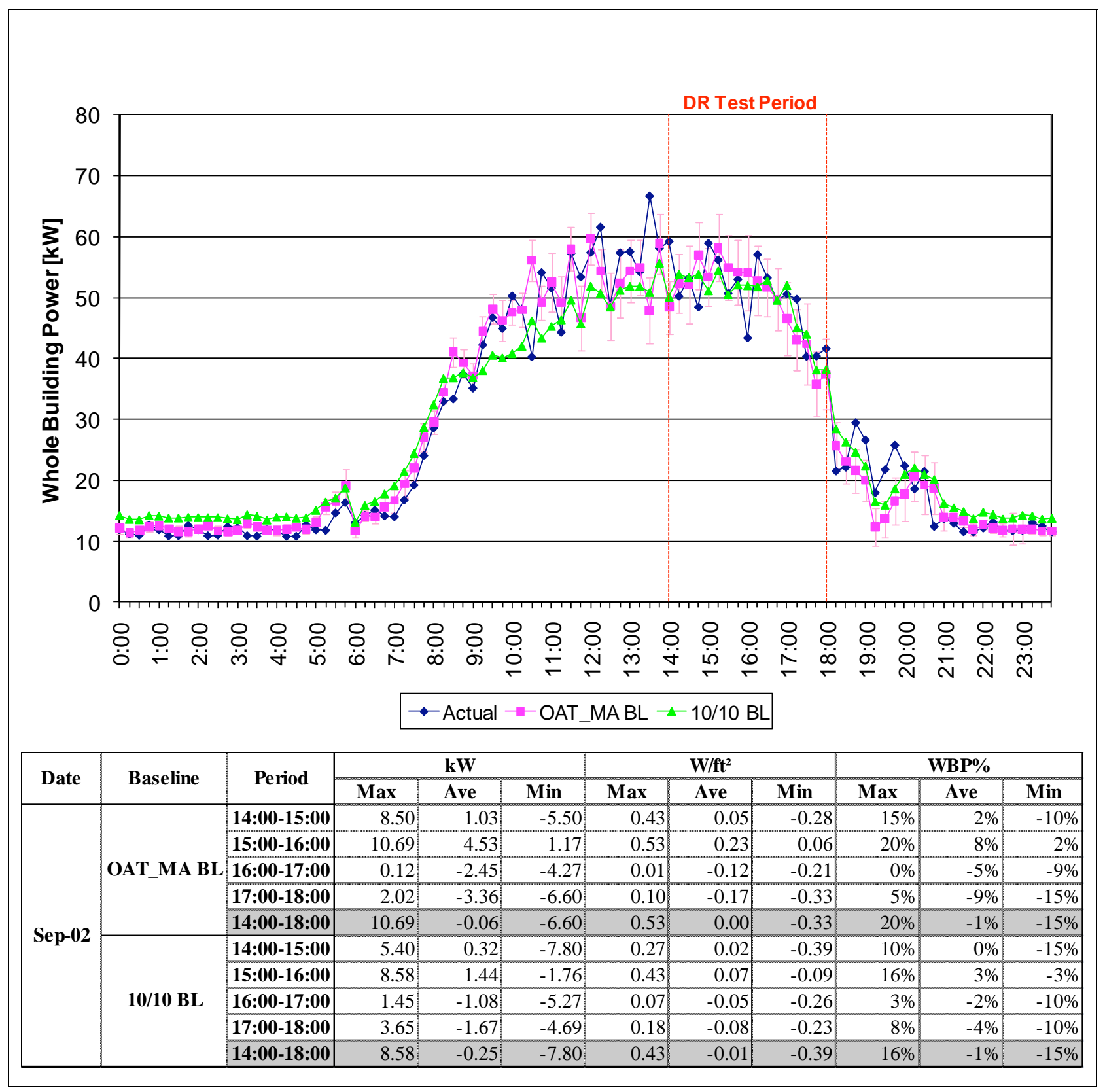


Figure C-46. Lutron, September 24, 2010 (Max OAT: 85 ${ }^{\circ} \mathrm{F}$ )

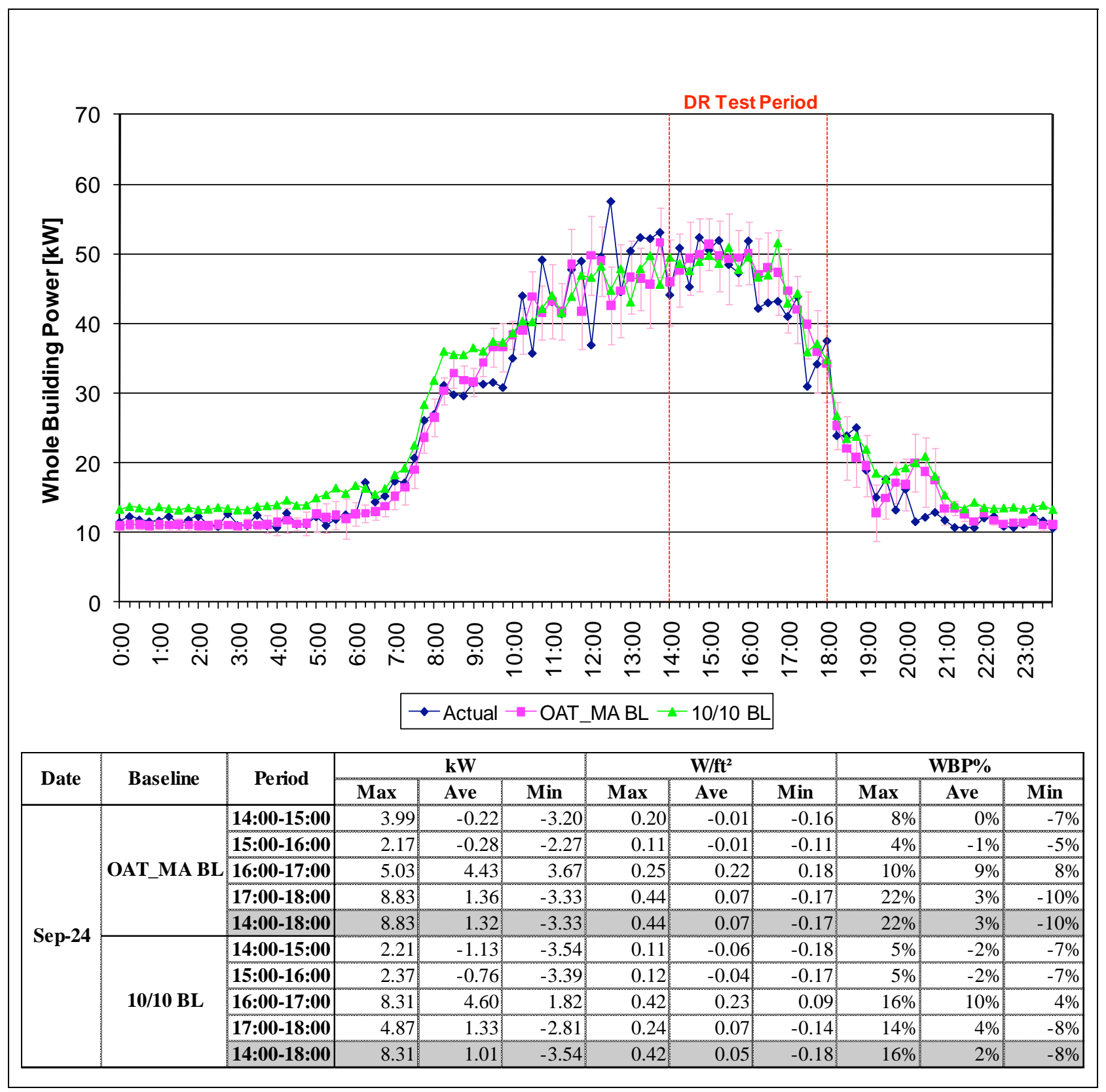


Figure C-47. Lutron, September 27, 2010 (Max OAT: 94 ${ }^{\circ} \mathrm{F}$ )

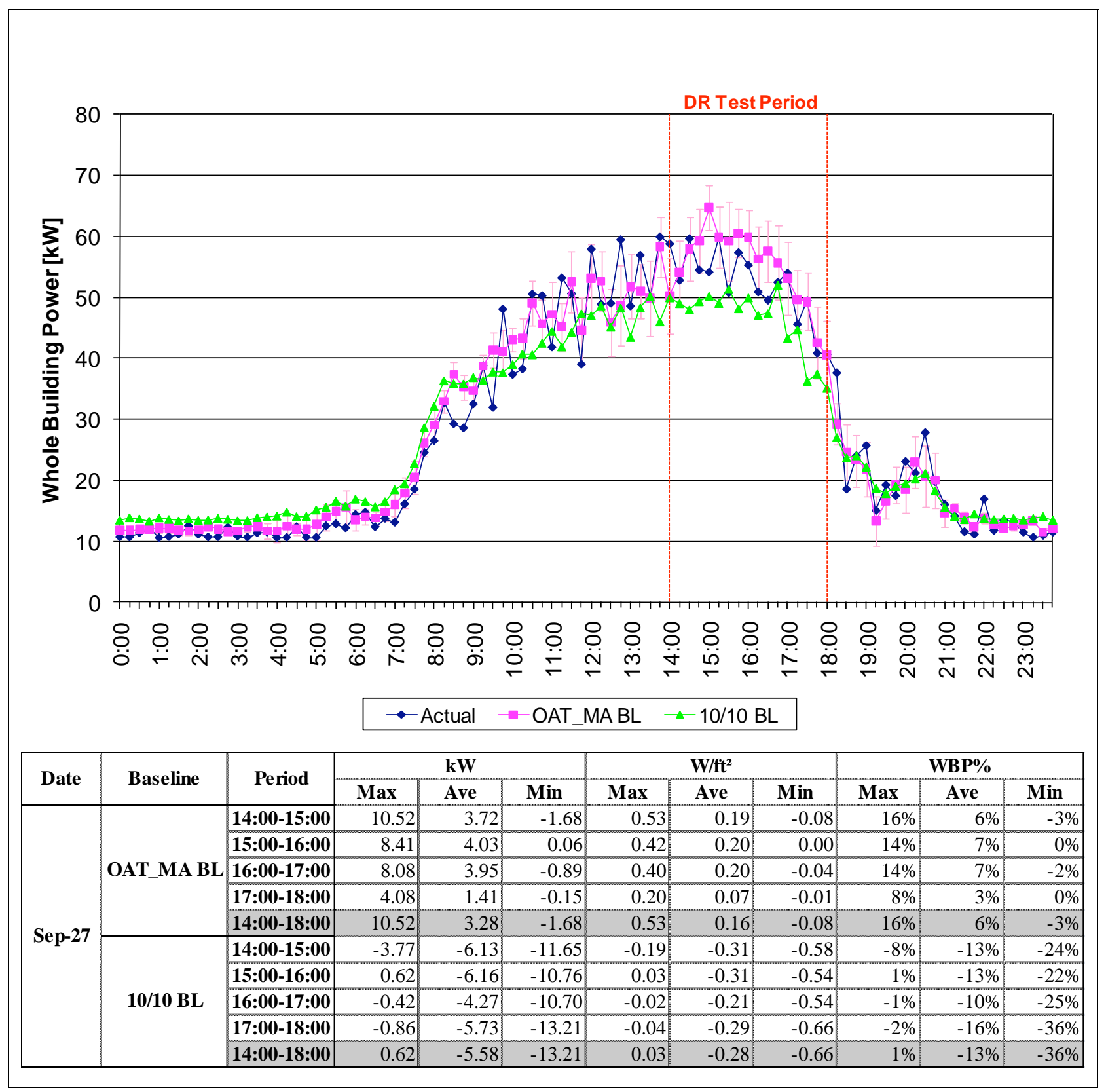


Figure C-48. Lutron, September 28, 2010 (Max OAT: 96 ${ }^{\circ} \mathrm{F}$ )

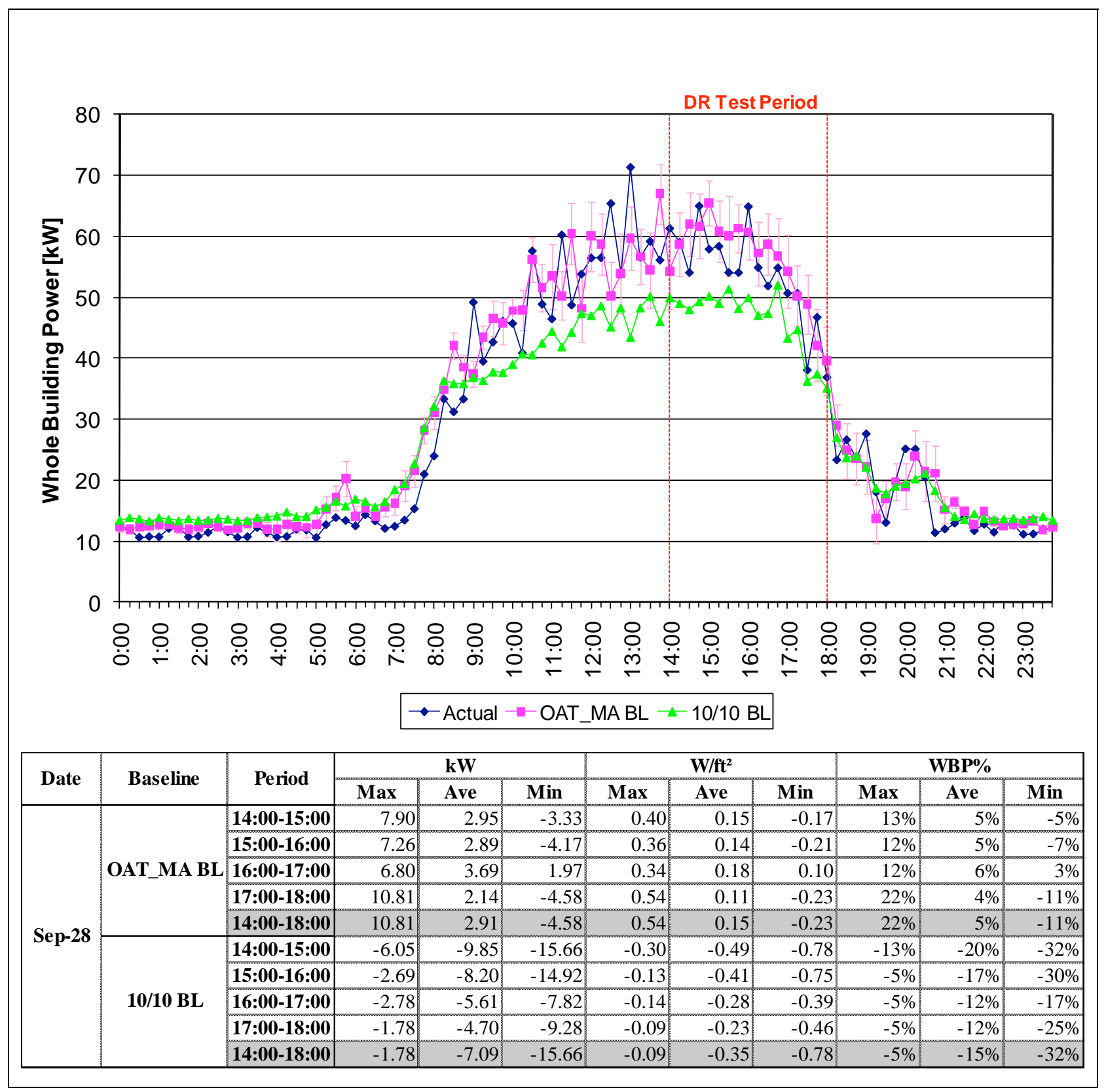


Figure C-49. Lutron, October 13, 2010 (Max OAT: 91ํF)

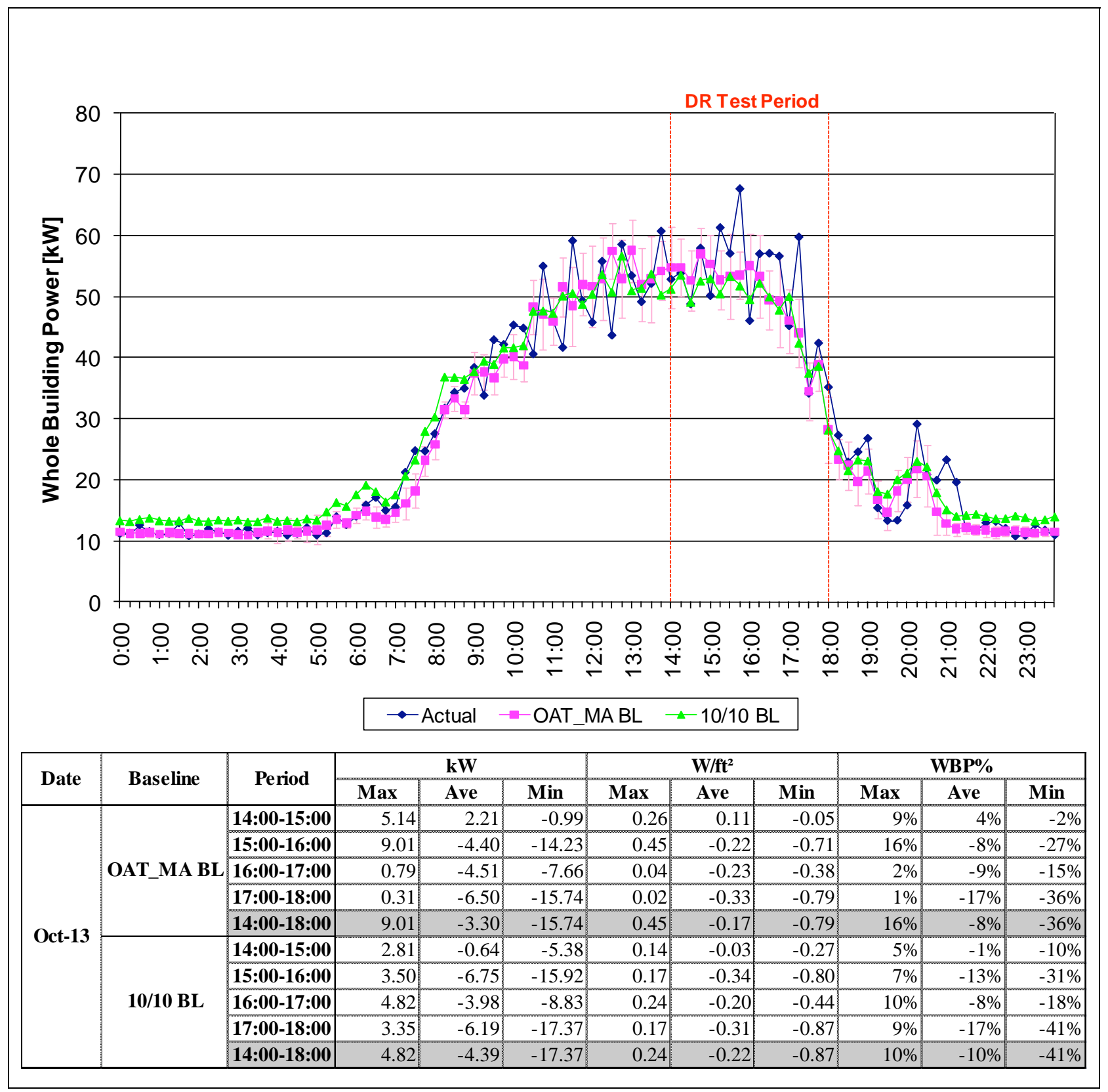


A special test was performed at this site to measure the lighting power reduction as a function of the lighting circuit's power demand (bottom graph and table) vs. the whole building's power demand (immediately below). When separated from other building loads, the response is clearly evident.

Figure C-50. Lutron, September 22, 2010 (Max OAT: 70 $\mathrm{F}$ )

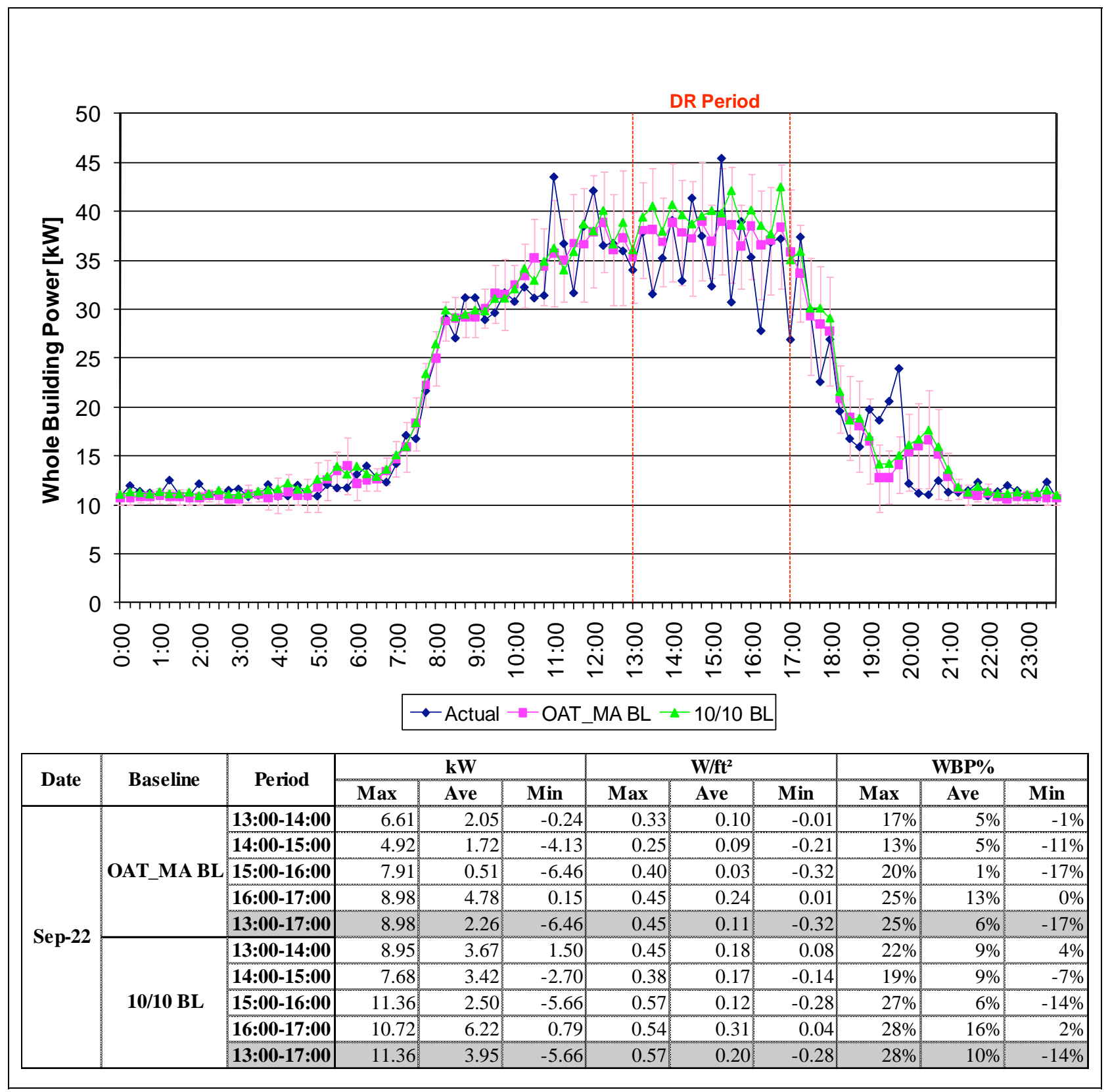


Figure C-51. Lutron-lighting, September 22, 2010 (Max OAT: 70 ${ }^{\circ} \mathrm{F}$ )

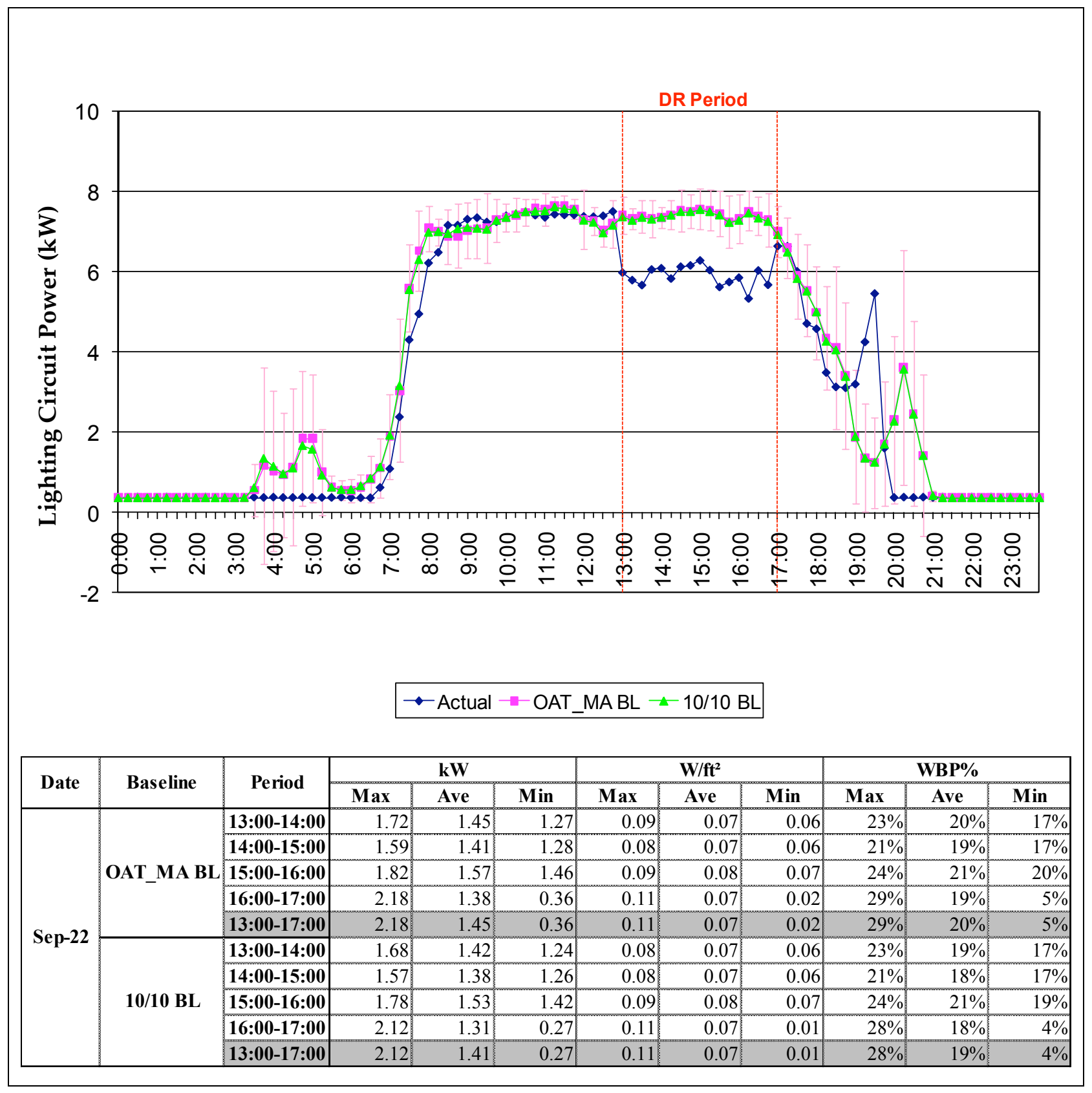




\section{Discussion}

Figure C-52. Oakland Site (Lutron)

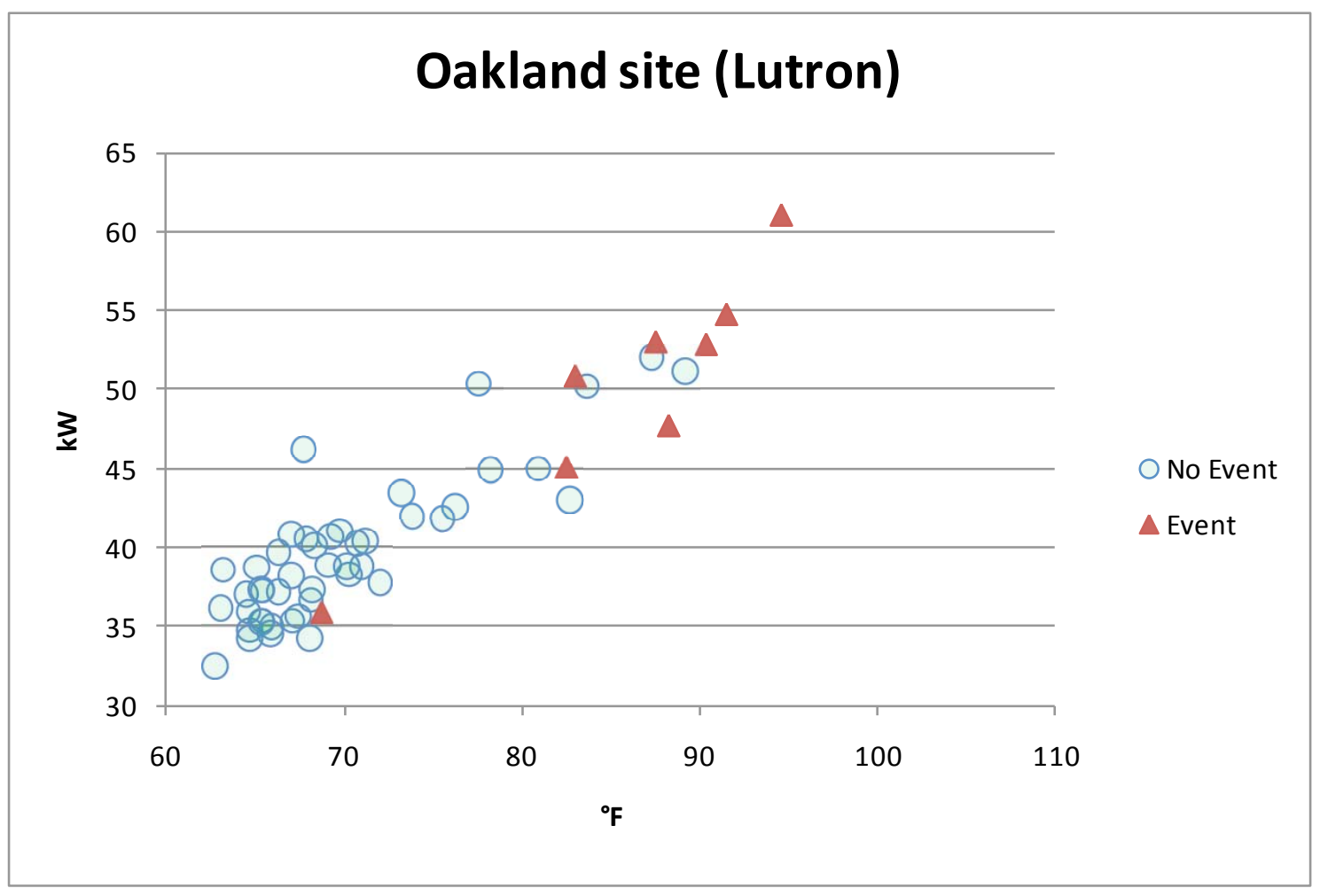

The strategy for this site involved controlling only the lights. As noted earlier, the dominant demand is from other sources, so it was difficult to see the effect of this strategy directly. However, the reduction in demand was obvious when examining only the lighting subcircuit. The data shown here reinforces the notion that HVAC dominated the demand for this site because there is a fairly linear correlation between demand (vertical axis) and outside air temperature (horizontal axis) over the entire test period. 


\section{C.7. Site Description - Palo Alto}

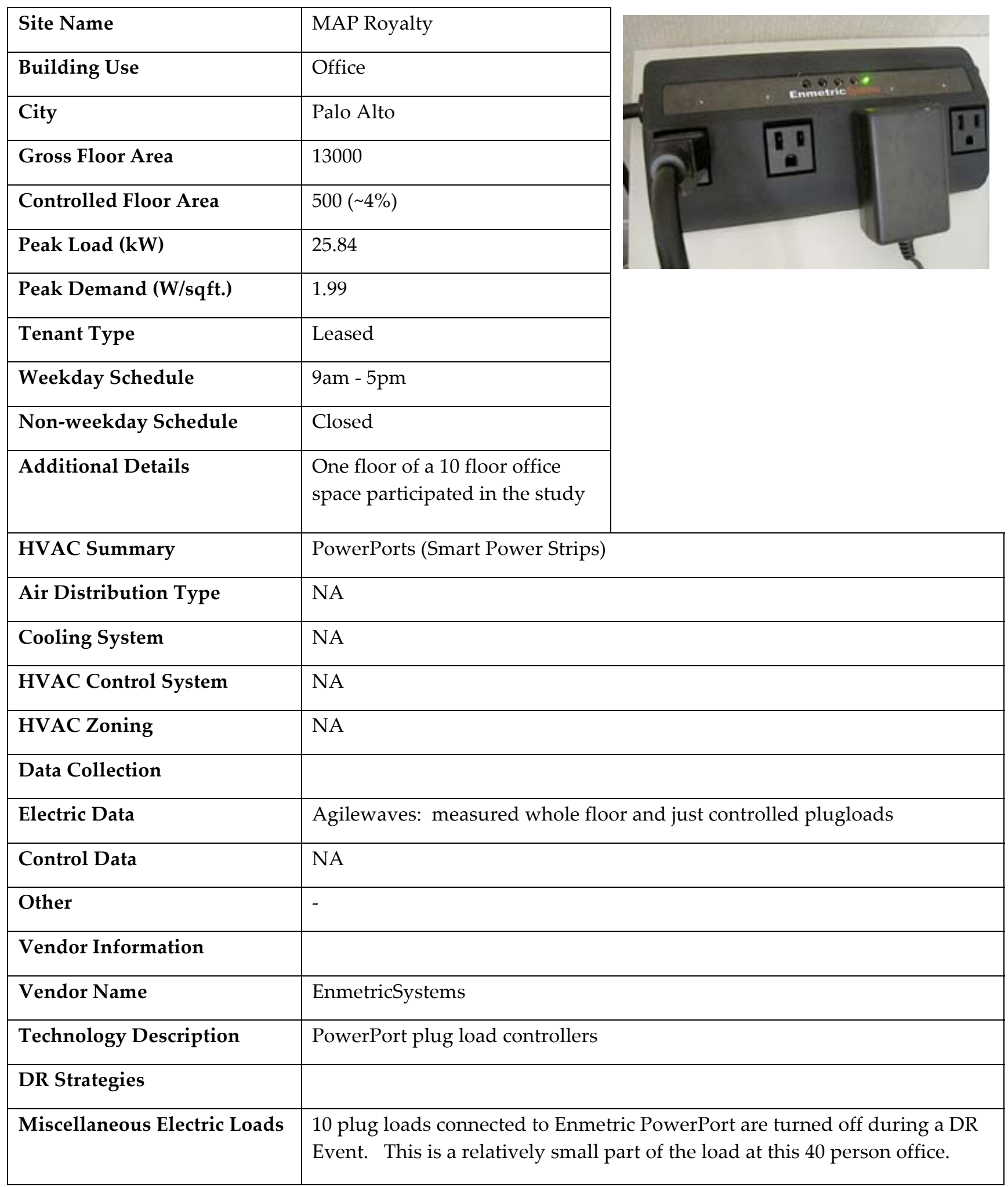




\section{Site Architecture}

Figure C-53. MAP Royalty, Inc. Site Architecture

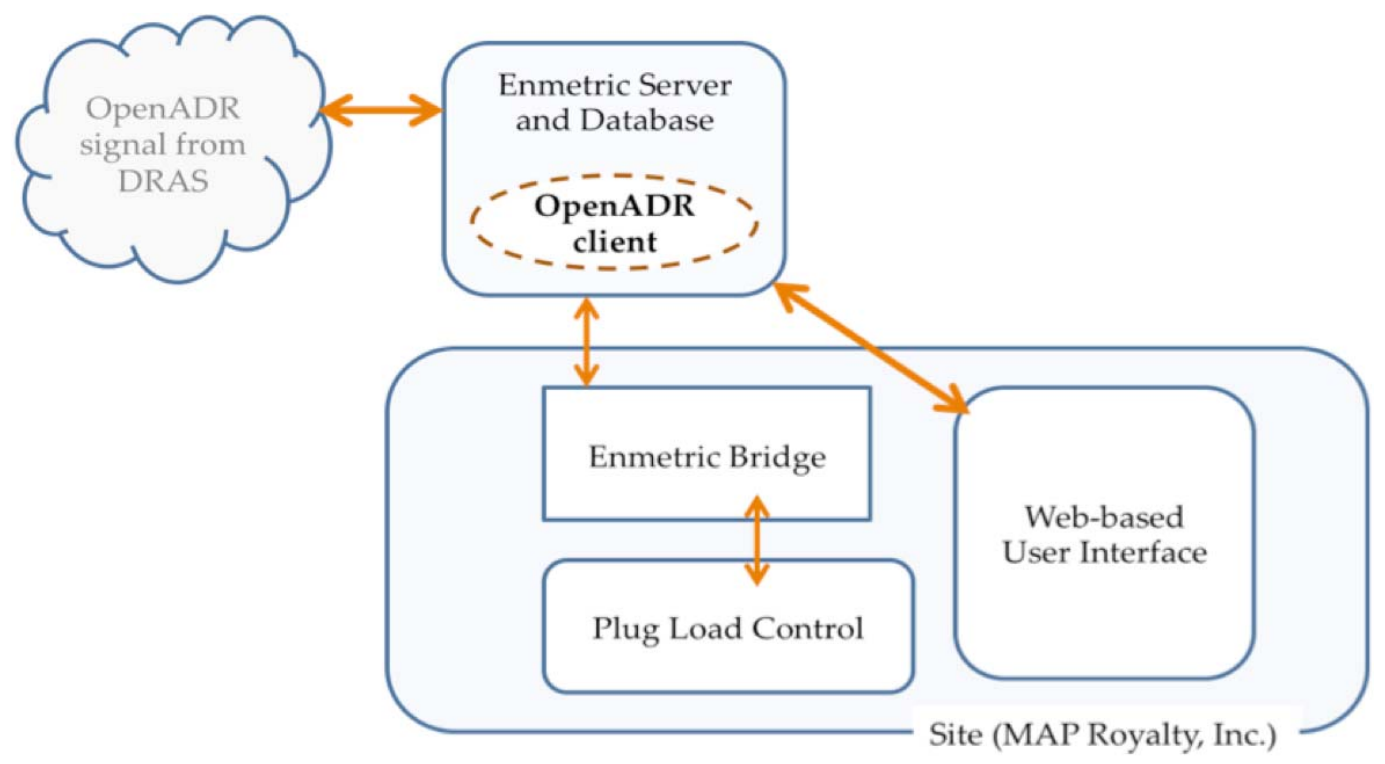

The office in which this equipment was installed occupied one entire floor of a tower. An onsite server farm required significantly more power (estimated 10-20 kW) than was controlled by the Enmetric plug load controllers (estimated $0.150 \mathrm{~kW}$ average, see range below). Nevertheless, the tests proved that the Enmetric server reliably received the OpenADR signal and translated it to the Enmetric bridge, which conveyed it to each plug load controller. At the same time, plug load controllers reported back on the status of connected loads so that they could be monitored remotely via a web interface. It was possible for users to override the plug load controllers if needed (to keep plugged in equipment running), but no overrides were reported.

Enmetric staff notes that while their "load reduction was not particularly noticeable compared to the overall consumption of the site (air handlers cycling on, etc.) [they] expect to add quite a bit of managed load to the system as the site participants get more familiar and comfortable with [their technology]." They further comment that "it's important to view the output of our system within the context of the entire site, as we currently get a bit lost in the noise. We're working on a better way to show our system's effect, perhaps by taking our existing numbers and modeling the output of a complete office system (we're only managing the equivalent of one office/cubicle now.)."

Enmetric technology sheds demand effectively within about 1 min of the DR event when their plug load controllers turn appliances off. Enmetric staff notes "a flurry of activity right before each event call, peaking at about $1.2 \mathrm{~kW}$. This is probably some combination of us and the guys at MAP checking the managed devices (thus 'waking' some of them up), etc." Enmetric staff thinks that "this value $(1.2 \mathrm{~kW})$ represents a solid 'in-use' potential value." Subsequently they note that there is often "a big spike right after the event, when the devices come back online, peaking at about $2.8 \mathrm{~kW}$. This is directly due to just a couple of devices (big laser printer, etc) that need to 'charge up' for a while before sliding back into an eventual idle/sleep state." They 
believe that "this number represents a great 'peak avoidance' value, in that this type of peak could very well happen during the DR times under normal circumstances, and [the Enmetric] system is actively preventing it during those times."

\section{Site Data}

Figure C-54. Enmetric, August 24, 2010 (Max OAT: 100 F)

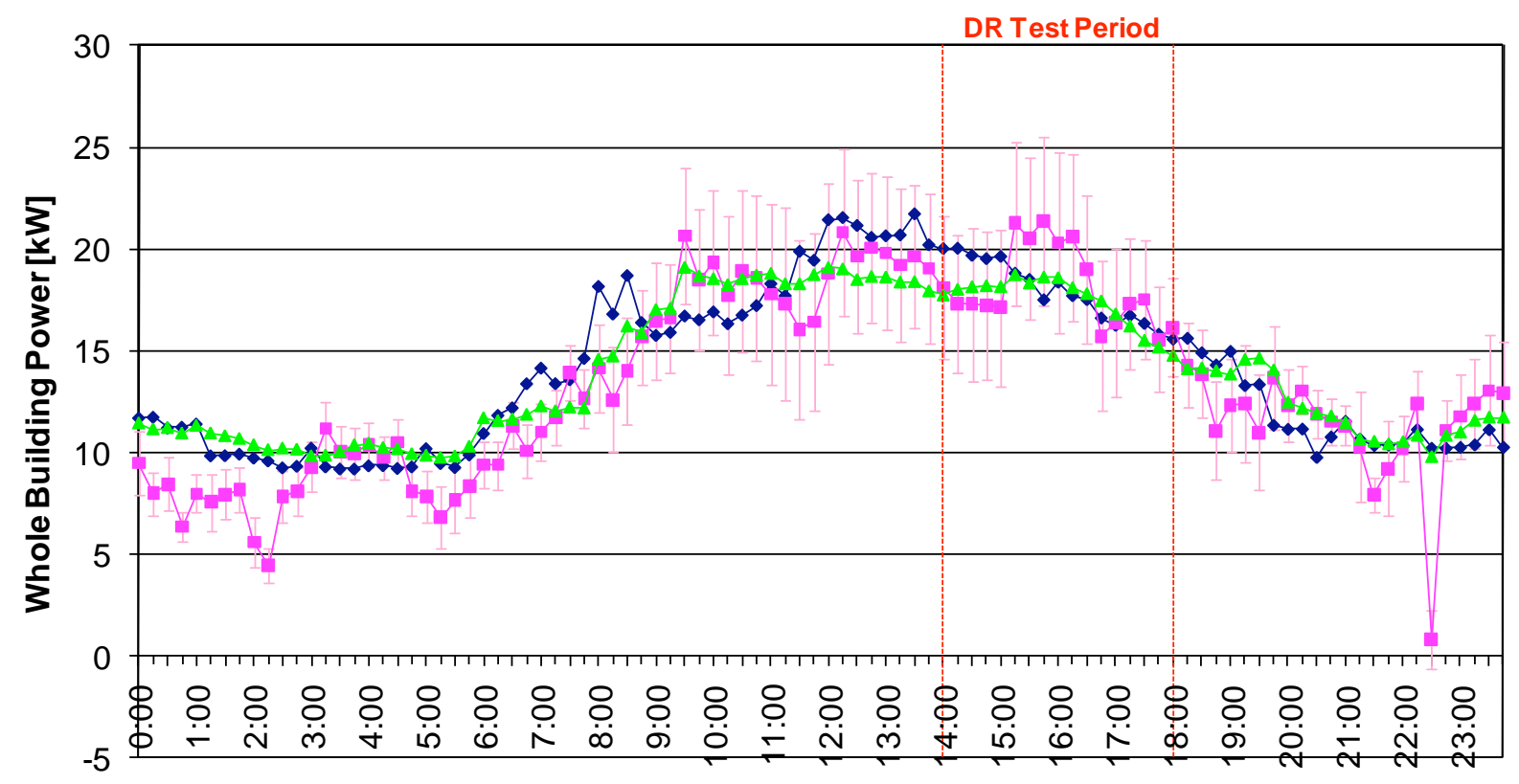

\begin{tabular}{|c|c|c|c|c|c|c|c|c|c|c|c|}
\hline & & & & - Actual & $-O A T$ & $\mathrm{AABL}-$ & $10 / 10 \mathrm{~B}$ & & & & \\
\hline \multirow{2}{*}{ Date } & \multirow{2}{*}{ Baseline } & \multirow{2}{*}{ Period } & \multicolumn{3}{|c|}{$\mathbf{k W}$} & \multicolumn{3}{|c|}{$\mathbf{W} / \mathbf{f t}^{2}$} & \multicolumn{3}{|c|}{ WBP\% } \\
\hline & & & Max & Ave & Min & Max & Ave & Min & Max & Ave & Min \\
\hline \multirow{10}{*}{ Aug-24 } & \multirow{5}{*}{ OAT_MA BL } & 14:00-15:00 & -2.29 & -2.47 & -2.70 & -4.58 & -4.94 & -5.40 & $-13 \%$ & $-14 \%$ & $-16 \%$ \\
\hline & & 15:00-16:00 & 3.87 & 2.57 & 1.94 & 7.75 & 5.15 & 3.87 & $18 \%$ & $12 \%$ & $10 \%$ \\
\hline & & 16:00-17:00 & 2.88 & 0.90 & -0.90 & 5.77 & 1.80 & -1.79 & $14 \%$ & $4 \%$ & $-6 \%$ \\
\hline & & 17:00-18:00 & 1.18 & 0.51 & -0.26 & 2.36 & 1.03 & -0.52 & $7 \%$ & $3 \%$ & $-2 \%$ \\
\hline & & 14:00-18:00 & 3.87 & 0.38 & -2.70 & 7.75 & 0.76 & -5.40 & $18 \%$ & $1 \%$ & $-16 \%$ \\
\hline & \multirow{5}{*}{ 10/10 BL } & 14:00-15:00 & -1.32 & -1.59 & -2.01 & -2.64 & -3.17 & -4.02 & $-7 \%$ & $-9 \%$ & $-11 \%$ \\
\hline & & 15:00-16:00 & 1.12 & 0.28 & -0.17 & 2.24 & 0.56 & -0.34 & $6 \%$ & $1 \%$ & $-1 \%$ \\
\hline & & 16:00-17:00 & 0.84 & 0.52 & 0.29 & 1.68 & 1.04 & 0.59 & $5 \%$ & $3 \%$ & $2 \%$ \\
\hline & & 17:00-18:00 & -0.52 & -0.71 & -0.84 & -1.05 & -1.41 & -1.69 & $-3 \%$ & $-5 \%$ & $-5 \%$ \\
\hline & & 14:00-18:00 & 1.12 & -0.37 & -2.01 & 2.24 & -0.75 & -4.02 & $6 \%$ & $-2 \%$ & $-11 \%$ \\
\hline
\end{tabular}


Figure C-55. Enmetric, September 1, 2010 (Max OAT: 91 ${ }^{\circ} \mathrm{F}$ )

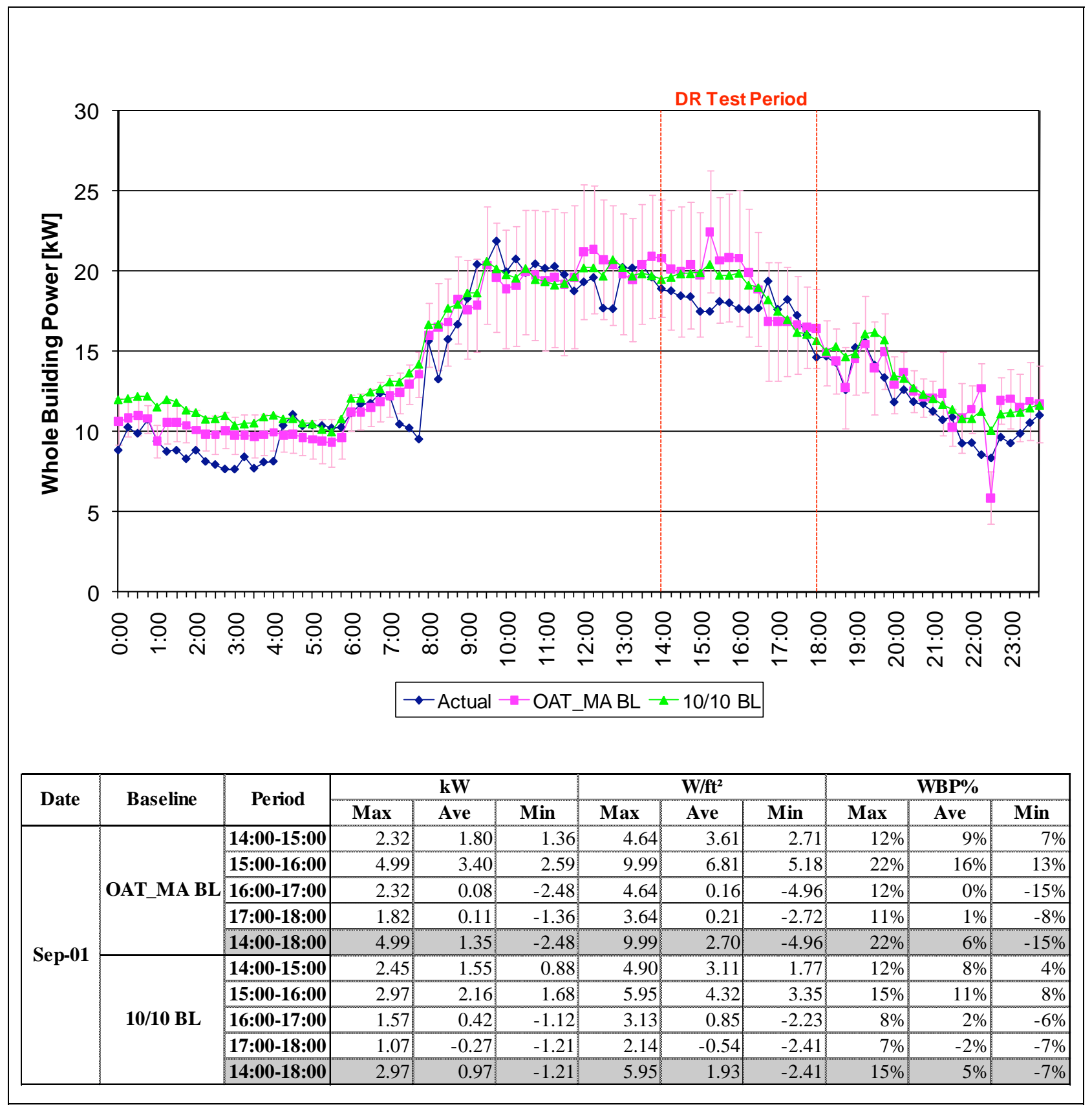


Figure C-56. Enmetric, September 2, 2010 (Max OAT: 91 ${ }^{\circ} \mathrm{F}$ )

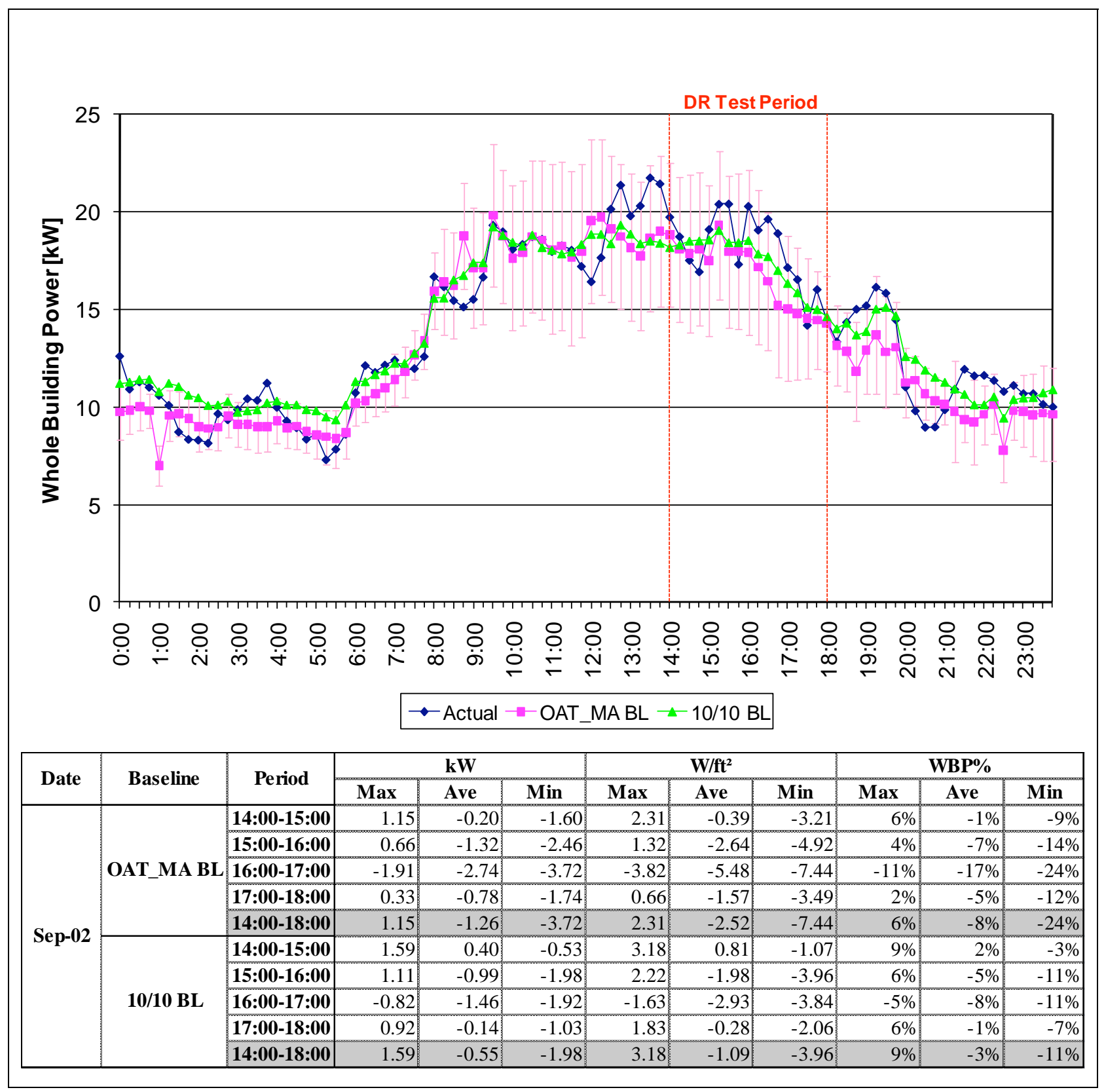


Figure C-57. Enmetric, September 24, 2010 (Max OAT: 85 F)

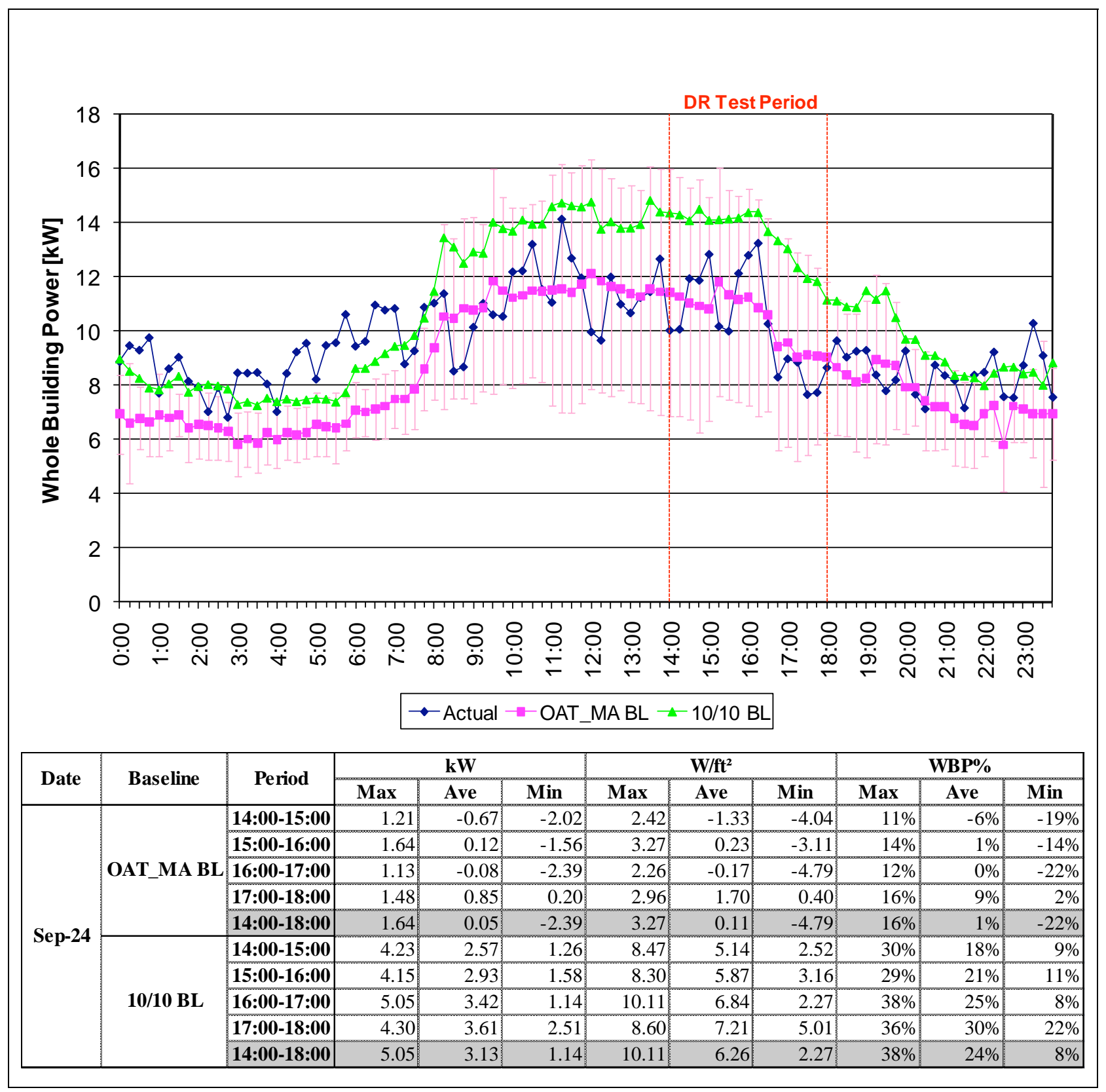


Figure C-58. Enmetric, September 27, 2010 (Max OAT: 92 ${ }^{\circ} \mathrm{F}$ )

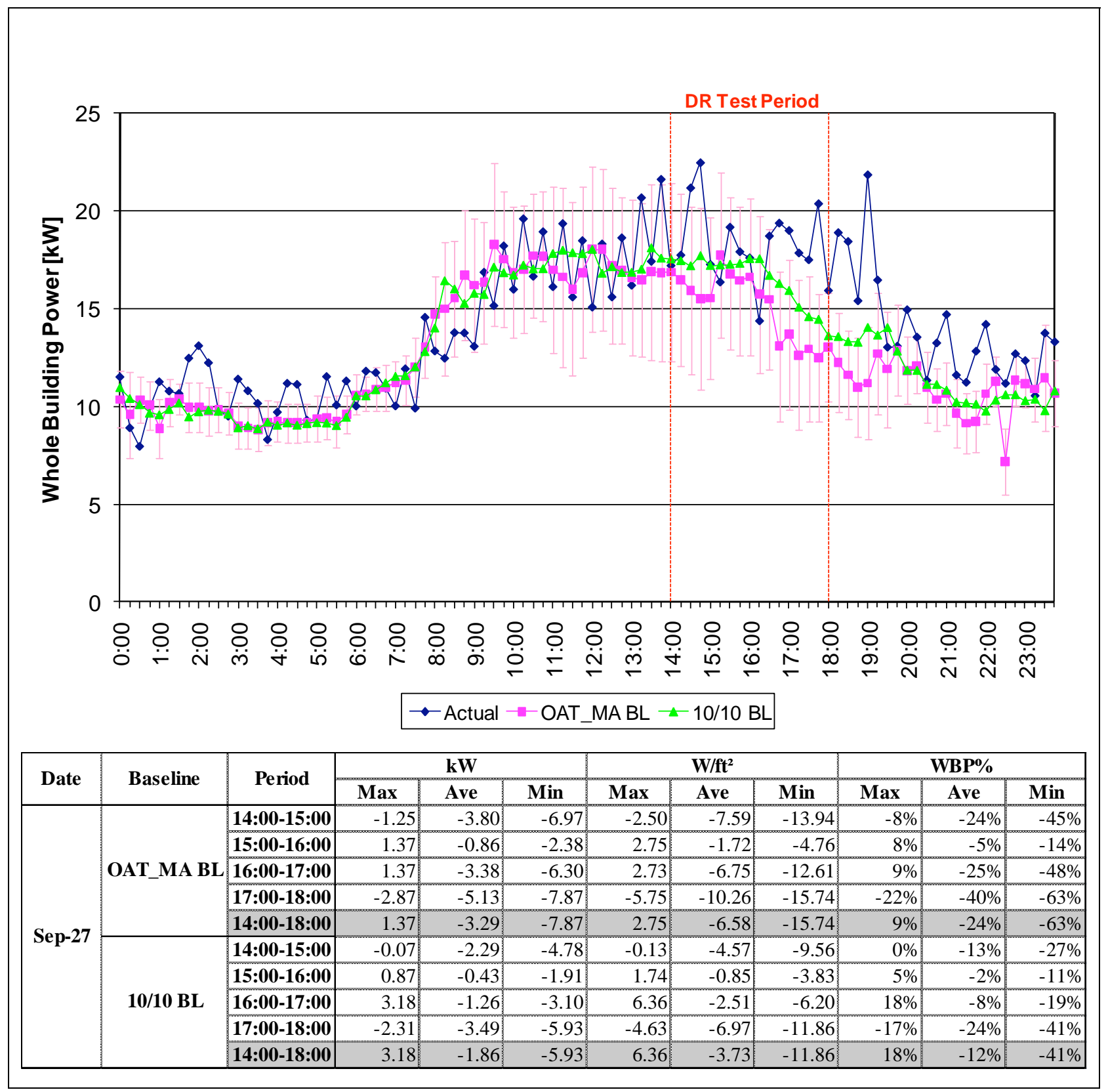


Figure C-59. Enmetric, September 28, 2010 (Max OAT: 95 ${ }^{\circ}$ )

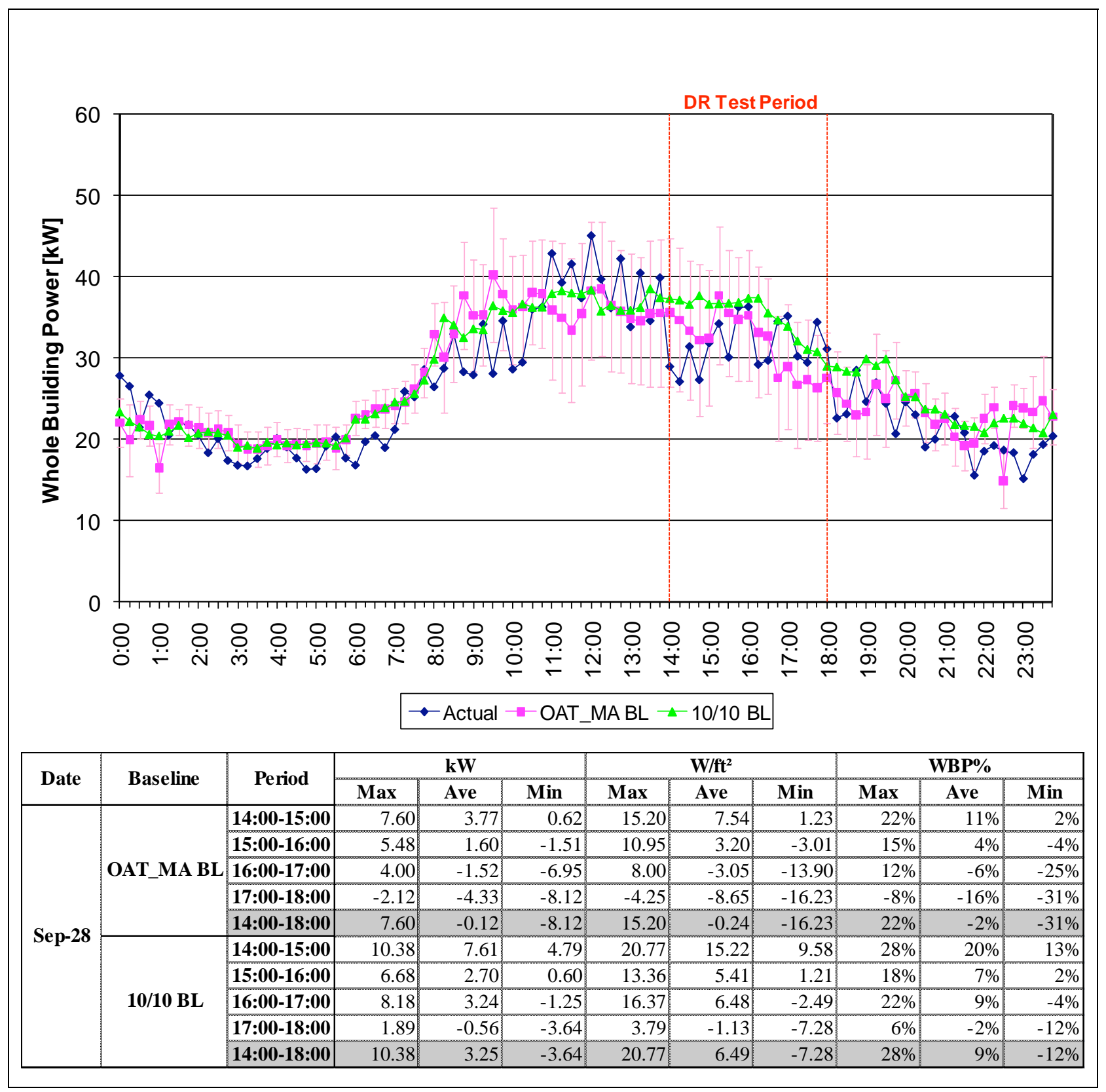


Figure C-60. Enmetric, October 13, 2010 (Max OAT: 90 ${ }^{\circ} \mathrm{F}$ )

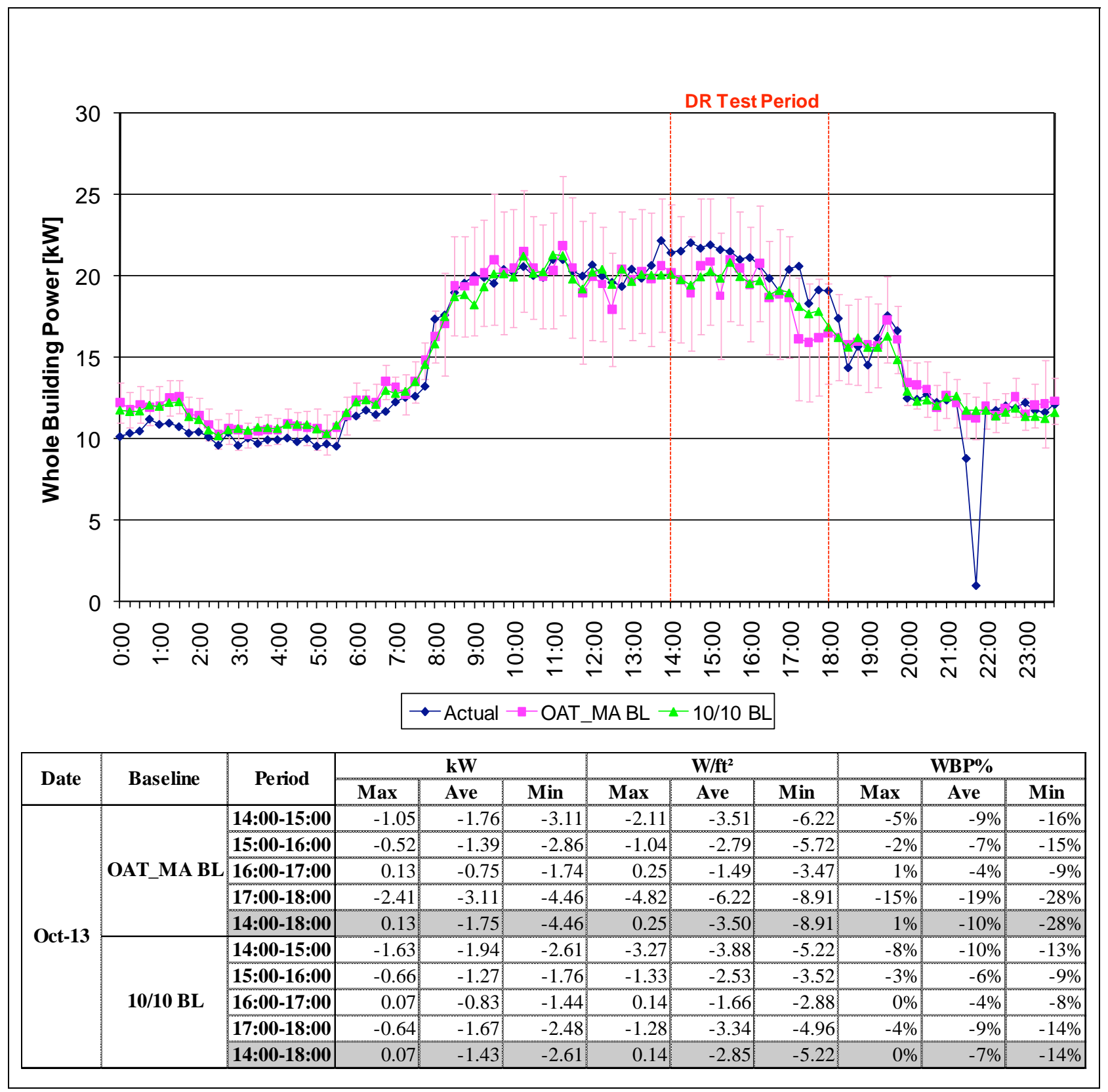




\section{Discussion}

Figure C-61. Palo Alto Site (Enmetric)

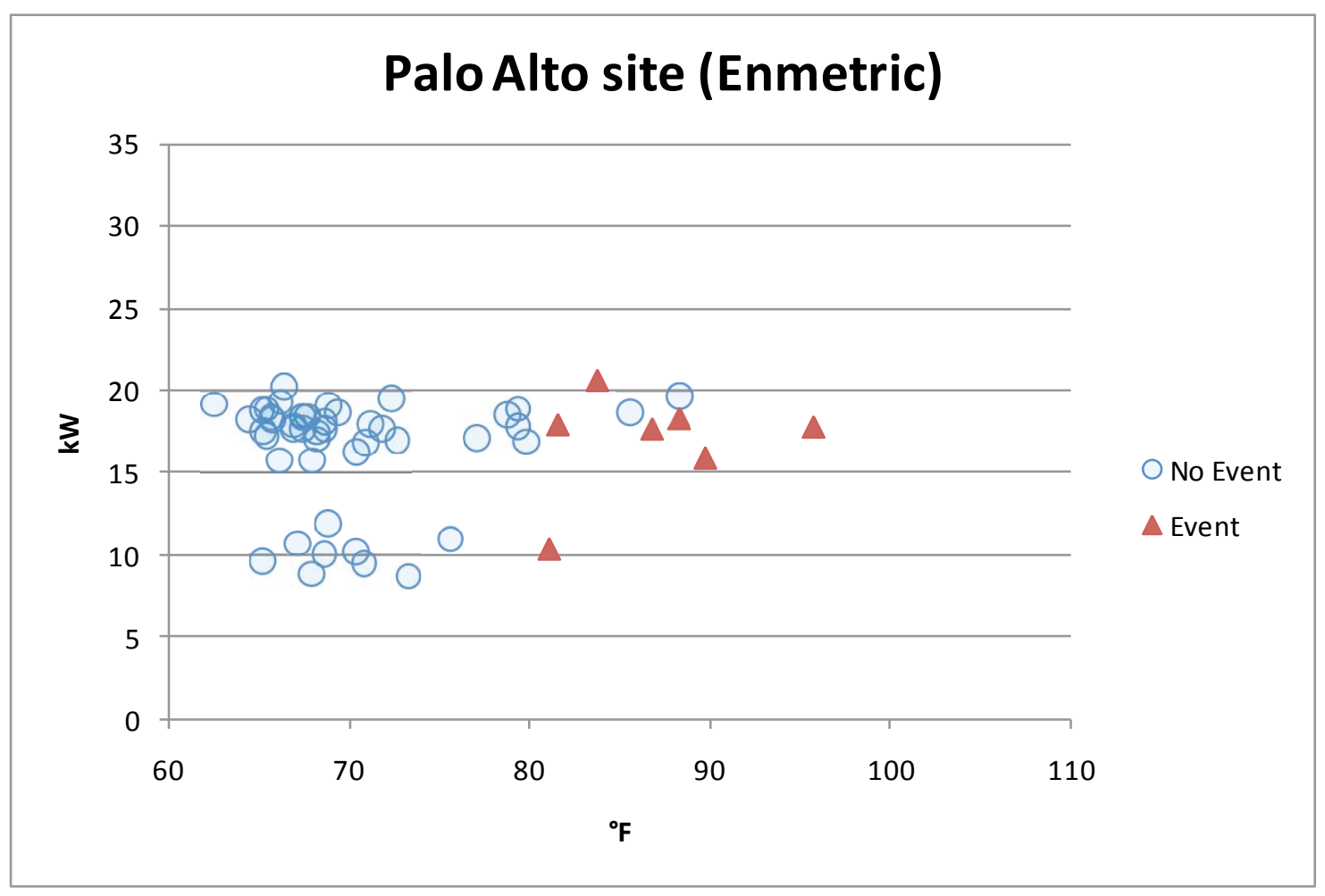

As noted in the main text, this site showed a clear distinction between Monday-Thursday operations and Friday operations. This site controlled only miscellaneous electric loads (MELs) via specialized plugstrips. The response to a DR event was immediate, but the demand reduction was much smaller than the overall demand of the site, so it was not easily discerned.

During the September 1st DR event, Enmetrics experimented with a different rule-set, such that the managed devices did not automatically turn back on after the event. They observed that the loads remained effectively off for well beyond the DR time (eventually to come back on over the next day or so).

The vendor reported that immediately prior to the September 24th event, onsite staff specifically tried to "awaken" equipment plugged into the test plugstrips that had fallen into a sleep state. It is not possible to discern if this made a difference because that was also the only event day on a Friday.

The vendor reported that for unknown reasons the October 13th event signal was received late $(\sim 4: 23 \mathrm{pm})$ and lasted until $\sim 11: 10$ am the following day. Here, the October 13th point is the only Event data point showing demand greater than $20 \mathrm{~kW}$ from $2 \mathrm{pm}$ to $6 \mathrm{pm}$. 
C.8. Site Description - Union City

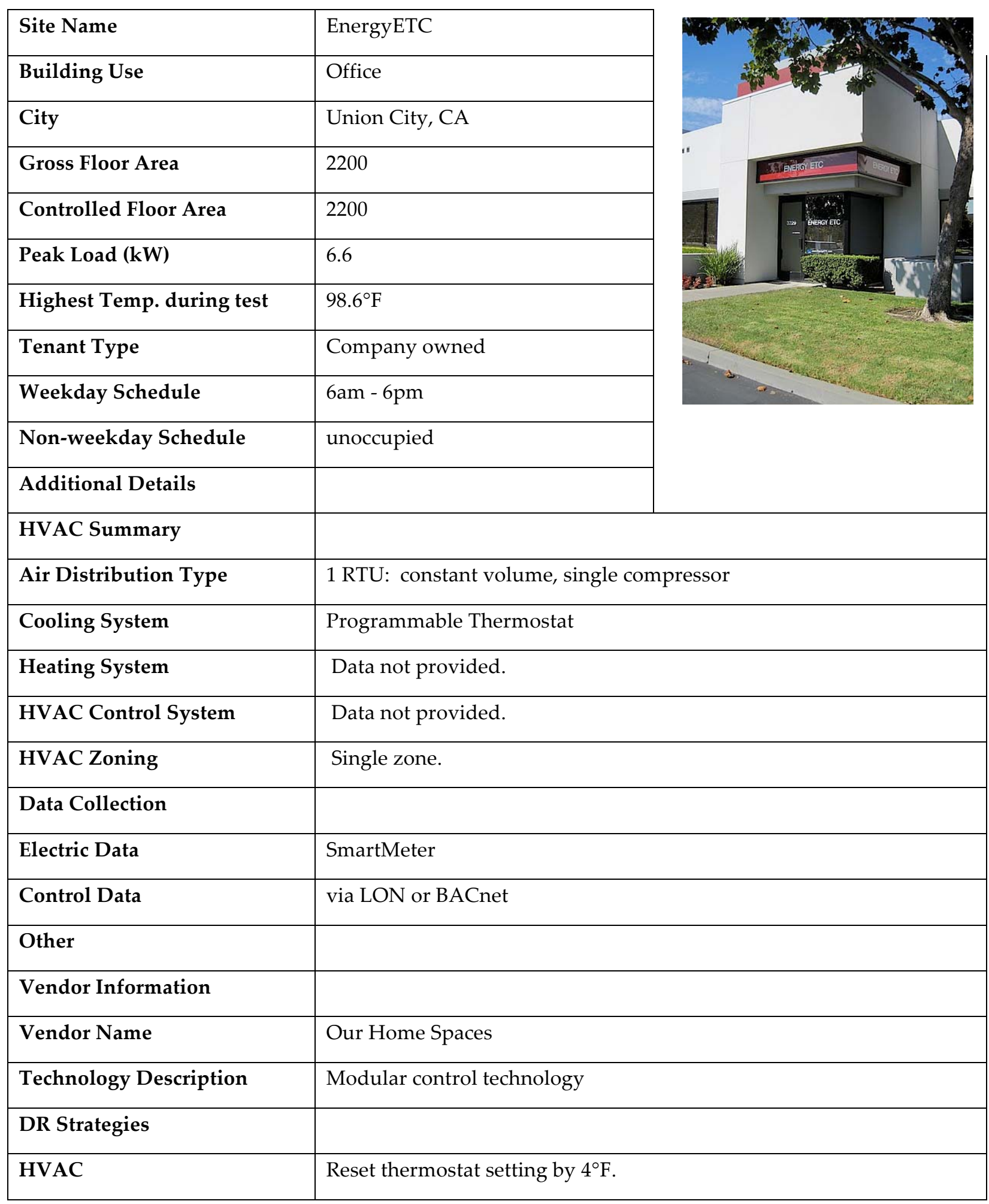


Figure C-62. EnergyETC Site Architecture

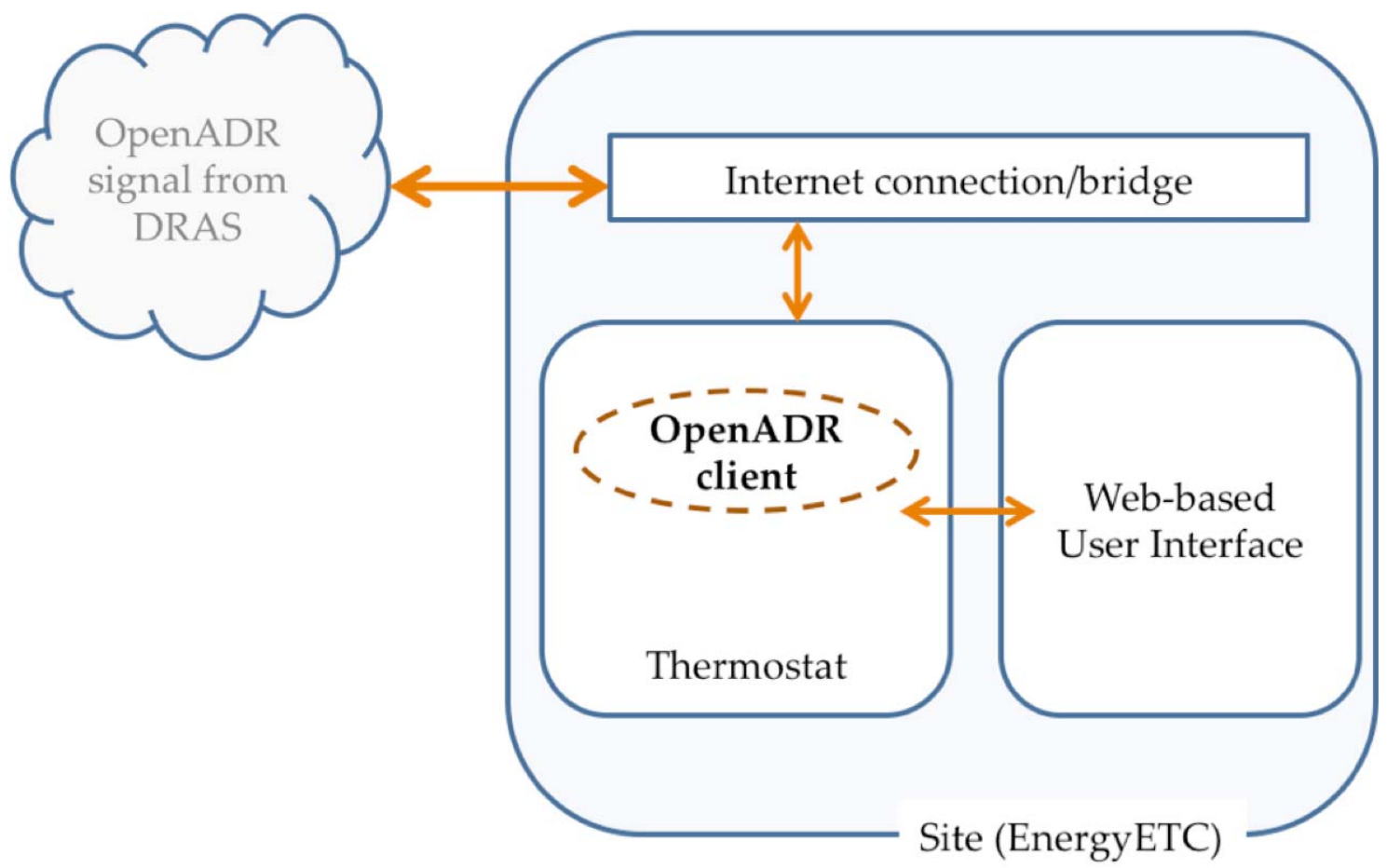

The architecture used here is the same as that used at the Novato site. The OpenADR client is physically embedded within each controlled device. Here, the device is a programmable thermostat. Upon receipt of the OpenADR signal, the thermostat's setpoint is immediately changed by four degrees Fahrenheit and returned to normal once the DR event is over.

The facility was a retrofitted warehouse space converted to office space. This meant that the building itself was lossy (not well insulated) and the HVAC appeared to be undersized for the space. Consequently, the HVAC has some difficulty maintaining the setpoint after the initial load drop. This is apparently in all but the last test, where the facility seemed to be able to maintain a reduced load more readily. 


\section{Site Data}

Figure C-63. EnergyETC, August 24, 2010 (Max OAT: 99 ${ }^{\circ} \mathrm{F}$ )

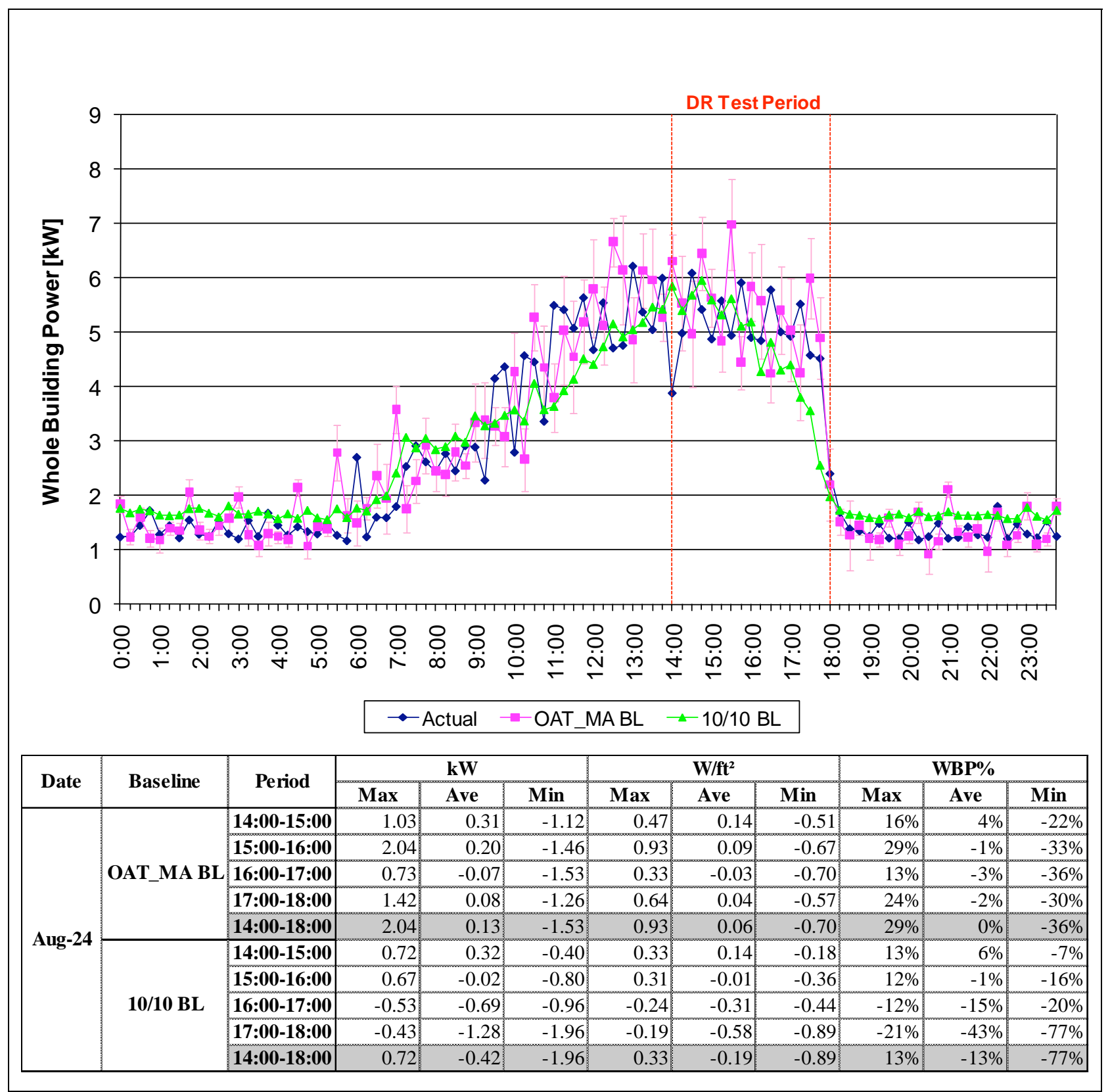


Figure C-64. EnergyETC, September 1, 2010 (Max OAT: 90 F)

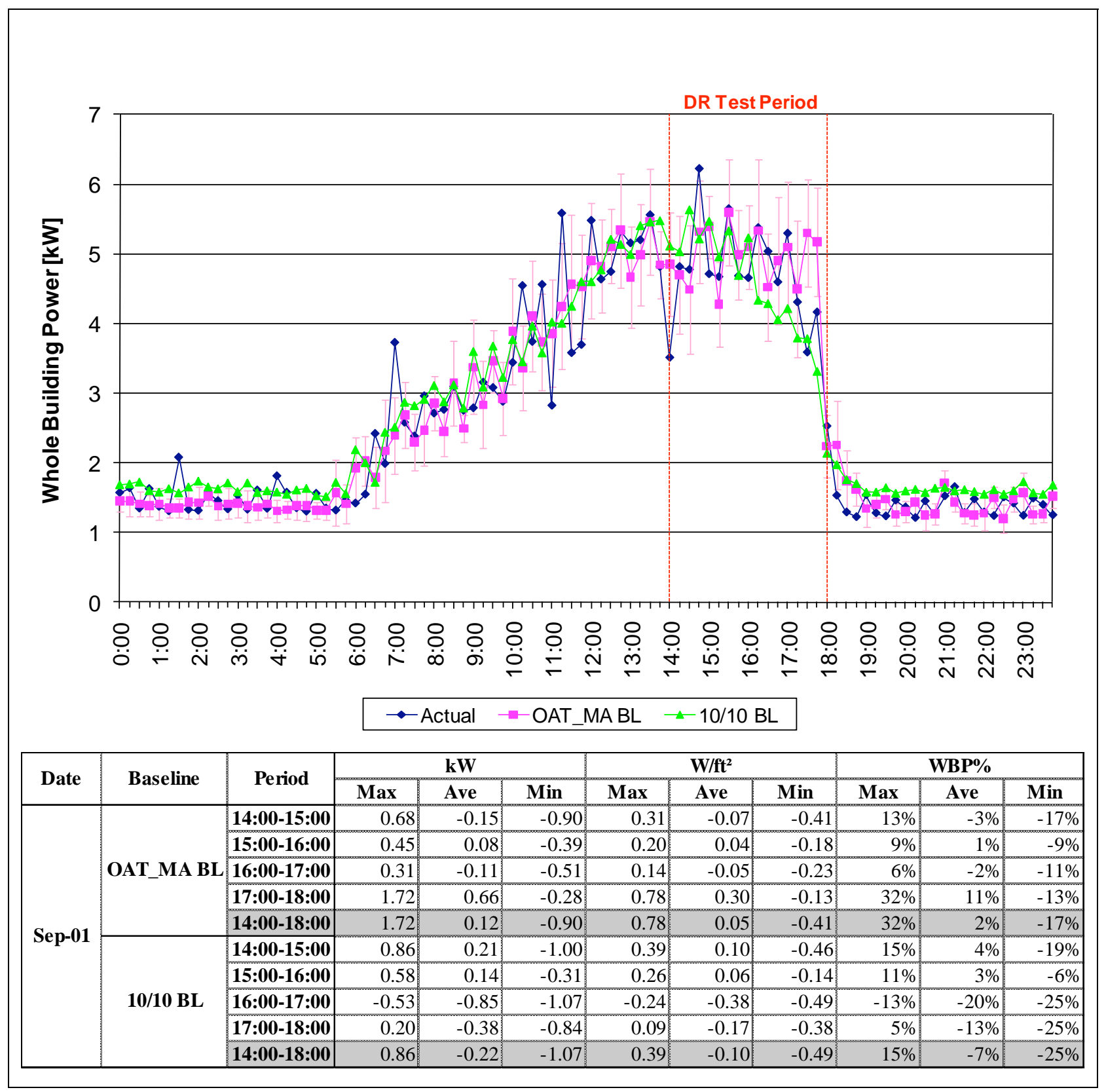


Figure C-65. EnergyETC, September 2, 2010 (Max OAT: 91ํF)

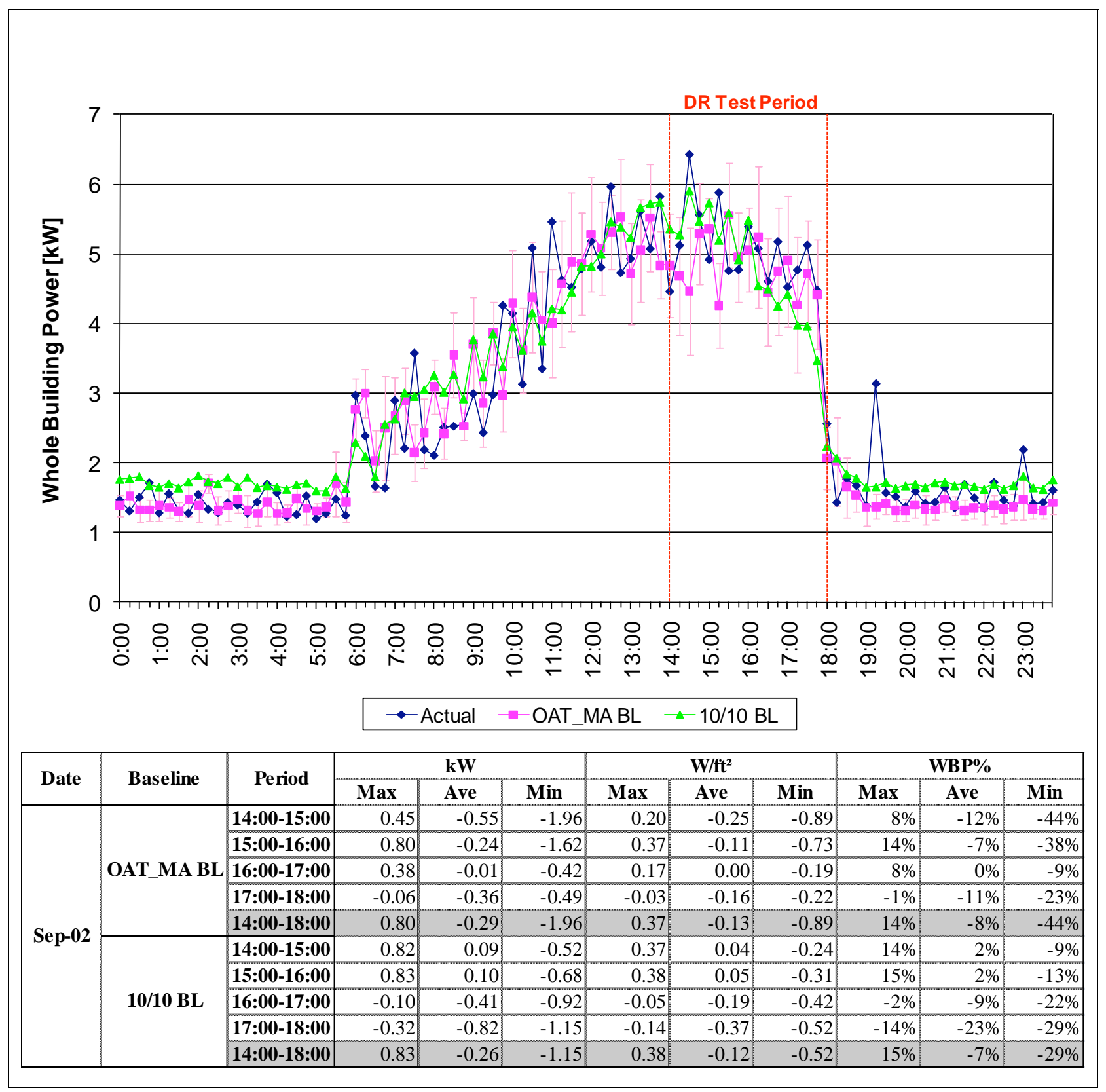


Figure C-66. EnergyETC, September 24, 2010 (Max OAT: 86 ${ }^{\circ} \mathrm{F}$ )

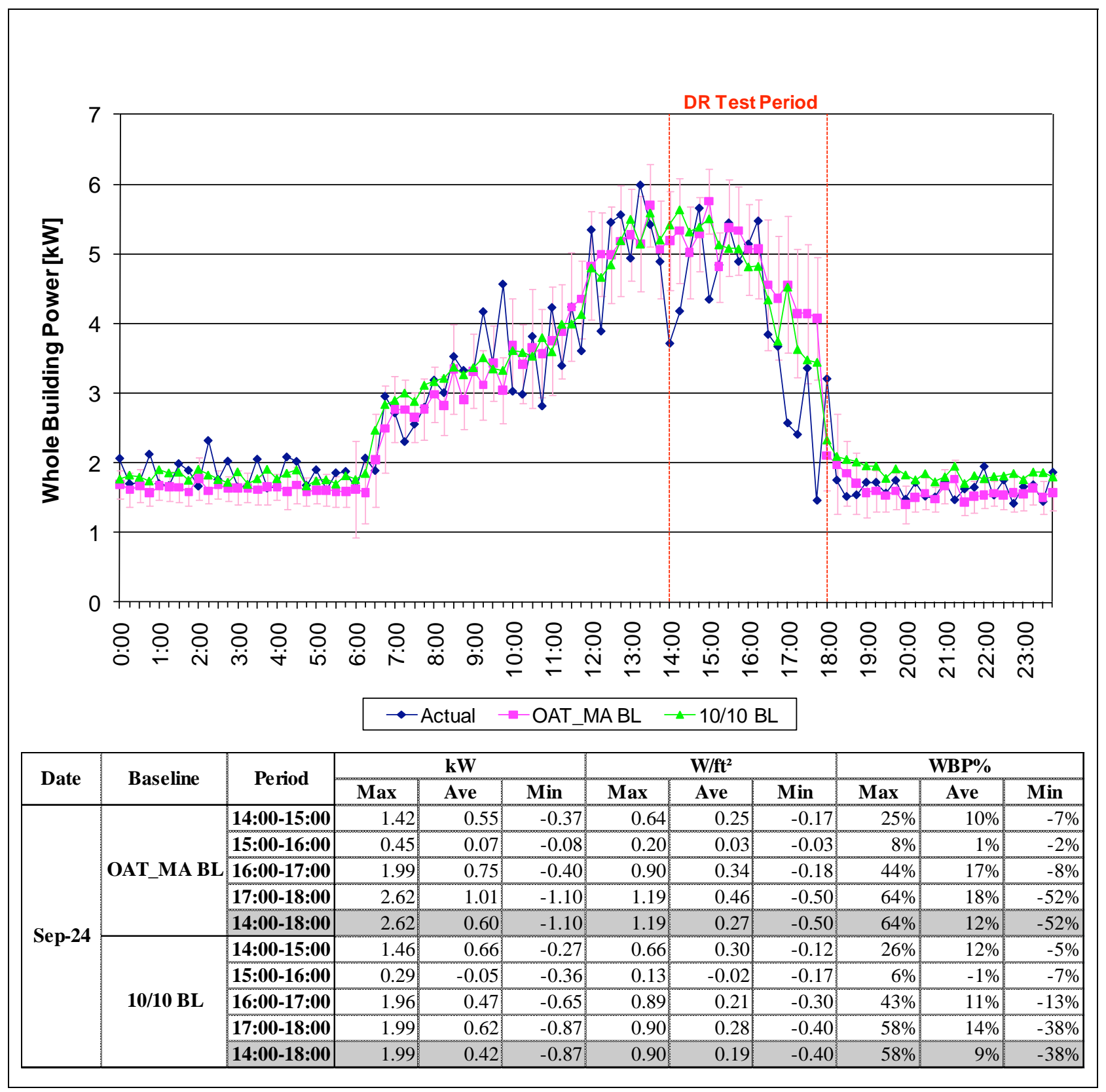


Figure C-67. EnergyETC, September 27, 2010 (Max OAT: $91^{\circ} \mathrm{F}$ )

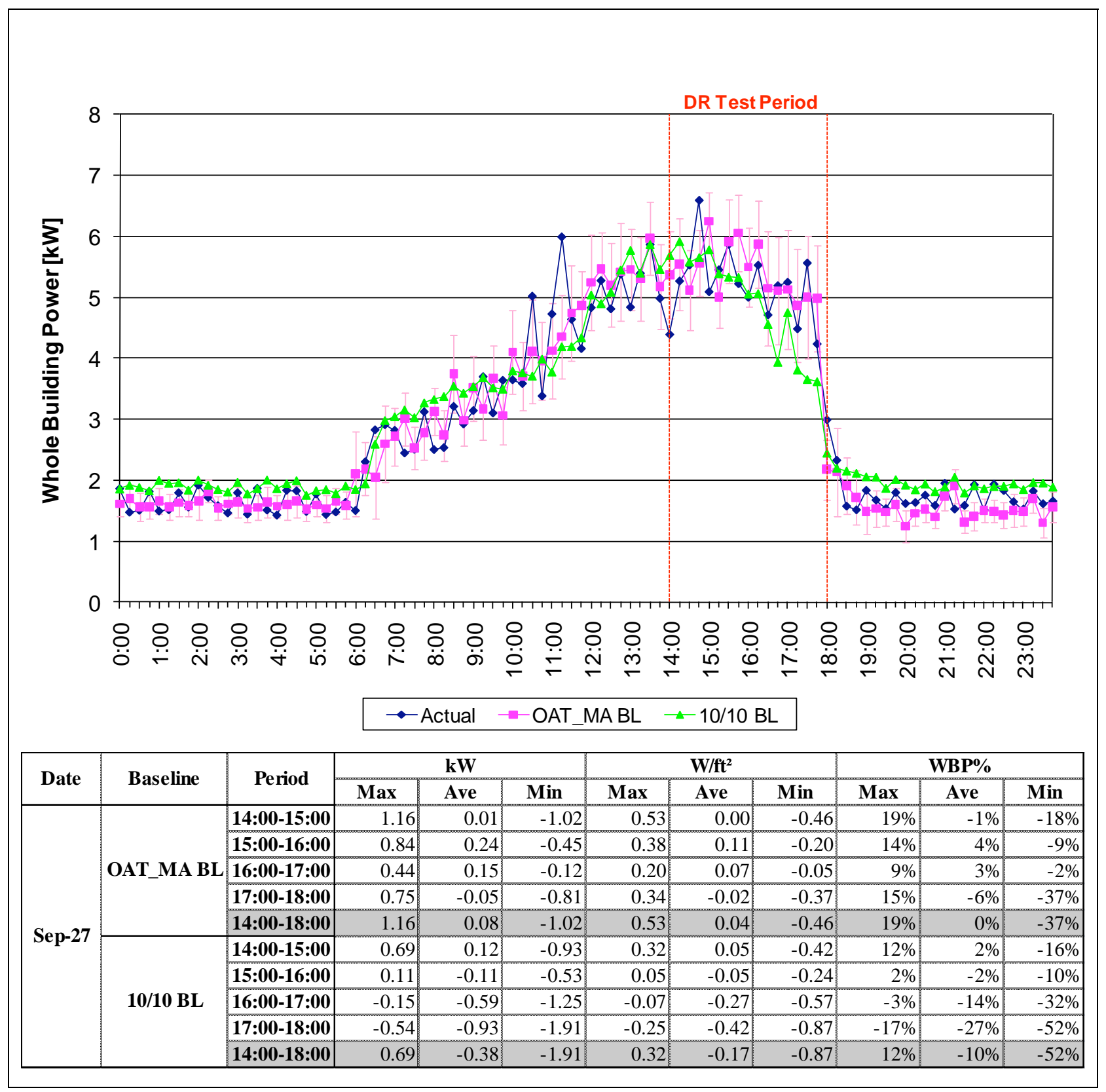


Figure C-68. EnergyETC, September 28, 2010 (Max OAT: 97 $\mathrm{F}$ )

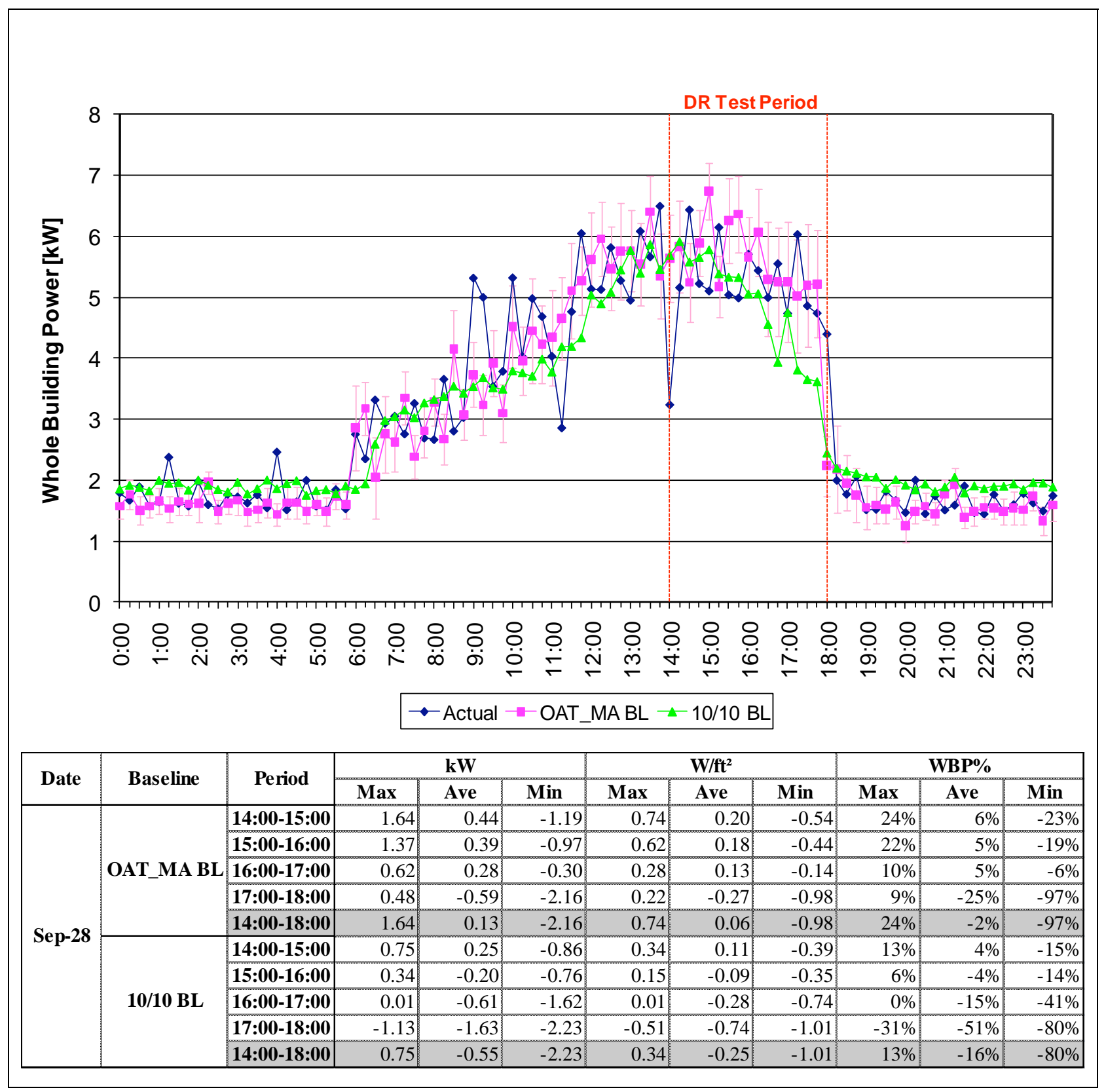


Figure C-69. EnergyETC, October 13, 2010 (Max OAT: 89 ${ }^{\circ}$ )

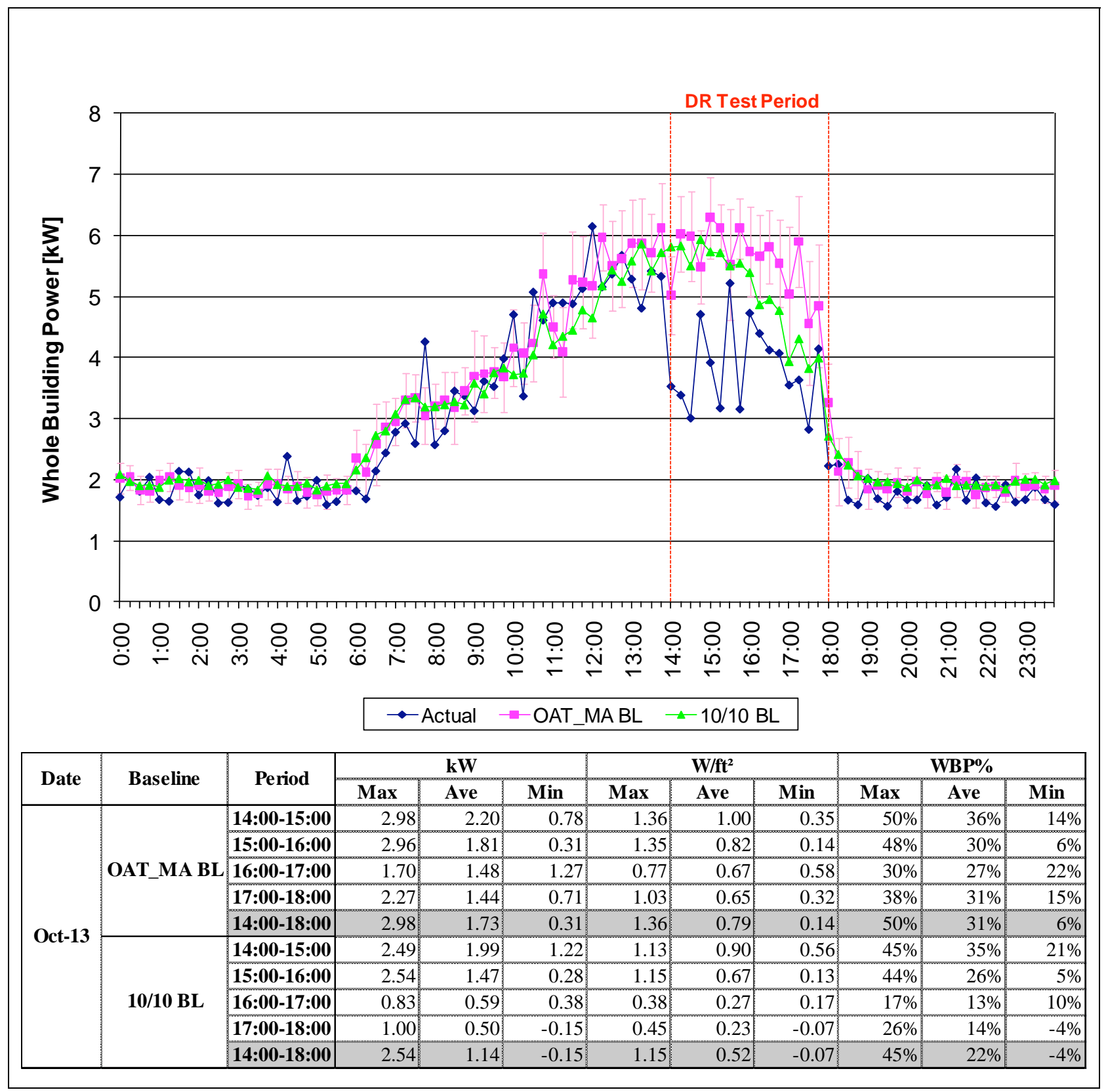




\section{Discussion}

Figure C-70. Union City Site (OHS with EnergyETC)

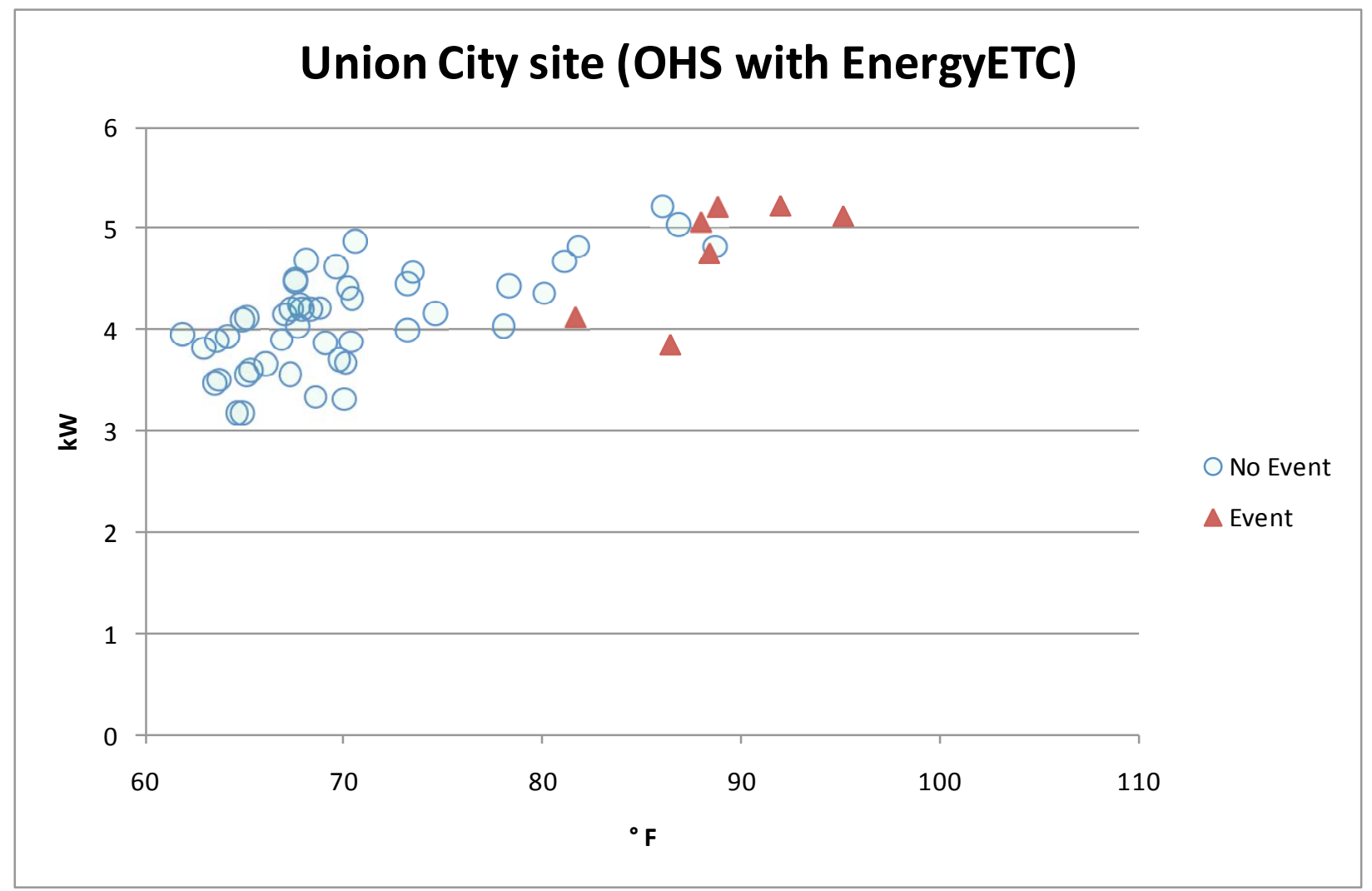

This site used the same technology as that installed on the Novato site.

Onsite staff reported that their response to the first DR event (August 24) was manual since they had a day ahead notification. That data point is the rightmost point on this graph. We requested that subsequent DR responses be automated. 


\section{C.9. Site Description - Campbell}

\begin{tabular}{|c|c|c|}
\hline Site Name & Applied Power Technologies & \\
\hline Building Use & Office & \\
\hline City & Campbell, CA & \\
\hline Gross Floor Area & 20000 (see note below) & \\
\hline Controlled Floor Area & 2070 & \\
\hline Peak Load $(k W)$ & 18.24 & \\
\hline Max. Temp. during tests & $101.9^{\circ} \mathrm{F}$ & \\
\hline Tenant Type & $\begin{array}{l}\text { Tenant with two other } \\
\text { businesses }\end{array}$ & - \\
\hline Weekday Schedule & 9am - 5pm M-F & \\
\hline Non-weekday Schedule & closed & \\
\hline Additional Details & $\begin{array}{l}\text { Not clear if reported data } \\
\text { includes power consumption } \\
\text { by two other businesses in } \\
\text { facility; one business is closed } \\
\text { on Friday, the other has } \\
\text { sporadic operations. }\end{array}$ & \\
\hline Lighting control & \multicolumn{2}{|c|}{$\begin{array}{l}\text { via installed wireless switches to control } 2 \text { banks of lighting ( } 7 \& 8 \text { fixtures, } \\
\text { respectively), } 70 \mathrm{~W} \text { per fixture }\end{array}$} \\
\hline \multicolumn{3}{|l|}{ HVAC Summary } \\
\hline Air Distribution Type & \multicolumn{2}{|l|}{2 RTUs: $20 \mathrm{~A}$ and $16 \mathrm{~A}$} \\
\hline \multicolumn{3}{|l|}{ Cooling System } \\
\hline HVAC Control System & \multicolumn{2}{|c|}{ Pulse Connector PC to IP enabled thermostats } \\
\hline HVAC Zoning & \multicolumn{2}{|l|}{ Single zone } \\
\hline \multicolumn{3}{|l|}{ Data Collection } \\
\hline Electric Data & \multicolumn{2}{|l|}{ SmartMeter } \\
\hline Control Data & \multicolumn{2}{|c|}{ Pulse Connector PC, 15 minute sliding window } \\
\hline Other & & \\
\hline
\end{tabular}




\begin{tabular}{|l|l|} 
Vendor Information & \\
\hline Vendor Name & Pulse Energy \\
\hline Technology Description & PC controller for lights \& thermostats \\
\hline DR Strategies & \\
\hline HVAC & reset thermostats to 75 deg F \\
\hline Lighting & turn off two banks of lights \\
\hline Refrigeration & N/A \\
\hline MELs & N/A \\
\hline
\end{tabular}

\section{Site Architecture}

Figure C-71. Applied Power Technologies, Inc. Site Architecture

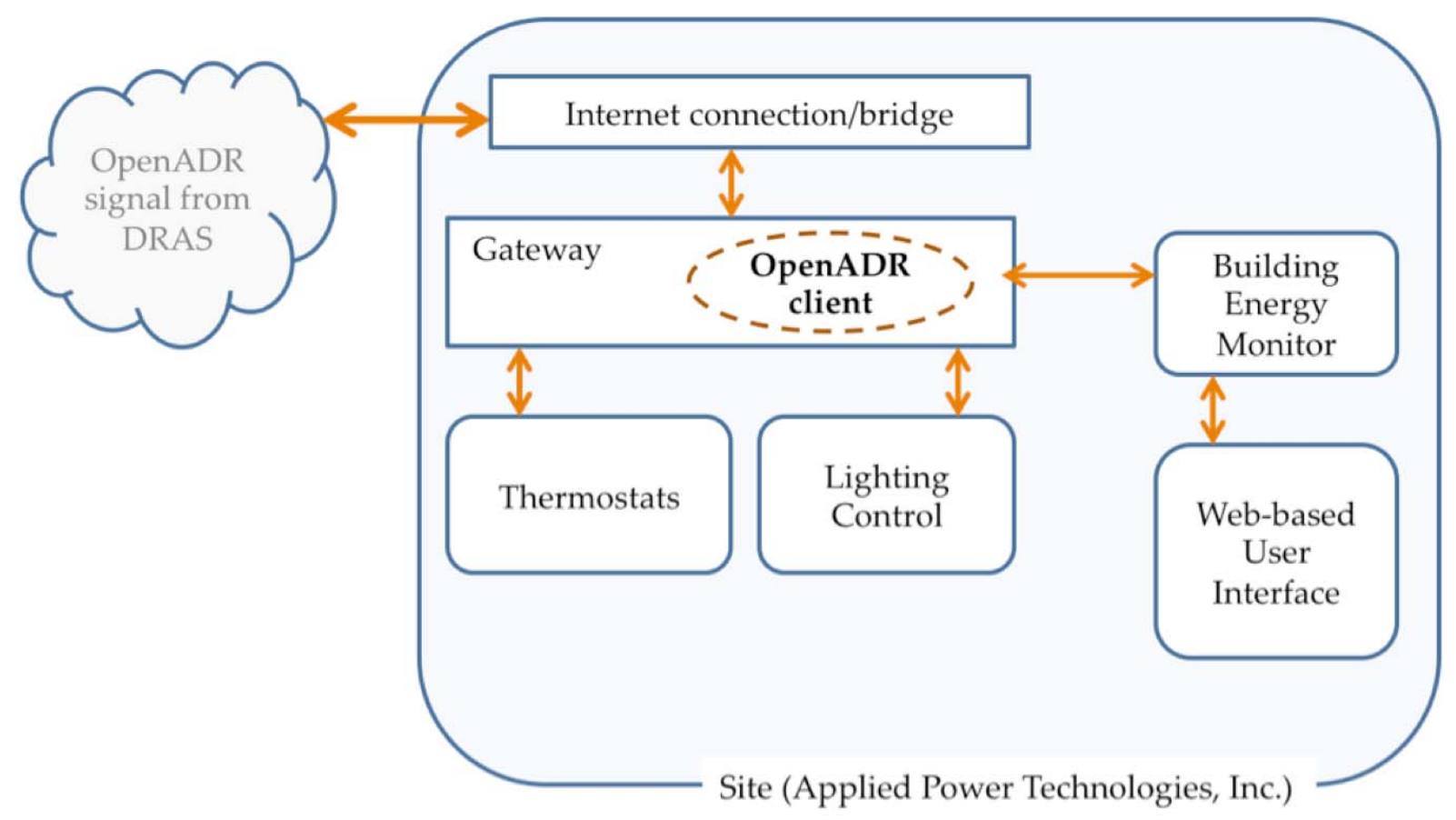

At this site, a gateway translated the DR event signal to the established strategies and relayed them to wireless lighting controls and a WiFi enabled thermostat. Simultaneously, Pulse Energy's Building Energy Monitor watched local power consumption to verify that the strategies were working. At the beginning of testing, the Building Energy Monitor allowed operators to promptly identify an incorrect start of the site's air conditioning when the temperature set point should have been adjusted to reduce air conditioning operations. 


\section{Site Data}

Figure C-72. PulseEnergy, August 24, 2010 (Max OAT: 102 ${ }^{\circ} \mathrm{F}$ )

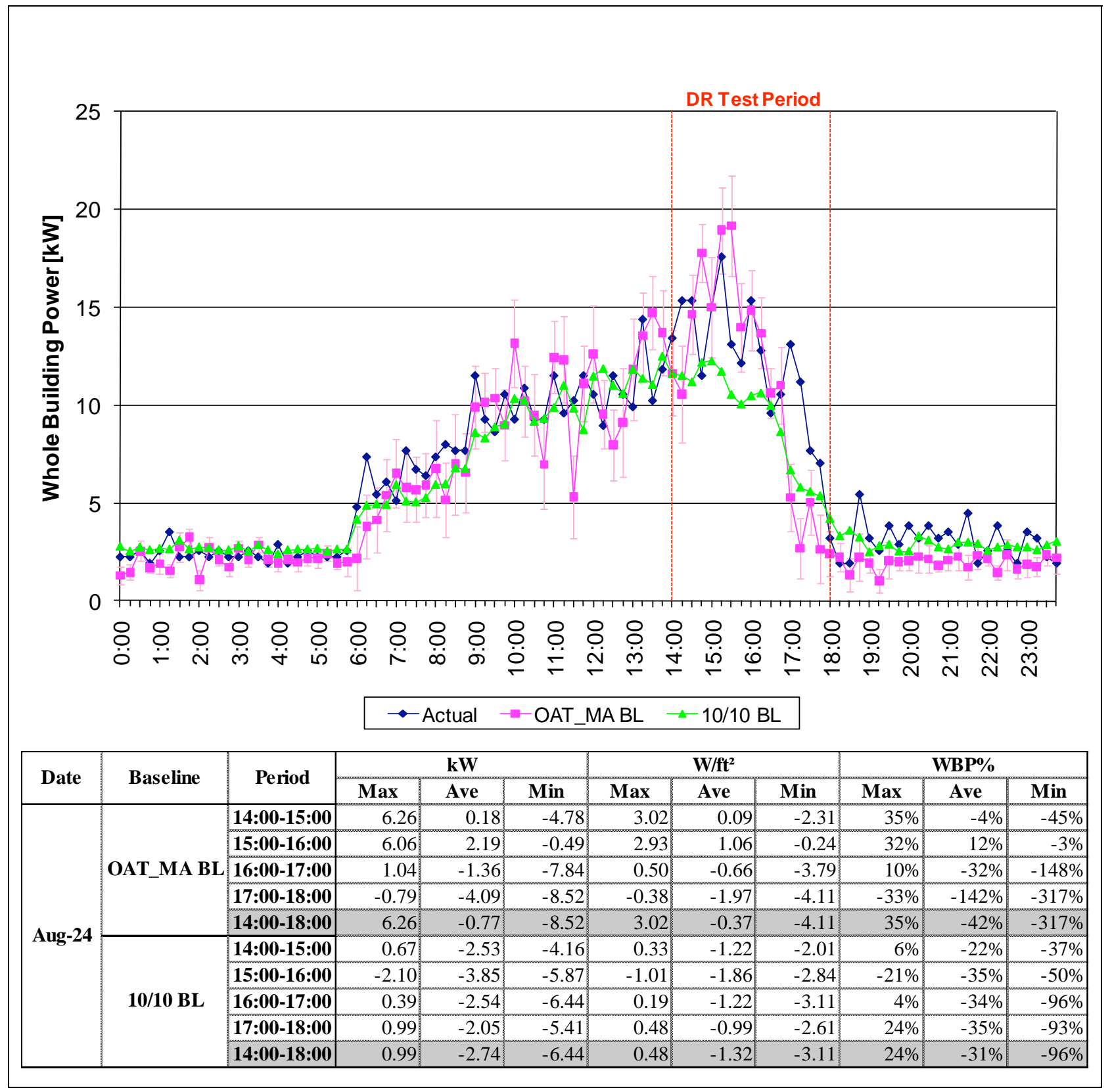


Figure C-73. PulseEnergy, September 1, 2010 (Max OAT: 93 $\mathrm{F}$ )

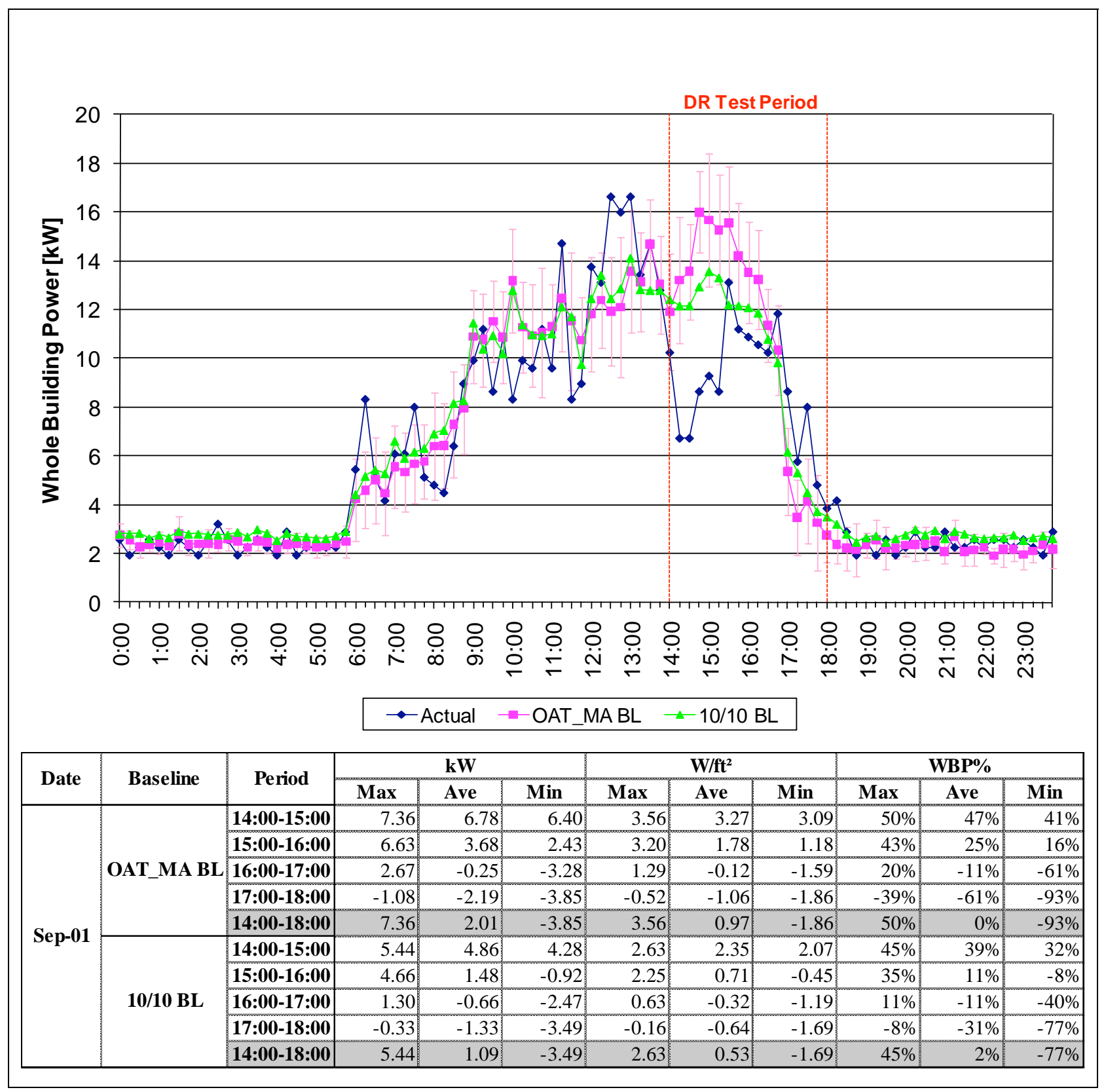


Figure C-74. PulseEnergy, September 2, 2010 (Max OAT: 96 ${ }^{\circ} \mathrm{F}$ )

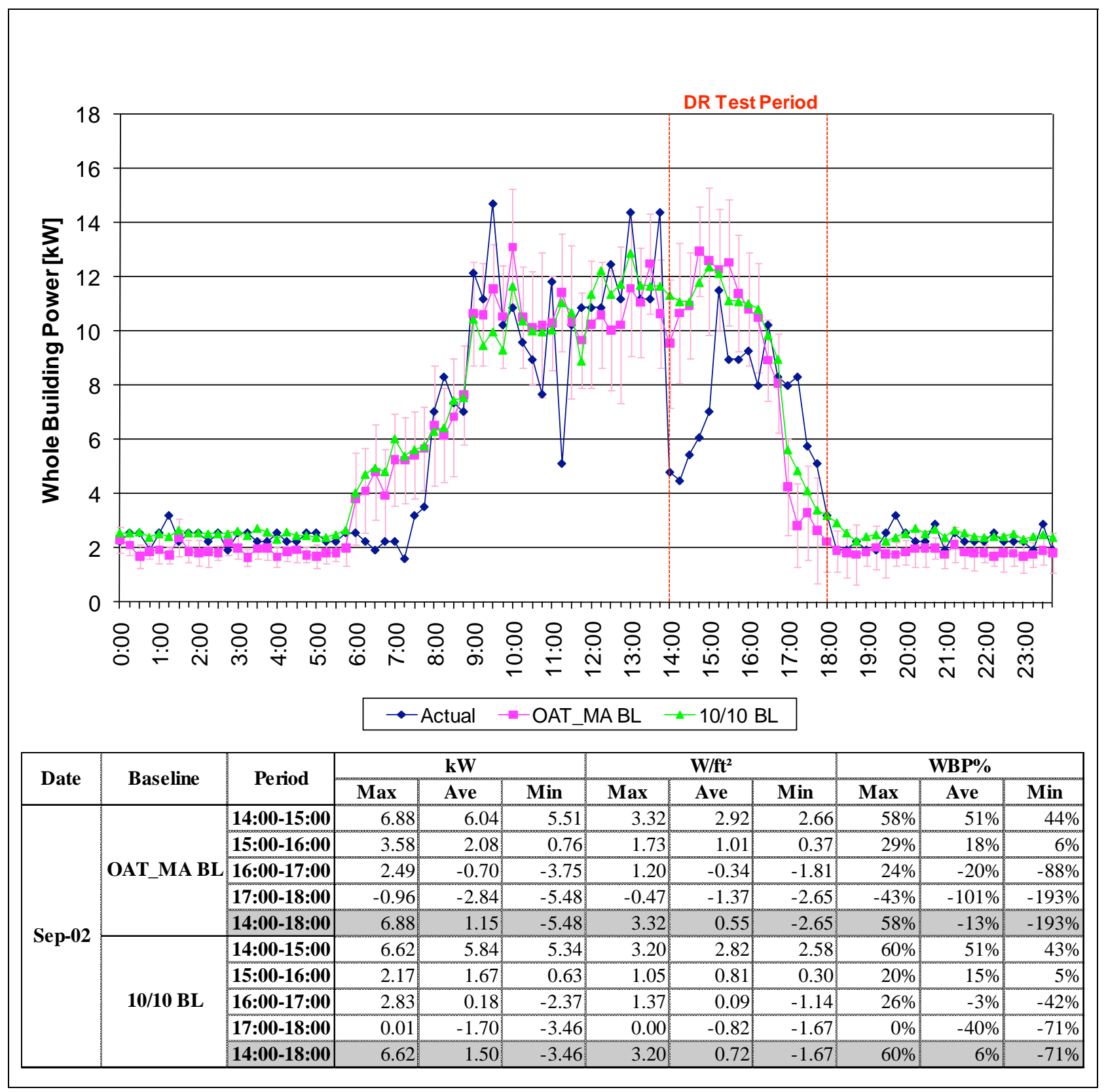


Figure C-75. PulseEnergy, September 24, 2010 (Max OAT: 86 F)

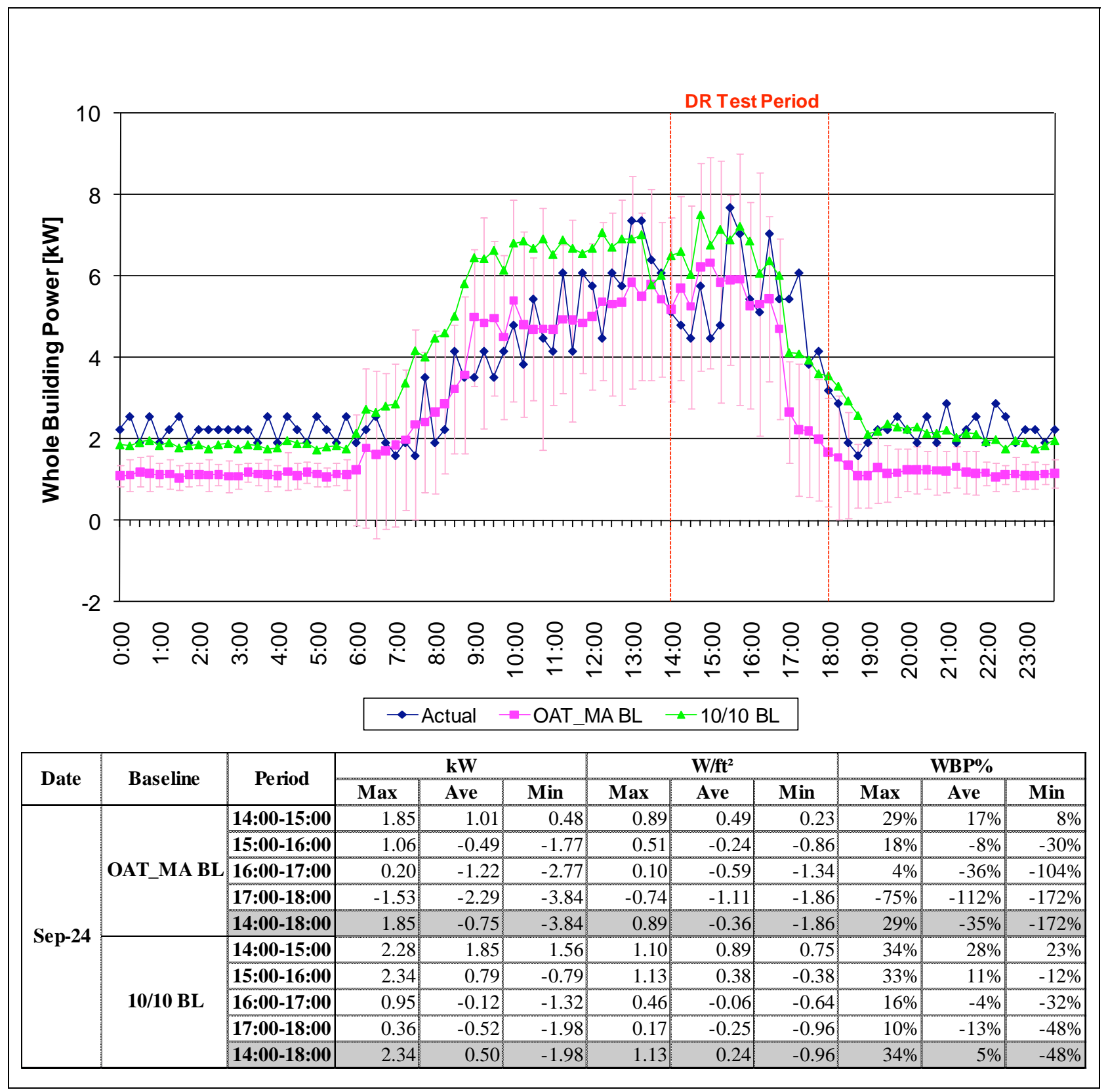


Figure C-76. PulseEnergy, September 27, 2010 (Max OAT: 96 F)

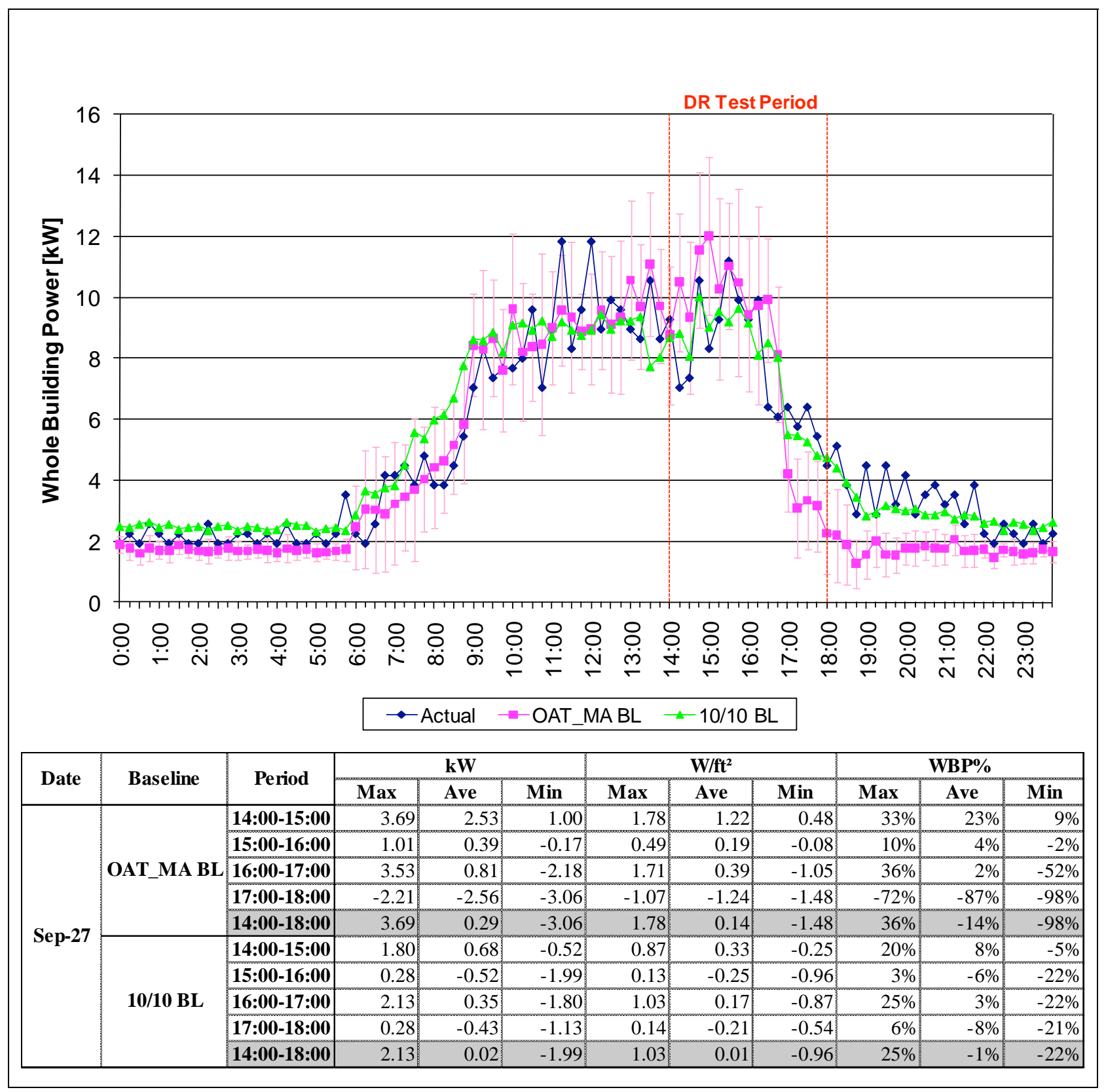


Figure C-77. PulseEnergy, September 28, 2010 (Max OAT: 99 F)

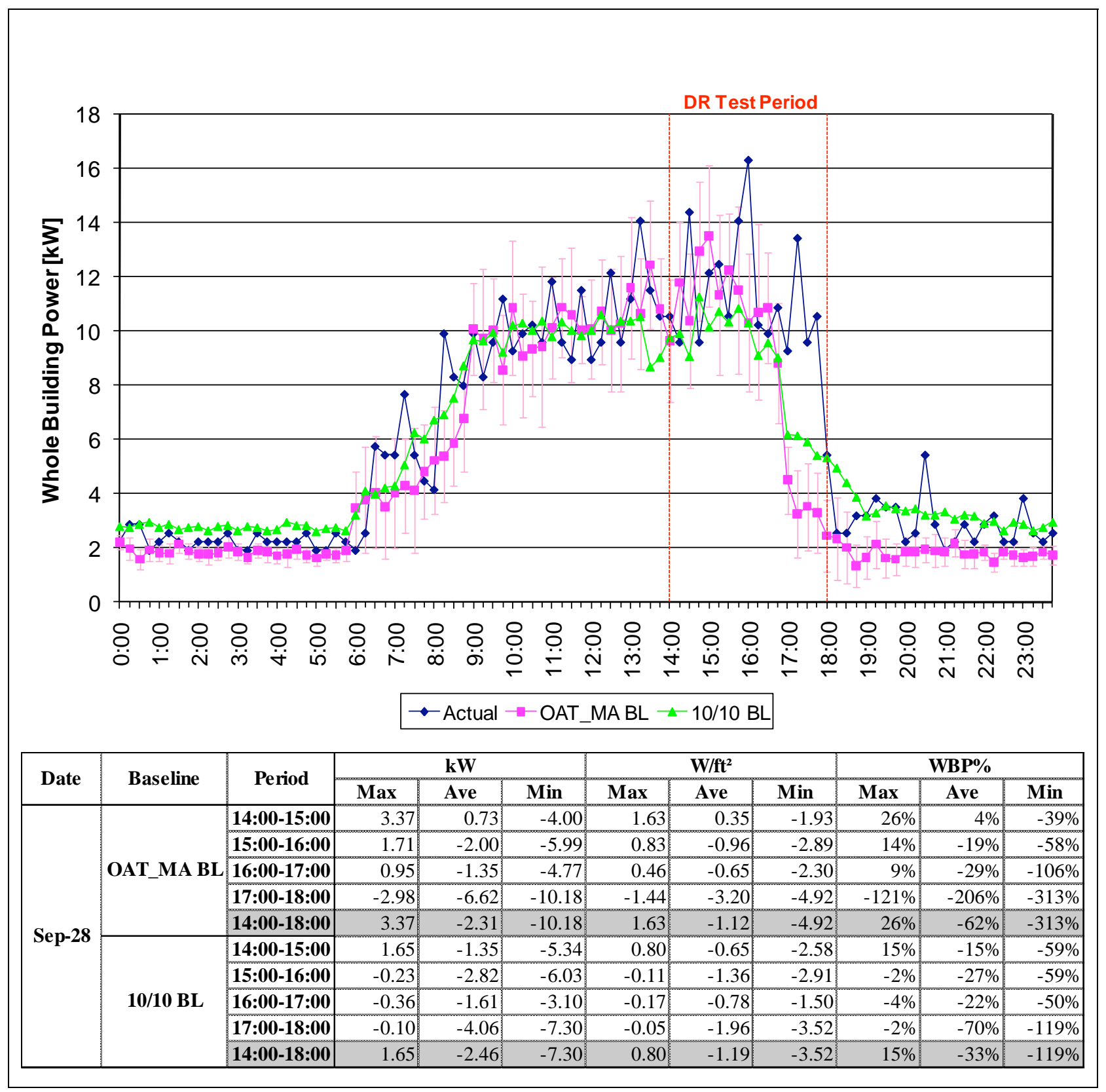


Figure C-78. PulseEnergy, October 13, 2010 (Max OAT: 92 ${ }^{\circ} \mathrm{F}$ )

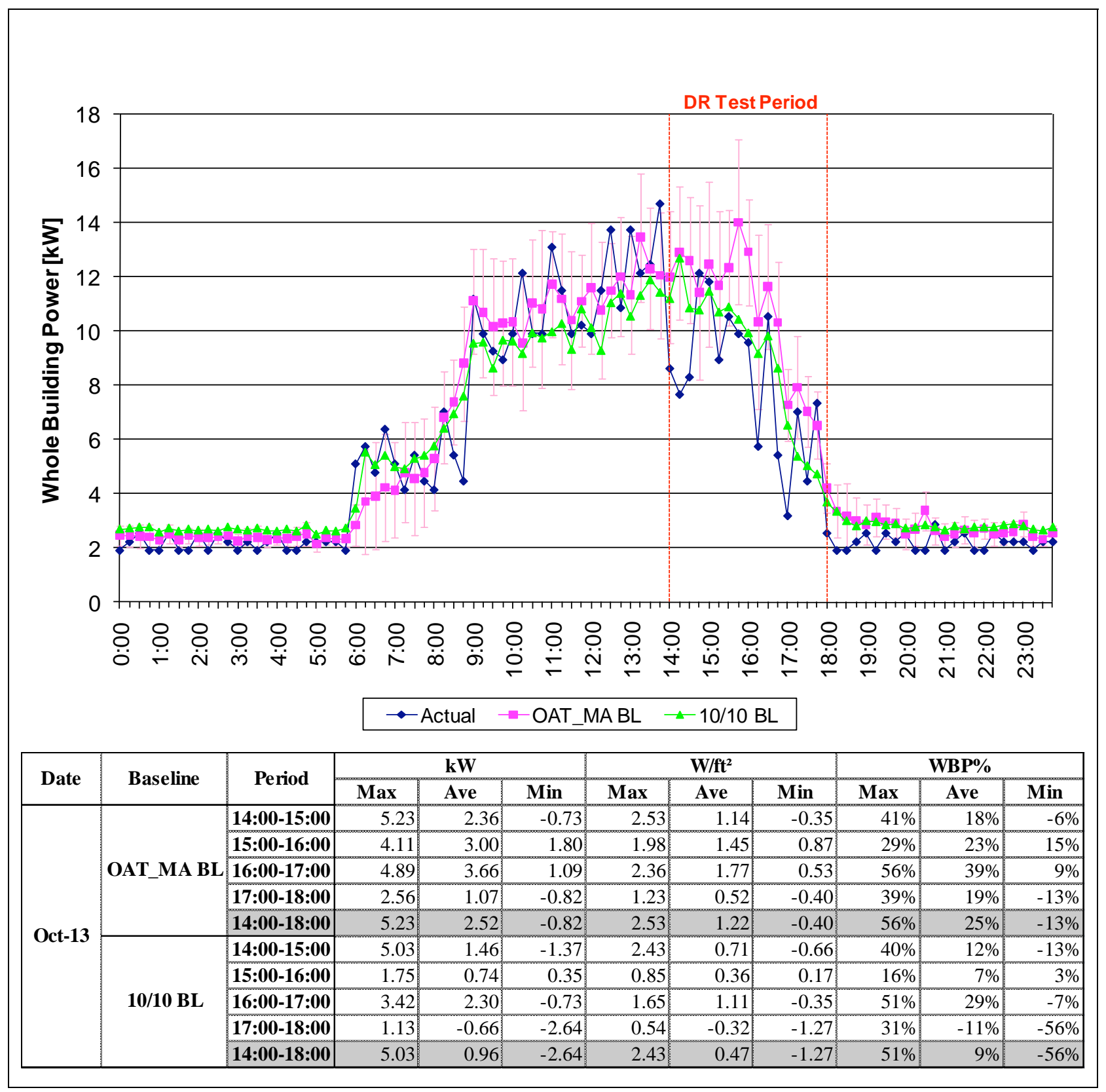




\section{Discussion}

Figure C-79. Campbell Site (Pulse Energy)

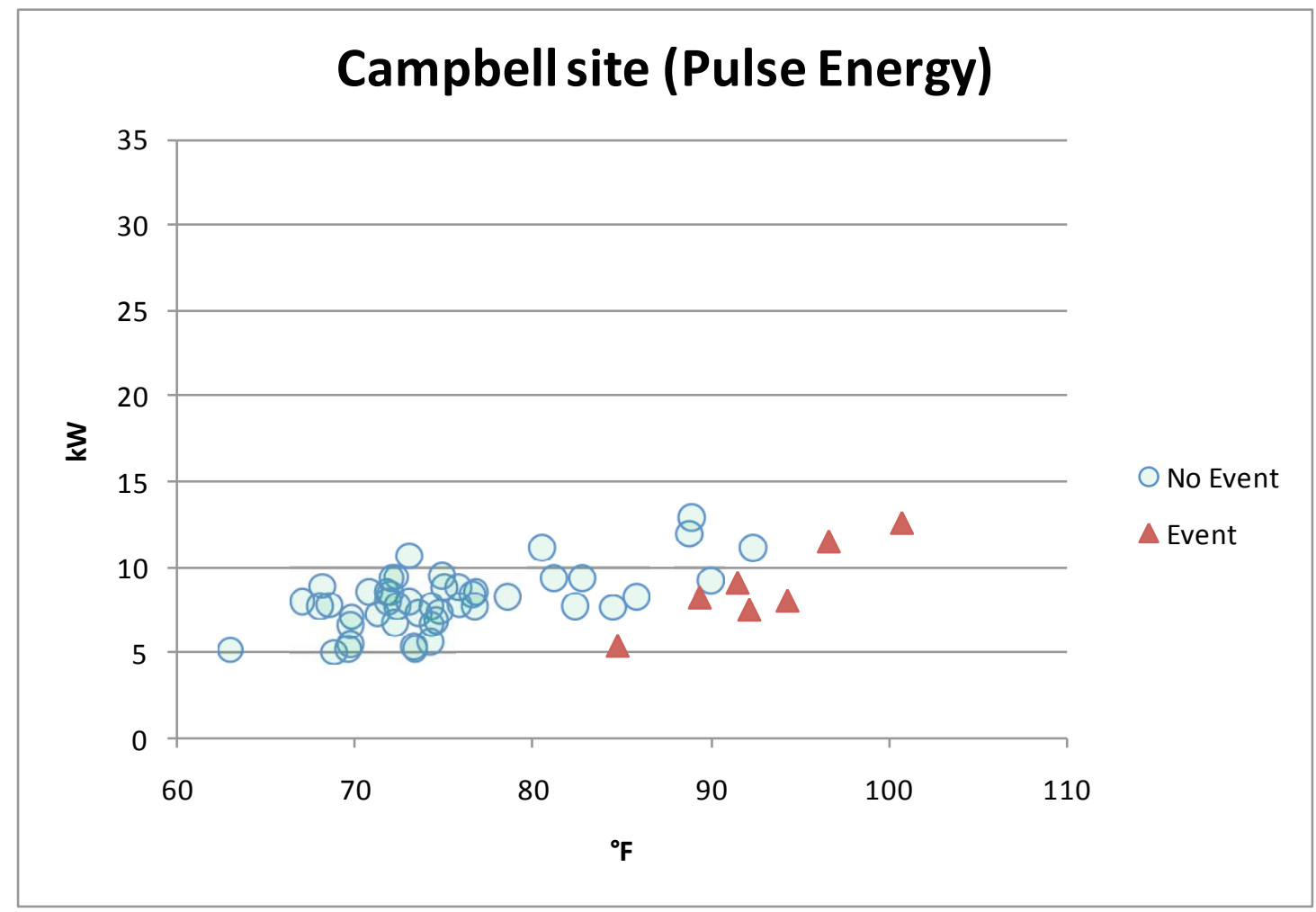

As noted above, the vendor reported that they "discovered too late that [they] had misconfigured the daytime setpoint on the thermostat prior to the demand response event. The cooling setpoint was set to 78 prior to the event (it should have been 72), and the DR cooling setpoint was set to 75, so [they] were actually trying to cool the building during the [August 24th] DR event." This event is represented by the rightmost point on the graph above. The vendor and site occupants fixed this problem as soon as they discovered it (on August 24th). 


\section{C.10. Site Description - Salinas}

\begin{tabular}{|c|c|c|}
\hline Site Name & Salinas Meat, Inc. & CArgate \\
\hline Building Use & $\begin{array}{l}\text { Meat distribution and retail } \\
\text { sales }\end{array}$ & 3 \\
\hline City & Salinas, CA & \\
\hline Gross Floor Area & 6000 & \\
\hline Controlled Floor Area & 6000 & \\
\hline Peak Load (kW) & 25.8 & \\
\hline Max. Temp. during test & $85.8^{\circ} \mathrm{F}$ & \\
\hline Tenant Type & Company owned & \\
\hline Weekday Schedule & 7:30am - 6:30 pm M-F & \\
\hline Non-weekday Schedule & 7:30am - 1:30pm Saturday & \\
\hline Additional Details & $\begin{array}{l}\text { Main freezer has } 10 \mathrm{hp} \\
\text { compressor }(30 \times 60) \text {, other } \\
\text { freezers are } 12 \times 30 \text { and } \\
12 \times 15\end{array}$ & \\
\hline \multicolumn{3}{|l|}{ HVAC Summary } \\
\hline Air Distribution Type & \multicolumn{2}{|c|}{ one constant volume, single compressor 5 ton rooftop unit } \\
\hline \multicolumn{3}{|l|}{ Cooling System } \\
\hline \multicolumn{3}{|l|}{ Heating System } \\
\hline HVAC Control System & \multicolumn{2}{|l|}{1 analog 1 digital thermostat } \\
\hline \multicolumn{3}{|l|}{ HVAC Zoning } \\
\hline \multicolumn{3}{|l|}{ Data Collection } \\
\hline Electric Data & \multicolumn{2}{|l|}{ Dent Scout 18} \\
\hline \multicolumn{3}{|l|}{ Control Data } \\
\hline Other & \multicolumn{2}{|c|}{$\begin{array}{l}\text { The main freezer has a } 10 \text { horsepower compressor (approx } 30 \times 60 \text { ), } \\
\text { another is } 12 \times 30 \text {, and a third is about } 12 \times 15 \text {. }\end{array}$} \\
\hline \multicolumn{3}{|l|}{ Vendor Information } \\
\hline Vendor Name & \multicolumn{2}{|l|}{ HD Supply; Universal Devices } \\
\hline Technology Description & \multicolumn{2}{|c|}{$\begin{array}{l}\text { Lighting and plug load controllers, programmable thermostats, EMCS } \\
\text { (Universal Devices) }\end{array}$} \\
\hline
\end{tabular}




\begin{tabular}{|l|l|}
\hline DR Strategies & \\
\hline HVAC & Change thermostat set point to $78^{\circ} \mathrm{F}$ \\
\hline Lighting & $\begin{array}{l}\text { Turn off office lights, outside lights: lights include CFLs, fluorescent, T- } \\
12 s, \text { and incandescent }\end{array}$ \\
\hline Refrigeration & $50 \%$ duty cycle for freezers during DR event \\
\hline MELs & Turned off water cooler, microwave \\
\hline Other & \\
\hline
\end{tabular}

\section{Site Architecture}

Figure C-80. Salinas Meats, Inc. Site Architecture

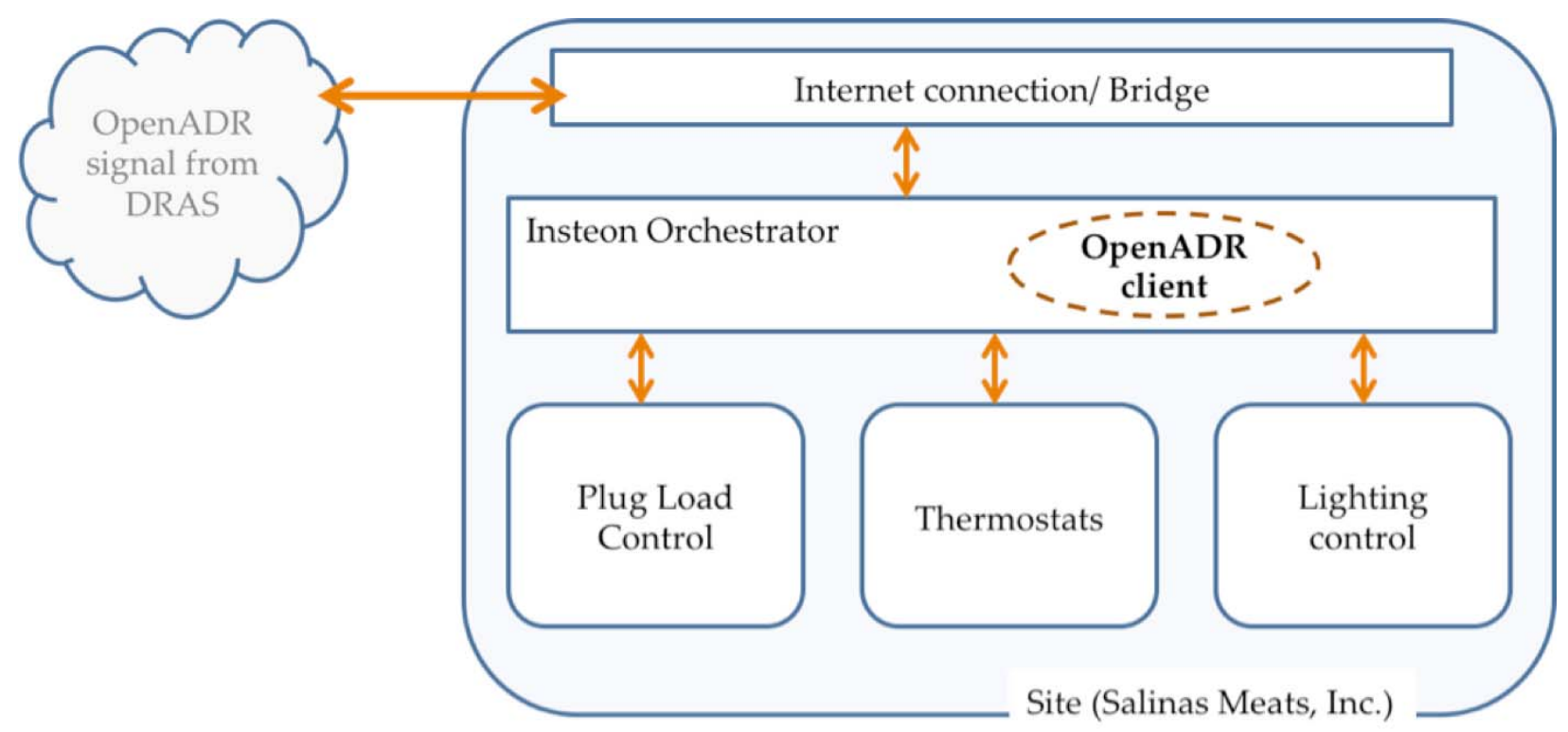

At this site, the OpenADR client was incorporated in the onsite Insteon Orchestrator. This provided the coordination of the response to a DR event. Only one test was conducted at this site, and the data recorder appears to have maintained a constant value for several days prior to and including part of the test day. 


\section{Site Data}

Figure C-81. Salinas, November 3, 2010 (Max OAT: $86^{\circ} \mathrm{F}$ )

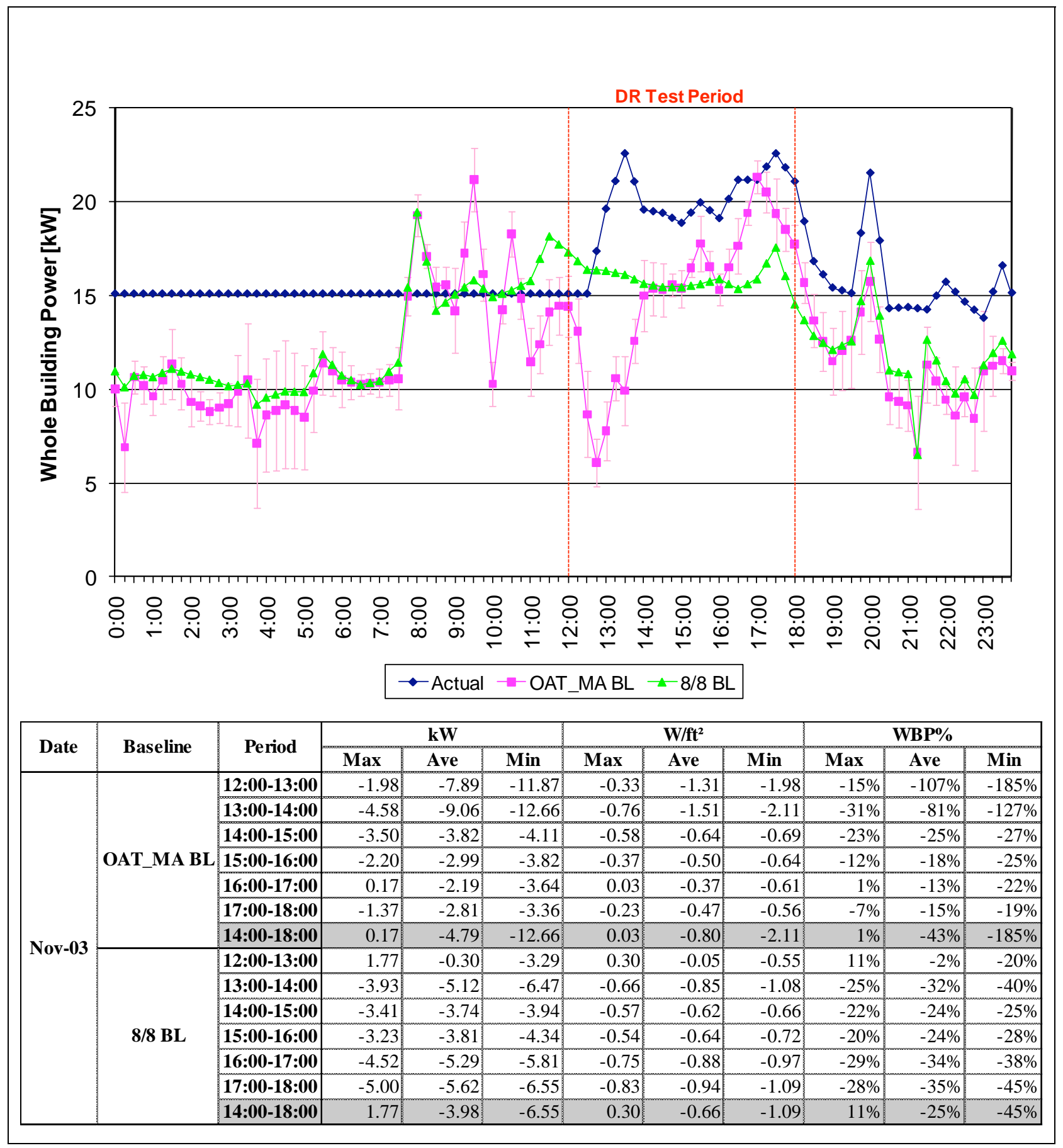




\section{Discussion}

Figure C-82. Salinas Site (HD Supply)

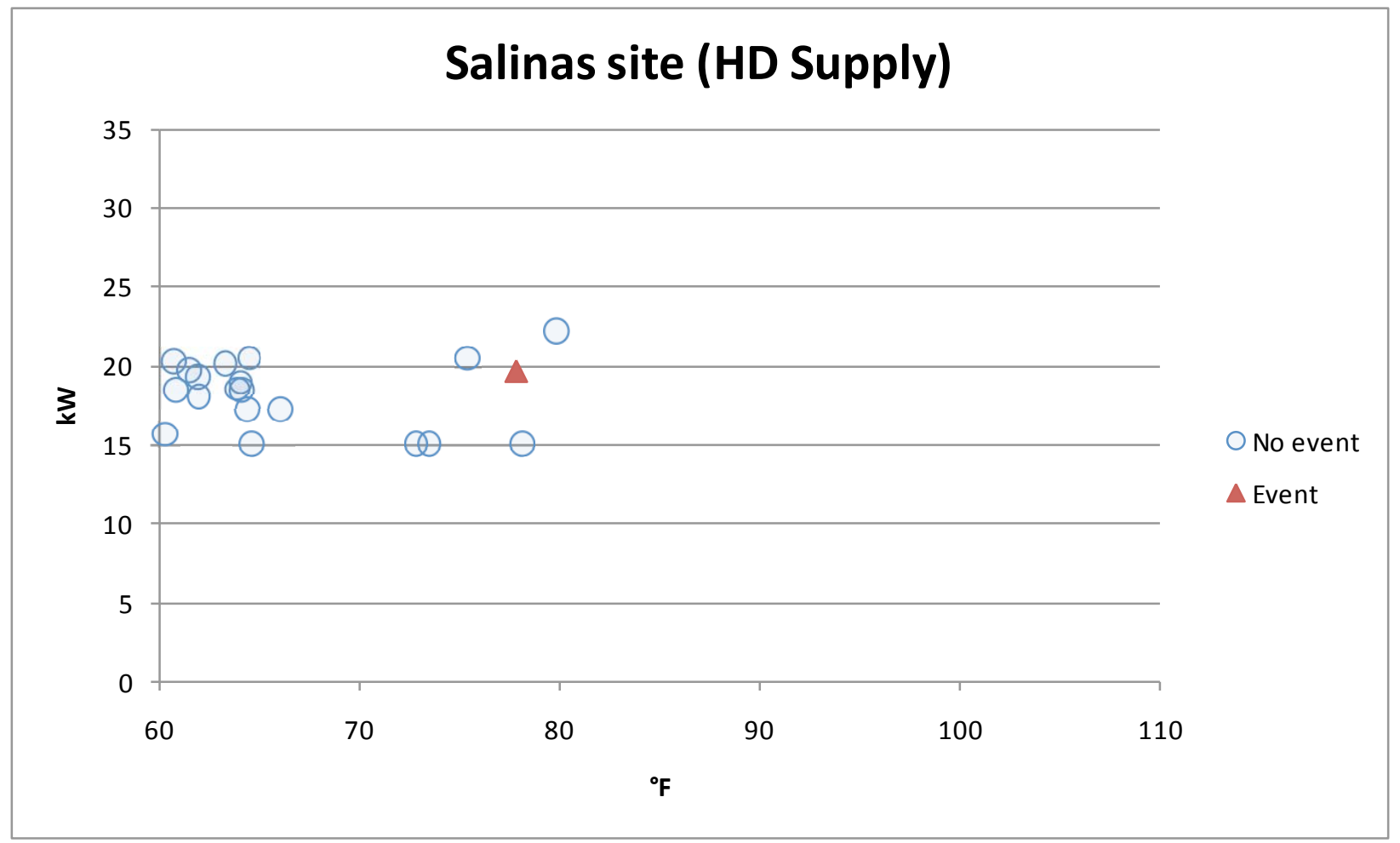

This site only participated in a single six hour event (noon -6pm) because of difficulties in establishing an internet connection on site. The data logger reported out a single value from 4:45pm October 27 until 12:45pm on the event day. 


\section{APPENDIX D. User Surveys Conducted by Lutron}

Lutron, a vendor in the Automated Demand Response Technology Demonstration Project for Small and Medium Commercial Buildings, sent a survey to the occupants of their controlled facility, Associated Lighting Representatives, Inc. (ALR), shortly after one of their DR events to inquire about how the lighting changes impacted people working in the facility. To calibrate the results, they also conducted a survey asking about the same thing on a day when there was no DR event (so no corresponding reduction in lighting levels).

The text below contains the original survey, a summary of those results, the followup survey, and a summary of the followup survey results.

ORIGINAL SURVEY (The survey was distributed on the morning of Friday 9/24, two days after the event (really 1.5 days). Most people (estimated 75\%) completed it on Friday, with the remainder completing it on Monday and Tuesday.)

Instructions: Please take some time to read this survey and provide your feedback as completely and accurately as possible. If you have questions, please contact Tom Nasti at Lutron Electronics (tnasti@lutron.com). We would like you to complete this survey by end of day Friday, September 24.

On Wednesday, September 22, 2010, your office participated in a lighting experiment. Light levels in certain areas of your building were lowered between the hours of 1:00 PM and 5:00 PM.

1. Where were you between 1:00 PM and 5:00 PM on Wednesday, September 22, 2010?

$$
\begin{array}{lll}
r & r & \text { Interior Open Office } \\
r & r & \text { Perimeter Open Office } \\
r & r & \text { Interior Private Office } \\
r & r & \text { Perimeter Private Office } \\
r & r & \text { Other }
\end{array}
$$

2. If you entered "Other" above, please specify:

3. How would you describe your recollection of the change in light level between 1:00 PM and 5:00 PM on Wednesday, September 22, 2010?
$r \cdot I^{\prime} m$ sure the lights changed
r. I think the lights changed
(1) I'm not sure
$(\cdot)$ I think the lights did not change 
(.) I'm sure the lights did not change

4. If the lights changed, enter an estimated amount (\% reduction).

5. If you noticed a change in light levels between 1:00 PM and 5:00 PM on Wednesday, September 22, 2010, how would you rate its impact on your productivity?

$\sigma \quad$ The lighting level changes had a significant negative impact on my productivity

( ) The lighting level changes had a minor negative impact on my productivity

( ) The lighting level changes did not impact my productivity

$r$ The lighting level changes had a minor positive impact on my productivity

$\checkmark r$ The lighting level changes had a significant positive impact on my productivity

6. If the lights changed, did you manually raise the lighting levels after they had been lowered?

r. Yes

r. No

7. If you have any other comments on the impact of light level changes between 1:00 PM and 5:00 PM on Wednesday, September 22, 2010, please enter them below.

8. How would you describe your area's lighting on a typical day?

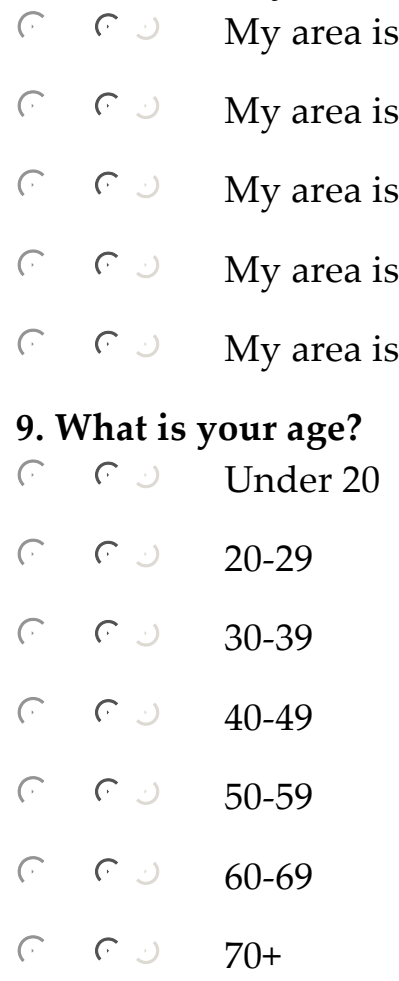

10. Offering to reduce your building's lighting levels during peak electricity demand periods helps the environment. Which statement below best describes how you feel about participating in these lighting level reductions? 
$\ulcorner$ I would be okay if lighting levels were reduced even more during these periods

( ) I can tolerate the current lighting level reductions, but nothing more

$\ulcorner\cdot$ The current lighting level reductions are too much, and I cannot tolerate them

r. I don't care

SUMMARY OF RESULTS (as provided by Lutron)

On Wednesday 9/22/2010, ALR's main office (Oakland, CA) participated in a demand response event in which lighting levels were reduced in some areas. A survey was distributed to the building's occupants later that week.

Out of 28 respondents, when asked to describe their recollection of the change in light level between 1:00 PM and 5:00 PM on Wednesday 9/22/2010:

- $\quad 9(31.0 \%)$ were sure the lights changed

- $\quad 8(27.6 \%)$ thought the lights changed

- $8(27.6 \%)$ were not sure

- $4(13.8 \%)$ thought the lights did not change

Of the 17 respondents that thought or were sure that the lights changed, 15 responded with an estimated dimming \%:

- $\quad 4(23.5 \%$ ) estimated $1-10 \%$ dimming (estimates of $2 \%, 5 \%, 10 \%$, and $10 \%$ )

- $\quad 3(17.6 \%$ ) estimated $11-20 \%$ dimming (estimates of $15 \%, 15 \%$, and $20 \%$ )

- $\quad 4$ (23.5\%) estimated $21-30 \%$ dimming (estimates of $25 \%, 25 \%, 25-30 \%$, and $30 \%$ )

- $\quad 1(5.9 \%$ ) estimated $31-40 \%$ dimming (estimate of $40 \%$ )

- $\quad 3(17.6 \%$ ) estimated $41-50 \%$ dimming (estimates of $45 \%, 50 \%$, and $50 \%$ )

The following shows estimates of dimming vs. actual for the spaces where lighting level changes were observed:

Interior Open Office $\quad$ (75\% under-estimated, $25 \%$ over-estimated)

Actual: $40 \%$ dimming

Estimates (ascending): 2\%, 5\%, 10\%, 15\%, 20\%, 25-30\%, 45\%, 50\%

Perimeter Open Office $\quad$ (100\% under-estimated)

Actual: $50 \%$ dimming

Estimates (ascending): 10\%

Interior Private Office $\quad(100 \%$ over-estimated)

Actual: $10 \%$ dimming

Estimates (ascending): 30\%, 40\%

Perimeter Private Office $\quad$ (100\% under-estimated)

Actual: $60 \%$

Estimates (ascending): 25\%, 25\%, 50\% 
Other - Storage $\quad(100 \%$ over-estimated $)$

Actual: $0 \%$ dimming

Estimates (ascending): 15\%

Out of 25 respondents, when asked to rate the light level change's impact on productivity:

- $1(4.0 \%)$ noted a significant negative impact on his/her productivity

- $6(24.0 \%)$ noted a minor negative impact on his/her productivity

- $18(72.0 \%)$ noted no impact on his/her productivity

The following shows the two negative impact groups above with their dimming estimates and actual dimming values:

Significant Negative Impact (Interior Open Office): 50\%

Minor Negative Impact (Interior Open Office): 5\%, 25-30\%, 45\%

Minor Negative Impact (Interior Private Office): 30\%

Minor Negative Impact (Perimeter Private Office): 25\%

Minor Negative Impact (Other: Storage): 15\% (actual: $40 \%$ )

(actual: $40 \%$ )

(actual: 10\%)

(actual: $60 \%$ )

(actual: 0\%)

Of the 17 respondents who thought or were sure that the lights changed, 7 noted a negative impact on their productivity. Of these 7, none manually adjusted their lights. One respondent manually raised his/her lighting levels, although they noted the dimming had no impact on their productivity.

When asked to describe their lighting on a typical day, 29 respondents answered as follows:

- $3(10.3 \%)$ described their area as somewhat over-lit

- $\quad 23(79.3 \%)$ described their area as properly lighted

- $\quad 3(10.3 \%)$ described their area as somewhat under-lit

The three respondents who described their area is under-lit all noted that the light level changes had no impact on their productivity.

The following describes respondents' impact on productivity vs. age:

Ages 20-29

No impact on productivity: 3 responses (100\%)

Ages 30-39

No impact on productivity: 4 responses (100\%)

Ages 40-49

Significant negative impact on productivity: 1 response $(10 \%)$

Minor negative impact on productivity: 3 responses (30\%)

No impact on productivity: 6 responses (60\%) 
Ages 50-59

Minor negative impact on productivity: 2 responses (28.6\%)

No impact on productivity: 5 responses $(71.4 \%)$

Ages 60-69

Minor negative impact on productivity: 1 response (100\%)

FOLLOWUP SURVEY (Lutron distributed an identical survey, but in this case a DR event had not happened. Here is a summary of the results. Again, the site was told that lighting levels had changed in "some areas" but in fact there were no Lutron- or DR-initiated light level changes within the specified period.)

Response Summary

Total Started Survey: 29

Total Completed Survey: 29 (100\%)

1. Where were you between 1:00 PM and 5:00 PM on Wednesday, October 6, 2010? Use the guide provided with the survey identify your area.

answered question 29

skipped question 0

Response (Percent/Response Count)

Interior Open Office $\quad 65.5 \% \quad 19$

Perimeter Open Office $\quad 6.9 \% \quad 2$

Interior Private Office $\quad 3.4 \% \quad 1$

Perimeter Private Office $\quad 10.3 \% 3$

Other $13.8 \% \quad 4$

2. If you entered "Other" above, please specify:

answered question 4

skipped question 25

1. warehouse Mon, Oct 11, 2010 10:57 AM

2. Out making sales calls. Fri, Oct 8, 2010 11:21 AM

3. Main entrance Fri, Oct 8, 2010 10:56 AM

4. out of the office Fri, Oct 8, 2010 10:47 AM

3. How would you describe your recollection of the change in light level between 1:00 PM and 5:00 PM on Wednesday, October 6, 2010?

answered question 29

skipped question 0

Response (Percent/Response Count)

I'm sure the lights changed $\quad 10.3 \% \quad 3$

I think the lights changed $\quad 10.3 \% \quad 3$ 
I'm not sure $\quad 58.6 \% \quad 17$

I think the lights did not change $13.8 \% \quad 4$

I'm sure the lights did not change $6.9 \% \quad 2$

4. If the lights changed, enter an estimated amount (\% reduction).

answered question 3

skipped question 26

Responses

1. I AM NOT SURE I WAS VERY BUSY Fri, Oct 8, 2010 11:00 AM

2. 25\% Fri, Oct 8, 2010 10:41 AM

3. 5\% Fri, Oct 8, 2010 10:33 AM

5. If you noticed a change in light levels between 1:00 PM and 5:00 PM on Wednesday, October 6, 2010, how would you rate its impact on your productivity?

answered question 20

skipped question 9

Response (Percent/Response Count)

- The lighting level changes had a significant negative impact on my productivity $0.0 \% 0$

- The lighting level changes had a minor negative impact on my productivity $5.0 \% 1$

- The lighting level changes did not impact my productivity $95.0 \% 19$

- The lighting level changes had a minor positive impact on my productivity $0.0 \% 0$

- The lighting level changes had a significant positive impact on my productivity $0.0 \% 0$

6. If the lights changed, did you manually raise the lighting levels after they had been lowered?

Yes $0.0 \% 0$

No $100.0 \% 20$

7. If you have any other comments on the impact of light level changes between 1:00 PM and 5:00 PM on Wednesday, October 6, 2010, please enter them below. answered question 1 (response not provided by Lutron) skipped question 28

8. How would you describe your area's lighting on a typical day? answered question 29 skipped question 0

Response (Percent/Response Count) 


$\begin{array}{lll}\text { My area is significantly over-lit } & 0.0 \% & 0 \\ \text { My area is somewhat over-lit } & 3.4 \% & 1 \\ \text { My area is properly lighted } & 72.4 \% & 21 \\ \text { My area is somewhat under-lit } & 20.7 \% & 6 \\ \text { My area is significantly under-lit } & 3.4 \% & 1\end{array}$

9. What is your age?

answered question 29

skipped question 0

Response (Percent/Response Count)

Under $20 \quad 0.0 \% \quad 0$

20-29 $\quad 17.2 \% \quad 5$

30-39 $\quad 17.2 \% \quad 5$

$40-49 \quad 41.4 \% \quad 12$

50-59 $\quad 20.7 \% \quad 6$

60-69 $\quad 3.4 \% \quad 1$

$70+\quad 0.0 \% \quad 0$

10. Offering to reduce your building's lighting levels during peak electricity demand periods helps the environment. Which statement below best describes how you feel about participating in these lighting level reductions?

answered question 29

skipped question 0

Response (Percent/Count)

- I would be okay if lighting levels were reduced even more during these periods $37.9 \% 11$

- I can tolerate the current lighting level reductions, but nothing more $41.4 \% 12$

- The current lighting level reductions are too much, and I cannot tolerate them $3.4 \% 1$

- I don't care

$17.2 \% 5$ 